\title{
Studies of the affective and developmental domains of psychopathology in psychosis
}

Citation for published version (APA):

Kaymaz, N. (2011). Studies of the affective and developmental domains of psychopathology in psychosis. [Doctoral Thesis, Maastricht University]. Maastricht University. https://doi.org/10.26481/dis.20110622nk

Document status and date:

Published: 01/01/2011

DOI:

10.26481/dis.20110622nk

Document Version:

Publisher's PDF, also known as Version of record

\section{Please check the document version of this publication:}

- A submitted manuscript is the version of the article upon submission and before peer-review. There can be important differences between the submitted version and the official published version of record.

People interested in the research are advised to contact the author for the final version of the publication, or visit the DOI to the publisher's website.

- The final author version and the galley proof are versions of the publication after peer review.

- The final published version features the final layout of the paper including the volume, issue and page numbers.

Link to publication

\footnotetext{
General rights rights.

- You may freely distribute the URL identifying the publication in the public portal. please follow below link for the End User Agreement:

www.umlib.nl/taverne-license

Take down policy

If you believe that this document breaches copyright please contact us at:

repository@maastrichtuniversity.nl

providing details and we will investigate your claim.
}

Copyright and moral rights for the publications made accessible in the public portal are retained by the authors and/or other copyright owners and it is a condition of accessing publications that users recognise and abide by the legal requirements associated with these

- Users may download and print one copy of any publication from the public portal for the purpose of private study or research.

- You may not further distribute the material or use it for any profit-making activity or commercial gain

If the publication is distributed under the terms of Article $25 \mathrm{fa}$ of the Dutch Copyright Act, indicated by the "Taverne" license above, 
STUDIES OF THE AFFECTIVE AND DEVELOPMENTAL DOMAINS OF PSYCHOPATHOLOGY IN PSYCHOSIS 
Cover illustration: 'Mijn hersenspinsels en gedachtekronkels' by Ziad Haider.

Ziad Haider werd in 1954 geboren in Amara, een stad in het zuiden van Irak, gelegen aan de Tigris, zo'n 200 kilometer ten zuiden van Bagdad. In 1972 ging studeren aan de Academie voor Schone Kunsten in Bagdad. In 1992 ontvluchtte hij Irak. Voor vijf jaar verbleef hij achtereenvolgens in Syrië en Jordanië, totdat hij in 1997 als vluchteling aan Nederland werd toegewezen. Vanaf zijn komst naar Nederland in 1997 exposeerde hij ondermeer in Belgie, Finland en Polen.

Het thema van zijn werk is de onzichtbare erfenis. De blijvende erfenis van de ervaring die in mensen besloten ligt. Ziad schilderde van binnen uit, vertaalde in kleur en beeld dat wat mensen beleven.

Het leven van het individu en een volk. Ziad Haider is in 2006 in Amsterdam overleden.

www.ziadhaider.net

Cover design \& printing by Datawyse / Universitaire Pers Maastricht 


\title{
STUDIES OF THE AFFECTIVE AND DEVELOPMENTAL DOMAINS OF PSYCHOPATHOLOGY IN PSYCHOSIS
}

\author{
ACADEMIC DISSERTATION
}

\author{
to obtain the degree of Doctor \\ at Maastricht University, \\ on the authority of the Rector Magnificus, \\ Prof. dr. G.P.M.F. Mols, \\ in accordance \\ with the decision of the Board of Deans, \\ to be defended in public on \\ $22^{\text {nd }}$ June 2011 at 14.00 hours
}

by

Nil Kaymaz

Born 02 July 1972 in Mazgirt, Turkey 


\section{Promotor}

- Prof. dr. J. van Os

\section{Beoordelingscommissie}

- $\quad$ Prof. dr. M. W. de Vries, voorzitter

- Dr. Ph. A. E. G. Delespaul

- Prof. dr. W. Nolen, Universitair Medisch Centrum Groningen

- Dr. F. P. M. L. Peeters

- Prof. dr. D. Wiersma, Universitair Medisch Centrum Groningen 


\section{Table of contents}

$\begin{array}{lll}\text { Chapter } 1 & \text { Introduction } & 7\end{array}$

$\begin{array}{lll}\text { Chapter } 2 & \text { Developmental studies of psychosis } & 27\end{array}$

$\begin{array}{lll}\text { Chapter } 3 & \text { Affective studies of psychosis } & 83\end{array}$

$\begin{array}{lll}\text { Chapter } 4 & \text { Prodromal studies of psychosis } & 115\end{array}$

$\begin{array}{lll}\text { Chapter } 5 & \text { Summary } & 141\end{array}$

$\begin{array}{lll}\text { Chapter } 6 & \text { Future directions } & 149\end{array}$

$\begin{array}{lll}\text { Chapter } 7 & \text { Summary in Dutch, Nederlandse samenvatting } & 155\end{array}$

Dankwoord 163

$\begin{array}{ll}\text { Curriculum vitae } & 169\end{array}$

$\begin{array}{ll}\text { Publications } & 171\end{array}$ 

CHAPTER 1

Introduction 
Ever since Kraepelin separated the classification of psychotic illnesses into dementia praecox and manic-depressive insanity, there has been controversy over whether these two disorders - now referred to as schizophrenia and bipolar disorder ${ }^{1}$ - are really distinct from each other. From a clinical perspective, the disorders may be distinguishable, more specifically in their seldom occurring pure forms, but there are no pathognomonic symptoms to differentiate them. During an exacerbation of bipolar disorder, many patients have first rank symptoms of schizophrenia in the form of characteristic delusions and hallucinations, and many patients with schizophrenia have symptoms of depression and mania. Current psychiatric nosology classifies schizophrenia and bipolar disorder as two distinct diagnostic categories with presumed independent aetiologies. There are, however models that challenge the traditional explanations of the aetiology of psychosis. One view is the categorical approach and the conceptualization of these as two distinct disorders in the classification systems of the American Psychiatric Association: Diagnostic and Statistical Manual of Mental Disorders (DSM) and the World Health Organization: International Statistical Classification of Diseases and Related Health Problems (ICD). The categorical approach is highlighted below for the two main disorders we focused on in this thesis: schizophrenia and bipolar disorder. The alternative view is that the different clinical forms of psychosis represent a continuum, with schizophrenia representing expressions at the most extreme end of the spectrum (Crow TJ, 1986) and schizoaffective disorder embodying the solution for the diagnostic conundrum induced by the considerable overlap between these disorders (Fig. 1). The main assumptions within the continuum theory are: 1) all diagnoses of psychotic disorder share genetic causes and, 2) the disorders show continuity not only with each other, but also with normal mentation in the general population. Thus, the notion of a continuum in this thesis is used to denote a continuum of disorders within the clinical population as well as a continuum of expression of psychosis across clinical and non-clinical populations.

A debate currently persists regards the merit of old diagnostic traditions in psychiatry. It is becoming clear that the strict separation of diagnostic entities set forth by the DSM and ICD classification systems has resulted in major missed opportunities to study the causes and treatments of psychiatric disorders. Most of the symptom domains, whether it is psychosis, mania, depression, cognitive impairment or negative symptoms, are found across the entire psychosis spectrum, which includes all non-affective and affective psychotic disorders. An elegant way of dealing with the discussions of categorical versus dimensional/continuum theory is by simply adding the dimensional indicators mentioned above to the categorical system, as it is depicted in Figure 1. In doing so, the basis for a new cross-diagnostic approach in psychiatry may be laid.

\footnotetext{
${ }^{1}$ The term bipolar disorder replaced name manic-depressive disorder in the American Psychiatric Association's DSMIII published in 1980.
} 


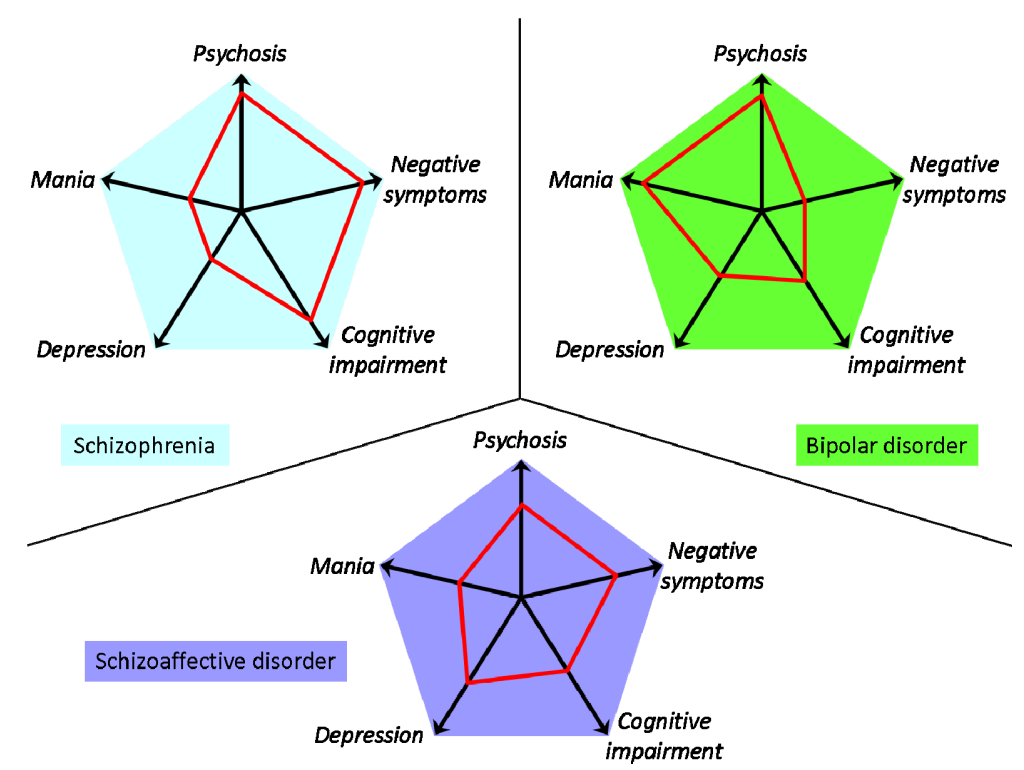

Figure 1 Three hypothetical patients diagnosed using a combination of categorical and dimensional representations. The categorical diagnoses of schizophrenia, bipolar disorder and schizoaffective disorder are accompanied by the patients' quantitative scores (connected by red lines) on five main dimensions (psychosis, negative symptoms, cognitive impairment, depression and mania) of psychopathology (Kaymaz et al., 2009 and Van Os \& Kapur, 2009).

In this thesis, we approached affective and non-affective psychotic disorders as entities pertaining to a multidimensional syndrome. Most of the studies in this thesis focused on schizophrenia as an example of non-affective psychotic disorder, and bipolar disorder as an example of affective psychotic disorder. We examined the epidemiological and genetic overlap between the two constructs by focusing on developmental and affective domains, and by examining how this is applicable to the ontogenesis of disorder, i.e. in the prodromal stage as well as in the context of prediction. We also investigated how the symptom dimensions found in affective and non-affective psychotic disorders co-vary with and affect each other at the subclinical and clinical level.

\section{General background information on bipolar disorder and schizophrenia Bipolar Disorder (type I and type II)}

Bipolar disorder is a chronic disorder associated with episodic extremes in mood, varying from depressive episodes to hypomanic (type II) or manic (type I) episodes. Patients may still experience residual symptoms in the periods between alternations of depressive and manic episodes, or between depressive and hypomanic episodes ${ }^{2}$. The longitudinal outcome of bipolar disorder is defined by recurrent manic and/or depressive mood episodes. These mood episodes have a severe impact on the lives of patients and their families, including job performance, personal relationships and responsibilities. Most of the studies have focused on the syndromal outcome of treatment of patients with bipolar disorder and less on the

\footnotetext{
${ }^{2}$ Mania and depression can co-occur in a mixed state.
} 
functional outcome. A study by Strakowski et al. (1998) showed a $61 \%$ syndromal recovery for bipolar disorder 12 months after hospitalization, whereas functional recovery was reported to be $36 \%$. In a recent naturalistic study in bipolar I disorder, these numbers were $87.5 \%$ and $53.5 \%$, respectively (Montoya et al., 2010).

Restoration of pre-episode quality of life and level of functioning is of primary importance in the treatment of bipolar disorder. In contrast to schizophrenia, very little is known about the basic clinical epidemiology of bipolar disorder. Studies on the incidence rates of bipolar disorder report rates varying from 1.7 to 4.5 for every 100,000 people per year (Lloyd et al., 2005; Ketter TA, 2010). Studies to date may have underestimated true incidence of the disorder. Earlier studies showed little age difference between men and women at onset, but more recent studies, using more strict operational criteria, have tended to show a later onset in women (Arnold LM, 2003; Ketter, 2010). It is also uncertain whether migrants have a higher incidence of bipolar disorder as well as of schizophrenia; although, earlier incidence studies have suggested that this may be so (Der \& Bebbington, 1987; Van Os et al., 1996). The prevalence rates vary from $0.5 \%-5.5 \%$ (Angst J, 1998), indicating a broad range possibly due to variances in the populations studied, but also due to the operationalisation and course of the illness (Bebbington \& Ramana, 1995) and overlap with other psychiatric disorders (Krishinan, 2005), which all make the diagnosis of bipolar disorder difficult.

Reported rates of bipolar syndromes are highly variable between studies because of age differences, differences in diagnostic criteria or restriction of sampling to clinical contacts. In a study of 1395 adolescents fourteen to seventeen years of age, Tijssen et al. (2010) measured DSM-IV hypomanic and manic episodes (in combination), use of mental health care and five ordinal subcategories representing the underlying continuous score of hypomanic and manic symptoms ${ }^{3}$ at baseline and approximately at 1.5, 4 and 10 years later. Incidence rates (IR) of mania and hypomania, defined both as DSM-IV episodes and as at least one DSM-IV core symptom were far higher than traditional estimates. In addition, independent of childhood disorders such as attention deficit hyperactivity disorder (ADHD), the risk of developing hypomanic or manic episodes was very low after reaching twenty-one years of age. Most individuals with hypomanic and manic episodes were never in care $(87 \%$ and $62 \%$, respectively) and did not present with comorbid depressive episodes (69\% and $60 \%$, respectively). The probability of mental health care usage increased linearly with the number of symptoms on the mania symptom scale. The incidence of the bipolar categories, in particular at the level of clinical morbidity, was strongly associated with previous childhood disorders and male gender. Therefore, this was the first time a study showed that experiencing hypomanic or manic symptoms is a common adolescent phenomenon that infrequently predicts the use of mental health care. The findings suggest that the onset of bipolar disorder can be elucidated by studying the pathway from non-pathological behavioural expression to dysfunction and the need for care (Regeer et al., 2009). This is similar to findings reported in nonaffective psychosis, which studies have shown also appears as a distribution in the general population (Van Os, Linscott, Myin-Germeys, Delespaul, \& Krabbendam, 2009).

\footnotetext{
${ }^{3}$ Tijssen et al. (2010) used a 'mania symptom scale' based on the CIDI.
} 


\section{Schizophrenia}

Schizophrenia is a major mental illness that frequently runs a chronic course, despite the enormous therapeutic advances from the new findings in research, which look not only at the aetiological findings, but also at the protective factors. Schizophrenia manifests itself during late adolescence or early adulthood and has profound effects, not only because of the direct and substantial suffering for the patients but also for their relatives (Sheitman et al., 1997; De Mamani AG, 2010). The symptoms of schizophrenia can be characterized by making a distinction between positive symptoms and negative symptoms. Positive symptoms refer to the abundance or distortion of normal behaviour. These symptoms are hallucinations such as hearing voices, or delusions, like believing one's thoughts are controlled by an external force. Bizarre behaviour caused by delusions and hallucinations and formal thought disorder (incoherence of speech) are also positive symptoms. Negative symptoms refer to the reduction of normal functions. The negative symptoms consist of flat affect expressed with a monotonous voice or immobile facial expression, avolition ${ }^{4}$ or apathy ${ }^{5}$, alogia ${ }^{6}$ and anhedonia ${ }^{7}$ (Andreasen NC, 1985).

The positive symptoms of schizophrenia are potentially responsive to or reversible with antipsychotic medicinal treatment. Negative symptoms, however, are usually stable or even progressive over time and relatively irreversible. The negative symptoms are associated with poor outcome in the long term. The clinical presentation of the disorder is heterogeneous. Either the positive symptoms or the negative symptoms predominate in patients. The onset of negative symptoms tends to occur about five years before the initial psychotic episode, with onset of positive symptoms much closer to the time of first hospitalization (Häfner et al., 1999).

The course of the disorder is also variable. Some patients are left with mild exacerbations of symptoms, while severe cases can involve persistent symptoms that result in hospitalization or even permanent hospitalization.

The estimated life risk varies strongly with the presence or absence of certain risk factors, which are called environmental risk factors, and is on average 1\% (Mueser \& McGurk, 2004). It seems to occur almost one and a half times more in men than in women (Aleman et al., 2003).

The symptoms of the disorder were fist clustered and described by Kraepelin, who called the illness dementia praecox in 1919. 'Dementia' refers to the clinical and cognitive deterioration that progresses during the course of the disease, and 'praecox' refers to the early onset of the symptoms of the illness. Bleuler, on the other hand, did not agree with Kraepelin that schizophrenia always had an early onset and that there was an inevitable deterioration in the course of the illness. In turn, he emphasized some core symptoms of the disorder such as the loss of goal-directed behaviour, difficulties in thinking straight and flattening of affect. Bleuler later named the disorder 'schizophrenia' in 1923, referring to the disintegration of personality that could occur in patients. Since then, many attempts have been made to redefine the diagnostic criteria of schizophrenia, resulting in the development of several diagnos-

\footnotetext{
${ }^{4}$ lack of desire, drive, or motivation to pursue meaningful goals

${ }^{5}$ a state of indifference or the suppression of emotions

${ }^{6}$ poverty of speech

${ }^{7}$ inability to experience pleasurable emotions
} 
tic classification systems, such as the American Psychiatric Association's Diagnostic and Statistical Manual (DSM) and International Classification of Diseases (ICD; World Health Organization, 1992). Today, we are moving from the DSM-IV-TR definition of schizophrenia as a chronic disorder characterized by psychotic episodes and a decline in social and occupational functioning toward developing the DSM-V, with the possible inclusion of new diagnostic entities such as 'Attenuated Psychotic Symptom Syndrome'. Another major development is that researchers and clinicians in psychiatry are critical about these classification systems. They are pose alternative views about categorical systems and introduce dimensional systems. They are also critical about the term schizophrenia (Van Os J, 2009) and opt to redefine it, as has already been done in Japan in 2006 with 'Integration Dysregulation Syndrome'. As mentioned earlier, there is evidence that the symptoms of schizophrenia are also expressed at subclinical level in the general population and form part of a continuum (Kaymaz \& Van Os, 2010; Linscott \& Van Os, 2010; Van Os et al., 2009).

\section{Aetiology of schizophrenia and bipolar disorder; similarities and dissimilarities}

For more than a century, it has been uncertain whether schizophrenia and bipolar disorder are distinct disease entities with specific genetic and/or environmental causes and neuroanatomical substrates. Several studies have published evidence from their particular perspective, challenging this dichotomy between the categorical view, which relies on the assumption that both diseases are distinct diagnostic entities, and the continuum theory or the dimensional view, which points out that there is little evidence for any risk factor, symptom, treatment or course type being specific to any diagnostic category within the functional psychosis (Van Os et al., 1999). It also promotes the idea that different forms of psychosis represent a continuum of disorders with schizophrenia at the most severe end of the spectrum (Crow TJ, 1986).

From a clinical perspective, there are no sharp symptomatic distinctions between the two disorders. Indeed, one piece of evidence for the overlap at the clinical level is the invention of the diagnosis schizoaffective disorder, manic type, which is a diagnosis of a psychopathological state that lies in between bipolar disorder and schizophrenia in terms of clinical symptomatology, showing both psychotic and mania symptoms. Patients with acute mania often display Schneiderian first rank symptoms, such as auditory hallucinations, broadcasting of thoughts, controlled thoughts (delusion of control) and delusional perception (WHO, 1973). Patients with depressive psychosis have delusions and hallucinations (Kendell \& Gourlay, 1970; Shergill et al., 1999). Many patients with schizophrenia show symptoms of mania and depression, and in $75 \%$ of cases, patients with schizophrenia have depression symptoms during their first schizophrenic episode (Koreen et al., 1993; Häfner et al., 1999). These early affective symptoms are often an early expression of an underlying schizophrenia process, or in some cases, they are viewed as an additional factor that precipitates the onset of psychosis in those who are biologically predisposed (Chadwick \& Birchwood, 1994). There are follow-up studies showing that in initially non-psychotic people experiencing auditory hallucinations, those who become depressed have a higher probability of subsequently developing 
psychotic disorders needing treatment than do those who do not become depressed (Escher et al., 2002a, 2002b; Krabbendam et al., 2004). Depression precedes the onset of mania in many cases of bipolar disorder. Other overlapping characteristics between bipolar disorder and schizophrenia are at a young age at the time of onset of the disorders, which is slightly earlier in males (Frangou et al., 2002; Kennedy et al., 2002) and they have a frequent occurrence of life events prior to the onset or relapse of illness (Ventura et al., 1989; Bebbington et al., 1993).

As for the question as to whether or not there is familial co-aggregation between bipolar disorder and schizophrenia, family studies consistently have shown that the first-degree relatives of probands who had schizophrenia are at an increased risk for schizophrenia, schizoaffective disorder and schizotypal personality disorder. Similarly, family studies have also revealed that first-degree relatives of bipolar probands are at an increased risk of developing bipolar disorder, schizoaffective disorder and unipolar depression (Taylor MA, 1992; Faridi et al., 2009). However, whether there is a cross-disorder familial risk for bipolar disorder and schizophrenia has been controversial. Inadequate sample sizes in the studies and low statistical power may have contributed to this lack of evidence. The familial aggregation of schizophrenia with itself is expected to be greater than its co-aggregation with bipolar disorder, however, most studies have examined the co-aggregation of schizophrenia or bipolar disorder with itself and few studies have examined their co-aggregation. One of the largest family studies to date used the Swedish inpatient register and found over 13,000 cases with schizophrenia and $\mathbf{5 0 0 0}$ with bipolar disorder. Cross-disorder incidence ratios were clearly increased for both full and half siblings, providing evidence for familial co-aggregation between schizophrenia and bipolar disorder (Osby et al., 2001). The study by Lichtenstein et al. (2009) on the same extended sample shows similar findings. In this study, the question of whether schizophrenia and bipolar disorder are the clinical outcomes of discrete or shared causative processes was investigated by assessing the genetic and environmental contributions to liability for schizophrenia, bipolar disorder and their comorbidity by using data from a multi-generation register. First-degree relatives of probands who had either schizophrenia or bipolar disorder were at increased risk of these disorders. Half siblings had a significantly increased risk, but substantially lower than that of the full siblings. When relatives of probands who had bipolar disorder were analysed, increased risk for schizophrenia existed for all relationships, including adopted children to biological parents with bipolar disorder. Heritability for schizophrenia and bipolar disorder was $64 \%$ and $59 \%$, respectively. Shared environmental effects were small but substantial for both disorders. The comorbidity between these two disorders was mainly due to additive genetic effects common for both disorders. This study shows, similar to molecular genetic studies, that schizophrenia and bipolar disorder partly share a common genetic cause. Another meta-analytic study carried out by Van Snellenberg \& De Candia (2009) found familial aggregation between these two disorders, which supports the continuum model.

Twin studies show that the siblings of index twins with schizophrenia show a similar prevalence of affective disorder and schizophrenia, while their parents were more likely to suffer affective disorder than schizophrenia (Shields \& Slater, 1975). A study by McGuffin et al. (1982) showed that in case of identical triplets, two diagnosed with schizophrenia and the third with bipolar disorder, highlighted how the same genetic makeup could result in diverse forms of psychosis. The study by Cardno et al. (2002) showed substantial cross diagnosis 
concordance for monozygotic twins and modest concordance for dizygotic twins. Common genetic contributions as well as diagnosis-specific genetic contributions to the variance in liability to schizophrenia and mania were found using model-fitting techniques. However, diagnosis-specific genetic effects were not found for schizoaffective disorder. The study by Cardno et al. (2002) shows a significant overlap in the genes contributing to schizophrenia, schizoaffective disorder and mania.

Both schizophrenia and bipolar disorder have high heritability estimates of around $80 \%$ 90\% (Cardno et al., 2002; McGuffin et al., 2003). There is evidence for an overlap in familial susceptibility for bipolar disorder and schizophrenia, but there is still a remaining question as to whether the origin of this overlap is due to genetic overlap, an overlap in causal factors (environmental factors) or to a genetic and environmental (GXE) interaction. If the overlap is of genetic origin, molecular genetic studies should report loci in common. Over the past 20 years, numerous genome scans have been carried out to search the susceptibility genes for both schizophrenia and bipolar disorder: their consistent findings have generated some confusion. Due to power limitations, few studies exceed the genome-wide significance levels and attempts to replicate a specific finding require even larger samples. In a study by Badner \& Gershon (2002), all the published genome-wide scan studies up until 2002 were identified. The most significant linkage zone for both schizophrenia and bipolar disorder were the two zones on chromosome $13 q$ and $22 q$.

They concluded that these two regions were likely to harbour susceptibility loci common to these two disorders. A year later, Lewis et al. (2003) published a meta-analysis on the same subject and found a number of candidate regions for either schizophrenia or bipolar disorder, but found no overlap of susceptibility regions between the two disorders. These conflicting results between the two meta-analyses, published only one year apart, may be due to the differences in statistical methodology and in the selection of datasets. However, irrespective of the outcome, the genomic regions covered are large and therefore some overlap in these zones does not necessarily mean that the same genes are involved in both disorders. However, more studies should be carried out that examine evidence for genetic overlap between these two disorders. In a study by Fallin et al. (2005), six genes (DPYSL2, DTNBP1, G30/G72, GRID1, GRM4 and NOS1) showed overlapping suggestive evidence for association in both disorders.

Unfortunately, many of the molecular genetic findings in schizophrenia and bipolar disorder have not been replicated consistently. The allelic association at the ZNF804A locus is now one of the most compelling in schizophrenia to date. In a recent study by Williams et al. (2010), the authors provided additional evidence for association through meta-analysis of a large data set patients with schizophrenia/schizoaffective disorder ( $N=18,945)$, schizophrenia plus bipolar disorder $(N=21,274)$ and controls $(N=38,675)$ and their data supports the suggestion of overlapping genetic risk between schizophrenia and bipolar disorder. In a recent study by Grozeva et al., (2010), who investigated the overlap in Copy Number Variations (CNV) between schizophrenia and bipolar disorder, it was found that schizophrenia and bipolar disorder differ with respect to CNV burden in general and association with specific CNVs in particular. Their data are consistent with the possibility that possession of large, rare deletions may modify the phenotype in those at risk of psychosis. They suggested that those possessing such events are more likely to be diagnosed with schizophrenia, i.e. psychotic disorder with a sizeable neurodevelopmental component. Those without them are more 
likely to be diagnosed with bipolar disorder, i.e. psychotic disorder without a neurodevelopmental component.

Although the genome-wide association studies (GWAS) are widely used in an attempt to unravel the genetics of psychiatric disorders, in particular schizophrenia, findings are not conclusive and explain only a fraction of the heritability. The number of studies reporting new candidate genes for schizophrenia and for brain structures is expanding; however, there are conflicting results regarding consistency. As linkage analysis and candidate gene hunting have resulted in a new gene almost on a daily basis, all hope was put on GWAS, with inclusion of many thousands of participants, as a result of collaboration of multiple centres across the world. Recent papers on genetic findings in schizophrenia, by Ingason et al. (2010) and by Stefansson et al. (2009) showed associations with several markers; these, however continue to explain only a fraction of the observed heritability. The influence of CNVs also does not necessarily conform to classical nosological disease boundaries in that some CNVs increase risk across a range of neurodevelopmental psychiatric disorders.

As for brain abnormalities being considered neurobiological markers of brain dysfunction and seen by many as reflecting the genetic basis to these disorders, i.e. representing endophenotypes; these are presumed to be more proximal to the actions of genes than the clinical syndrome. The endophenotype approach can be used to study the variation among candidate neurobiological markers in subjects with increasing genetic risk. The brain abnormalities have been studied more in schizophrenia than in bipolar disorder and are thought to represent an endophenotype because they are heritable, measurable in both affected and unaffected subjects, manifest whether or not the illness is active, associated with the illness in the general population and found more frequently in the unaffected relatives of patients than controls (Leboyer et al., 1998; Gottesman \& Gould, 2003). The research of brain abnormalities in subjects with bipolar disorder and their relatives is less active compared to schizophrenia. Brain imaging studies in schizophrenia have consistently shown reduced whole brain volume as well as enlarged lateral and third ventricles (Wright et al., 2000). In a study by Hoge et al. (1999), seven studies were reviewed which had examined brain size in patients with bipolar disorder and controls and they reported that there were no differences. These findings were similar to those in the study by McDonald et al. (2004). However, in a recent meta-analysis brain changes in bipolar disorder (Arnone et al., 2009) were compared to the brain changes in schizophrenia; the main conclusions were that individuals with bipolar disorder are characterized by significant whole brain and prefrontal lobe reductions and by enlargement of the lateral ventricles and globus pallidus. These findings did not distinguish bipolar disorder from schizophrenia, although schizophrenia was characterized by a greater degree of ventricular enlargement and amygdala volume reduction. The authors concluded that because no such reduction was found in the two previous meta-analyses by Hoge et al. (1999) and McDonald et al. (2004), which encompassed 7 and 11 studies, respectively, the presence of a small effect might require a larger pool of studies to allow detection. The individuals with schizophrenia showed a greater ventricular enlargement compared to those with bipolar disorder. The similarities in the brain changes, but also the differences (greater enlargement of the ventricles in schizophrenia) between bipolar disorder and schizophrenia can be perceived as evidence that they represent the same disorder with a different severity or, less parsimoniously, as two separate processes with a similar outcome. 


\section{Objectives and outline of this thesis}

In this thesis, several studies are described concerning the developmental and affective aspects of schizophrenia and bipolar disorder, in terms of where they differ and overlap, and how that potentially overlaps in the prodrome. The genetic and environmental factors, shared by these two disorders, were investigated. We also examined evidence for the conceptually different models, from an aetiological perspective, of the categorical (point of rarity, developmental specificity) versus the continuum view (mean differences, no specificity) of bipolar disorder and schizophrenia. In addition, in the search for evidence for aetiological models explaining psychotic disorders, it is necessary to discuss the diagnostic implications of differences in developmental and non-developmental risks across the categories. A literature search of studies concerning these issues was carried out and data was extracted from published work.

One of our publications, the meta-analysis on the maintenance treatment of depression, may be considered an outlier within the global objectives and themes of this thesis. However, our approach to psychosis is one of a multidimensional syndrome, with depression being one of the main symptom dimensions (see Figure 1 above). The presence of affective symptom dimensions increases the probability of early relapse of psychotic disorders and their presence in the prodromal phase may act as a risk factor for transition to psychosis later in life (Strakowski et al., 1995; Bechdolf et al., 2002; Lewandowski et al., 2006). Therefore, the goal of the meta-analysis was to investigate if there is a difference in sensitivity to treatment between first and recurrent episodes of a major depressive disorder. One of our hypotheses was that recurrent depressive patients would have higher relapse rates and would benefit less from the protective effects of antidepressants. If confirmed, the next question is if this can be explained by the behavioural sensitisation model. There is evidence (Post RM, 1992) for behavioural sensitisation in the course of affective illness and Post emphasized the importance of preventing episodes of depression by preventing relapses by prophylactic treatment to inhibit sensitisation. According to the sensitisation model, a subgroup of patients exists, that becomes more vulnerable or sensitised to affective episode precipitants with each recurrent episode. For example, in cases of anticipated stresses or imagined losses, if sufficiently conditioned, the behavioural, physiologic and biochemical alterations usually associated with an affective episode might be produced. It may also explain how stressinduced mood alterations might become so sensitised that they also occur spontaneously. The behavioural sensitisation model may not only be applicable to depression but also to other symptom dimensions, such as psychosis or other psychotic disorders in which depression is a main component, such as bipolar disorder and schizophrenia. Indeed, there is more and more evidence from the literature that behavioural sensitisation plays an important role in relapses of psychoses.

\section{Developmental domains}

Developmental impairments, during childhood, preceding the onset in schizophrenia in late adolescence, have been documented extensively for schizophrenia, specifically in the domains of cognition, language, motor performance, social, emotion and behaviour (Jones et al., 1994; David et al., 1997; Cannon et al., 2002; Blanchard et al., 2010). For affective psychosis, broadly defined, there has been some documentation of developmental impairments, 
but the effects are not as strong as they are for schizophrenia (David et al., 1997; Van Os et al., 1997; Crow et al., 1995) and they seem to be present only in early onset cases (Van Os et al., 1997). Only a few studies have investigated the childhood development preceding bipolar disorder or mania. In the Dunedin birth cohort (Cannon et al., 2002), one of the larger prospective studies in this area, children who later met criteria for schizophrenia had shown developmental impairment in all domains tested. This was in contrast to children who later developed mania, who showed difficulties in social, behavioural, and emotional development, but not in motor, language or cognition. They even showed better childhood motor performance than the control group (Cannon et al., 2002). It seems that emotional and interpersonal difficulties in childhood reflect a general predisposition to adult psychiatric illnesses, but that early developmental impairments in psychomotor, language and cognitive function show some specificity to schizophrenia outcomes and are not seen in those who later develop bipolar disorder. One explanation is that genes responsible for these developmental impairments are associated with schizophrenia (Jones \& Murray, 1991), but not with bipolar disorder, or, that there is a differential occurrence of early environmental insults in those two disorders (Murray et al., 2004).

In Chapter 2, the neurodevelopmental component, in relation to genetic factors, was investigated in the disorder most strongly associated with developmental impairment, e.g.schizophrenia. In addition, the degree to which developmental factors discriminate between schizophrenia and bipolar disorder was examined, and to what extent it may be expected that these psychotic phenotypes are distributed categorically or dimensionally.

The first article, 'Heritability of structural brain traits; an endophenotype approach to deconstruct schizophrenia', focuses on the heritability of brain structures, using the endophenotype approach to deconstruct schizophrenia. We examined evidence for genetic influence on aberrant neurodevelopment by conducting a literature search on the heritability of brain structures in healthy people, in people with schizophrenia and in pedigrees in order to deconstruct schizophrenia. In addition to this, a search for molecular genetic variation underlying these brain structures was carried out as well.

The second article is called: 'Murray et al. (2004) revisited: is bipolar disorder identical to schizophrenia without developmental impairment?'. It is a review of literature focusing on work published in the past ten years that examines the actual status of the prediction offered by Murray and colleagues more than five years ago, which said that bipolar disorder may be largely similar to schizophrenia, but without associated developmental impairment. This issue is important to investigate, given the upcoming revisions of diagnostic systems in psychiatry, with the main question of how bipolar disorder and schizophrenia should be discriminated from each other in DSM-V and ICD-11.

In the third article, 'Extended psychosis phenotype-yes: single continuum - unlikely', phenotypic continuity in the sense of continuity with normal mentation, as suggested both for schizophrenia and bipolar disorder, is examined form the conceptual point of view. Causation predicts the type of distribution of disease; therefore, given the hypothesized multifactorial aetiology for psychotic disorder, we examined the continuum hypothesis of psychopathology, and why people may shift over the continuum from low values, associated with subclinical psychotic experiences, to higher levels of psychotic disorder. 


\section{The affective domain}

The paradox of emotional dysfunction in psychotic disorder is historic. It was Bleuler who first argued that problems of affect lie at the heart of schizophrenia and that hallucinations and delusions are merely accessory and common to many forms of disorders. This was the view which gave way to the now familiar distinction between affective and non-affective psychosis. However, emotional dysfunction in patients with schizophrenia is common with the core symptoms and disabilities, develops rapidly and aggressively during the prodrome and early phase of the illness into a psychotic episode (Harrison et al., 2001). Following the first episode of psychosis, $50 \%$ of patients with schizophrenia report post-psychotic depression (Birchwood et al., 2000) for a period with a high risk for suicide (Westermeyer et al., 1991). One third of the patients report traumatic reactions, fulfilling the criteria of PTSD (McGorry et al., 1991), and 50\% report a fear of social interaction, i.e. social anxiety disorder (Cosoff et al., 1998). The most important issue for patients with psychotic disorders is the problem of developing and maintaining intimate relationships, leaving most of the patients in isolated and marginalized positions from social networks. The main question is whether these emotional problems are just a part of the psychotic disorder and should be categorized as negative symptoms such as blunted or flattened affect, or if they should be seen as the (childhood) emotional symptoms of (developing) psychotic disorder. The presence of affective dysregulation may be important, given that the presence of emotional disorders increases the probability of early relapse, and their presence in the prodromal phase may act as a risk factor for transition to psychotic disorder (Strakowski et al., 1995; Bechdolf et al., 2002; Lewandowski et al., 2006). One of the major findings in the study by Debbane et al. (2009) is that the expression of positive schizotypy during adolescence is modulated by emotional factors of depression and anxiety. These affective domains of psychosis, whether it is an affective or a non-affective psychotic disorder, will unfold in a social environment, e.g. the urban environment, social factors influencing the morbidity and outcome of psychotic disorder.

In Chapter 3, in the first article, 'Evidence that the urban environment specifically impacts on the psychotic but not the affective dimension of bipolar disorder', the potential overlap of environmental factors on the impact of affective and non-affective symptomatology was examined, specifically focusing on urbanicity and what the impact is of urbanicity on affective and psychotic symptom domains of bipolar disorder. In the first article, the main effect of urbanicity on the rate of the bipolar phenotype, narrowly and broadly defined, was examined in relation to specific symptom dimensions.

In the second article, 'The impact of subclinical psychosis on the transition from subclinical mania to bipolar disorder', the prevalences of subclinical mania and psychotic symptoms in the general population were examined and compared with their clinical counterparts. In addition, we examined how these subclinical population phenotypes, which are more prevalent than the clinical counterparts, co-vary with and impact on each other.

In the third article, 'Evidence that patients with single versus recurrent depressive episodes are differentially sensitive to treatment discontinuation: a meta-analysis of placebocontrolled randomized trials', we searched for evidence if there is a difference in sensitivity to treatment in depression, given that this is an affective symptom domain that is pertinent to psychotic disorder, including schizophrenia. The aim was to examine the issue of sensitisa- 
tion, in terms of progressively greater sensitivity to environmental stress, using a relapse rate paradigm following treatment over short or extended periods of time.

\section{Application to the prodrome}

In most cases of schizophrenia or bipolar disorder, the onset of disease is not a sudden event. Before onset, it has been found that in most cases the hospitalization was preceded by a prepsychotic phase in which attenuated or prodromal psychotic symptoms had been present for about a year, but sometimes as long as five years in the case of non-specific and negative symptoms (Hafner H, 2001). In this study, the onset of social disabilities also pre-dated the first admission to hospital by more than a year and pre-dated even the onset of positive symptoms. As a consequence of these findings, replicated across many studies (Cannon et al., 2008; McGorry et al., 2009; Valmaggia et al., 2009), the issue of prediction of psychosis requires further examination, given that: 1 ) the prodromal phase is present in the majority of patients with first-episode psychosis (Hafner $\mathrm{H}, 2001), 2$ ) it is a source of substantial suffering on the part of patients and their families, 3) deficits occur in the prodromal phase, and 4) help-seeking frequently occurs in the prodromal phase (Addington et al., 2002). Early detection and early treatment of psychosis may reduce the psychological, social and possibly biological alterations and deficits (Pantelis et al., 2003) that can lead to poor outcome. However, there is much confusion from different studies about the initial prodrome of psychosis or at risk mental state as the high-risk studies are based on the attenuated psychotic symptoms in selected groups of help-seeking individuals. Data are also needed on the prodrome and the risk of transition to psychotic disorder in representative general population samples.

In Chapter 4, we discuss in the first article, 'DSM-V and the 'Psychosis Risk Syndrome': Babylonic confusion', the validity of diagnostic entities in the psychosis spectrum and the new paradigm shift in clinical psychiatry to introduce a new category called the Psychosis Risk Syndrome in DSM-V, which now likely be relabelled as Attenuated Psychotic Symptom syndrome. The introduction of this new category is related to 1) important pioneering work on early intervention in selected high-risk populations and 2) international efforts emphasizing the major impact of early intervention on the course and outcome of psychotic disorders. This paper addresses whether the introduction of another new category in psychosis spectrum is required and whether it is based on valid nosological entities.

The second article entitled, 'The case of the missing evidence: what do subclinical psychosis spectrum experiences predict in unselected representative population samples? A systematic review enriched with new results', is a meta-analysis of existing literature, enriched with new results. We review literature on the risk of developing psychotic disorder given earlier expression of subclinical psychotic experiences in representative, general population samples. We also examine the risk of conversion to non-psychotic, mainly affective disorders, given presence of subclinical psychotic experiences in the general population and investigate which symptom factors moderate risk of conversion to a clinical disorder.

In Chapter 5, an English summary of all the studies included in this thesis is given.

In Chapter 6 the findings and conclusions of all studies described in this thesis are discussed, with recommendations for future research.

In Chapter $\mathbf{7}$ a Dutch summary of all the studies included in this thesis is given. 


\title{
Background information on the data of the two longitudinal studies used in the published studies
}

\author{
Introducing the NEMESIS study
}

In this thesis, we used the data pertaining to the Netherlands Mental Health Survey and Incidence Study (NEMESIS) in several publications (chapter 3, 4). A more detailed outline of the NEMESIS study is published by Bijl et al., (1998). This is a brief introduction to the NEMESIS study.

The NEMESIS study is a prospective study of prevalence, incidence and course of psychiatric disorders in a representative sample of non-institutionalized Dutch adults. A total of 7146 men and women eighteen to sixty-four years of age, contacted through a multistage sample of municipalities and households, were interviewed at home in 1996. The primary diagnostic interview of the NEMESIS study was the CIDI, which determines the lifetime occurrence of DSM-III-R disorders. The disorders that were included were mood disorders, anxiety disorders, eating disorders, schizophrenia and other non-affective psychotic disorders and dependence, and abuse of psychoactive substances. In this thesis, diagnostic data were used for all disorders with the exception of data regarding eating disorders. Follow-ups of the NEMESIS sample were scheduled at 12 and 36 months. The NEMESIS study had three measurement occasions: 1996, 1997 and 1999. The net response of the first measurement was $69.7 \%$. All respondents, with or without mental disorders at the time of the initial interview in 1996, were monitored for the whole duration of the study. There was no attrition that was differential with regard to mental health.

The objectives of the NEMESIS study are to obtain data on:

1) The prevalence of psychiatric morbidity amongst adults, eighteen to sixty-four years of age, in terms of subthreshold/subclinical (groups of symptoms that are potentially clinically relevant but that fail to satisfy the DSM criteria for a disorder) or clinical psychiatric disorders and the co-occurrence of psychological and (mainly chronic) somatic ailments. Psychiatric disorders are determined with the aid of DSM-III-R classification (APA, 1987).

2) The consequences of mental disorders in terms of care use and care needs, quality of life and functional impairments.

3) The incidence and course of disorders. By repeating the measurements, the identification of cases and monitoring of the course of existing disorders over time, in relation to changing life circumstances, was possible. NEMESIS was the first large-scale nationwide population study that was fully prospective.

4) Determinants of the emergence and the course of mental disorders were identified: in particular, socio-demographic characteristics, distressing recent and early life events (e.g. family history), care received, personality and vulnerability traits (e.g. self-esteem, neuroticism, locus of control) and support from the social environment. Biological and physical examinations are not provided in the NEMESIS study.

\section{Introducing the EDSP study}

In one publication, we also used data from the Early Developmental Stages of Psychopathology Study (EDSP). Detailed descriptions of the EDSP study have been published by Lieb et 
al., 2000; a brief introduction to the study will be given here. The EDSP study is a prospective longitudinal study investigating substance use and other mental disorders in a representative population sample of 3021 subjects, fourteen to twenty-one years of age (birth cohort 19701981) at baseline (TO) living in Munich, Germany. The age range was especially chosen specifically to address the early developmental stages of substance use, abuse and dependence and other mental disorders. Two follow-up investigations were conducted after the baseline investigation covering an overall period of three to four years. In the first follow-up moment (T1) only the younger cohort, fourteen to seventeen years of age at baseline was investigated, in order to be able to focus on the early developmental stages of psychopathology and substance use. In the final follow-up session (T2), the entire baseline sample was assessed again. Special design features are the linkage with a family supplement (EDSP-FS), an independent family survey to investigate familial contributions to the development of substance use and other mental disorders, as well as neurobiological laboratory studies of high-risk subjects. The response rates in the different waves of investigation ranged from $70.9 \%-88.0 \%$ and overall response rate was $84.3 \%$. The interviewers in all assessment stages comprised mainly graduated psychologists. Parental interviewers were in the age range of the targeted mothers and they were blind to the diagnoses of the respondents. All interviewers received training for one week for both the computerized as the paper-pencil version of the M-CIDI.

1) The primary goal of the EDSP study is to provide prevalence and incidence estimates of substance use, abuse and dependence among adolescents and young adults.

2) Secondly, the EDSP aims to study the natural course of early stages of substance use and substance use disorders (e.g. initiation of use, progression to abuse) over a period of several years and to identify risk factors that are associated with changes from one stage to another.

3) Further main goals of the EDSP study are to include the examination of comorbidity of substance use disorders with each other as well as with mental disorders and the investigation of familial vulnerability factors and mechanisms that may be involved in the onset and course of substance use disorders.

\section{Limitations of (epidemiological) studies}

One of the limitations of the NEMESIS data is that, although it was set up to reach a broad range of populations, it has not been able to reach certain groups, such as people with no fixed address, those with insufficient proficiency in Dutch and those who are institutionalized for a prolonged time. It is unclear what the impact is of missing data on these populations. For example, it is well known that the prevalence of psychiatric disorders is high in the group of homeless people, about two or three times higher as in the general population (Health Council, 1995), possibly missing out on an estimated $3 \%-5 \%$ of people with schizophrenia among the 20,000 homeless people in the Netherlands. The diagnosis of schizophrenia might not only be limited by this fact, but also because people with a diagnosis of schizophrenia can be presumed to be less willing or able to take part in an interview. Almost $38 \%$ of the people who, on the reference date, had been in hospital for over one year were diagnosed with schizophrenia (Mental Health Care Yearbook, 1995/1996). That means the schizophrenia prevalence found by the NEMESIS study is an absolute minimum. One other limitation con- 
cerns ethnicity. First generation immigrants were probably not well represented in the NEMESIS study because of language problems (inability to speak Dutch) and/or because of reduced willingness to participate. However, the younger age groups of these ethnic categories (Turkish and Moroccan origin) were reached by NEMESIS.

The advantage of the NEMESIS study is that a response rate above $60 \%$ is satisfactory and rare, because there are many scientific, non-scientific and commercial surveys in the Netherlands. The non-response group did not differ significantly from the response group in terms of psychiatric morbidity; they even had a better mental health. Another strength of the study is that the instrument (CIDI) used is widely used internationally. This creates possibilities to compare the NEMESIS data with data from abroad. Moreover, the fact that a computerized interviewing procedure has more advantages in terms of banning partial nonresponse, which avoids one major source of errors when data is entered manually. However, computerized interviews have their disadvantages, one of which was a technical error that led to missing data of 71 respondents. Another strong feature of the NEMESIS study is the one-step procedure in which all respondents underwent a full psychiatric interview. This is in contrast to other population studies in which a two-step approach is used that results in an indirect estimate. What they entail is a first step when a limited number of people for the interview are selected, and a second step logistic regression analysis has to be performed to compute for every score on the screening instrument the probability that the corresponding subject had a psychiatric disorder. These conversion factors are then applied to the entire sample to estimate the total prevalence of psychiatric cases (Health Council, 1995), leaving us with indirect estimates that may contain substantial error. The NEMESIS prevalence rates are not indirect estimates, and have a greater number of respondents, resulting in more accurate estimates and narrower confidence intervals than those in other studies.

As for the EDSP study, the strengths of this study are that it is a combined longitudinal characterization of psychopathology and substance use behaviours and disorders. It is a longitudinal prospective assessment of various risk and protective factors that are involved in the development of substance use and other mental disorders and conducted in a representative sample of adolescents and in young adults with a characterization of family factors. The fact that the EDSP study is conducted in a prospective longitudinal fashion, in a representative population sample, is essential for an unbiased characterization of the psychopathology status of the population and the identification of risk factors, in contrast to clinical samples that are usually influenced by selection bias and in general allow only for retrospective approaches. Therefore, the EDSP study not only provides a description of prevalence and prospectively observed incidence patterns of substance use and mental disorders in a target population on various diagnostic levels such as asymptomatic, symptomatic, subthreshold and full diagnostic level, but it also offers an adequate basis for investigating a variety of familial, cognitive-behavioural and social risk factors, and in particular, their status as causal risk factors. The study also enables one to study various public health related consequences of substance use and other mental disorders prospectively and unaffected by recall bias. 


\section{References}

Addington J, Van Mastrigt S, Hutchinson J, Addington D (2002). Pathways to care: help-seeking behaviour in firstepisode psychosis. Acta Psychiatr Scand, 106(5):358-64.

Aleman A, Kahn RS, Selten JP (2003). Sex differences in the risk of schizophrenia: evidence from meta-analysis. Arch Gen Psychiatry, 60(6):565-71.

Andreasen NC (1985). Positive vs. negative schizophrenia: a critical evaluation. Schizophr Bull, 11(3):380-9.

Angst J (1998). The emerging epidemiology of hypomania and bipolar II disorder. J Affect Disord, 50(2-3):143-51.

Arnold LM (2003). Gender differences in bipolar disorder. Psychiatr Clin North Am, 26(3):595-620.

Arnone D, Cavanagh J, Gerber D, Lawrie SM, Ebmeier KP, McIntosh AM (2009). Magnetic resonance imaging studies in bipolar disorder and schizophrenia: meta-analysis. Br J Psychiatry, 195(3):194-201.

Badner JA \& Gershon ES (2002). Meta-analysis of whole-genome linkage scans of bipolar disorder and schizophrenia. Mol Psychiatry, 7(4):405-11.

Bebbington P, Ramana R (1995). The epidemiology of bipolar affective disorder. Soc Psychiatry Psychiatr Epidemiol, 30(6):279-92.

Bebbington P, Wilkins S, Jones P, Foerster A, Murray R, Toone B, Lewis S (1993). Life events and psychosis. Initial results from the Camberwell Collaborative Psychosis Study. Br J Psychiatry, 162:72-9.

Bechdolf A, Schultze-Lutter F \& Klosterkotter, J (2002). Self-experienced vulnerability, prodromal symptoms and coping strategies preceding schizophrenic and depressive relapses. Eur Psychiatry, 17(7), 384-393.

Bijl RV, van Zessen G, Ravelli A, de Rijk C, Langendoen Y (1998). The Netherlands Mental Health Survey and Incidence Study (NEMESIS): objectives and design. Soc Psychiatry Psychiatr Epidemiol, 33(12):581-6.

Birchwood M, Iqbal Z, Chadwick P, Trower P (2000). Cognitive approach to depression and suicidal thinking in psychosis. 1. Ontogeny of post-psychotic depression. Br J Psychiatry, 177:516-21.

Blanchard JJ, Kring AM, Horan WP \& Gur R (2010). Toward the Next Generation of Negative Symptom Assessments: The Collaboration to Advance Negative Symptom Assessment in Schizophrenia. Schizophr Bull, Sep 22. [Epub ahead of print].

Cannon M, Caspi A, Moffitt TE, Harrington H, Taylor A, Murray RM, Poulton R (2002). Evidence for early-childhood, pan-developmental impairment specific to schizophreniform disorder: results from a longitudinal birth cohort. Arch Gen Psychiatry. 2002 May;59(5):449-56.

Cannon TD, Cadenhead K, Cornblatt B, Woods SW, Addington J, Walker E, Seidman LJ, Perkins D, Tsuang M, McGlashan T \& Heinssen R (2008). Prediction of psychosis in youth at high clinical risk: a multisite longitudinal study in North America. Arch Gen Psychiatry, 65(1), 28-37.

Cardno AG, Rijsdijk FV, Sham PC, Murray RM, McGuffin P (2002). A twin study of genetic relationships between psychotic symptoms. Am J Psychiatry, 159(4):539-45.

Chadwick P, Birchwood M (1994). The omnipotence of voices. A cognitive approach to auditory hallucinations. Br J Psychiatry, 164(2):190-201.

Cosoff SJ, Häfner RJ (1998). The prevalence of comorbid anxiety in schizophrenia, schizoaffective disorder and bipolar disorder. Aust N Z J Psychiatry, 32(1):67-72.

Crow TJ (1986). The continuum of psychosis and its implication for the structure of the gene. Br J Psychiatry, 149:419-29.

Crow TJ, Done DJ, Sacker A (1995). Childhood precursors of psychosis as clues to its evolutionary origins. Eur Arch Psychiatry Clin Neurosci, 224: 61-69.

David AS, Malmberg A, Brandt L, Allebeck P, Lewis G (1997). IQ and risk for schizophrenia: a population-based cohort study. Psychol Med, 27(6):1311-23.

Debbane M, Van der Linden M, Gex-Fabry M \& Eliez S (2009). Cognitive and emotional associations to positive schizotypy during adolescence. J Child Psychol Psychiatry, 50(3), 326-334.

De Mamani AG (2010). Self-conscious emotions, general emotional distress, and expressed emotion in family members of patients with schizophrenia. J Nerv Ment Dis, 198(4), 305-308.

Der G, Bebbington P (1987). Depression in inner London. A register study. Soc Psychiatry, 22(2):73-84.

Escher S, Romme M, Buiks A, Delespaul P, Van Os J (2002a). Independent course of childhood auditory hallucinations: a sequential 3-year follow-up study. Br J Psychiatry, Suppl. 43:s10-8.

Escher S, Romme M, Buiks A, Delespaul P, Van Os J (2002b). Formation of delusional ideation in adolescents hearing voices: a prospective study. Am J Med Genet, 114(8):913-20. 
Fallin MD, Lasseter VK, Avramopoulos D, et al. (2005). Bipolar I disorder and schizophrenia: a 440-single-nucleotide polymorphism screen of 64 candidate genes among Ashkenazi Jewish case-parent trios. Am J Hum Genet, 77(6), 918-936.

Faridi K, Pawliuk N, King S, Joober R \& Malla AK (2009). Prevalence of psychotic and non-psychotic disorders in relatives of patients with a first-episode psychosis. Schizophr Res, 114(1-3), 57-63.

Frangou S, Raymont V, Bettany D (2002). The Maudsley bipolar disorder project. A survey of psychotropic prescribing patterns in bipolar I disorder. Bipolar Disord, 4(6):378-85.

Gottesman II \& Gould TD (2003). The endophenotype concept in psychiatry: etymology and strategic intentions. Am J Psychiatry, 160(4):636-45.

Grozeva D, Kirov G, Ivanov D, et al. (2010). Rare copy number variants: a point of rarity in genetic risk for bipolar disorder and schizophrenia. Arch Gen Psychiatry, 67(4), 318-327.

Häfner H, van der Heiden W (1999). The course of schizophrenia in the light of modern follow-up studies: the $A B C$ and WHO studies. Eur Arch Psychiatry Clin Neurosci, 249 Suppl 4:14-26.

Häfner H (2001). Onset and early course as determinants of the further course of schizophrenia. Acta Psychiatr Scan Suppl. (407):44-8.

Harrison G, Hopper K, Craig T, et al. (2001). Recovery from psychotic illness: a 15- and 25-year international followup study. Br J Psychiatry, 178, 506-517.

Hoge EA, Friedman L, Schulz SC (1999). Meta-analysis of brain size in bipolar disorder. Schizophr Res, 25; 37(2):17781.

Ingason A, Giegling I, Cichon S, et al. (2010). A large replication study and meta-analysis in European samples provides further support for association of AHI1 markers with schizophrenia. Hum Mol Genet, 19(7), 1379-1386.

Jones P \& Murray RM (1991). The genetics of schizophrenia is the genetics of neurodevelopment. Br J Psychiatry, 158:615-23.

Jones P, Rodgers B, Murray R, Marmot M (1994). Child development risk factors for adult schizophrenia in the British 1946 birth cohort. Lancet, 19; 344(8934):1398-402.

Kaymaz N, Van Os J (2009). Murray et al. (2004) revisited: is bipolar disorder identical to schizophrenia without developmental impairment? Acta Psychiatr Scand. Oct;120(4):249-52.

Kaymaz, N., \& van Os, J. (2010). Extended psychosis phenotype - yes: single continuum - unlikely. Psychological Medicine, 40(12), 1963-1966.

Kendell RE, Gourlay J (1970). The clinical distinction between the affective psychoses and schizophrenia. Br J Psychiatry, 117(538): 261-6.

Kennedy BL, Dhaliwal N, Pedley L, Sahner C, Greenberg R, Manshadi MS (2002). Post-Traumatic Stress Disorder in subjects with schizophrenia and bipolar disorder. J Ky Med Assoc, 100(9): 395-9.

Ketter TA (2010). Diagnostic features, prevalence, and impact of bipolar disorder. J Clin Psychiatry. Jun;71(6):e14. Review.

Koreen AR, Siris SG, Chakos M, Alvir J, Mayerhoff D, Lieberman J (1993). Depression in first-episode schizophrenia. Am J Psychiatry, 150(11):1643-8.

Krabbendam L, Myin-Germeys I, De Graaf R, Vollebergh W, Nolen WA, ledema J, Van Os J (2004). Dimensions of depression, mania and psychosis in the general population. Psychol Med, 34(7):1177-86.

Krishnan KR (2005). Psychiatric and medical comorbidities of bipolar disorder. Psychosom Med, 67(1):1-8.

Leboyer M, Bellivier F, Nosten-Bertrand M, Jouvent R, Pauls D, Mallet J (1998). Psychiatric genetics: search for phenotypes. Trends Neurosci, 21(3):102-5.

Lewandowski KE, Barrantes-Vidal N, Nelson-Gray RO, Clancy C, Kepley HO, Kwapil TR (2006). Anxiety and depression symptoms in psychometrically identified schizotypy. Schizophr Res. Apr;83(2-3):225-35.

Lewis CM, Levinson DF, Wise LH, et al. (2003). Genome scan meta-analysis of schizophrenia and bipolar disorder, part II: Schizophrenia. Am J Hum Genet, 73(1):34-48.

Lichtenstein P, Yip BH, Björk C, Pawitan Y, Cannon TD, Sullivan PF, Hultman CM (2009). Common genetic determinants of schizophrenia and bipolar disorder in Swedish families: a population-based study. Lancet. Jan 17;373(9659):234-9.

Lieb R, Isensee B, von Sydow K, Wittchen HU (2000). The Early Developmental Stages of Psychopathology Study (EDSP): a methodological update. Eur Addict Res, 6(4):170-82.

Linscott RJ \& Van Os J (2010). Systematic reviews of categorical versus continuum models in psychosis: evidence for discontinuous subpopulations underlying a psychometric continuum. Implications for DSM-V, DSM-VI, and DSMVII. Annu Rev Clin Psychol, 6, 391-419. 
Lloyd T, Kennedy N, Fearon P, Kirkbride J, Mallett R, Leff J, Holloway J, Harrison G, Dazzan P, Morgan K, Murray RM, Jones PB; AESOP study team (2005). Incidence of bipolar affective disorder in three UK cities: results from the AESOP study. Br J Psychiatry, 186:126-31.

McDonald C, Bullmore ET, Sham PC, Chitnis X, Wickham H, Bramon E, Murray RM (2004). Association of genetic risks for schizophrenia and bipolar disorder with specific and generic brain structural endophenotypes. Arch Gen Psychiatry, 61(10):974-84.

McGorry PD, Chanen A, McCarthy E, Van Riel R, McKenzie D, Singh BS (1991). Post-traumatic stress disorder following recent-onset psychosis. An unrecognized post-psychotic syndrome. J Nerv Ment Dis, 179(5):253-8.

McGorry PD, Yung AR, Pantelis C, Hickie IB (2009). A clinical trials agenda for testing interventions in earlier stages of psychotic disorders. Med J Aust, 190(4 Suppl):S33-6.

McGuffin P, Reveley A, Holland A. (1982). Identical triplets: non-identical psychosis. Br J Psychiatry, 140:1-6.

McGuffin P, Rijsdijk F, Andrew M, Sham P, Katz R, Cardno A (2003). The heritability of bipolar affective disorder and the genetic relationship to unipolar depression. Arch Gen Psychiatry, 60(5):497-502.

Montoya A, Tohen M, Vieta E, Casillas M, Chacón F, Polavieja P, Gilaberte I (2010). Functioning and symptomatic outcomes in patients with bipolar I disorder in syndromal remission: a 1-year, prospective, observational cohort study.J Affect Disord. Dec;127(1-3):50-7.

Mueser KT, McGurk SR (2004). Schizophrenia. Lancet, 19;363(9426):2063-72.

Murray RM, Sham P, Van Os J, Zanelli J, Cannon M, McDonald C (2004). A developmental model for similarities and dissimilarities between schizophrenia and bipolar disorder. Schizophr Res, 71(2-3):405-16.

Osby U, Hammar N, Brandt L, Wicks S, Thinsz Z, Ekbom A, Sparén P (2001). Time trends in first admissions for schizophrenia and paranoid psychosis in Stockholm County, Sweden. Schizophr Res, 47(2-3):247-54.

Pantelis C, Yücel M, Wood SJ, McGorry PD, Velakoulis D (2003). Early and late neurodevelopmental disturbances in schizophrenia and their functional consequences. Aust N Z J Psychiatry, 37(4):399-406.

Post RM (1992). Transduction of Psychosocial Stress Into the Neurobiology of Recurrent Affective Disorder. Am J Psychiatry 1992; 149:999-1010.

Regeer E J, Krabbendam L, De Graaf R, Have MT, Nolen WA \& Van Os, J (2009). Berkson's bias and the mood dimensions of bipolar disorder. Int J Methods Psychiatr Res, 18(4), 279-286.

Sheitman BB, Lee H, Strous R, Lieberman JA (1997). The evaluation and treatment of first-episode psychosis. Schizophr Bull, 23(4):653-61. Erratum in: Schizophr Bull 2006, 32(2):401.

Shergill SS, Robertson MM, Stein G, Bernadt M, Katona CL (1999). Outcome in refractory depression. J Affect Disord, 54(3):287-94.

Shields J \& Slater E (1975). Genetic aspects of schizophrenia. Br J Psychiatry, Spec No 9:32-40.

Stefansson H, Ophoff RA, Steinberg S, et al. (2009). Common variants conferring risk of schizophrenia. Nature, 460(7256):744-7.

Strakowski SM, Keck PE Jr, McElroy SL, West SA, Sax KW, Hawkins JM, Kmetz GF, Upadhyaya VH, Tugrul KC, Bourne ML (1998). Twelve-month outcome after a first hospitalization for affective psychosis. Arch Gen Psychiatry. Jan;55(1):49-55.

Strakowski SM, Keck PE Jr, McElroy SL, Lonczak HS, West SA (1995). Chronology of comorbid and principal syndromes in first-episode psychosis. Compr Psychiatry, 36(2):106-12.

Taylor MA (1992). Are schizophrenia and affective disorder related? A selective literature review. Am J Psychiatry, 149(1):22-32.

Tijssen MJ, Van Os J, Wittchen HU, Lieb R, Beesdo K, Mengelers R, et al. (2010). Evidence that bipolar disorder is the poor outcome fraction of a common developmental phenotype: an 8-year cohort study in young people. Psychol Med, 40(2), 289-299.

Valmaggia LR, McCrone P, Knapp M, Woolley JB, Broome MR, Tabraham P, Johns LC, Prescott C, Bramon E, Lappin J, Power P, McGuire PK (2009). Economic impact of early intervention in people at high risk of psychosis. Psychol Med, 39(10):1617-26.

Van Os J (2009). 'Salience syndrome' replaces 'schizophrenia' in DSM-V and ICD-11: psychiatry's evidence-based entry into the 21st century? Acta Psychiatr Scand, 120(5):363-72.

Van Os J \& Kapur S (2009). Schizophrenia. Lancet, 374(9690):635-45.

Van Os J, Linscott RJ, Myin-Germeys I, Delespaul P \& Krabbendam L (2009). A systematic review and meta-analysis of the psychosis continuum: evidence for a psychosis proneness-persistence-impairment model of psychotic disorder. Psychol Med, 39(2), 179-195.

Van Os J, Jones P, Lewis G, Wadsworth M, Murray R (1997). Developmental precursors of affective illness in a general population birth cohort. Arch Gen Psychiatry, 54(7):625-31. 
Van Os J, Takei N, Castle DJ, Wessely S, Der G, MacDonald AM, Murray RM (1996). The incidence of mania: time trends in relation to gender and ethnicity. Soc Psychiatry Psychiatr Epidemiol, 31(3-4):129-36.

Van Os J, Verdoux H, Maurice-Tison S, Gay B, Liraud F, Salamon R, Bourgeois M (1999). Self-reported psychosis-like symptoms and the continuum of psychosis. Soc Psychiatry Psychiatr Epidemiol, 34(9):459-63.

Van Snellenberg JX \& de Candia T (2009). Meta-analytic evidence for familial co-aggregation of schizophrenia and bipolar disorder. Arch Gen Psychiatry, 66(7), 748-755.

Ventura J, Nuechterlein KH, Lukoff D, Hardesty JP (1989). A prospective study of stressful life events and schizophrenic relapse. J Abnorm Psychol, 98(4):407-11.

Westermeyer JF, Harrow M, Marengo JT (1991). Risk for suicide in schizophrenia and other psychotic and nonpsychotic disorders. J Nerv Ment Dis, 179(5):259-66.

Wright IC, Rabe-Hesketh S, Woodruff PW, David AS, Murray RM, Bullmore ET (2000). Meta-analysis of regional brain volumes in schizophrenia. Am J Psychiatry, 157(1):16-25. 
CHAPTER 2

Developmental studies of psychosis 


\title{
HERITABILITY OF STRUCTURAL BRAIN TRAITS: AN ENDOPHENOTYPE APPROACH TO DECONSTRUCT SCHIZOPHRENIA
}

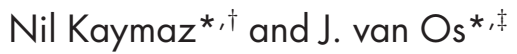 \\ *Department of Psychiatry and Psychology, University of Maastricht, \\ P.O. Box 616 (DRT10) Maastricht, The Netherlands \\ ${ }^{\dagger}$ Mediant GGZ/Mental Health Care, Postbus 775, 7500 AT Enschede, The Netherlands \\ ${ }^{\ddagger}$ Division of Psychological Medicine, Institute of Psychiatry, London, United Kingdom
}

I. Introduction

A. Endophenotypic Approach to Studying Schizophrenia

B. Neuroanatomic Measures as Endophenotype

C. Heritability Estimates to Determine Contribution of Genetic

Factors to Structural Brain Traits

D. Nonhuman Primate Model for Studying Brain Neurostructural Studies

II. Heritability of Brain Structure Phenotypes

A. Heritability of Brain Structures in Healthy Persons

B. Heritability of Brain Structures in Patients with Schizophrenia Compared to Healthy Controls

C. Heritability of Brain Structures in Nonhuman Primates (Monkeys)

III. Genes for Brain Structures in Healthy and Persons with Schizophrenia

A. Genes for Brain Structures in Healthy Persons

B. Genes for Brain Structures in Patients with Schizophrenia

IV. Limitations and Clinical Relevance of the Studies
A. Limitations of Neuroimaging Studies
B. Limitations of Twin Studies
C. Limitations of Nonhuman Primate Studies
D. Clinical Relevance of the Heritability Estimations
E. Implications of These of Brain Volumes as Endophenotypes for Genetics of Psychiatric Disorders
References

Structural brain phenotypes are quantitative traits showing considerable variation in human populations. Quantitative structural brain abnormalities are also repeatedly reported in patients with psychiatric disorders such as schizophrenia. Studying the genetic and environmental causes of these differences might therefore highlight biological mechanisms underlying neuroanatomical phenotypes and directly result in the identification of risk factors for schizophrenia. Heritability estimates indicate a strong genetic component contributing to neuroanatomical phenotypes. Brain structure volumes have substantial heritability 
rates ranging from high (70-95\%) for total brain volume, cerebellar, gray and white matter, and corpus callosum, to moderate (40-70\%) determined for the hippocampus, the four lobes (frontal, temporal, occipital, and parietal lobe), temporal horn volume, brain parenchyma, white matter hyperintensity, and planum temporal asymmetry. Middle structures of the brain show high heritability scores for the deeper structures (ontogenetically earlier formed) and moderate heritability scores for the surface structures. Structures formed earlier in development show consistently higher heritability rates than brain structures formed later in development, for example, surface structures, which seem to be influenced by environmental factors. Even higher heritability reaching 0.99 for total brain volume are estimated in nonhuman primate (NHP) models employing inbred extended pedigree and highly uniform rearing conditions, reducing the effects of environmental factors. Applying highly heritable structural brain phenotypes may serve as an endophenotype for gene mapping studies and lead to identification of genes that are involved in the regulation of human brain volume and the biological mechanisms involved in the causal mechanisms of psychiatric disorders.

\section{Introduction}

\section{A. Endophenotypic Approach to Studying Schizophrenia}

Schizophrenia is a highly heritable disorder (Cannon et al., 1998; Cardno and Gottesman, 2000; Sullivan et al., 2003) characterized by delusions, hallucinations, disorganized speech (frequent derailment or incoherence), grossly disorganized or catatonic behavior, and negative symptoms, that is, affective flattening, alogia (poverty of speech) and avolition (general lack of desire, interest or motivation to pursue meaningful goals) (DSM-IV-Tr, 2000). It is believed that this complex phenotype of schizophrenia is a result of underlying complex genetic architecture involving interactions between multiple loci and environmental factors (van Os et al., 2008). Another source of difficulty is the reliability of phenotypic assessments. Schizophrenia diagnostics employ a patient's self-reports rather than biochemical, electrophysiological, or other reliably measurable biomarkers. The validity of schizophrenia as a diagnostic entity has therefore been criticized by a number of scientists and clinicians as lacking in scientific validity and diagnostic reliability (Bentall et al., 2004; Boyle, 2002; Kendell and Jablensky, 2003; Linscott et al., 2009; van Os, 2009; van Os and Murray, 2008). Due to the diagnostic heterogeneity and the genetic and phenotypic complexity of 
schizophrenia, as well as other complex brain-related disorders, identification of a genetic basis of this disease is a very challenging task.

The endophenotypic approach is one of several strategies that have been adopted to deal with the complexities of these disorders and identify underlying genes (Gottesman and Gould, 2003). The principle of this approach is to reduce complex phenotypes into components (neurophysiological, biochemical, endocrine, cognitive, neuropsychological, or neuroanatomical phenotypes) that could be reliably quantified and are under close regulation by genetic variation. The endophenotype (or intermediate phenotype) is therefore a kind of biomarker that, unlike disease diagnosis, has a clearer underlying biological and genetic basis. They are expected to be genetically correlated with disease liability, and can be measured in both affected and unaffected individuals. Since quantitative endophenotypes are generally closer to the action of the gene and are measurable in both unaffected and controls, they exhibit higher genetic signal-to-noise ratios and are anticipated to provide a greater power to localize and identify disease-related quantitative trait loci (QTLs) than affection status alone (Blangero et al., 2003).

Human studies often use endophenotypes that are related to evolutionary conserved traits and therefore can be extended to animal models.

\section{B. Neuroanatomic Measures as Endophenotype}

Volumes of various brain structures are quantitative phenotypes that can be reliably measured on MRI scans using either automated (voxel-based morphometry method, VBM; deformation-based morphometry; surface-based morphometry) or manual tracing (region and volume of interest, ROI and VOI method) (Ashburner and Friston, 2000; Good et al., 2001a; Thompson and Toga, 1997; Thompson et al., 1996a,b). Brain structure measurements show considerable interindividual variation in general populations and differences between healthy and affected persons, and are therefore considered promising candidate endophenotypes that might facilitate investigations of a genetic basis into the natural variation of brain-related traits in populations and for psychiatric disorders such as schizophrenia. When measuring brain structure and the heritability of these structures, normal neuroanatomical variations in the human brain should be taken into account (Allen et al., 2002). These neuroanatomical variations are under the influence of variables such as gender (Cosgrove et al., 2007; Giedd, 2008) and age (Carne et al., 2006; Good et al., 2001b), or other components of genetic variety such as height (Kappelman, 1993). Intelligence seems to be related to brain volume as well. In humans, brain volume is a quantitative trait with high heritability (Posthuma et al., 2002b; Thompson et al., 2001, 2002). Previous studies have shown that brain volume is also correlated with general intelligence, working memory, perceptual organization, and processing speed, which are also highly 
heritable (Posthuma et al., 2003; Roth and Dicke, 2005). In recent years, it has been discovered that the structure of the adult human brain changes when new cognitive or motor skills, including vocabulary, are learned (Lee et al., 2007), and that this structural neuroplasticity (increased gray matter volume), after 3 months of training a visual motor skill, seems to last for at least 3 months without further practicing (Driemeyer et al., 2008; Ilg et al., 2008). Another example is the impact of handedness, which has a significant genetic component (Annett, 1974; McManus and Bryden, 1991) and is strongly related with cerebral asymmetry (Alexander and Annett, 1996; Geschwind and Galaburda, 1985). To what extend the cerebral asymmetry is also heritable remains unclear (Geschwind et al., 2002). The neuroanatomical phenotype and the heritability of brain structures varies among individuals with a neuropsychiatric disorder, meaning that the influence the disease state has on the heritability is such that the morphology of brain structures can be altered by the disease state and these morphologically altered brain structures can be inherited. For example, there are studies showing small hippocampal volumes in adult humans with recurrent major depression (Bremner et al., 2000; Sheline et al., 1999) and posttraumatic stress disorder (Bremner et al., 1995). Hippocampal morphology is also altered by stress in carefully controlled studies with rodents (Gould and Tanapat, 1999; Magarinos et al., 1995; Sapolsky, 2000). These smaller hippocampi have been taken as evidence that stress-related disorders induce hippocampal volume loss (Sapolsky, 2000; Sheline et al., 1999). One possible pathway by which altered brain morphology changes might be inherited is that small hippocampal volumes are inherited and act as predisposing factors toward the development of psychiatric disorders that are triggered by stress (Gurvits et al., 1996; Sapolsky, 2000).

When measuring brain structure volumes and calculating heritability estimates, these variables, having a strong genetic component themselves, should be taken into account.

\section{Heritability Estimates to Determine Contribution of Genetic Factors to Structural Brain Traits}

\section{(to study genetics of both natural and disease-related variation)}

Twin and adoption studies have shown substantial genetic influences are involved in the risk of developing schizophrenia (Cannon et al., 1998; Cardno et al., 2002; Kendler and Diehl, 1993; McGuffin et al., 1984). The identification of predisposing genes has been hampered by difficulties in detecting nonpenetrant carriers and by uncertainties concerning the extent of locus of heterogeneity (McDonald and Murphy, 2003). By studying the inheritance of endophenotypes, we can increase the power to detect the genes involved in clarifying the pathways leading from genetic predisposition to clinical disorder 
(Gottesman and Gould, 2003). One of the most extensively studied endophenotypes in schizophrenia research is the study of structural brain abnormalities. These structural changes are well established in schizophrenia. The most robust findings from meta-analyses of these structural brain abnormalities is increased total ventricular volume, reduction of whole brain and intracranial volume, reduced hippocampal and amygdalar volume (Lawrie and Abukmeil, 1998; Ward et al., 1996; Wright et al., 2000). These brain abnormalities are also present in unaffected family members of patients with schizophrenia, to a less degree, but significantly more than in controls according to a meta-analysis reporting on brain changes in unaffected family members of patients with schizophrenia (Boos et al., 2007; van Haren et al., 2004).

One hypothesis in using these structural abnormalities as endophenotypes, in order to get closer to the action of the genes, suggests that there might be an overlap in the neurodevelopmental genes responsible for both the volume change and the development of the illness, that is, the existence of a genetic correlation. Schizophrenia may involve genetically determined pathological processes of early brain development which continue to unfold as the brain matures through neuronal loss and synaptic pruning during adolescence. Neurodevelopmental abnormalities then lead to the activation of pathological neural circuits, which respond to environmental stressors, leading to the emergence of symptoms (Deutch, 1993). This hypothesis is supported by the finding that MRI abnormalities are present at the onset of the illness, and progress very slowly if at all (Weinberger, 1995). A contrasting view on the etiology of schizophrenia is that the relationship between schizophrenia and brain volumes might be environmental in nature. For example, perinatal trauma has been shown to be an important determinant of some brain structure abnormalities in schizophrenia (Cannon et al., 2003; McNeil, 2000; Verdoux et al., 1997).

Defining to what degree the development of these brain structures is of genetic origin, that is, the heritability of brain structures, and using these brain structures as an endophenotype may be helpful in better identifying the action of these neurodevelopmental genes. Heritability estimates for brain structures in healthy persons and persons with schizophrenia will help to differentiate between disease related alterations in brain morphology and genetic influences (heritability).

Twin studies are considered important in investigating genetic influences on variation in human brain morphology in healthy individuals and those with schizophrenia. The twin model is particularly helpful in determining the relative contribution of genetic, common, and unique environmental influences on variation in brain structures (Posthuma and Boomsma, 2000). Heritability estimates of brain structure are usually based on data from monozygotic twins (MZ, who are nearly genetically identical) and dizygotic twins (DZ, who share on average $50 \%$ of their segregating genes). If heritability estimates are based on the assumption that for a certain brain measure, $\mathrm{MZ}$ twin pairs will resemble each other more closely than DZ twin pairs, it can be inferred that variation of the brain measure is 
heritable. However, in addition to genetic influences, common (or shared) environmental influences may play a role in explaining resemblances. The effects of shared environmental factors may be suggested when correlations in DZ twins are larger than half of the MZ correlation (Boomsma et al., 2002). The effects of unique environmental factors are obtained from the extent to which MZ twins do not resemble each other. However, the twin method has been criticized for its nongeneralizability due to differences in intrauterine and family environment differences between the twins and compared with singletons (Price, 1950).

Heritability estimates and the search for genes in diseased and nondiseased humans are difficult due to the impact of environmental factors. Studies in nonhuman primates (NHPs) might be helpful in elucidating the impact of environmental factors.

\section{Nonhuman Primate Model for Studying Brain Neurostrugtural Studies}

Obstacles in investigating complex traits in human subjects involve the hard-tocontrol and extensive effects of environment, personal development, and medical history including administrated medications. To a large extent, these problems can be overcome by applying an animal model. Particularly useful are NHPs due to the high conservation of anatomical, neurophysiological and cognitive traits as well genetic sequence with humans. NHP pedigrees have helped studies of various complex traits including the neruoanatomical due mostly to the availability of pedigree facilitating genetic studies, established genetic relationships among pedigree animals, well-documented medical and developmental history and uniform rearing conditions reducing the influence of environmental factors.

To disentangle the possible mechanisms by which genetic and environmental factors contribute to the morphological abnormalities in the brain animal models may be used, specifically NHPs, for example, monkey brains, in which the influence of environment is reduced. The evolution of cognitive function in hominoids, for example, depends largely on our understanding of the organization of the frontal lobes in extant humans and apes (Semendeferi et al., 1997). There are studies with findings showing similarities to human brains, such as the possibility of microstructural plasticity in the NHP hippocampus (Sapolsky et al., 1990; Siegel et al., 1993; Uno et al., 1989). Other studies show the impact of environmental factors on the volumes of different brain structures, such as the affect of differential rearing on the corpus callosum size in rhesus monkeys (Sánchez et al., 1998). Studies on brain characteristics and the genetic variation of regional brain morphologies of NHPs will help us understand the meaning of the brain characteristics in humans as well. They will also help us determine whether certain assumptions, such as those about certain brain characteristics 
being strictly unique to humans, are correct. For example, it is often claimed that the frontal lobe is disproportionately larger in humans than in other species, but conflicting reports exist on this issue. Results of a study by Semendeferi et al. (1997) indicate that although the absolute volume of the brain and the frontal lobe is the largest in humans, the relative size of the frontal lobe is similar across hominoids and humans do not have a larger frontal lobe than expected from a primate brain of human size. Other important functional parts of the brain, like area 10 in cortical areas of the frontal lobe, which is involved in higher cognitive functions, also seem to form the frontal pole in chimpanzee, bonobo, orangutan, macaque, and gibbon brains. Area 10 has similar cytoarchitectonic features in the hominoid brain, but aspects of its organization vary slightly across species, including relative width of its cortical layers and the space available for connections (Semendeferi et al., 2001). Although some features of the human brain, like the asymmetric Broca's area and the planum temporal in Wernicke's posterior receptive language area in the left hemisphere, were thought to be unique to humans, studies in great apes (Cantalupo and Hopkins, 2001) and chimpanzees (Gannon et al., 1998) show the same anatomic hemispheric asymmetry in the Broca's area and planum temporal, respectively.

\section{Heritability of Brain Structure Phenotypes}

Heritability estimates allow for determining which neuroanatomical measures are traits with marked genetic components and could therefore be interesting both from the perspective of natural variation in brain related processes in population and as an attractive endopehnotype for schizophrenia studies. Investigating heritability in various aspects in healthy individuals, in relation to schizophrenia and in the NHP model, may answer two essential questions: (1) to what degree are brain volumes genetically determined? and, (2) which brain volumes are mostly heritable and therefore useful as endophenotypes for genetic studies?

\section{A. Heritability of Brain Structures in Healthy Persons}

There are 24 studies reporting on heritability of brain structures in healthy persons. These studies are listed in Tables I and II, where the measured brain structures, the heritability rates of these brain structures or regions (denoted as $h^{2}$ or as ICG or as Risch's $\lambda$ ), and the method of calculating heritability (in superscript) is given, besides the sample size/mean age of the persons (twins, singletons, family members)/sex ratio/other variables, whenever available and mentioned in the articles are reported in the table as well, with the study ID and 


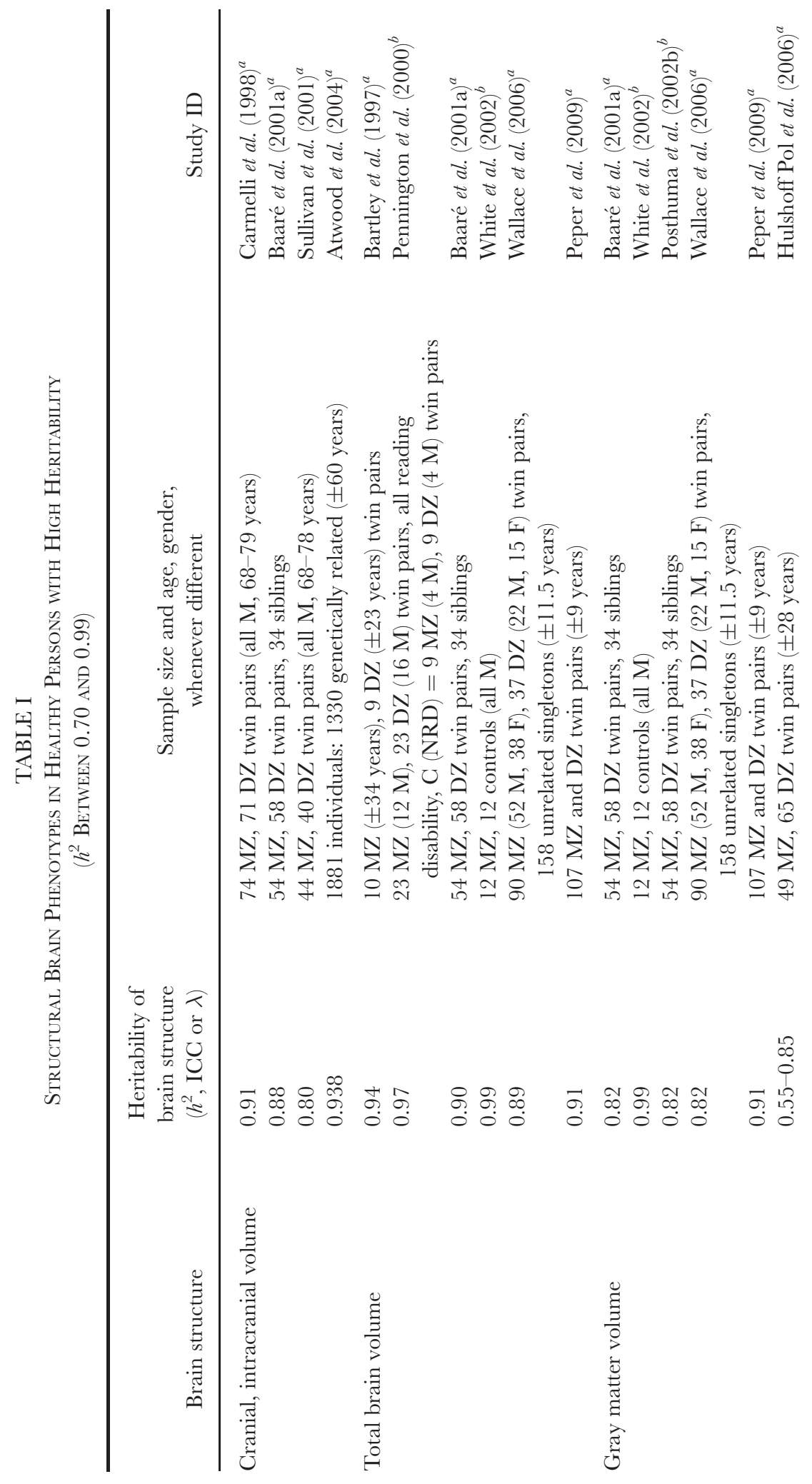




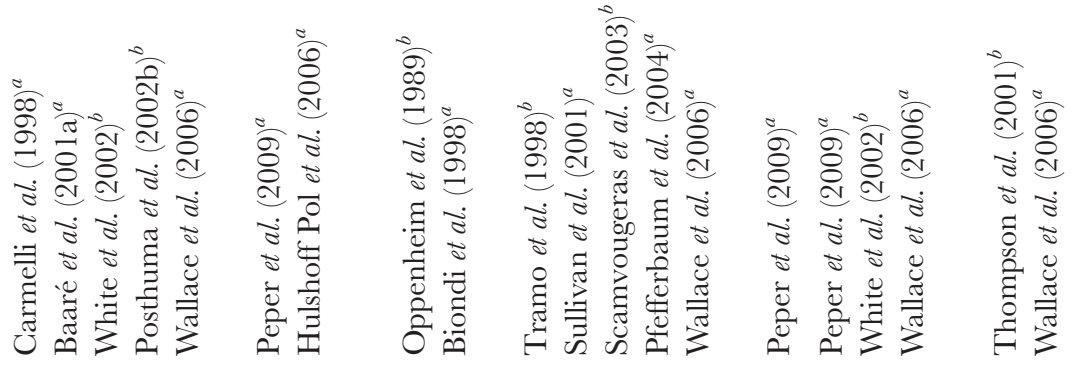

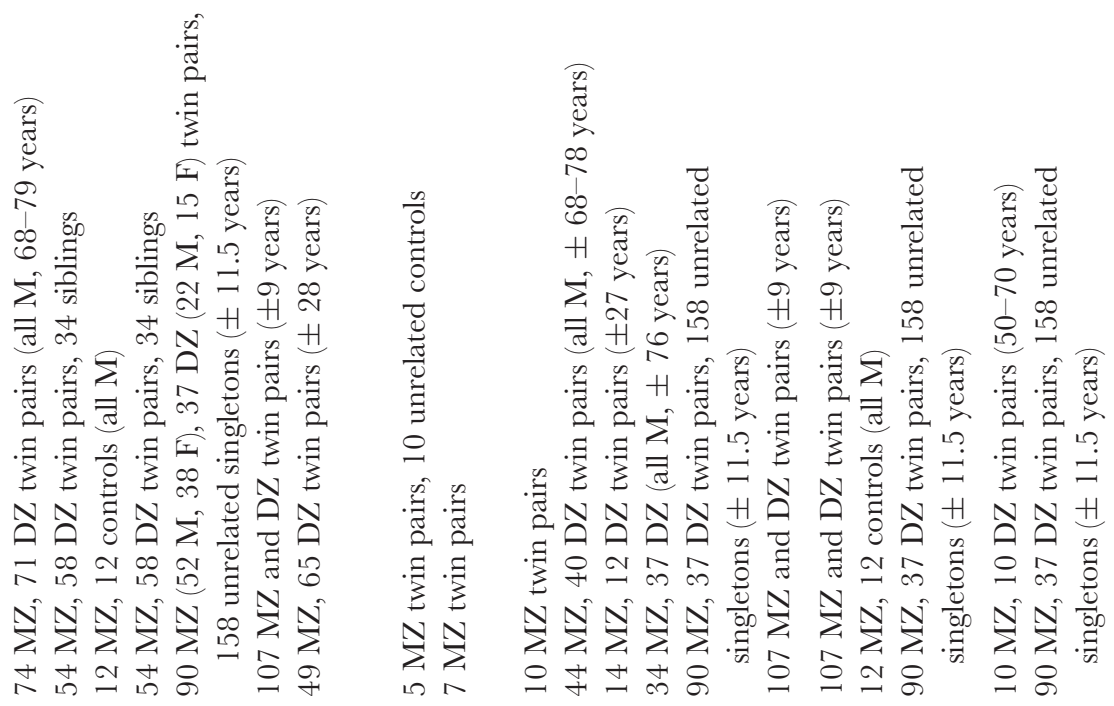

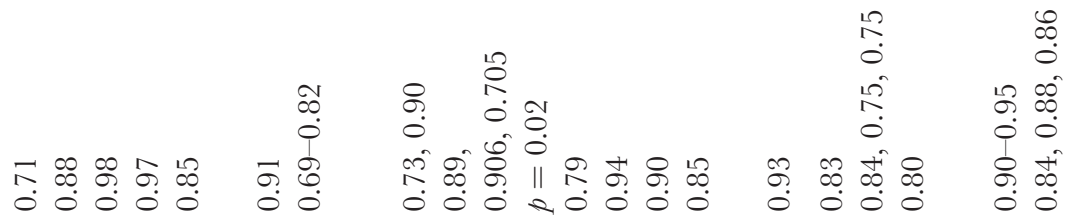

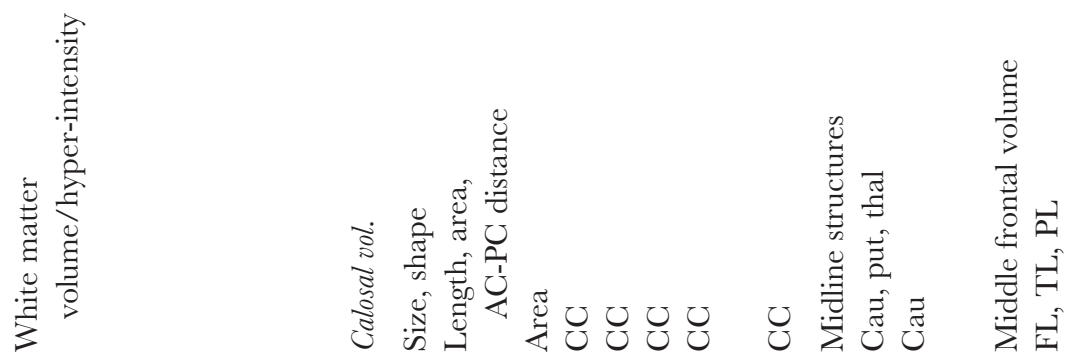




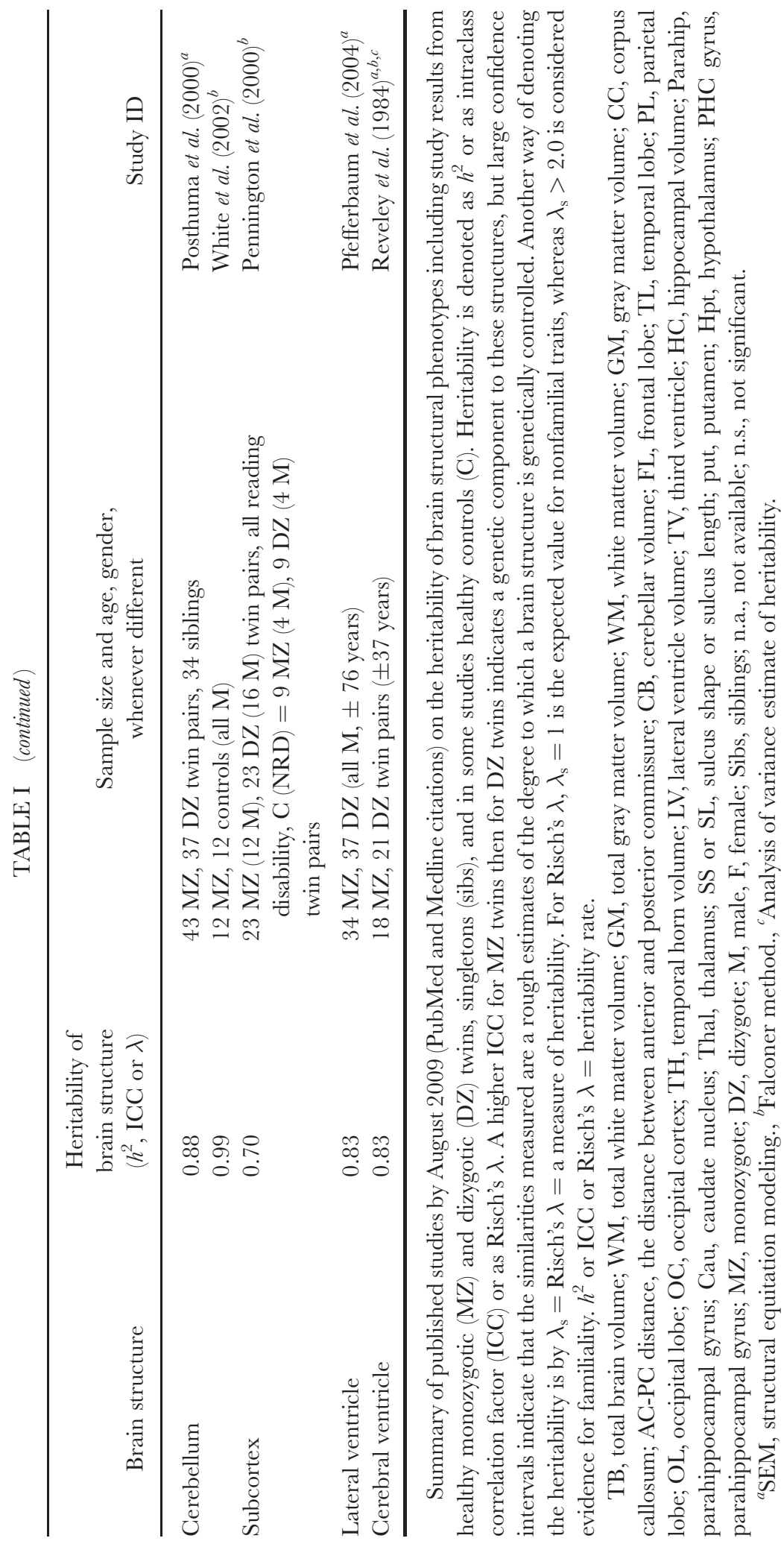




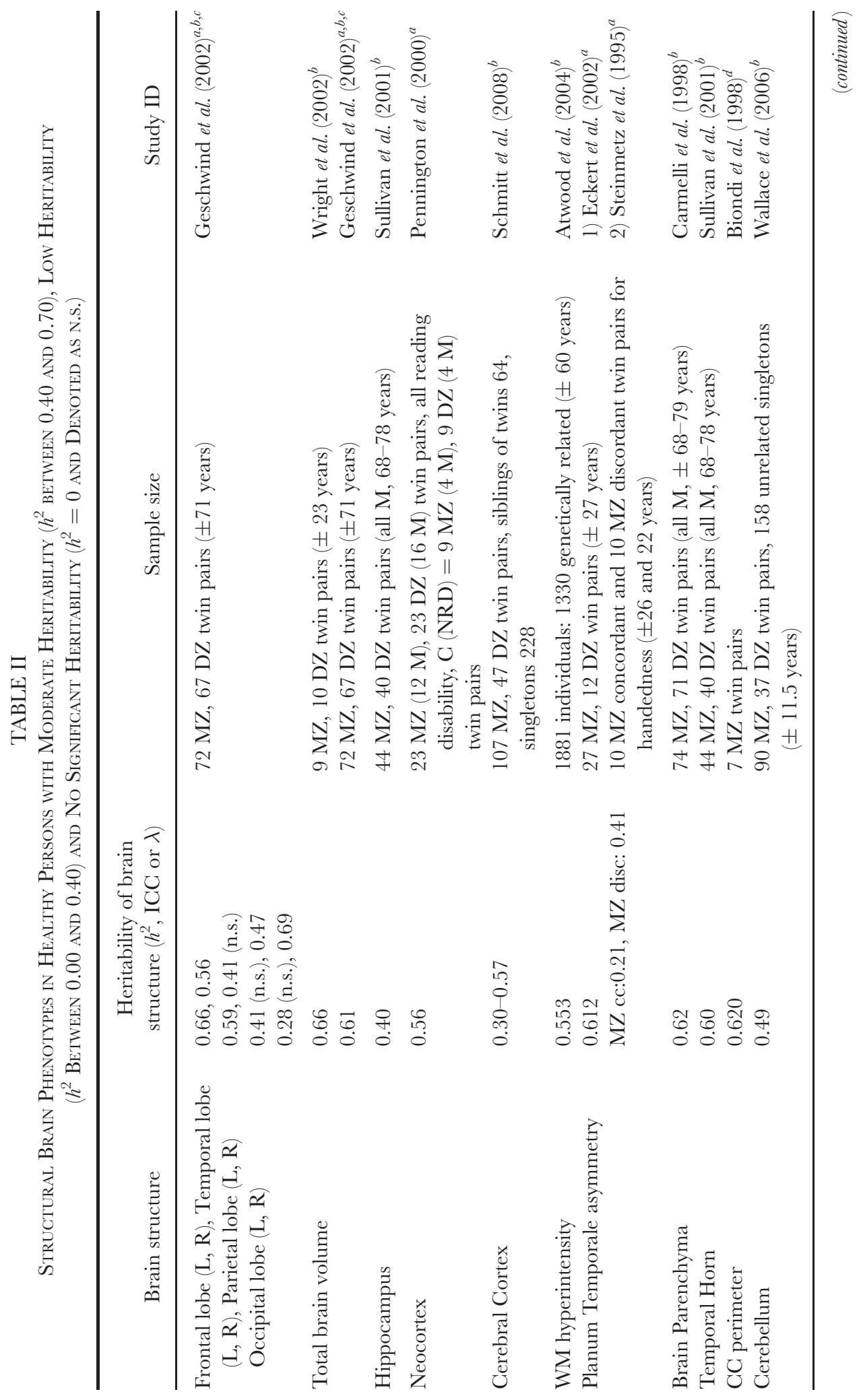




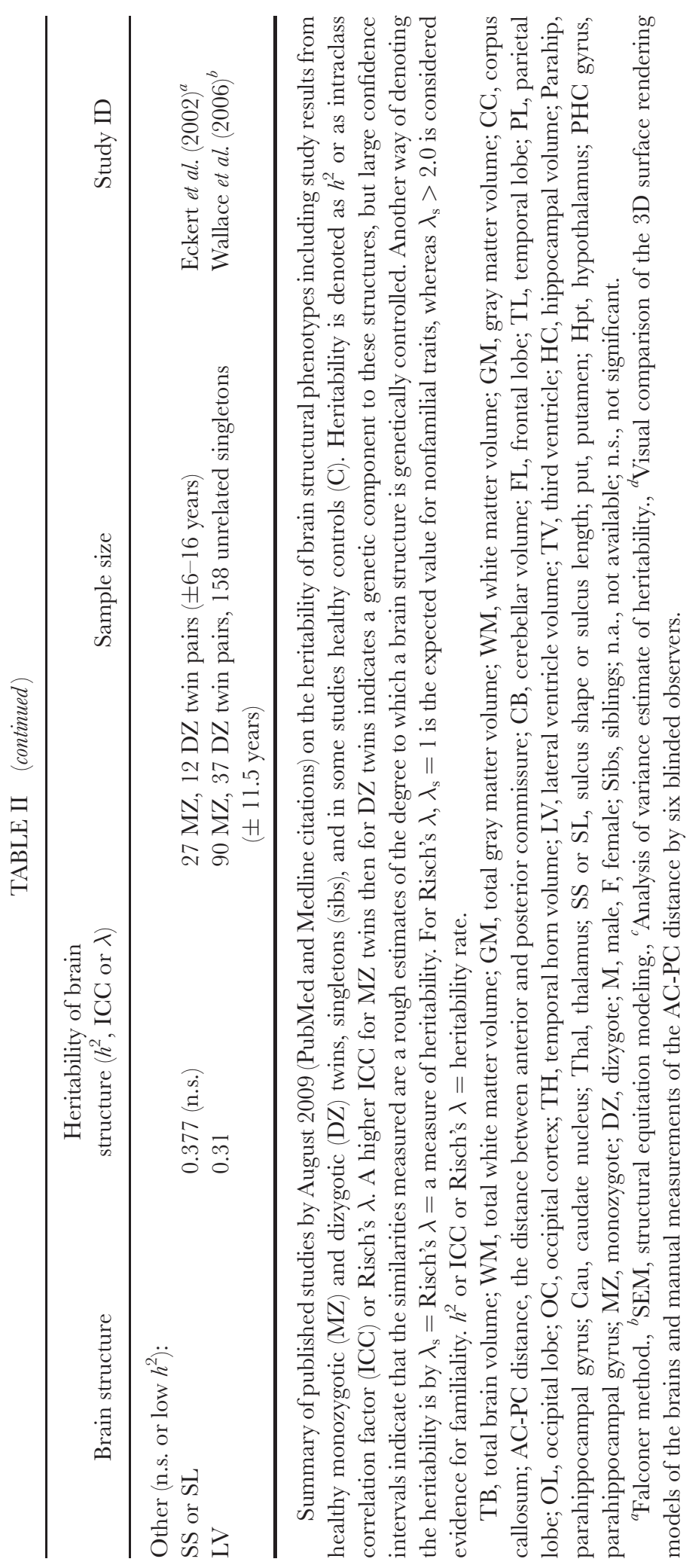


year of publication. Magnetic resonance imaging (MRI scans) brain scans were obtained from MZ and dizigotic (DZ) healthy twin pairs. The inclusion of monozygotic, dizygotic, singletons, and family members, but also unrelated controls is done to assess the extent of genetic control over these structures. Within pair similarities for certain brain structures can be compared for each group, for example within pair similarity for brain structures with high heritability rates such as the total brain volume increases as pair members are more closely related genetically (monozygotic $>$ siblings (included dizygotic) $>$ unrelated controls) . In one study healthy controls were also included (Oppenheim et al., 1989). In five studies, unrelated and related singletons were included as well (Baaré et al., 2001a; Posthuma et al., 2000, 2002b; Schmitt et al., 2008; Wallace et al., 2006), and in one study (Atwood et al., 2004) family members were also included. In three studies the heritability rates were investigated only in a male population (Carmelli et al., 1998; Eckert et al., 2002; Sullivan et al., 2001), and the remaining studies consisted of a mixed population. The age range for most of the studies was between 23 and 80 years, except for one study (Peper et al., 2009) in which 9-year-old children were included.

There were 37 structures measured in total. Some structures were measured in multiple studies, such as the total brain volume (six studies), total cranial/intracranial volume (four studies), white matter (seven studies), white matter hyperintensity (two studies), gray matter (six studies), corpus callosum (eight studies), cerebellar volume (three studies), frontal/temporal/parietal lobe (two studies), lateral ventricle (two studies), amygdalar and caudate (two studies), sulcus shape/length (two studies), planum temporal asymmetry (two studies), and ventricular volume (three studies). The rest of the structures were measured in a single study. In one study (Hulshoff Pol et al., 2006) gray matter and white matter volume was measured for different brain parts such as superior frontal, medial frontal, postcentral gyrus, posterior cingulated, and Heschl's gyrus for the left and the right part. In Table I, the heritability rates ranging from 0.55 to 0.85 for gray matter and 0.69-0.82 for white matter volume are given. In another study (Schmitt et al., 2008) various parts of the cerebral cortex were investigated and in Table II heritability rates between 0.30 and 0.57 for the cerebral cortex are recorded.

\section{Results on the Heritability of the Reviewed Studies}

Gross brain structures show higher heritability rates than specific structures. High heritability rates ranging from 0.70 to 0.99 are characteristic to intracranial volume, whole brain volume, total gray matter volume, total white matter volume, calosal volume, middle frontal volume, midline structures, and the volumes of both the right and left hemispheres (Table I). Studies including DZ, resulting in a full twin study (Bartley et al., 1997; Carmelli et al., 1998; Pennington et al., 2000), reported heritability of $>0.90$ for total brain volume. A moderate heritability rate was found on the four lobes investigated, such as frontal, temporal, occipital, and 
parietal lobe, ranging from 0.41 to 0.70 (Geschwind et al., 2002), but conflicting results were reported on the lobes by Wallace et al. (2006) for the frontal, temporal and parietal lobe, resulting in high $h^{2}$ scores between 0.84 and 0.88 . Moderate heritability rates are also reported for temporal horn volume, brain parenchyma, hippocampus, neocortex, white matter hyperintensity, and planum temporal asymmetry ranging from 0.60 to 0.63 . Studies showing a moderate or a low heritability of brain structures are listed in Table II.

\section{Effects of Gender, Age, Handedness, and Development in Time}

Some studies have investigated variables that could have an influence on heritability rates. In a study by Steinmetz et al. (1995), the effect of gender on measuring the midsagittal area of the corpus callosum and total brain volume in 120 healthy young adults was shown, finding that the forebrain volume-adjusted size of the corpus callosum was larger in women than in men and that handedness had no effect on this measurement. However, an effect of handedness on cerebral asymmetry was found in two studies (Eckert et al., 2002; Steinmetz et al., 1995) reporting a lack of cerebral asymmetry in persons who were left handed. This might be explained by the hypothesis that early "epigenetic" events that take place during embryogenesis may contribute to a significant variability in the development of the anatomofunctional laterality of the cerebral hemispheres. In a study by Peper et al. (2009), children $(n=47)$ with signs of secondary sexual characteristics (based on Tanner stages) were compared to children without these signs and the heritability of brain structures was estimated using MRI scans. They found high heritability for most gross brain structures (see Table I) and regional brain structures. They also found that the onset of secondary sexual characteristics of puberty were associated with decreased frontal and parietal gray matter densities that accompany the transition of our brains from childhood into adulthood, still showing high heritability for brain structures such as global brain volumes, white matter density in fronto-occipital and superior longitudinal fascicles and gray matter density of (pre)frontal and temporal areas. Only one study (Pfefferbaum et al., 2004) investigated the heritability rates examined over time and found no evidence for new genetic variance on the $h^{2}$ scores of corpus callosum and lateral ventricles recalculated after 4 years. The heritability of surface morphology, which is formed later in development and assumed to be under more environmental influence than the deeper structures (formed earlier in life and under more genetic control) indicate that sulcal depth effect was stronger for related twins. These results show that the shape of the deeper sulci is more strongly predetermined than that of superficial sulci, for example, sulcal depth having an influence on sulcal similarity. Also, subjects with similar brain shape have more similar patterns of their sulci, suggesting both features are the result of ontogenetically related processes (Bartley et al., 1997; Biondi et al., 1998; 
Lohmann et al., 1999; White et al., 2002). This anatomical similarity was also found for the corpus callosum shape and size (Oppenheim et al., 1989).

\section{Conflicting Results on Some Brain Structures}

Two studies (Posthuma et al., 2000; White et al., 2002) report high $h^{2}$ rates for cerebellar volume and one study (Wallace et al., 2006) reports a moderate $h^{2}$ rate. This might be due to the age difference of the participants, and thus, the ongoing development of the brain. In the first two studies, adults were included, whereas the latter study, included adolescents (mean age of 11.5 years). A low heritability rate for lateral ventricle volume was found in one study (Wallace et al., 2006), but a high $h^{2}$ score was reported in another (Pfefferbaum et al., 2004), and an $h^{2}$ of 0.00 is recorded by Wright et al. (2002). The differences in these studies might be due to the differences in age of the participants, but could also be due to the differences in sample size. The mean age of the participants in the study by Wallace et al. (2006) was 11.5 years, reflecting results of brains in development. Additionally, the sample size in the study by Wright et al. (2002) is small compared to the bigger sample sizes of the other two studies. Conflicting results also exist on the heritability of sulcus shape and length, with one study indicating moderate heritability rate (Bartley et al., 1997) and not reaching significance in another (Eckert et al., 2002). There is a difference in the mean age between the studies, resulting in an older mean age (23 years) in the study by Bartley et al. (1997) and younger (6-16 years) in the study by Eckert et al. (2002). However, it is unclear what might be of influence in the differences between these studies, because different statistical heritability estimates were used in both. Other conflicting results are found for the ventricle volume, having a high $h^{2}$ rate in one study (Reveley et al., 1984) and not being significant in other studies (Baaré et al., 2001a; White et al., 2002). In the study by Reveley et al. (1984), three statistical ways of calculating heritability rates were used, whereas the other two studies used one of the methods (both different from each other).

The differences between the studies with conflicting results might be a result of the differences in sample size, age, gender of the population (only male participants vs. mixed group), statistical method applied to calculate the heritability rates and the way measurements of the brain structures is done. As for the latter, some studies used the manual measurement of brain structures (region or VOI) and others automated (VBM, deformation based morphometry).

Seven studies used the Falconer method of heritability calculation and 15 studies used the structural equitation modeling (SEM), in which the unique environmental factors are also included. Two studies (Geschwind et al., 2002; Reveley et al., 1984) used all three methods of heritability calculation, reaching significance in both studies for the three methods.

Heritability estimates show considerable differences between gross and specific brain structures. High heritability is characteristic for gross brain structures, such as intracranial volume, whole brain volume, cerebellar volume, total gray 
matter and white matter volume, and calosal volume, with effect sizes in the high range. Moderate effect sizes have been found for structures such as the heritability of the different lobes, sulcus shape or length, white matter hyperintensity, hippocampal volume, and other brain structures like brain parenchyma, middle frontal regions, temporal horn and planum temporal asymmetry. The highly heritable gross brain structures are also the brain structures that are examined in multiple studies. The volume measurements of these brain structures and thus, the heritability rates, are easier to calculate than the specific, middle brain, deeper or small brain structures in both the manual and automated quantitative measurement techniques. From the reviewed literature, these brain structures with high and moderate heritability rates seem to be useful as endophenotypes.

\section{B. Heritability of Brain Strugtures in Patients with Schizophrenia Compared to Healthy Controls}

Heritability calculations of the brain structures of patients with schizophrenia compared to healthy controls is very complicated, due to the impact of disease related factors on brain changes, together with the effect of medication intake and the use of drugs (Kanaan et al., 2009; Rais et al., 2008; van Haren et al., 2007). Some studies show an increase in brain structure volumes and others a decrease. However, use of medication does not account for the total changes in the brain structures of patients with schizophrenia, since there are also studies showing brain changes in medication naïve patients (Cahn et al., 2001; Okugawa et al., 2007; Weinberger, 1995). Using twins concordant and discordant for schizophrenia in these studies would help elaborate the disease's effect on the brain changes to a certain degree.

Until now, there have been nine studies published on the heritability of brain structures in patients with schizophrenia compared to healthy controls. These studies are listed in Table III. The studies report on the heritability rates of brain structures in twins concordant and discordant for schizophrenia, monozygotic, and DZ, compared to healthy twins. These studies included adult patients, females, and males. Some brain structures have been studied in multiple studies, such as the total brain volume (four studies), gray matter volume (two studies), hippocampal volume (four studies), and the rest of the brain structures listed on the table in single studies.

High heritability for the intracranial volume, total gray and white matter volume, ranging from 0.72 to 0.89 was found (Table III). The overall gray matter volume was also found to be highly heritable in monozygote twins, both in the control and in the group of patients with schizophrenia. The heritability of total brain volume was found to be high in two studies (Hulshoff Pol et al., 2004; Rijsdijk et al., 2005) and high in patients with schizophrenia, but moderate in healthy controls in another study (Narr et al., 2002). In one study (Rijsdijk et al., 2005), a low heritability rate was found for the hippocampus, third and lateral ventricle. 


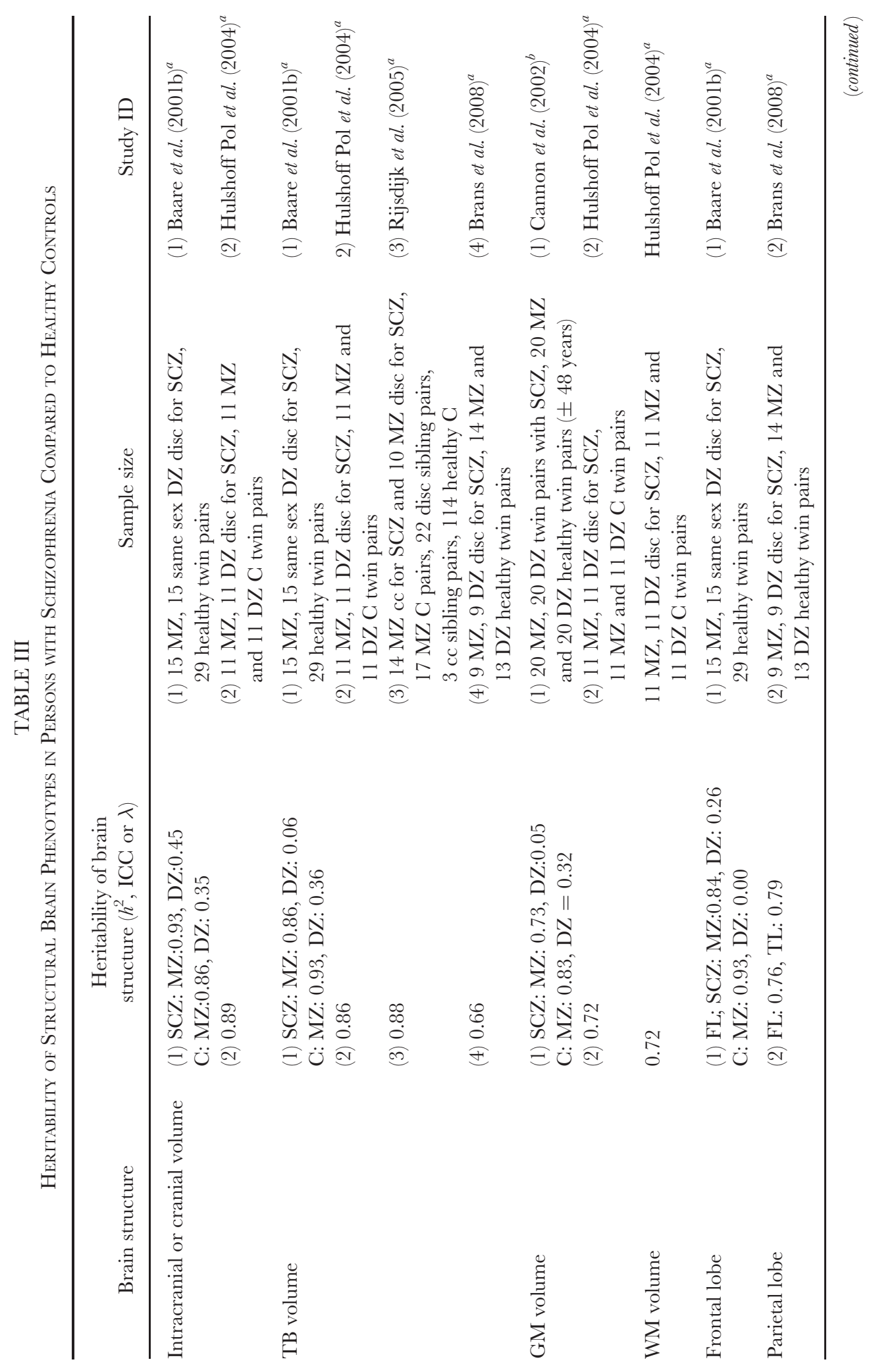




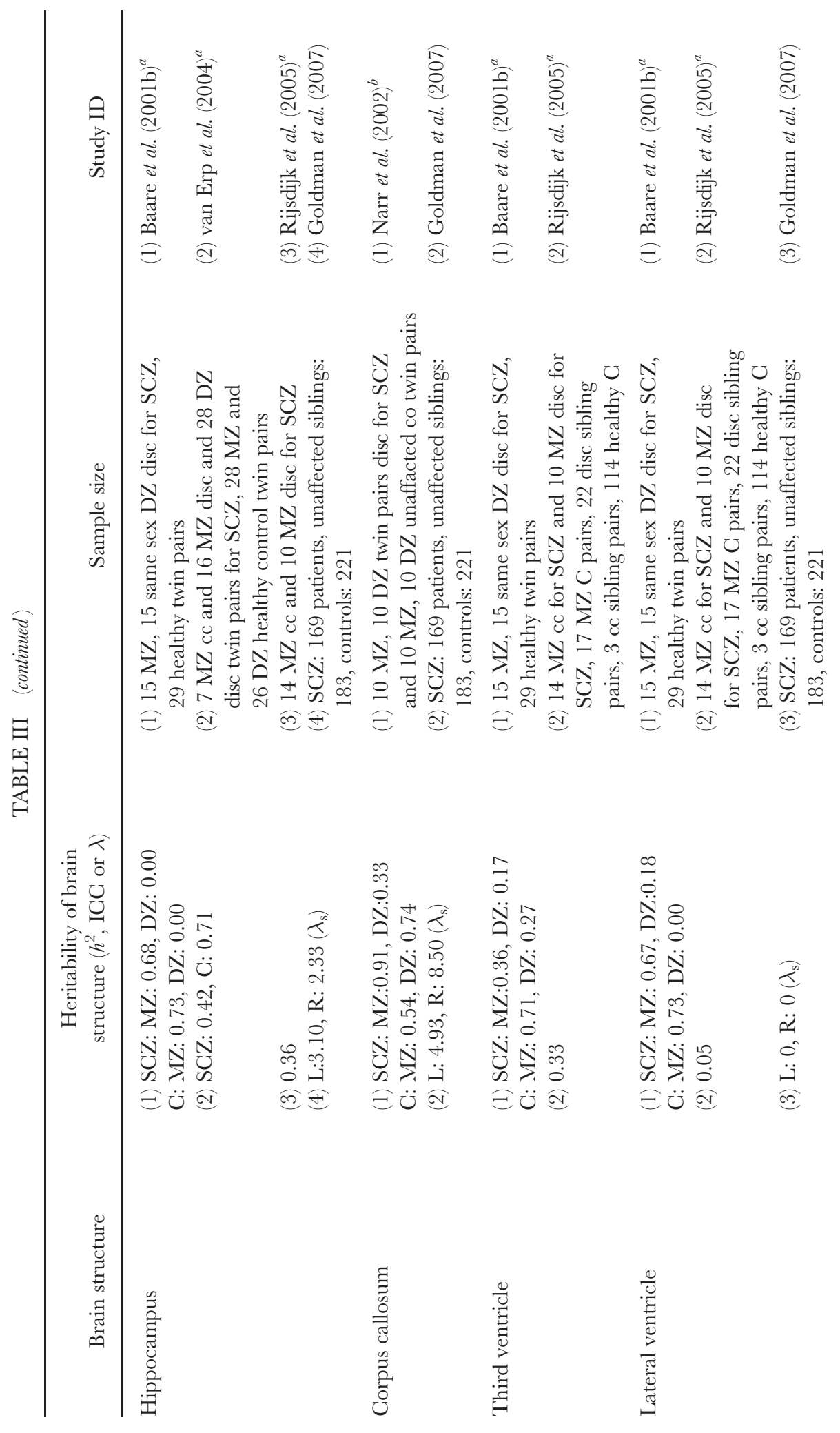




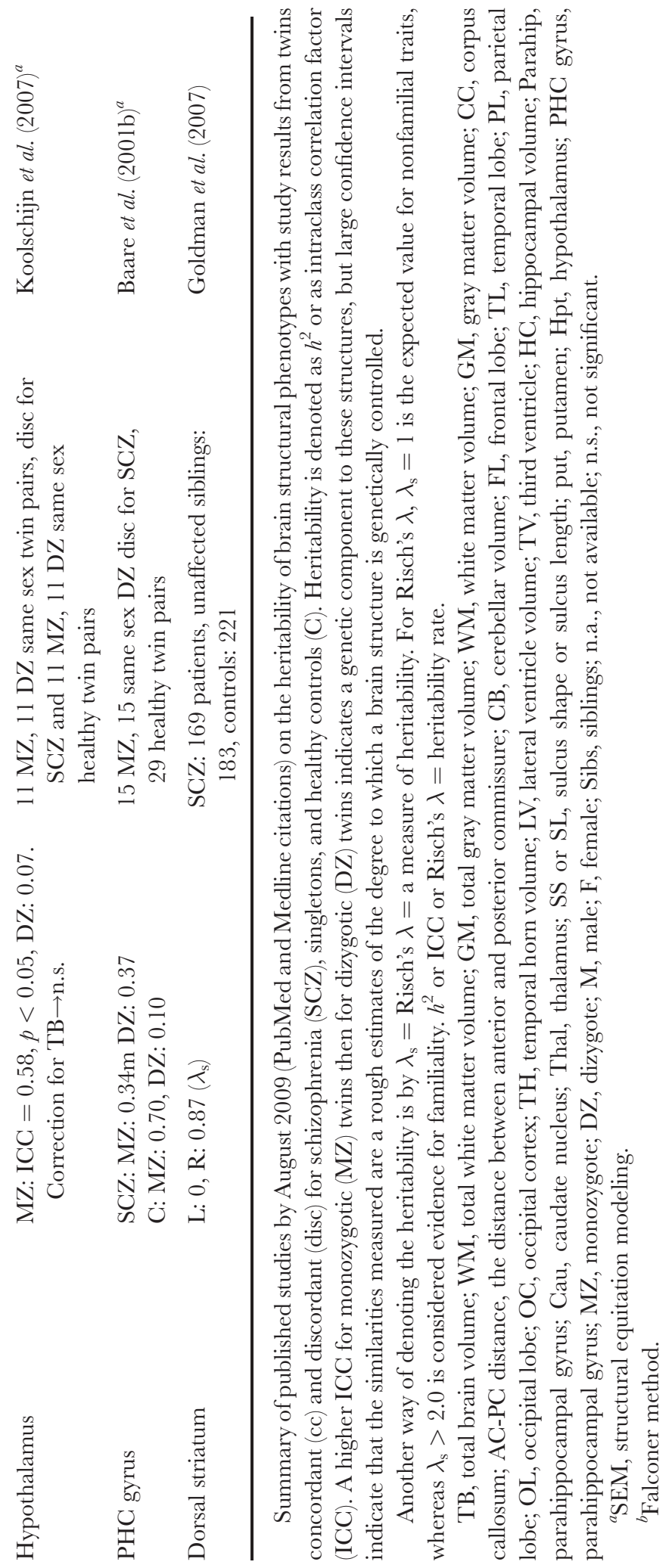


Low heritability rates were also found in the group of DZ twins discordant for schizophrenia (Narr et al., 2002), for the overall gray matter volume in control DZ twins and in DZ twins with schizophrenia. There was no significant heritability found for the parahippocampal gyrus, third and lateral ventricle (Baaré et al., 2001b) or for the hypothalamus (Koolschijn et al., 2007). The study by Brans et al. (2008) reports on whether genetic (heritability) and/or environmental factors are associated with progressive brain volume changes in schizophrenia. They found that significant decreases over time in whole brain, frontal, and temporal lobe volume in patients with schizophrenia and in their unaffected co-twins compared with control twins revealed significant additive influences on the correlations between schizophrenia liability and progressive whole brain (0.66), temporal (0.79), and frontal (0.76) lobe changes.

The samples in these studies consist of both healthy MZ and DZ twins and twins concordant and discordant for schizophrenia, with the exception of three studies (Baaré et al., 2001b; Hulshoff Pol et al., 2004; Koolschijn et al., 2007) where twins concordant for schizophrenia were not included, resulting in a sample group where environmental factors played a more important role in the development of the disorder and a genotypic estimation of the true population genetic variance was not possible.

Three studies (Cannon et al., 2002; Narr et al., 2002) used the Falconer method of heritability estimates and four studies used the SEM method (Brans et al., 2008; Hulshoff Pol et al., 2004; Rijsdijk et al., 2005; Van Erp et al., 2004). The study by Koolschijn et al. (2007) used the intraclass correlation factor (ICG) to estimate the heritability rates of the hypothalamus. One study, by Goldman et al. (2007), used ICG and also Risch's relative risk for siblings $\left(\lambda_{\mathrm{s}}\right)$ for heritability measurements of each region. Risch's relative risk for siblings $\left(\lambda_{\mathrm{s}}\right)$, was calculated to quantitatively measure the likelihood that siblings of patients with volumetric reductions or increases would express the phenotype themselves. Because this parameter depends on the presence or absence of the phenotype, cutoffs were defined on the basis of the distribution of the volumes in patients.

One complicating factor in the heritability estimates of brain structures in twin studies is that the twin discordant for schizophrenia also shows, to a milder degree, brain changes seen in their co-twins with schizophrenia. The unaffected twins show lower brain volume, lower hemispheric volumes and/or frontal lobe gray matter volume decrease. These observations may suggest the involvement of genetic factors in cortical gray matter deficits in patients with schizophrenia (Baaré et al., 2001b; Reveley et al., 1984; Suddath et al., 1990). As suggested by Cannon et al. (2002), it is important that these studies include an evaluation of the regional cortical variation and that individual differences in gyral/sulcal patterning and shape are taken into account. It is not clear to what extent these changes are similar to the changes in their co-twins who have schizophrenia. A distinction between these possibly genetic differences and the disease related changes in the 
brain should be done by isolating the topography of nongenetic, disease related differences in cortical gray matter volume, as suggested by Cannon et al. (2002).

\section{Heritability of Brain Structures in Nonhuman Primates (Monkeys)}

Studies in pedigrees, where there is an extensive control of the environmental factors, are particularly useful in heritability calculations. Studies in NHPs are therefore a good model for genetic control and could be useful in heritability calculations as mentioned previously.

There are five studies published on the heritability of brain structures in NHPs (e.g., monkeys). These studies are listed in Table IV. Results of these studies strongly support findings from human studies showing the heritability of gross brain structures in the high effect size range, such as whole brain volume, cerebral volume, and cranial size. The moderate effect size range for heritability was reported for cranial capacity, sulcus length, brain weight, hippocampus and surface area, and gray matter. The number of studies reporting on heritability of brain structures in NHPs is limited and the sample sizes of monkeys included in these studies is small. There are only two studies (Mahaney et al., 1993; Rogers et al., 2007) in which the same monkey type was included, but these studies did not look at the same brain structure, which makes comparison difficult. Only the study by Fears et al. (2009) used a big sample size of vervet monkeys and calculated heritability estimates using manual tracings as well as automated tracings of brain structures. In this study, high heritability rates are found for gross brain structures, such as total brain volume, cerebral volume and corpus callosum. In contrast to other NHP heritability estimations of the hippocampus, this study showed a high heritability rate for the hippocampus. The findings from the NHP studies support the findings in human twin studies.

Table IV shows that samples consist of different types of monkeys, making it difficult to compare the conflicting results between studies on the same brain structure, such as the hippocampus, where Lyons et al. (2001) find moderate heritability rates and Fears et al. (2009) find a high heritability rate. There is also a big difference in the sample sizes.

One other complicating factor is the method of measuring the volume of brain structures (manual vs. automated or both), particularly, the calculation of heritability of brain structures across the different studies. The method used by Lyons et al. (2001) consists of obtaining MRI scans of Guyanese monkeys and quantitative estimates of the heritability rates were generated by using the one-way ANOVA as used to evaluate paternal half siblings effect. Rogers et al. (2007) used the VBM approach to look at the regional differences in the genetic effects on brain structure and calculated the heritability estimates. The study by Cheverud et al. (1990) shows that brain size was defined as endocranial capacity 


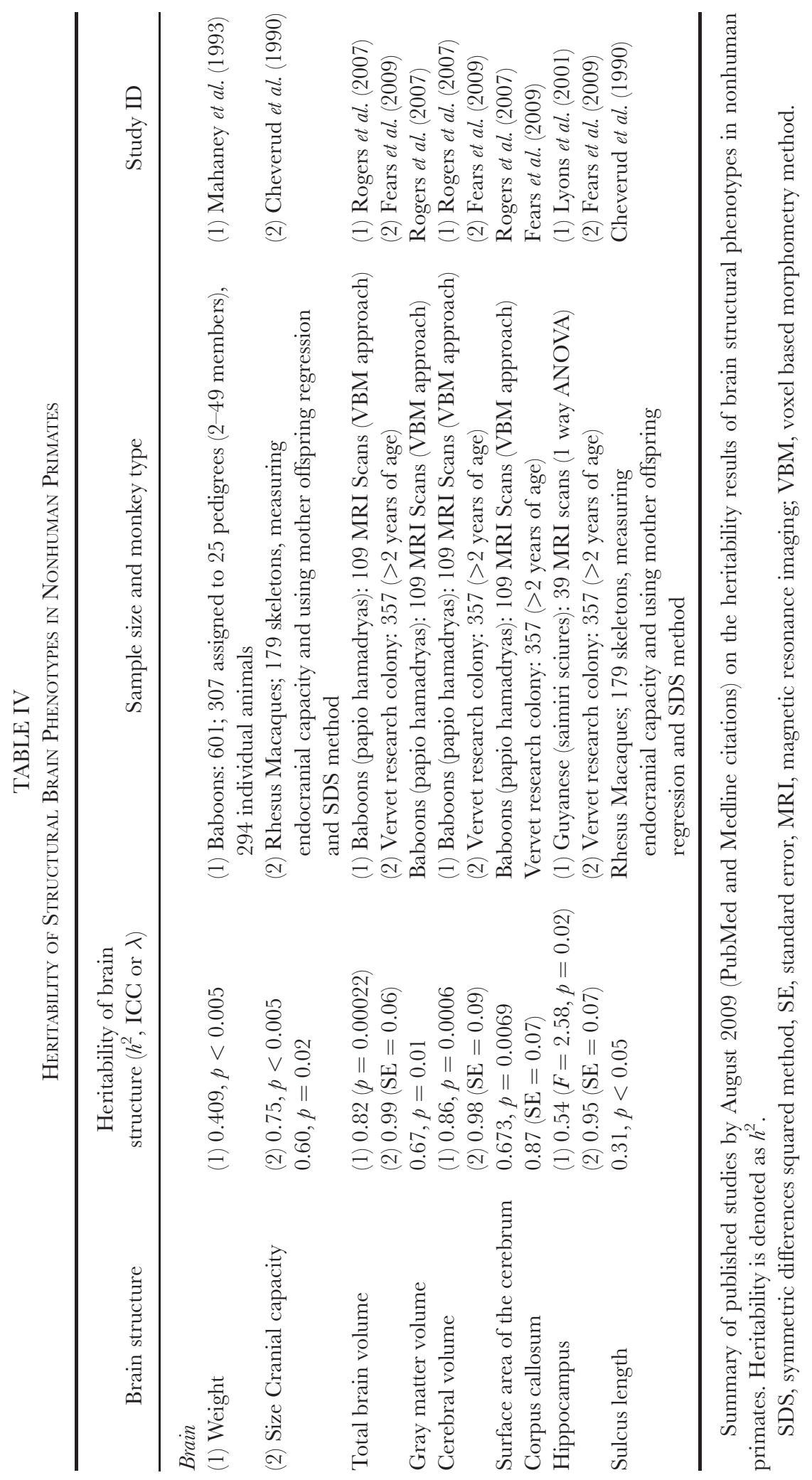


and was measured by filling the cranium with mustard seed, then pouring the enclosed seed into a graduated cylinder. The cube root of cranial capacity was used in statistical analysis to better fit the data with statistical models. The heritability was estimated by standard mother-offspring regression (Falconer and Mackay, 1996; Falconer et al., 1981) and a slight modification of the symmetric-differences-squared (SDS) method (Bruckner and Slanger, 1986). In the study by Mahaney et al. (1993), the heritability estimates, specifically of the brain weight, were measured by quantitative genetic analyses on available loge-transformed organ weights. Fears et al. (2009) used both manual and deformation based volume measurements (automated) to measure volumes of brain structures.

Despite the difference in heritability rates of brain structures between the few studies published on this topic, the results are nonetheless comparable to the human studies. The newest publications on this subject in NHP (Fears et al., 2009; Rogers et al., 2007) have used big sample sizes and also comparable volume measurements on the MRI scans as seen in human studies. More research on heritability in NHPs will help us get more insight into the genetic control on brain structures and will create the potential for future genetic mapping of QTLs underlying the variance in the heritability of these brain structures.

\section{Genes for Brain Structures in Healthy and Persons with Schizophrenia}

The dramatically increased brain volume plays an important role in the origin of our species. In humans, brain volume is a quantitative trait with high heritability (Posthuma et al., 2002b; Thompson et al., 2001). Disturbances in brain development is one of the explanations for neuropsychiatric disorders such as schizophrenia (Weinberger, 1995), suggesting that developmental genes involved in the development of the brain may overlap with the causal genes, for example, potential candidate genes, for schizophrenia (Murray, 1994). However, no susceptibility genes with high effect sizes have been found for schizophrenia. Therefore, most studies have focused on the testing of specific genetic markers in a known candidate gene for association with the different endophenotypes. In this study, research using brain structures as neuroanatomical endophenotypes in healthy and patients with schizophrenia are reviewed. Studies on the association between specific genes and brain structures and between genes and brain morphological changes in schizophrenia will be reviewed.

\section{A. Genes for Brain Structures in Healthy Persons}

There are eight studies published on the genes for brain structures in healthy persons. These studies are listed in Table V. These studies looked at brain structures and specific genes (and alleles or SNPs, single nucleatide polymorphisms) for these brain structures and at the interaction between these genes. 


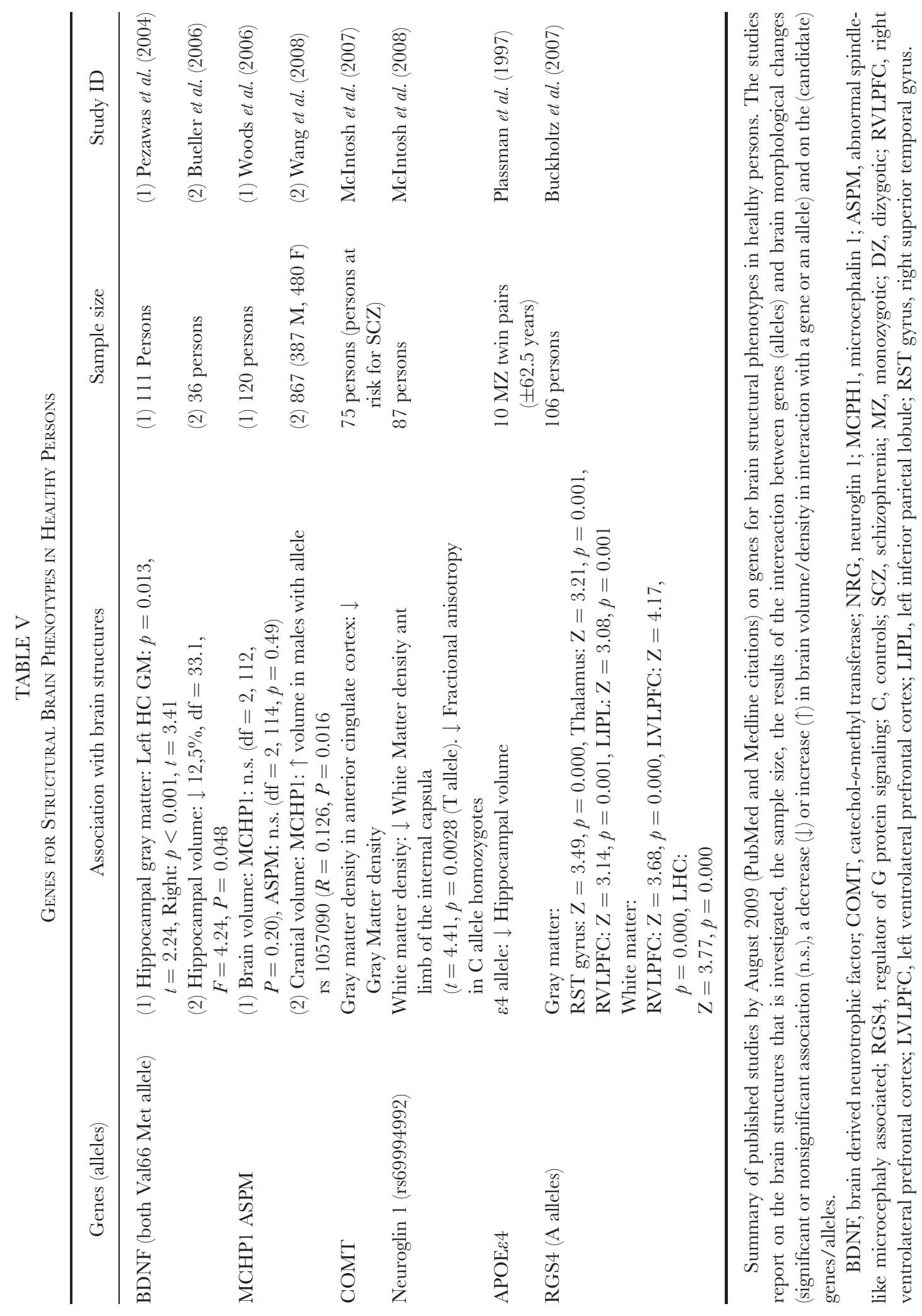


In some of the studies the interaction of the specific genes with the variance in brain morphology is expressed in quantitative measures.

As presented in Table $\mathrm{V}$, the genetics of heritability of brain structures indicate that in one study (Wang et al., 2008) there is a significant association ( $p=0.016)$ between the MCPH1 gene and intracranial volume, reaching bigger intracranial volume in patients with the rs1057090 allele and not reaching a significant association in another study (Woods et al., 2006), not for the MCPH1 gene $(p=0.20)$ nor for the ASPM gene $(p=0.49)$. The heritability of gray matter density has been investigated in three studies. In the first study, there was a significant association for the right $(p<0.001)$ and left hippocampus ( $p=0.013)$ for the $B D \mathcal{N} F$ gene for the Val66met allele carriers (Pezawas et al., 2004). In the second study, there was a significant association in the right superior gyrus, temporal lobe, right prefrontal cortex, and left inferior parietal lobe ( $p=0.001)$ (Buckholtz et al., 2007) for the RGS4 gene and specifically persons carrying the A allele. In the third study, there was a significant association in the anterior cingulate cortex for the COMT gene, specifically for persons carrying the Val gene (McIntosh et al., 2007). The white matter density shows a significant association with two genes, namely, the $R G S 4$ gene (A allele carriers, $p=0.000$ ) in the right and left ventral prefrontal cortex and left hippocampus in one study (Buckholtz et al., 2007) and neuroglin 1 (rs699994992 allele carriers, $p=0.00028$ ) with a white matter density decrease in anterior limb of the internal capsula in another study (McIntosh et al., 2007). The hippocampal volume and the association with the APOE 4 gene shows HG volume decrease in one study (Plassman et al., 1997) and of $11.2 \%$ reduction in volume in another study $(p=0.048)$ (Bueller et al., 2006) for the BDNF gene Val66met allele carriers.

The samples consist of healthy individuals, not related, except for one study in which 10 MZ twin pairs were compared (Plassman et al., 1997) and in another study, persons at risk for schizophrenia were included (McIntosh et al., 2007). In the study by Woods et al. (2006), individuals from different ethnic backgrounds were included, but correcting the data for race, ethnicity or sex did not change the results. The sample in the study by Wang et al. (2008) consisted of 90\% Chinese and $10 \%$ other ethnic minorities. The study by Buckholtz et al. (2007) consisted of Caucasian subjects of European descent. The sample in the study by McIntosh et al. (2007) consisted of persons at risk for schizophrenia.

The method used by the studies in Table III varies from one study to the other. In the study by Woods et al. (2006), heritability of brain volume related to genotype was estimated by using the coefficient of the genetic terms in the full fitted ANOVA model to compute the variance attributable to genotype. This variance was then divided by the total variance to estimate heritability. This method was also used by Bueller et al. (2006) and Pezawas et al. (2004). The study by Wang et al. (2008) used the linear regression model to do the single SNP association analysis. Buckholtz et al. (2007) used multimodal neuroimaging to 
investigate the impact on brain structure and function and looking at allelic variation. The study by McIntosh et al. (2007) imported the data into SAS (version 9.1, SAS Institute, Cary, North Carolina) and the effects of group status by COMT group interactions were investigated by analysis of variance.

\section{B. Genes for Brain Structures in Patients with Schizophrenia}

There are 23 studies where the genetics of variation on heritability of brain structures was investigated in patients with schizophrenia compared to healthy controls. These studies report on the association between specific genes and brain morphological changes in schizophrenia. Several candidate genes for schizophrenia have been studied and the association with specific brain morphological changes has been examined. There are multiple studies on the Brain Derived Neurotrophic Factor gene ( $B D N F$ gene) (five studies), Catecol- $O$-Methyl Transferase gene (COMT gene) (three studies), Disrupted in Schizophrenia 1 (DISC1) (two studies), APOE $\varepsilon 4$ gene (two studies) and Interleukin-1 receptor antagonist gene (IL 1) (two studies). These studies are listed in Table VI. There are single studies on the Neuroglin 1 (NRG1), prion protein (PP gene), tumor necrosis factor receptor-II gene (TNF-RII gene), NOTCH4 gene, PCM1 gene, Plexin B3 gene, GAD1 gene, PROHD gene, regulation of $\mathrm{G}$ protein signaling $(R G S 4)$ and neurotrophin gene. These studies are listed in Table VII. The brain structures that are looked at in multiple studies include: the brain lobes (six studies), hippocampal volume (eight studies), ventricles (three studies), gray matter volume (seven studies), white matter volume (seven studies) and cerebrospinal fluid (CSF) volume (three studies). The following structures have been studied in a single study: cerebral asymmetry, intracranial volume, regional gray matter volume/density, prefrontal cortex, caudate, putamen, and cerebellum.

One of the most investigated genes is the $B D N F$ gene. BDNF is a neurotrophic factor involved in the development and maintenance of the nervous system. It is neuroprotective and prevents cell loss in the cerebral cortex, the striatum, and the hippocampus (Angelucci et al., 2005). The BDNF gene consists of several polymorphisms that affect the amino acid sequence and possibly the function of the protein. In patients with schizophrenia, lower concentrations of BDNF have been found in cortical areas and the hippocampus as well as in the blood serum. The COMT gene is thought to be involved in the degradation of dopamine. The BDNF allele, in particular the Met allele, was found to be associated with a decrease in hippocampal volume (Bueller et al., 2006) and with frontal lobe and occipital lobe gray matter in two other studies (Ho et al., 2006; Pezawas et al., 2004). Szeszko et al. (2005) found an association in a post hoc analysis between hippocampal volume decrease for schizophrenia patients only and no association with the intracranial volume. Wassink et al. (1999) studied the BDNF alleles in 48 trios and found an association with the parietal lobe, but not with the temporal or 


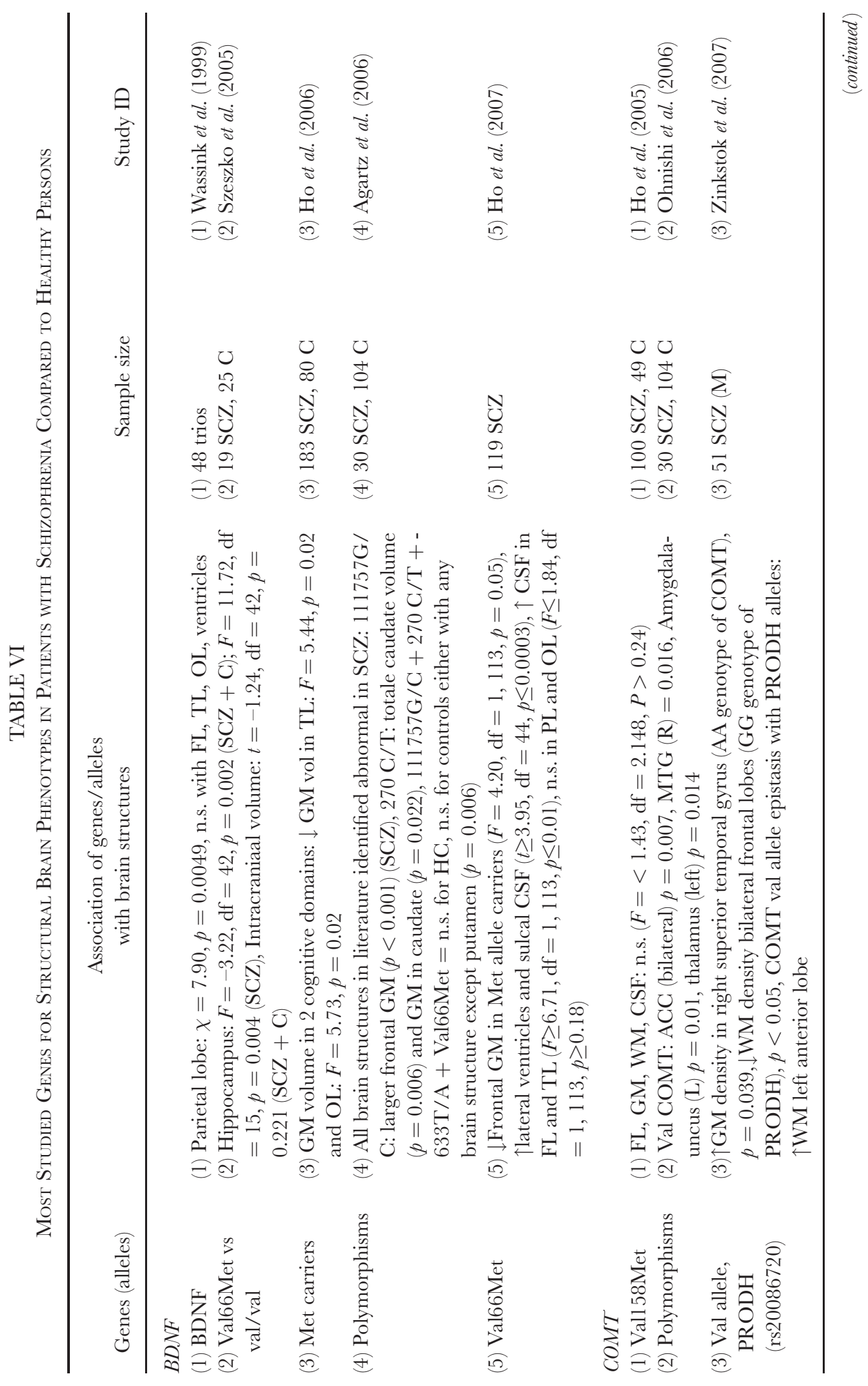




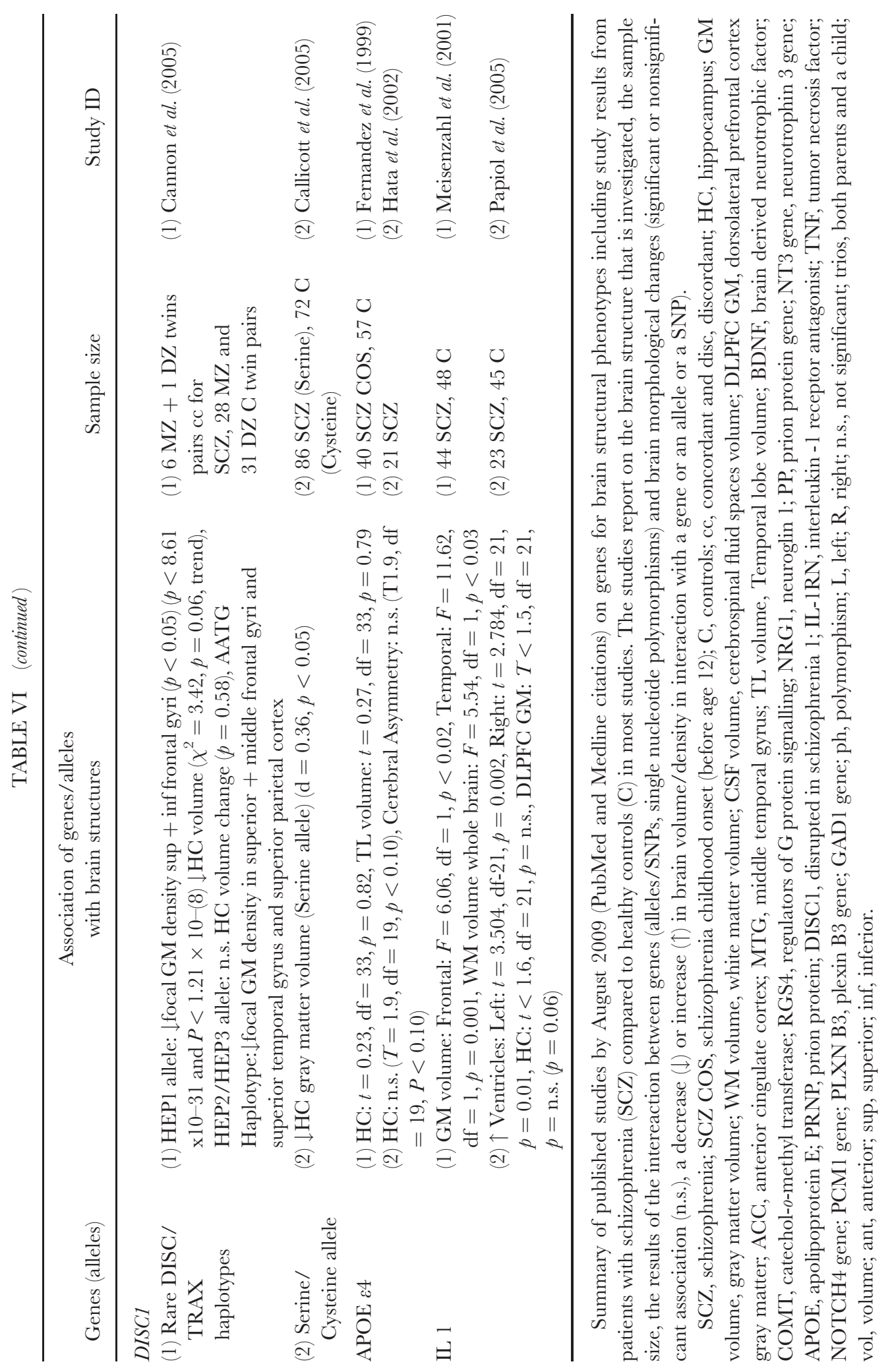




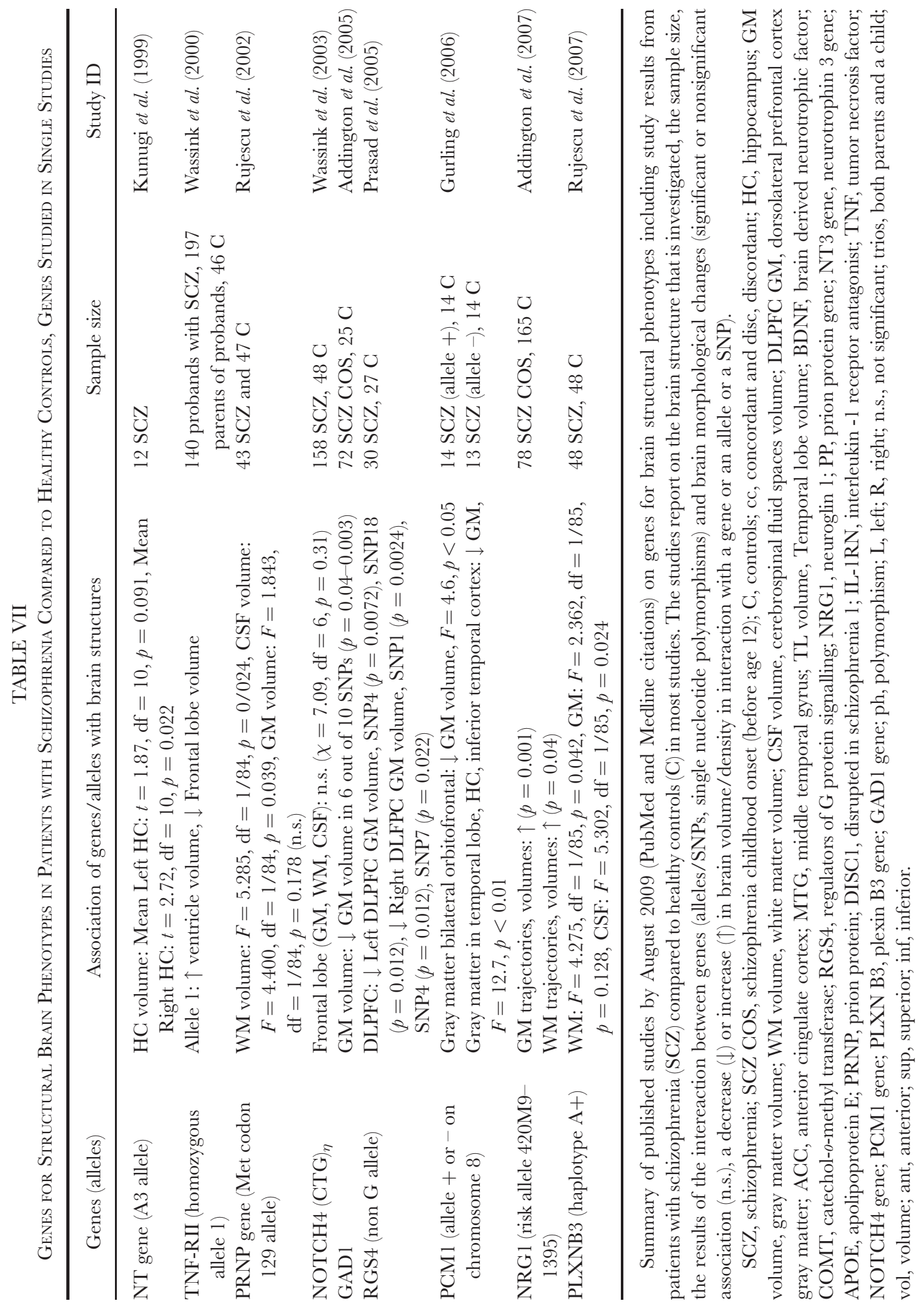


frontal lobe. Ho et al. (2007) found an association between Met allele and a decrease in frontal gray matter and with an increase in lateral ventricles and in CSF sulcal volume and an increase in CSF volume in the frontal and temporal lobe, but not in the parietal and occipital lobe. Agartz et al. (2006) found a significant association of the $11757 \mathrm{G} / \mathrm{C}$ polymorphism with larger frontal gray matter and a $270 \mathrm{C} / \mathrm{T}$ ph association with caudate volume and gray matter volume in caudate and no association with hippocampus, nor with brain volumes in controls except for the association between the $-633 \mathrm{~T} / \mathrm{A}$ polymorphisms and putamen. This COMT gene is the second most investigated gene and is located in a region of chromosome $22 \mathrm{q} 11$, which is deleted in patients with the velocardio-facial syndrome. In $25 \%$ of these patients, schizophrenia is diagnosed as well. In a recent metanalyses the COMT gene has not been strongly associated with schizophrenia (Williams et al., 2007). DISC1 gene is one of the genes found to be associated with several psychiatric disorders, such as schizophrenia, bipolar disorder, and depression (Hennah et al., 2006). This gene was studied in a large Scottish family study, where a translocation was found to be inherited with different psychiatric disorders (Porteous, 2008). In persons with schizophrenia, there was a disruption of a gene of unknown function on one of the chromosomal breakpoints, and was therefore named disrupted in schizophrenia 1. This gene and the enzymes it codes for are of influence to neuronal migration and memory. In the study by Cannon et al. (2005), logistic regression was used to evaluate associations of DISC1 and TRAX haplotypes with diagnostic status, entering age, sex, substance use disorder, and parental social class as covariates and controlling for the dependency of observations within twin pairs using generalized estimation equations. The data of this study show that one of the three haplotypes (HEP 1) was associated with schizophrenia. The HEP1 haplotype (i.e., TCG) defines a 3-SNP segment located near the translocation break point of DISC1. The HEP1 haplotype was more often associated with individuals with schizophrenia $(61.0 \%$; $\left.\chi^{2}=6.8[p=0.02] ; \mathrm{OR}=2.6 ; 95 \% \mathrm{CI}=1.2-5.6\right)$ when a recessive mode of transmission was assumed, but not among their nonschizophrenic co-twins $\left(49.1 \% ; \chi^{2}=0.8[p=0.38]\right)$. This haplotype was also significantly associated with small, focal reductions of gray matter in the superior and inferior frontal gyri. The HEP1 haplotype also shows evidence of an association with hippocampal volume reduction $\left(\chi^{2}=3.42, p=0.06\right)$. The regions affected by DISG1 and TRAX haplotypes identified in these maps have previously been shown to be highly heritable in normal twins (Thompson et al., 2001). These regions are also sensitive to the degree of genetic relationship to an affected individual in twins discordant for schizophrenia (Cannon et al., 2002; Van Erp et al., 2004).

The APOE $\varepsilon 4$ allele is a major risk allele for late-onset Alzheimer's disease (Mahaney et al., 1993). The study by Hata et al. (2002) shows similar findings to studies carried out in patients with Alzheimer's disease (Soininen and Riekkinen, 1996; Tohgi et al., 1997) in that there is a decrease in hippocampal volume of the 
$\varepsilon 4$ allele carriers compared to noncarriers. The IL-RII gene has been studied twice until now, one showing an association between a high activity allele in the interleukin-1b (IL-1b) gene and orbitofrontotemporal volume reductions of gray and white matter in schizophrenia subjects but not in controls (Meisenzahl et al., 2001) and the other study showing variability at the $I L-1 R \mathcal{N}$ gene contributing to the ventricular volumetric variation in patients with schizophrenia. The PP gene, with a Val/Met polymorphism at position 129 in the prion protein gene (PRNP), is known as a risk factor for Creutzfeldt-Jakob disease, which is accompanied by psychosis in the early stages. It is unclear whether this PP gene is also associated with schizophrenia (Martorell et al., 2007), but in the study by Rujescu et al. (2002), there was a decrease in white matter volume and larger CSF volume in both the controls as well as the patients with the Met homozygotes. The other genes are studied in just one study. These studies have all been analyzed in detail in previous reviews (Pearlson and Calhoun, 2007; Van Haren et al., 2008).

While the reviewed studies suggest high heritability rates for some brain structures, limitations on the neuroimaging, twin studies and NHP studies make the interpretation and the generalizability of their findings difficult.

\section{Limitations and Clinical Relevance of the Studies}

\section{A. Limitations of Neuroimaging Studies}

A number of limitations in imaging studies need to be acknowledged, such as the validity and reliability of measures (e.g., using measurements that rely on a representative slice vs. whole volume or do not correct for total brain volume). Measurements of brain volumes reveal differences between affected subjects and healthy controls, but the magnitude of these differences is moderate and there is always a substantial overlap in the distributions of the comparison groups. However, looking at the heritability of brain volumes and shapes in healthy twin studies shows high heritability rates of these brain measurements. One solution to this problem might be to shape analysis to quantify subtle differences in brain structures, in order to enhance the identification of structural brain abnormalities that might be associated with neurological and psychiatric disorders such as schizophrenia. Another limitation of the reported studies is the sample size, which is a major issue since imaging techniques and genetic studies require considerable statistical power. Although the gross differences in size or symmetry of brain structures might be quantified, the individual cells and cell layers cannot yet be visualized. This means that, although the volume and shape of brain structures may be determined, the underlying cause of any differences cannot. Another limitation in imaging studies is the method applied to measure 
the volumes of brain structures. Some studies use the ROI analyses, where specific brain areas are manually traced. This method does not accommodate changes at sites distant to the ROI, and thus may be inherently biased in spatial terms. Investigating covariation between structures is important, for it may suggest that different brain structures are being influenced by the same gene or sets of genes. This approach may also be less sensitive to small variations in brain structure or tissue type distribution than more modern modeling methods (Good et al., 2001a, 2002). There is also a wide intra- and inter-rater variability, and ROI measurement errors are likely to be greater for smaller structures with complex architectures, particularly if anatomical borders are defined by arbitrary criteria. Other studies used the VBM method to measure volumes of brain structures, a fully automated whole brain technique. The VBM method avoids many of the constraints of ROI analyses, but it incorporates a series of preprocessing steps that may complicate the simple interpretation of regional changes of gray matter loss. One new method used in the heritability estimates is the elastic deformation procedure, used by Thompson et al. (2001), in which researchers modeled the genetic influences on neuroanatomic variation between healthy MZ and DZ twin pairs at each voxel on the surface of the cortex. Findings from these analyses showed a significant influence of the genetic factors on the gray matter density in subregions of prefrontal and temporal lobes, particularly in Broca's and Wernicke's language areas. Other areas within these structures were found less heritable, suggesting that heritability estimates based on gross lobular regions of interest blur more subtle local differences.

\section{B. Limitations of Twin Studies}

Twin studies cannot solve the problem of sources of variance, such as the gene-environment interactions, nonrandom assortative mating, and the possibility of differential interactions of environment in $\mathrm{MZ}$ and $\mathrm{DZ}$ twin pairs and the chorion type in MZ twins. Reliable detection of differences in correlations may therefore require hundreds of twin pairs. Interpretation of all the data in the reported studies is based on three assumptions in the classical twin designs: (1) MZ twins share $100 \%$ and DZ twins share on average $50 \%$ of their polymorphic genetic material and current methods adequately identify zygosity, (2) the environment shared among MZ and DZ twins is similar, and (3) twins are similar to singletons such that findings in twins can be generalized to nontwin populations. Conflicting results exist on the first assumption in schizophrenia, specifically that MZ twins discordant for schizophrenia share the same genetic material. Some studies (Guidry et al., 1999; Petronis and Kennedy, 1995; Petronis et al., 2003; Singh et al., 2002) suggest that twins discordant for schizophrenia share less of their polymorphic material than concordant and healthy twins in contrast to 
other studies claiming there is no empirical evidence for this (Nguyen et al., 2003; Tsujita et al., 1998; Vincent et al., 1998). The second assumption, that twins share the same environmental factors, has been criticized because of the physical maternal stress, which may be higher for twins then for singletons. There may also be more competition between the twins regarding nutrition. Although classic twin studies attempt to estimate unique environmental effects (events occurring to one twin but not to the other), as well as genetic (heritability) and environmental effects, one limitation of the model is that the gene-environment correlation and interaction is not discernible as a distinct effect. Another limitation is that there is no opportunity in the classic twin design to consider both shared environment and nonadditive genetic effects simultaneously. This limitation can be addressed by including additional siblings to the design, which was done by some studies in the healthy twin studies (Tables I and II). None of the studies reported in this review indicate the impact of possible prenatal and perinatal obstetric complications, except for the study by Van Erp et al. (2004) in which the obstetric records of half of the studied twin pairs did not differ between discordant MZ and DZ twin pairs, and the study by Wallace et al. (2006) in which data were corrected for the 29 weeks postgestational weight of the individuals included in the study. The third assumption on the generalizability of twin data to singletons is not possible according to some, because twins are not a random sample of the population and they differ in their developmental environment; in this sense they are not representative (Kempthorne and Osborne, 1961). Other studies claim that twins differ very little from their non-twin siblings and that measured studies on personality and intelligence of twins suggests that they have scores on these traits very similar to those of nontwins (Deary et al., 2005). Only one study, by Hulshoff Pol et al. (2002), addresses this question and suggests that the data from twin studies can be generalized to singletons, when correcting for the intracranial volume for the second born twin compared to the first born, since second born twins have lower intracranial volume. All other volumes are comparable as well, suggesting that twin studies provide reliable estimates of heritability and can be generalized to singletons.

\section{G. Limitations of Nonhuman Primate Studies}

Due to the close anatomical, physiological, biochemical, and genetic similarity to humans, NHPs play an important role as model in many aspects of research, specifically for genetic analysis of individual variation in brain structure. The most used species are the baboons, belonging to the old-world monkeys the rhesus macaques, cynomolgus macaques, and vervet monkeys, and being very closely related to the humans. Other primate species that are more similar to humans are the chimpanzees and gorillas. These species would represent a better model for the human neuroanatomy, but they present only minimal opportunities 
for intraspecies genetic analyses due to the lack of extensive multigeneration pedigrees (Rogers et al., 2007). Due to the use of large colonies, the analysis of complex phenotypes in the old world monkey can help us understand more about the genetic basis of individual variation in important traits.

One of the limitations of the NHP studies is that the heritability estimates in monkeys are specific to the population and circumstances in which they are assessed. Genetically diverse populations in homogeneous environments demonstrate larger heritability than do inbred populations in diverse environments (Falconer and Mackay, 1996).

Very few parents in the monkey colonies that make up study cohorts share a common mother or father, and extended family pedigrees cannot be determined from monkey breeding colony records. The generality of the NHP studies should therefore be tested in studies of other populations (Lyons et al., 2001).

It may be clear that the human brain is more than simply a large monkey brain. On the one hand, the monkey and the human brains share a common plan of organization, but on the other hand, striking species differences and specific regional differences exist. In the course of evolution, besides an increase in mean size, the brain of the newborn human is exposed to the physical, social, and cultural environmental factors for an extended period compared to the monkey, resulting in "cultural imprints," such as learning the spoken and written language (Deheane et al., 2005).

\section{Glinical Relevance of the Heritability Estimations}

Study of the influence of genetic factors on brain structures will help us to understand normal development and age, gender, and other variable associated changes, and will moreover help us understand the meaning of morphological changes found in schizophrenia.

One of the functional relevancies of the heritability of brain volumes is demonstrated best by the association between brain volumes and intelligence. In a study by Posthuma et al. (2002b), the association between brain volumes and intelligence was found to be of genetic origin. In two other studies (Thompson et al., 2001; Thompson et al., 2002), the association between frontal gray matter volume and intelligence was shown to be due to genetic factors. In a recent study by Hulshoff Pol et al. (2006), an association between intelligence and gray matter of the frontal and occipital lobe, the parahippocampus and the connecting white matter was found. While these findings suggest a common set of genes and intelligence, a study by Carmelli et al. (1998), shows that in elderly twins, the association between frontotemporal brain volumes, and executive function were found to be associated with common environmental influences shared by twins from the same family. Whether there is a gene-environment interaction, for example, persons with high level of cognitive functioning leading to select an 
environment that also increases brain size, or the possibility of overlapping sets of genes or common environmental influences causing variation in two distinct phenotypes, the cause of the findings between intelligence, and these brain structures, remains unknown. The heritability estimates are necessary to estimate the degree to which genetic factors and environmental factors have influence on the phenotype. Estimation of the impact of environmental factors is much more complicated and generally the effect size of environmental factors are considered to be the remaining part of the total heritability of a disease once the heritability due to genetic factors is known. In addition to the heritability measurements, genes involved in brain structures that are under the influence of genetic factors would be more easily investigated than looking at genes for brain structures in patients with schizophrenia, without knowing the origin (e.g., genetic vs. environmental, a gene- ${ }^{-}$environment interaction or disease related) of these brain changes. This is where the studies in NHPs might be useful, specifically since the impact of the environmental factors can be controlled and questions regarding the evolution of different brain parts and of human cognition only can be addressed adequately if the differences and similarities in the underlying neural circuitry of humans and all extant apes can be identified. Some data from older studies have been used by investigators to address these issues, but problems regarding the methodology used in the measurements, the incomplete representation of hominoid species and the small samples included makes the interpretation of these data difficult.

\section{E. Implications of These of Brain Volumes as Endophenotypes for Genetics of Psychiatric Disorders}

Despite the limitations of the twin studies and neuroimaging studies, it is fair to say that these studies only represent a subset of the possible genetic and environmental relationship and that the heritability estimates from these studies represent a first step in understanding the genetics of brain structures.

Using the brain structures with high heritability scores as endophenotypes and looking at the gene action for these endophenotypes, might solve problems in neuroimaging and genetic studies. In this study we found that global structures, with high heritability rates, such as total brain volume, hemispheres, cerebrum, cerebellum, gray and white matter, the four lobes (frontal, temporal, occipital and parietal), and corpus callosum seem to be more useful as endophenotype markers than specific structures with lower heritability rates. These structures are indeed formed earlier in development and the high heritability rates are suggestive of more genetic influences on early developed structures. Lower heritability rates for the specific structures might be due to lower sample sizes found in most of the studies, due to differences in methods measuring the volumes or due to difference in age in participating persons. The studies in NHPs show the same results on the 
heritability of gross brain structures, although there are few studies on the heritability of brain structures in NHPs. Looking at the genes for brain structures in healthy persons and persons with schizophrenia shows us that gene approach studies do not show a causal pathway for the brain morphological changes in patients with schizophrenia, and no susceptibility gene with a high effect size has yet been found for schizophrenia.

To summarize, the findings of the reviewed studies suggest that the overall brain volume is highly heritable, comparable with twin based estimates for the most highly genetically determined human traits, including fingerprint ridge count $\left(h^{2}=0.98\right)$ (Spence et al., 1977), height $\left(h^{2}=0.66\right)$ (Lettre, 2009; Silventoinen, 2003), and systolic blood pressure $\left(h^{2}=0.57\right)$ (Williams et al., 1990). The structures that are formed earlier in development (Rubenstein and Rakic, 1999; Rubenstein et al., 1999) and located deeper in the brain may be more genetically influenced thus, they show higher heritability scores than the structures which are formed later in development (Rakic, 1988) or are located on surface areas (Nadarajah and Parnavelas, 2002; Rakic, 1972). These structures are also under more environmental influence. Heritability studies on the genetic control of the human brain structure and how much individual genotype accounts for the wide variations among individual brains using neuranatomically defined endophenotypes will make it easier to look for the actions of genes on brain structures. However, a critical look at the genetic and or disease related changes in the brains of patients with complex disorders such as schizophrenia is necessary, as is suggested by Cannon et al. (2002). Further research on the influences of genetic, common, and unique environmental factors is necessary with advanced quantitative genetic methods. Genotyping studies in search of genes for brain structures in healthy subjects and for brain morphological changes in diseased need to be replicated; however, until now individual studies have been generally underpowered in replicating the small number of promising susceptibility genes (Ross et al., 2006) with small effect sizes (OR $<1.5)$. Looking for an association between brain morphological changes with genes, in particular the search for rare variants for overall genetic risk, with a more advanced method like the Genome Wide Association studies in combination with brain morphological changes, could bring new findings in causal pathways wherein genes interact with brain morphology. This may also shed light on understanding the relationship between schizophrenia and other major psychiatric disorders.

\section{Acknowledgments}

This research was supported by the Netherlands Organization for Scientific Research (NWO) under project number 017.002.048. We also thank A. Jasinska, Ph.D., UCLA/Los Angeles/USA, for her advices. 


\section{HERITABILITY OF STRUCTURAL BRAIN TRAITS}

\section{References}

Addington, A. M., Gornick, M., Duckworth, J., Sporn, A., Gogtay, N., Bobb, A., Greenstein, D., Lenane, M., Gochman, P., Baker, N., Balkissoon, R., Vakkalanka, R. K., et al. (2005). GAD1 (2q31.1), which encodes glutamic acid decarboxylase (GAD67), is associated with childhood-onset schizophrenia and cortical gray matter volume loss. Mol. Psychiatry 10(6), 581-588.

Addington, A. M., Gornick, M. C., Shaw, P., Seal, J., Gogtay, N., Greenstein, D., Clasen, L., Goffey, M., Gochman, P., Long, R., and Rapoport, J. L. (2007). Neuregulin 1 (8p12) and childhood-onset schizophrenia: Susceptibility haplotypes for diagnosis and brain developmental trajectories. Mol. Psychiatry 12(2), 195-205.

Agartz, I., Sedvall, G. C., Terenius, L., Kulle, B., Frigessi, A., Hall, H., and Jönsson, E. G. (2006). BDNF gene variants and brain morphology in schizophrenia. Am. F. Med. Genet. B Neuropsychiatr. Genet 141B(5), 513-523.

Alexander, M. P., and Annett, M. (1996). Crossed aphasia and related anomalies of cerebral organization: Case reports and a genetic hypothesis. Brain Lang. 55(2), 213-239. Review.

Allen, J. S., Damasio, H., and Grabowski, T. J. (2002). Normal neuroanatomical variation in the human brain: An MRI-volumetric study. Am. F. Phys. Anthropol. 118(4), 341-358.

Angelucci, F., Brenè, S., and Mathé, A. A. (2005). BDNF in schizophrenia, depression and corresponding animal models. Mol. Psychiatry 10(4), 345-352. Review.

Annett, M. (1974). Handedness in the children of two left-handed parents. Br. F. Psychol. 65(1), 129-131.

Ashburner, J., and Friston, K. J. (2000). Voxel-based morphometry: The methods. Neuroimage 11 (6 Pt 1), 805-821. Review.

Atwood, L. D., Wolf, P. A., Heard-Costa, N. L., Massaro, J. M., Beiser, A., D’Agostino, R. B., and DeCarli, C. (2004). Genetic variation in white matter hyperintensity volume in the Framingham Study. Stroke 35(7), 1609-1613.

Baaré, W. F., Hulshoff Pol, H. E., Boomsma, D. I., Posthuma, D., de Geus, E. J., Schnack, H. G., van Haren, N. E., van Oel, C. J., and Kahn, R. S. (2001a). Quantitative genetic modeling of variation in human brain morphology. Cereb Cortex 11(9), 816-824.

Baaré, W. F., van Oel, C. J., Hulshoff Pol, H. E., Schnack, H. G., Durston, S., Sitskoorn, M. M., and Kahn, R. S. (2001b). Volumes of brain structures in twins discordant for schizophrenia. Arch. Gen. Psychiatry 58(1), 33-40.

Bartley, A. J., Jones, D. W., and Weinberger, D. R. (1997). Genetic variability of human brain size and cortical gyral patterns. Brain 120((Pt 2), 257-269.

Bentall, R. P., Read, J. E., and Mosher, L. R. (2004). Models of Madness: Psychological, Social and Biological Approaches to Schizophrenia Brunner-Routledge, Philadelphia. ISBN 1-58391-906-6.

Biondi, A., Nogueira, H., Dormont, D., Duyme, M., Hasboun, D., Zouaoui, A., Chantôme, M., and Marsault, C. (1998). Are the brains of monozygotic twins similar? A three-dimensional MR study. AFNR Am. F. Neuroradiol. 19(7), 1361-1367.

Blangero, J., Williams, J. T., and Almasy, L. (2003). Novel family-based approaches to genetic risk in thrombosis. F. Thromb. Haemost $\mathbf{1}$ (7), 1391-1397.

Boyle, M. (2002). Schizophrenia: A Scientific Delusion? Routledge, New York. ISBN 0-415-22718-6.

Boos, H. B., Aleman, A., Cahn, W., Hulshoff Pol, H., and Kahn, R. S. (2007). Brain volumes in relatives of patients with schizophrenia: A meta-analysis. Arch. Gen. Psychiatry 64(3), 297-304.

Boomsma, D., Busjahn, A., and Peltonen, L. (2002). Classical twin studies and beyond. Nat. Rev. Genet. 3(11), 872-882. Review.

Brans, R. G., van Haren, N. E., van Baal, G. C., van Baal, G. C., Schnack, H. G., Kahn, R. S., and Hulshoff Pol, H. E. (2008). Heritability of changes in brain volume over time in twin pairs discordant for schizophrenia. Arch. Gen. Psychiatry 65(11), 1259-1268. 


\section{KAYMAZ AND VAN OS}

Bremner, J. D., Krystal, J. H., Southwick, S. M., and Charney, D. S. (1995). Functional neuroanatomical correlates of the effects of stress on memory. F. Trauma Stress $\mathbf{8}(4), 527-553$. Review.

Bremner, J. D., Narayan, M., Anderson ER Staib, L. H., Miller, H. L., and Charney, D. S. (2000). Hippocampal volume reduction in major depression. Am. F. Psychiatry 157(1), 115-118.

Bruckner, C. M., and Slanger, W. D. (1986). Symmetric differences squared and analysis of variance procedures for estimating genetic and environmental variances and covariances for beef cattle weaning weight: (a) Comparison via simulation (b) Estimates from a data set. F. Anim. Sci. 63(6), 1779-1793.

Buckholtz, J. W., Meyer-Lindenberg, A., Honea, R. A., Straub, R. E., Pezawas, L., Egan, M. F., Vakkalanka, R., Kolachana, B., Verchinski, B. A., Sust, S., Mattay, V. S., Weinberger, D. R., et al. (2007). Allelic variation in RGS4 impacts functional and structural connectivity in the human brain. F. Neurosci. 27(7), 1584-1593.

Bueller, J. A., Aftab, M., Sen, S., Gomez-Hassan, D., Burmeister, M., and Zubieta, J. K. (2006). BDNF Val66Met allele is associated with reduced hippocampal volume in healthy subjects. Biol. Psychiatry 59(9), 812-815.

Cahn, W., Hulshoff Pol, H. E., Bongers, M., Schnack, H. G., Mandl, R. C., Van Haren, N. E., Durston, S., Koning, H., Van Der Linden, J. A., and Kahn, R. S. (2001). Brain morphology in antipsychotic-naïe schizophrenia: A study of multiple brain structures. Br. F. Psychiatry. 43 (Suppl.), s66-s72.

Callicott, J. H., Straub, R. E., Pezawas, L., Egan, M. F., Mattay, V. S., Hariri, A. R., Verchinski, B. A., Meyer-Lindenberg, A., Balkissoon, R., Kolachana, B., Goldberg, T. E., and Weinberger, D. R. (2005). Variation in DISC1 affects hippocampal structure and function and increases risk for schizophrenia. Proc. Natl Acad. Sci. USA 102(24), 8627-8632.

Cardno, A. G., and Gottesman, A. G. (2000). Twin studies of schizophrenia: From bow-and-arrow concordances to star wars Mx and functional genomics. Am. F. Med. Genet 97(1), 12-17. Review.

Cardno, A. G., Thomas, K., and McGuffin, P. (2002). Clinical variables and genetic loading for schizophrenia: Analysis of published Danish adoption study data. Schizophr. Bull. 28(3), 393-399.

Carmelli, D., DeCarli, C., Swan, G. E., Jack, L. M., Reed, T., Wolf, P. A., and Miller, B. L. (1998). Evidence for genetic variance in white matter hyperintensity volume in normal elderly male twins. Stroke 29(6), 1177-1181.

Cannon, T. D., Kaprio, J., Lönnqvist, J., Huttunen, M., and Koskenvuo, M. (1998). The genetic epidemiology of schizophrenia in a Finnish twin cohort. A population-based modeling study. Arch. Gen. Psychiatry 55(1), 67-74.

Cannon, T. D., Thompson, P. M., van Erp, T. G., Toga, A. W., Poutanen, V. P., Huttunen, M., Lonnqvist, J., Standerskjold-Nordenstam, C. G., Narr, K. L., Khaledy, M., Zoumalan, C. I., Dail, R., et al. (2002). Cortex mapping reveals regionally specific patterns of genetic and diseasespecific gray-matter deficits in twins discordant for schizophrenia. Proc. Natl Acad. Sci. USA 99(5), 3228-3233.

Cannon, T. D., van Erp, T. G., Bearden, C. E., Loewy, R., Thompson, P., Toga, A. W., Huttunen, M. O., Keshavan, M. S., Seidman, L. J., and Tsuang, M. T. (2003). Early and late neurodevelopmental influences in the prodrome to schizophrenia: Contributions of genes, environment, and their interactions. Schizophr. Bull. 29(4), 653-669.

Cannon, T. D., Hennah, W., van Erp, T. G., Thompson, P. M., Lonnqvist, J., Huttunen, M., Gasperoni, T., Tuulio-Henriksson, A., Pirkola, T., Toga, A. W., Kaprio, J., Mazziotta, J., et al. (2005). Association of DISC1/TRAX haplotypes with schizophrenia, reduced prefrontal gray matter, and impaired short- and long-term memory. Arch. Gen. Psychiatry 62(11), 1205-1213.

Cantalupo, C., and Hopkins, W. D. (2001). Asymmetric Broca's area in great apes. Nature 414(6863), 505.

Carne, R. P., Vogrin, S., Litewka, L., and Cook, M. J. (2006). Cerebral cortex: An MRI-based study of volume and variance with age and sex. F. Clin. Neurosci 13(1), 60-72. 


\section{HERITABILITY OF STRUCTURAL BRAIN TRAITS}

Cheverud, J. M., Falk, D., Vannier, M., Moore, A. J., Helmkamp, R. G., and Vannier, M. (1990). Heritability of brain size and surface features in rhesus macaques (Macaca mulatta). F. Hered $\mathbf{8 1}(1)$, 51-57.

Cosgrove, K. P., Mazure, C. M., and Staley, J. K. (2007). Evolving knowledge of sex differences in brain structure, function, and chemistry. Biol. Psychiatry 62(8), 847-855. Review.

Deary, I. J., Pattie, A., Wilson, V., and Whalley, L. J. (2005). The cognitive cost of being a twin: Two whole-population surveys. Twin. Res. Hum. Genet 8(4), 376-383.

Dehaene, S., Duhamel, J.-R. D., Hauser, M. D., and Rizzolatti, G. (2005). Genes, brains, and culture: From monkey to human. In "Monkey Brain to Human Brain".

Deutch, A. Y. (1993). Prefrontal cortical dopamine systems and the elaboration of functional corticostriatal circuits: Implications for schizophrenia and Parkinson's disease. F. Neural Transm. Gen. Sect. 91(2-3), 197-221. Review.

Diagnostic and Statistical Manual of Mental Disorders (DSM-IV-Tr) (2000). American Psychiatric Association (APA).

Driemeyer, J., Boyke, J., Gaser, C., Büchel, C., and May, A. (2008). Changes in gray matter induced by learning-revisited. PLoS One 3(7), e2669.

Eckert, M. A., Leonard, C. M., Molloy, E. A., Blumenthal, J., Zijdenbos, A., and Giedd, J. N. (2002). The epigenesis of planum temporale asymmetry in twins. Cereb. Cortex 12(7), 749-755.

Falconer, D. S., and Mackay, T. F. G. (1996). Introduction to Quantitative Genetics 4th Ed. Addison Wesley Longman, Harlow, Essex, UK.

Falconer, D. S., Gauld, I. K., Roberts, R. C., and Williams, D. A. (1981). The control of body size in mouse chimaeras. Genet. Res 38(1), 25-46.

Fears, S. C., Melega, W. P., Service, S. K., Lee, C., Chen, K., Tu, Z., Jorgensen, M. J., Fairbanks, L. A., Cantor, R. M., Freimer, N. B., and Woods, R. P. (2009). Identifying heritable brain phenotypes in an extended pedigree of vervet monkeys. F. Neurosci. 29(9), 2867-2875.

Fernandez, T., Yan, W. L., Hamburger, S., Rapoport, J. L., Saunders, A. M., Schapiro, M., Ginns, E. I., and Sidransky, E. (1999). Apolipoprotein E alleles in childhood-onset schizophrenia. Am. J. Med. Genet 88(2), 211-213.

Gannon, P. J., Holloway, R. L., Broadfield, D. C., and Braun, A. R. (1998). Asymmetry of chimpanzee planum temporale: Humanlike pattern of Wernicke's brain language area homolog. Science 279 (5348), 220-222.

Geschwind, N., and Galaburda, A. M. (1985). Cerebral lateralization. Biological mechanisms, associations, and pathology: III. A hypothesis and a program for research. Arch. Neurol. 42(7), 634-654.

Geschwind, D. H., Miller, B. L., DeCarli, C., and Carmelli, D. (2002). Heritability of lobar brain volumes in twins supports genetic models of cerebral laterality and handedness. Proc. Natl. Acad. Sci. USA 99(5), 3176-3181.

Giedd, J. N. (2008). The teen brain: Insights from neuroimaging. F. Adolesc. Health 42(4), 335-343. Review.

Good, C. D., Ashburner, J., and Frackowiak, R. S. (2001a). Computational neuroanatomy: New perspectives for neuroradiology. Rev. Neurol. (Paris) 157(8-9 Pt 1), 797-806. Review.

Good, C. D., Johnsrude, I. S., Ashburner, J., Henson, R. N., Friston, K. J., and Frackowiak, R. S. (2001b). A voxel-based morphometric study of ageing in 465 normal adult human brains. Neuroimage 14(1 Pt 1), 21-36.

Good, C. D., Scahill, R. I., Fox, N. C., Ashburner, J., Friston, K. J., Chan, D., Crum, W. R., Rossor, M. N., and Frackowiak, R. S. (2002). Automatic differentiation of anatomical patterns in the human brain: Validation with studies of degenerative dementias. Neuroimage 17(1), 29-46.

Goldman, M. B., Torres, I. J., Keedy, S., Marlow-O’Connor, M., Beenken, B., and Pilla, R. (2007). Reduced anterior hippocampal formation volume in hyponatremic schizophrenic patients. Hippocampus 17(7), 554-562.

Gottesman, I. I., and Gould, T. D. (2003). The endophenotype concept in psychiatry: Etymology and strategic intentions. Am. F. Psychiatry 160(4), 636-645. Review. 


\section{KAYMAZ AND VAN OS}

Gould, E., and Tanapat, P. (1999). Stress and hippocampal neurogenesis. Biol. Psychiatry 46(11), 1472-1479. Review.

Guidry, J., and Kent, T. A. (1999). New genetic hypothesis of schizophrenia. Med. Hypotheses. 52(1), 69-75.

Gurling, H. M., Gritchley, H., Datta, S. R., McQuillin, A., Blaveri, E., Thirumalai, S., Pimm, J., Krasucki, R., Kalsi, G., Quested, D., Lawrence, J., Bass, N., et al. (2006). Genetic association and brain morphology studies and the chromosome 8p22 pericentriolar material 1 (PCM1) gene in susceptibility to schizophrenia. Arch. Gen. Psychiatry 63(8), 844-854. Erratum in: Arch. Gen. Psychiatry 64(11), 1258.

Gurvits, T. V., Shenton, M. E., Hokama, H., Ohta, H., Lasko, N. B., Gilbertson, M. W., Orr, S. P., Kikinis, R., Jolesz, F. A., McCarley, R. W., and Pitman, R. K. (1996). Magnetic resonance imaging study of hippocampal volume in chronic, combat-related posttraumatic stress disorder. Biol. Psychiatry 40(11), 1091-1099.

Hata, T., Kunugi, H., Nanko, S., Fukuda, R., and Kaminaga, T. (2002). Possible effect of the APOE epsilon 4 allele on the hippocampal volume and asymmetry in schizophrenia. Am. F. Med. Genet $\mathbf{1 1 4}(6), 641-642$.

Hennah, W., Thomson, P., Peltonen, L., and Porteous, D. (2006). Genes and schizophrenia: Beyond schizophrenia - The role of DISC1 in major mental illness. Schizophr. Bull. 32(3), 409-416. Review.

Ho, B. C., Wassink, T. H., O’Leary, D. S., Sheffield, V. C., and Andreasen, N. C. (2005). Catechol-Omethyl transferase Val158Met gene polymorphism in schizophrenia: Working memory, frontal lobe MRI morphology and frontal cerebral blood flow. Mol. Psychiatry 10(3), 229, 287-298.

Ho, B. C., Milev, P., O’Leary, D. S., Librant, A., Andreasen, N. G., and Wassink, T. H. (2006). Cognitive and magnetic resonance imaging brain morphometric correlates of brain-derived neurotrophic factor Val66Met gene polymorphism in patients with schizophrenia and healthy volunteers. Arch. Gen. Psychiatry 63(7), 731-740.

Ho, B. C., Andreasen, N. C., Dawson, J. D., and Wassink, T. H. (2007). Association between brainderived neurotrophic factor Val66Met gene polymorphism and progressive brain volume changes in schizophrenia. Am. J. Psychiatry 164(12), 1890-1899.

Hulshoff Pol, H. E., Posthuma, D., Baaré, W. F., De Geus, E. J., Schnack, H. G., van Haren, N. E., van Oel, C. J., Kahn, R. S., and Boomsma, D. I. (2002). Twin-singleton differences in brain structure using structural equation modelling. Brain. 125(Pt 2), 384-390.

Hulshoff Pol, H. E., Brans, R. G., van Haren, N. E., Schnack, H. G., Langen, M., Baaré, W. F., van Oel, C. J., and Kahn, R. S. (2004). Gray and white matter volume abnormalities in monozygotic and same-gender dizygotic twins discordant for schizophrenia. Biol. Psychiatry 55(2), 126-130.

Hulshoff Pol, H. E., Schnack, H. G., Posthuma, D., Mandl, R. C., Baaré, W. F., van Oel, C., van Haren, N. E., Collins, D. L., Evans, A. C., Amunts, K., Bürgel, U., Zilles, K., et al. (2006). Genetic contributions to human brain morphology and intelligence. F. Neurosci. 26(40), 10235-10242.

Ilg, R., Wohlschläger, A. M., Gaser, C., Liebau, Y., Dauner, R., Wöller, A., Zimmer, C., Zihl, J., and Mühlau, M. (2008). Gray matter increase induced by practice correlates with task-specific activation: A combined functional and morphometric magnetic resonance imaging study. f. Neurosci. 28(16), 4210-4215.

Kanaan, R., Barker, G., Brammer, M., Giampietro, V., Shergill, S., Woolley, J., Picchioni, M., Toulopoulou, T., and McGuire, P. (2009). White matter microstructure in schizophrenia: Effects of disorder, duration and medication. Br. F. Psychiatry 194(3), 236-242.

Kappelman, J. (1993). The evolution of body mass and relative brain size in fossil hominoids. F. Human Evol. 30, 243-276.

Kempthorne, O., and Osborne, R. H. (1961). The interpretation of twin data. Am. F. Hum. Genet. 13, 320-339.

Kendell, R., and Jablensky, A. (2003). Distinguishing between the validity and utility of psychiatric diagnoses. Am. J. Psychiatry 160(1), 4-12. 


\section{HERITABILITY OF STRUCTURAL BRAIN TRAITS}

Kendler, K. S., and Diehl, S. R. (1993). The genetics of schizophrenia: A current, genetic-epidemiologic perspective. Schizophr. Bull. 19(2), 261-285.

Koolschijn, P. G., van Haren, N. E., Hulshoff Pol, H. E., and Kahn, R. S. (2007). Hypothalamus volume in twin pairs discordant for schizophrenia. Eur. Neuropsychopharmacol. 18(4), 312-315.

Kunugi, H., Hattori, M., Nanko, S., Fujii, K., Kato, T., and Nanko, S. (1999). Dinucleotide repeat polymorphism in the neurotrophin-3 gene and hippocampal volume in psychoses. Schizophr. Res. 37(3), 271-273.

Lawrie, S. M., and Abukmeil, S. S. (1998). Brain abnormality in schizophrenia. A systematic and quantitative review of volumetric magnetic resonance imaging studies. Br. f. Psychiatry 172, 110-120.

Lee, H., Devlin, J. T., Shakeshaft, C., Stewart, L. H., Brennan, A., Glensman, J., Pitcher, K., Crinion, J., Mechelli, A., Frackowiak, R. S., Green, D. W., and Price, C. J. (2007). Anatomical traces of vocabulary acquisition in the adolescent brain. F. Neurosci. 27(5), 1184-1189.

Lettre, G. (2009). Genetic regulation of adult stature. Curr. Opin. Pediatr. 21(4), 515-522.

Linscott, R.J., Allardyce, J., and van Os, J. (2009). Seeking verisimilitude in a class: A systematic review of evidence that the criterial clinical symptoms of schizophrenia are taxonic. Schizophr. Bull. [Epub ahead of print].

Lohmann, G., von Cramon, D. Y., and Steinmetz, H. (1999). Sulcal variability of twins. Cereb. Cortex $\mathbf{9}(7), 754-763$.

Lyons, D. M., Yang, C., Sawyer-Glover, A. M., Moseley, M. E., and Schatzberg, A. F. (2001). Early life stress and inherited variation in monkey hippocampal volumes. Arch. Gen. Psychiatry 58(12), 1145-1151.

Magariños, A. M., and McEwen, B. S. (1995). Stress-induced atrophy of apical dendrites of hippocampal CA3c neurons: Comparison of stressors. Neuroscience. 69(1):83-88.

Mahaney, M. C., Williams-Blangero, S., Blangero, J., and Leland, M. M. (1993). Quantitative genetics of relative organ weight variation in captive baboons. Hum. Biol 65(6), 991-1003.

Martorell, L., Valero, J., Mulet, B., Gutiérrez-Zotes, A., Cortés, M. J., Jariod, M., Pérez, M., Labad, A., and Vilella, E. (2007). M129V variation in the prison protein gene and psychotic disorders: Relationship to neuropsychological and psychopathological measures. F. Psychiatr. Res. 41(10), 885-892.

McDonald, C., and Murphy, K. G. (2003). The new genetics of schizophrenia. Psychiatry Clin. North Am. 26(1), 41-63. Review.

McGuffin, P., Famer, A. E., Gottesman, I. I., Murray, R. M., and Reveley, A. M. (1984). Twin concordance for operationally defined schizophrenia. Confirmation of familiality and heritability. Arch. Gen. Psychiatry 41(6), 541-545.

McIntosh, A. M., Baig, B. J., Hall, J., Job, D., Whalley, H. C., Lymer, G. K., Moorhead, T. W., Owens, D. G., Miller, P., Porteous, D., Lawrie, S. M., and Johnstone, E. C. (2007). Relationship of catechol- $O$-methyltransferase variants to brain structure and function in a population at high risk of psychosis. Biol. Psychiatry 61(10), 1127-1134.

McIntosh, A. M., Moorhead, T. W., Job, D., Lymer, G. K., Muñoz Maniega, S., McKirdy, J., Sussmann, J. E., Baig, B. J., Bastin, M. E., Porteous, D., Evans, K. L., Johnstone, E. C., et al. (2008). The effects of a neuregulin 1 variant on white matter density and integrity. Mol. Psychiatry 13(11), 1054-1059.

McManus, I. C., and Bryden, M. P. (1991). Geschwind's theory of cerebral lateralization: Developing a formal, causal model. Psychol. Bull. 110(2), 237-253. Review.

McNeil, T. F. (2000). Perinatal risk factors and schizophrenia: Selective review and methodological concerns. Epidemiol. Rev. 17(1), 107-112. Review.

Meisenzahl, E. M., Rujescu, D., Kirner, A., Giegling, I., Kathmann, N., Leinsinger, G., Maag, K., Hegerl, U., Hahn, K., and Möller, H. J. (2001). Association of an interleukin-1beta genetic polymorphism with altered brain structure in patients with schizophrenia. Am. F. Psychiatry 158(8), 1316-1319. 


\section{KAYMAZ AND VAN OS}

Murray, R. M. (1994). Neurodevelopmental schizophrenia: The rediscovery of dementia praecox. $\mathrm{Br}$. 7. Psychiatry 25(Suppl.), 6-12. Review.

Nadarajah, B., and Parnavelas, J. G. (2002). Modes of neuronal migration in the developing cerebral cortex. Nat Rev Neurosci. 3(6), 423-432. Review.

Narr, K. L., van Erp, T. G., Cannon, T. D., Woods, R. P., Thompson, P. M., Jang, S., Blanton, R., Poutanen, V. P., Huttunen, M., Lönnqvist, J., Standerksjöld-Nordenstam, C. G., Kaprio, J., et al. (2002). A twin study of genetic contributions to hippocampal morphology in schizophrenia. Neurobiol. Dis. 11(1), 83-95.

Nguyen, G. H., Bouchard, J., Boselli MGTolstoi, L. G., Keith, L., Baldwin, G., Nguyen, N. C., Schultz, M., Herrera, V. L., and Smith, C. L. (2003). DNA stability and schizophrenia in twins. Am. F. Med. Genet. B Neuropsychiatr. Genet. 120B(1), 1-10.

Ohnishi, T., Hashimoto, R., Mori, T., Nemoto, K., Moriguchi, Y., Iida, H., Noguchi, H., Nakabayashi, T., Hori, H., Ohmori, M., Tsukue, R., Anami, K., et al. (2006). The association between the Val158Met polymorphism of the catechol-O-methyl transferase gene and morphological abnormalities of the brain in chronic schizophrenia. Brain 129(Pt 2), 399-410.

Okugawa, G., Nobuhara, K., Takase, K., and Kinoshita, T. (2007). Cerebellar posterior superior vermis and cognitive cluster scores in drug-naive patients with first-episode schizophrenia. Neuropsychobiology 56(4), 216-219.

Oppenheim, J. S., Skerry, J. E., Tramo, M. J., and Gazzaniga, M. S. (1989). Magnetic resonance imaging morphology of the corpus callosum in monozygotic twins. Ann. Neurol. 26(1), 100-104.

Papiol, S., Molina, V., Desco, M., Rosa, A., Reig, S., Gispert, J. D., Sanz, J., Palomo, T., and Fañanás, L. (2005). Ventricular enlargement in schizophrenia is associated with a genetic polymorphism at the interleukin-1 receptor antagonist gene. Neuroimage 27(4), 1002-1006.

Pearlson, G. D., and Calhoun, V. (2007). Structural and functional magnetic resonance imaging in psychiatric disorders. Can F. Psychiatry 52(3), 158-166. Review.

Pennington, B. F., Filipek, P. A., Lefly, D., Chhabildas, N., Kennedy, D. N., Simon, J. H., Filley, C. M., Galaburda, A., and DeFries, J. C. (2000). A twin MRI study of size variations in human brain. 7. Cogn. Neurosci. 12(1), 223-232.

Peper, J. S., Schnack, H. G., Brouwer, R. M., Van Baal, G. C., Pjetri, E., Székely, E., van Leeuwen, M., van den Berg, S. M., Collins, D. L., Evans, A. C., Boomsma, D. I., Kahn, R. S., et al. (2009). Heritability of regional and global brain structure at the onset of puberty: A magnetic resonance imaging study in 9-year-old twin pairs. Hum. Brain Mapp. 30(7), 2184-2196.

Petronis, A., and Kennedy, J. L. (1995). Unstable genes: Unstable mind? Am. F. Psychiatry 152(2), 164172. Review.

Petronis, A., Gottesman, I. I., Kan, P., Kennedy, J. L., Basile, V. S., Paterson, A. D., and Popendikyte, V. (2003). Monozygotic twins exhibit numerous epigenetic differences: Clues to twin discordance? Schizophr. Bull. 29(1), 169-178.

Pezawas, L., Verchinski, B. A., Mattay, V. S., Callicott, J. H., Kolachana, B. S., Straub, R. E., Egan, M. F., Meyer-Lindenberg, A., and Weinberger, D. R. (2004). The brain-derived neurotrophic factor val66met polymorphism and variation in human cortical morphology. 7 . Neurosci. 24(45), 10099-10102.

Pfefferbaum, A., Sullivan, E. V., and Carmelli, D. (2004). Morphological changes in aging brain structures are differentially affected by time-linked environmental influences despite strong genetic stability. Neurobiol. Aging 25(2), 175-183.

Plassman, B. L., Welsh-Bohmer, K. A., Bigler, E. D., Johnson, S. C., Anderson, C. V., Helms, M. J., Saunders, A. M., and Breitner, J. C. (1997). Apolipoprotein E epsilon 4 allele and hippocampal volume in twins with normal cognition. Neurology 48(4), 985-989.

Posthuma, D., and Boomsma, D. I. (2000). A note on the statistical power in extended twin designs. Behav. Genet. 30(2), 147-158. 


\section{HERITABILITY OF STRUCTURAL BRAIN TRAITS}

Posthuma, D., de Geus, E. J., Neale, M. C., Hulshoff Pol, H. E., Baaré, W. F., Kahn, R. S., and Boomsma, D. (2000). Multivariate genetic analysis of brain structure in an extended twin design. Behav. Genet. 30(4), 311-319.

Posthuma, D., Mulder, E. J., Boomsma, D. I., and de Geus, E. J. (2002a). Genetic analysis of IQ, processing speed and stimulus-response incongruency effects. Biol. Psychol 61(1-2), 157-182.

Posthuma, D., De Geus, E. J., Baaré, W. F., Hulshoff Pol, H. E., Kahn, R. S., and Boomsma, D. I. (2002b). The association between brain volume and intelligence is of genetic origin. Nat. Neurosci. $\mathbf{5}(2), 83-84$.

Posthuma, D., Baaré, W. F., Hulshoff Pol, H. E., Kahn, R. S., Boomsma, D. I., and De Geus, E. J. (2003). Genetic correlations between brain volumes and the WAIS-III dimensions of verbal comprehension, working memory, perceptual organization, and processing speed. Twin Res. 6(2), 131-139.

Prasad, S., Chowdari, K. V., Wood, J., Bhatia, T., Deshpande, S. N., Nimgaonkar, V. L., and Thelma, B. K. (2005). Association analysis of NOTCH 4 polymorphisms with schizophrenia among two independent family based samples. Am. F. Med. Genet. B Neuropsychiatr. Genet. 131B(1), 6-9.

Price, B. (1950). Primary biases in twin studies; a review of prenatal and natal difference-producing factors in monozygotic pairs. Am. 7. Hum. Genet. 2(4), 293-352.

Porteous, D. (2008). Genetic causality in schizophrenia and bipolar disorder: Out with the old and in with the new. Curr. Opin Genet. Dev. 18(3), 229-234. Review.

Rais, M., Cahn, W., Van Haren, N., Schnack, H., Caspers, E., Hulshoff Pol, H., and Kahn, R. (2008). Excessive brain volume loss over time in cannabis-using first-episode schizophrenia patients. $\mathrm{Am}$. 7. Psychiatry 165(4), 490-496.

Rakic, P. (1972). Mode of cell migration to the superficial layers of fetal monkey neocortex. F. Comp. Neurol. 145(1), 61-83.

Rakic, P. (1988). Specification of cerebral cortical areas. Science 241(4862), 170-176. Review.

Reveley, A. M., Reveley, M. A., Chitkara, B., et al. (1984). The genetic basis of cerebral ventricular volume. Psychiatry Res. 13(3), 261-266.

Rijsdijk, F. V., van Haren, N. E., Picchioni, M. M., McDonald, C., Toulopoulou, T., Hulshoff Pol, H. E., Kahn, R. S., Murray, R., and Sham, P. C. (2005). Brain MRI abnormalities in schizophrenia: Same genes or same environment? Psychol. Med. 35(10), 1399-1409.

Rogers, J., Kochunov, P., Lancaster, J., Shelledy, W., Glahn, D., Blangero, J., and Fox, P. (2007). Heritability of brain volume, surface area and shape: An MRI study in an extended pedigree of baboons. Hum. Brain Mapp. 28(6), 576-583.

Ross, G. A., Margolis, R. L., Reading, S. A., Pletnikov, M., and Coyle, J. T. (2006). Neurobiology of schizophrenia. Neuron 52(1), 139-153. Review.

Roth, G., and Dicke, U. (2005). Evolution of the brain and intelligence. Trends Cogn. Sci. 9(5), 250-257.

Rubenstein, J. L., and Rakic, P. (1999). Genetic control of cortical development. Cereb. Cortex 9(6), 521-523.

Rubenstein, J. L., Anderson, S., Shi, L., Miyashita-Lin, E., Bulfone, A., and Hevner, R. (1999). Genetic control of cortical regionalization and connectivity. Cereb. Cortex $\mathbf{9}(6), 524-532$.

Rujescu, D., Meisenzahl, E. M., Giegling, I., Kirner, A., Leinsinger, G., Hegerl, U., Hahn, K., and Möller, H. J. (2002). Methionine homozygosity at codon 129 in the prion protein is associated with white matter reduction and enlargement of CSF compartments in healthy volunteers and schizophrenic patients. Neuroimage 15(1), 200-206.

Rujescu, D., Meisenzahl, E. M., Krejcova, S., Giegling, I., Zetzsche, T., Reiser, M., Born, G. M., Möller, H. J., Veske, A., Gal, A., and Finckh, U. (2007). Plexin B3 is genetically associated with verbal performance and white matter volume in human brain. Mol. Psychiatry 12(2), 190-194. 115.

Sapolsky, R. M., Uno, H., Rebert, C. S., and Finch, C. E. (1990). Hippocampal damage associated with prolonged glucocorticoid exposure in primates. F. Neurosci. 10(9), 2897-2902. 


\section{KAYMAZ AND VAN OS}

Sánchez, M. M., Hearn, E. F., Do, D., Rilling, J. K., and Herndon, J. G. (1998). Differential rearing affects corpus callosum size and cognitive function of rhesus monkeys. Brain Res $\mathbf{8 1 2}(1-2)$, 38-49.

Sapolsky, R. M. (2000). Glucocorticoids and hippocampal atrophy in neuropsychiatric disorders. Arch. Gen. Psychiatry 57(10), 925-935.

Scamvougeras, A., Kigar, D. L., Jones, D., Weinberger, D. R., and Witelson, S. F. (2003). Size of the human corpus callosum is genetically determined: An MRI study in mono and dizygotic twins. Neurosci. Lett. 338(2), 91-94.

Schmitt, J. E., Lenroot, R. K., Wallace, G. L., Ordaz, S., Taylor, K. N., Kabani, N., Greenstein, D., Lerch, J. P., Kendler, K. S., Neale, M. C., and Giedd, J. N. (2008). Identification of genetically mediated cortical networks: A multivariate study of pediatric twins and siblings. Cereb. Cortex 18(8), 1737-1747.

Semendeferi, K., Damasio, H., Frank, R., and Van Hoesen, G. W. (1997). The evolution of the frontal lobes: A volumetric analysis based on three-dimensional reconstructions of magnetic resonance scans of human and ape brains. 7. Hum. Evol. 32(4), 375-388.

Semendeferi, K., Lu, A., Schenker, N., Damasio, H., and Damasio, H. (2001). Humans and great apes share a large frontal cortex. Nat. Neurosci. 5(3), 272-276.

Siegel, S. J., Ginsberg, S. D., Hof, P. R., Foote, S. L., Young, W. G., Kraemer, G. W., McKinney, W. T., and Morrison, J. H. (1993). Effects of social deprivation in prepubescent rhesus monkeys: Immunohistochemical analysis of the neurofilament protein triplet in the hippocampal formation. Brain Res. 619(1-2), 299-305.

Silventoinen, K. (2003). Determinants of variation in adult body height. F. Biosoc. Sci. 35(2), 263-285.

Singh, S. M., Murphy, B., and O'Reilly, R. (2002). Epigenetic contributors to the discordance of monozygotic twins. Clin. Genet. 62(2), 97-103. Review.

Sheline, Y. I., Sanghavi, M., Mintun, M. A., and Gado, M. H. (1999). Depression duration but not age predicts hippocampal volume loss in medically healthy women with recurrent major depression. 7. Neurosci. 19(12), 5034-5043.

Soininen, H. S., and Riekkinen, P. J. Sr. (1996). Apolipoprotein E, memory and Alzheimer's disease. Trends Neurosci. 19(6), 224-228.

Spence, M. A., Westlake, J., and Lange, K. (1977). Estimation of the variance components for dermal ridge count. Ann. Hum. Genet. 41(1), 111-115.

Steinmetz, H., Herzog, A., Schlaug G Huang, Y., and Jäncke, L. (1995). Brain (A) symmetry in monozygotic twins. Cereb. Cortex 5(4), 296-300.

Suddath, R. L., Christison, G. W., Torrey, E. F., Casanova, M. F., and Weinberger, D. R. (1990). Anatomical abnormalities in the brains of monozygotic twins discordant for schizophrenia. N. Engl. F. Med. 322(12), 789-794.

Sullivan, E. V., Pfefferbaum, A., Swan, G. E., and Carmelli, D. (2001). Heritability of hippocampal size in elderly twin men: Equivalent influence from genes and environment. Hippocampus 11(6), 754-762.

Sullivan, P. F., Kendler, K. S., and Neale, M. C. (2003). Schizophrenia as a complex trait: Evidence from a meta-analysis of twin studies. Arch. Gen. Psychiatry 60(12), 1187-1192.

Szeszko, P. R., Lipsky, R., Mentschel, G., Robinson, D., Gunduz-Bruce, H., Sevy, S., Ashtari, M., Napolitano, B., Bilder, R. M., Kane, J. M., Goldman, D., and Malhotra, A. K. (2005). Brainderived neurotrophic factor val66met polymorphism and volume of the hippocampal formation. Mol. Psychiatry 10(7), 631-636.

Tohgi, H., Takahashi, S., Kato, E., Homma, A., Niina, R., Sasaki, K., Yonezawa, H., and Sasaki, M. (1997). Reduced size of right hippocampus in 39- to 80-year-old normal subjects carrying the apolipoprotein E epsilon4 allele. Neurosci. Lett. 236(1), 21-24.

Thompson, P. M., and Toga, A. W. (1997). Detection, visualization and animation of abnormal anatomic structure with a deformable probabilistic brain atlas based on random vector field transformations. Med. Image Anal. 1(4), 271-294. 


\section{HERITABILITY OF STRUCTURAL BRAIN TRAITS}

Thompson, P. M., Schwartz, C., and Toga, A. W. (1996a). High-resolution random mesh algorithms for creating a probabilistic 3D surface atlas of the human brain. Neuroimage 3(1), 19-34.

Thompson, P. M., Schwartz, C., Lin, R. T., Khan, A. A., and Toga, A. W. (1996b). Three-dimensional statistical analysis of sulcal variability in the human brain. F. Neurosci. 16(13), 4261-4274.

Thompson, P. M., Cannon, T. D., Narr, K., van Erp, T., Poutanen, V. P., Huttunen, M., Lönnqvist, J., Standertskjöld-Nordenstam, G. G., Kaprio, J., Khaledy, M., Dail, R., Zoumalan, C. I., et al. (2001). Genetic influences on brain structure. Nat. Neurosci. 4(12), 1253-1258.

Thompson, P., Cannon, T. D., and Toga, A. W. (2002). Mapping genetic influences on human brain structure. Ann. Med. 34(7-8), 523-536. Review.

Tramo, M. J., Loftus, W. C., Stukel, T. A., Green, R. L., Weaver, J. B., and Gazzaniga, M. S. (1998). Brain size, head size, and intelligence quotient in monozygotic twins. Neurology 50(5), 1246-1252.

Tsujita, T., Niikawa, N., Yamashita, H., Imamura, A., Hamada, A., Nakane, Y., and Okazaki, Y. (1998). Genomic discordance between monozygotic twins discordant for schizophrenia. Am. 7. Psychiatry 155(3), 422-424.

Uno, H., Tarara, R., Else, J. G., Suleman, M. A., and Sapolsky, R. M. (1989). Hippocampal damage associated with prolonged and fatal stress in primates. F. Neurosci. 9(5), 1705-1711.

van Erp, T. G., Saleh, P. A., Huttunen, M., Lönnqvist, J., Kaprio, J., Salonen, O., Valanne, L., Poutanen, V. P., Standertskjöld-Nordenstam, C. G., and Cannon, T. D. (2004). Hippocampal volumes in schizophrenic twins. Arch. Gen. Psychiatry 61(4), 346-353.

van Haren, N. E., Picchioni, M. M., McDonald, G., Marshall, N., Davis, N., Ribchester, T., Hulshoff Pol, H. E., Sharma, T., Sham, P., Kahn, R. S., and Murray, R. (2004). A controlled study of brain structure in monozygotic twins concordant and discordant for schizophrenia. Biol. Psychiatry 56(6), 454-461.

van Haren, N. E., Hulshoff Pol, H. E., Schnack, H. G., Cahn, W., Mandl, R. C., Collins, D. L., Evans, A. C., and Kahn, R. S. (2007). Focal gray matter changes in schizophrenia across the course of the illness: A 5-year follow-up study. Neuropsychopharmacology 32(10), 2057-2066.

van Haren, N. E., Bakker, S. G., and Kahn, R. S. (2008). Genes and structural brain imaging in schizophrenia. Curr. Opin. Psychiatry 21(2), 161-167. Review.

van Os, J. (2009). A salience dysregulation syndrome. Br. F. Psychiatry 194(2), 101-103.

van Os, J., and Murray, R. (2008). Gene-environment interactions in schizophrenia. Introduction. Schizophr. Bull. 34(6), 1064-1065.

van Os, J., Rutten, B. P., and Poulton, R. (2008). Gene-environment interactions in schizophrenia: Review of epidemiological findings and future directions. Schizophr. Bull. 34(6), 1066-1082.

Verdoux, H., Geddes, J. R., Takei, N., Lawrie, S. M., Bovet, P., Eagles, J. M., Heun, R., McCreadie, R. G., McNeil, T. F., O’Callaghan, E., Stöber, G., Willinger, M. U., et al. (1997). Obstetric complications and age at onset in schizophrenia: An international collaborative metaanalysis of individual patient data. Am. F. Psychiatry 154(9), 1220-1227.

Vincent, J. B., Kalsi, G., Klempan, T., Tatuch, Y., Sherrington, R. P., Breschel, T., McInnis, M. G., Brynjolfsson, J., Petursson, H., Gurling, H. M., Gottesman, I. I., Torrey, E. F., et al. (1998). No evidence of expansion of CAG or GAA repeats in schizophrenia families and monozygotic twins. Hum. Genet. $\mathbf{1 0 3}(1), 41-47$.

Wallace, G. L., Eric Schmitt, J., Lenroot, R., Viding, E., Ordaz, S., Rosenthal, M. A., Molloy, E. A., Clasen, L. S., Kendler, K. S., Neale, M. C., and Giedd, J. N. (2006). A pediatric twin study of brain morphometry. 7. Child Psychol. Psychiatry 47(10), 987-993.

Wang, J. K., Li, Y., and Su, B. (2008). A common SNP of MCPH1 is associated with cranial volume variation in Chinese population. Hum. Mol. Genet. 17(9), 1329-1335.

Ward, K. E., Friedman, L., Wise, A., and Schulz, S. C. (1996). Meta-analysis of brain and cranial size in schizophrenia. Schizophr. Res. 22(3), 197-213.

Wassink, T. H., Nelson, J. J., Crowe, R. R., and Andreasen, N. C. (1999). Heritability of BDNF alleles and their effect on brain morphology in schizophrenia. Am. F. Med. Genet. 88(6), 724-728. 


\section{KAYMAZ AND VAN OS}

Wassink, T. H., Crowe, R. R., and Andreasen, N. C. (2000). Tumor necrosis factor receptor-II: Heritability and effect on brain morphology in schizophrenia. Mol. Psychiatry 5(6), 678-682.

Wassink, T. H., Nopoulos, P., Pietila, J., Crowe, R. R., and Andreasen, N. C. (2003). NOTCH4 and the frontal lobe in schizophrenia. Am. F. Med. Genet. B Neuropsychiatr. Genet. 118B(1), 1-7.

Weinberger, D. R. (1995). From neuropathology to neurodevelopment. Lancet 346(8974), 552-557. Review.

White, T., Andreasen, N. C., and Nopoulos, P. (2002). Brain volumes and surface morphology in monozygotic twins. Cereb Cortex 12(5), 486-493.

Williams, R. R., Hunt, S. C., Hasstedt, S. J., Hopkins, P. N., Wu, L. L., Berry, T. D., Stults, B. M., Barlow, G. K., and Kuida, H. (1990). Genetics of hypertension: What we know and don't know. Clin. Exp. Hypertens. A. 12(5), 865-876.

Williams, H. J., Owen, M. J., and O’Donovan, M. G. (2007). Is COMT a susceptibility gene for schizophrenia? Schizophr. Bull. 33(3), 635-641.

Woods, R. P., Freimer, N. B., De Young, J. A., Fears, S. C., Sicotte, N. L., Service, S. K., Valentino, D. J., Toga, A. W., and Mazziotta, J. C. (2006). Normal variants of Microcephalin and ASPM do not account for brain size variability. Hum. Mol. Genet. 15(12), 2025-2029.

Wright, I. C., Rabe-Hesketh, S., and Woodruff, P. W. (2000). Meta-analysis of regional brain volumes in schizophrenia. Am. J. Psychiatry 157(1), 16-25.

Wright, I. C., Sham, P., Murray, R. M., Weinberger, D. R., and Bullmore, E. T. (2002). Genetic contributions to regional variability in human brain structure: Methods and preliminary results. Neuroimage 17(1), 256-271.

Zinkstok, J., Schmitz, N., van Amelsvoort, T., de Haan, L., Yusuf, M. A., Baas, F., and Linszen, D. (2007). Genetic variation in COMT and PRODH is associated with brain anatomy in patients with schizophrenia. Genes Brain Behav. 7(1), 61-69. 


\section{Editorial}

\section{Murray et al. (2004) revisited: is bipolar disorder identical to schizophrenia without developmental impairment?}

In 2004, Murray et al. (1) suggested that the main difference between bipolar disorder (BPD) and schizophrenia $(\mathrm{Sz})$ was a larger prevalence of developmental impairments in the latter. A number of recent articles in Acta Psychiatrica Scandinavica suggest that categories of affective and non-affective psychosis may be similar in their pattern of associations with measures as diverse as social cognition (2), brain volumes (3) and metabolic dysregulation (4), begging the question what the actual status is of the prediction offered by Murray et al. more than 5 years ago. These issues are particularly important given the upcoming revisions of diagnostic systems in psychiatry: how should bipolar disorder and schizophrenia be classified in DSM-V and ICD-11?

A review was conducted of studies focussing on this issue, with a special focus on work published in the last 10 years; results are displayed in Table 1 below.

Both Sz and BPD have onset in adolescence and young adulthood, with an earlier onset in men. The incidence of both disorders is low and associated with a high prevalence:incidence ratio, indicative of a high rate of chronicity. Schizophrenia patients have high rates of affective symptoms, although lower than in BPD, and bipolar patients have negative symptoms and cognitive impairment, although lower than in Sz. The diagnostic contrast between $\mathrm{Sz}$ and BPD is high for affective symptoms, but this is mostly due to artificial diagnostic exclusion criteria.

$\mathrm{Sz}$ and BPD have correlated genetic liabilities, some of which is becoming substantiated in recent genome-wide molecular genetic association studies. Of interest, however, is the fact that genetic risk for $\mathrm{Sz}$ is strongly expressed as neurocognitive impairment whereas genetic risk for BPD is only weakly expressed in the neurocognitive domain. Danish studies have shown that BPD and $\mathrm{Sz}$ have a high population comorbidity index; general population studies have shown that both BPD and Sz phenotypes are associated with psychometric risk states in healthy individuals, and that BPD and $\mathrm{Sz}$ psychometric risk states are similarly highly comorbid with each other. Risk factors representing social stress and defeat as well as early emotional alterations are associated with both BPD and $\mathrm{Sz}$ whereas risk factors reflecting early motor and cognitive alterations appear specific for schizo-
Fig. 1. A combined dimensional and categorical system of diagnosis of psychotic disorders. Categorical diagnoses of schizophrenia (yellow), bipolar disorder (brown), and schizoaffective disorder (pink) are accompanied by a patient's quantitative scores (connected by red lines) on five main dimensions of psychopathology.

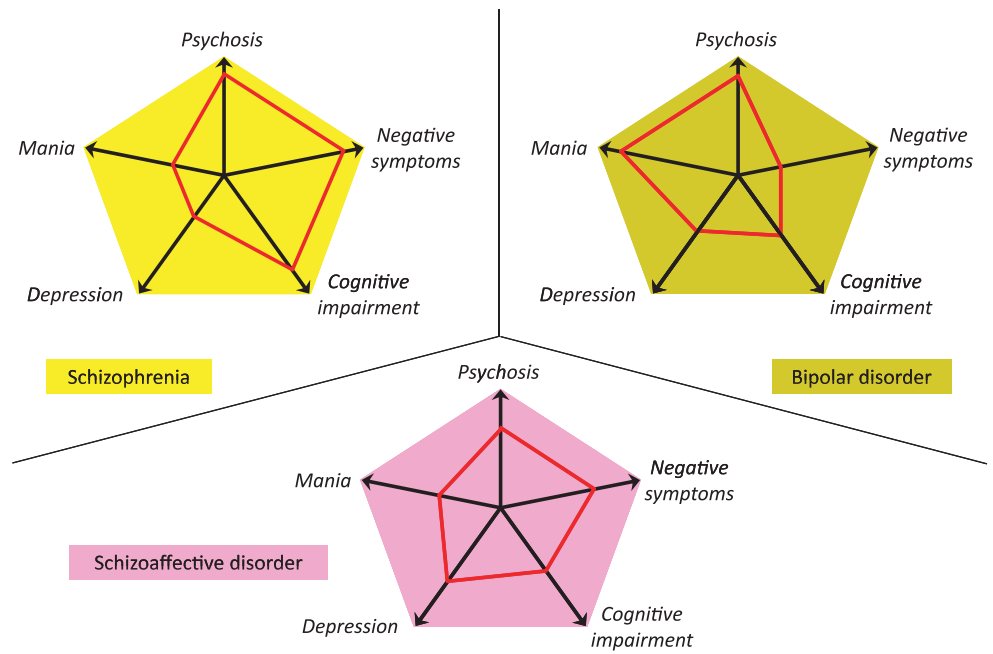




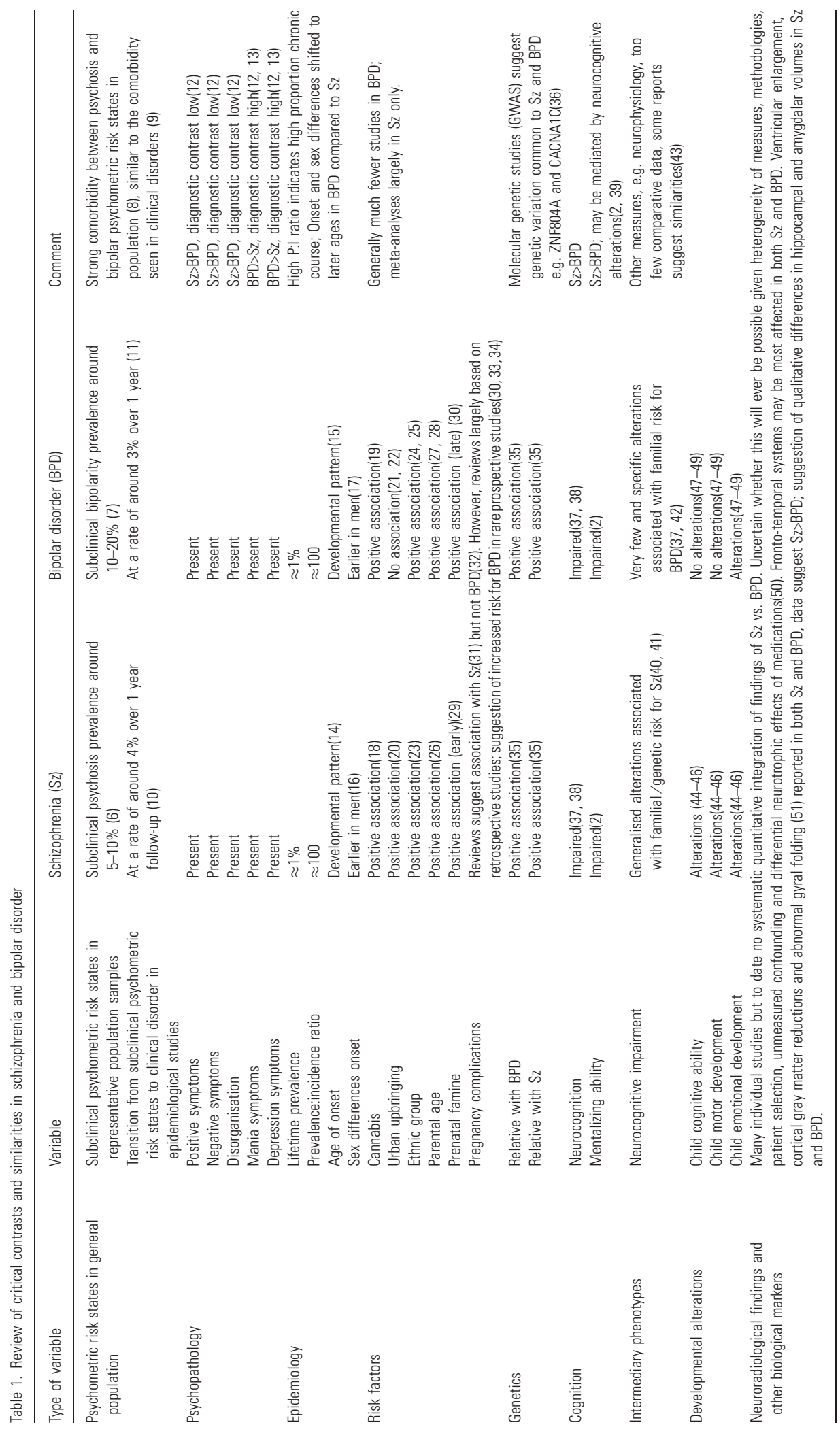


phrenia. Interesting is the differential association with growing up in an urban environment (not associated with bipolar disorder), suggesting that this exposure impacts on specific developmental alterations associated with schizophrenia.

The literature on neuroimaging, biological variables and prenatal life suggests differences and similarities as regards their prevalences in $\mathrm{Sz}$ and BPD; firm conclusions, however, cannot be drawn because of many methodological constraints and the lack of direct comparisons.

In conclusion, science is catching up with century-old diagnostic traditions in psychiatry. It is becoming apparent that due to the strict separation imposed by DSM and ICD on the domains of affective and non-affective psychotic disorder, major opportunities have been missed to study the causes and treatment of psychiatric disorders. Psychotic disorders appear to be originating from (partly) overlapping areas of risk, one more developmental associated with cognitive impairment, and one more associated with affective dysregulation. It has been suggested that where these areas of risk overlap and interact with environmental risks, delusions and hallucinations may ensue through a final common pathway of dopamine dysregulation and affective cognitive biases (5). Therefore an elegant way of adapting the revisions of DSM and ICD diagnostic manuals to the scientific reality is to keep diagnostic categories more or less as they were and add cross-disorder dimensions of psychopathology, as depicted in Fig. 1. The simple addition of dimensions would finally clear the way for an official cross-diagnostic approach in psychiatry, ending a dysfunctional and rigid system of artificial partitioning.

\section{Acta Psychiatrica Scandinavica $\mathrm{Nil}$ Kaymaz and Jim van Os Invited Guest Editors}

\section{Acknowledgement}

Nil Kaymaz is supported by the Netherlands Organisation for Scientific Research (NWO) under project number: 017.002.048.

\section{References}

1. Murray RM, Sham P, Van Os J, Zanelli J, Cannon M, McDonald C. A developmental model for similarities and dissimilarities between schizophrenia and bipolar disorder. Schizophr Res 2004;71:405-416.

2. Bora E, Yucel M, Pantelis C. Theory of mind impairment: a distinct trait-marker for schizophrenia spectrum disorders and bipolar disorder? Acta Psychiatr Scand 2009; 120:253-264.
3. Sun J, Maller JJ, Daskalakis ZJ, Furtado CC, Fitzgerald $\mathrm{PB}$. Morphology of the corpus callosum in treatmentresistant schizophrenia and major depression. Acta Psychiatr Scand 2009;120:265-273.

4. Huang MC, Lu ML, Tsai CJ et al. Prevalence of metabolic syndrome among patients with schizophrenia or schizoaffective disorder in Taiwan. Acta Psychiatr Scand 2009; 120:274-280.

5. VAN Os J, KapUR S. Schizophrenia. Lancet 2009;374:635-645.

6. Van Os J, Linscott RJ, Myin-Germeys I, Delespaul P, KRABbendam L. A systematic review and meta-analysis of the psychosis continuum: evidence for a psychosis proneness-persistence-impairment model of psychotic disorder. Psychol Med 2009;39:179-195.

7. Tussen MJA, Van Os J, Wittchen HU et al. Evidence that bipolar disorder is the poor outcome fraction of a common developmental phenotype: an 8-year cohort study in young people. Psychol Med 2009;11:1-11.

8. van Rossum I, Dominguez M, Lieb R, Wittchen HU, van Os J. Affective dysregulation and reality distortion: a 10-year prospective study of their association and clinical relevance. Submitted manuscript 2009.

9. Laursen TM, Agerbo E, Pedersen CB. Bipolar disorder, schizoaffective disorder, and schizophrenia overlap: a new comorbidity index. J Clin Psychiatry 2009; [Epub ahead of print].

10. Hanssen M, Bak M, Bijl R, Vollebergh W, van Os J. The incidence and outcome of subclinical psychotic experiences in the general population. Br J Clin Psychol 2005;44:181191.

11. Regeer EJ, Krabbendam L, de Graaf R, ten Have M, Nolen WA, van Os J. A prospective study of the transition rates of subthreshold (hypo)mania and depression in the general population. Psychol Med 2006;36:619-627.

12. Van Os J, Gilvarry C, Bale R et al. Diagnostic value of the DSM and ICD categories of psychosis: An evidence-based approach. Soc Psychiatry Psychiatr Epidemiol 2000;35: 305-311.

13. Peralta V, Cuesta MJ. Characterization of affective domains within the nonaffective psychotic disorders. Schizophr Res 2009;111:61-69.

14. McGrath J, Saha S, Chant D, Welham J. Schizophrenia: a concise overview of incidence, prevalence, and mortality. Epidemiol Rev 2008;30:67-76.

15. Kennedy N, Everitt B, Boydell J, Van Os J, Jones PB, MurRAY RM. Incidence and distribution of first-episode mania by age: results from a 35-year study. Psychol Med 2005;35:855-863.

16. Castle DJ, Murray RM. The neurodevelopmental basis of sex differences in schizophrenia. Psychol Med 1991;21: $565-575$.

17. Kennedy N, Boydell J, Kalidindi $\mathrm{S}$ et al. Gender differences in incidence and age at onset of mania and bipolar disorder over a 35-year period in Camberwell, England. Am J Psychiatry 2005;162:257-262.

18. Henquet C, Murray R, Linszen D, van Os J. The environment and schizophrenia: the role of cannabis use. Schizophr Bull 2005;31:608-612.

19. Henquet C, Krabbendam L, de Graaf R, ten Have M, van Os J. Cannabis use and expression of mania in the general population. J Affect Disord 2006;95:103-110.

20. Krabbendam L, van Os J. Schizophrenia and urbanicity: a major environmental influence-conditional on genetic risk. Schizophr Bull 2005;31:795-799.

21. Mortensen PB, Pedersen CB, Melbye M, Mors O, Ewald H. Individual and familial risk factors for bipolar affective 


\section{Editorial}

disorders in Denmark. Arch Gen Psychiatry 2003;60:12091215.

22. Kaymaz N, Krabbendam L, de Graaf R, Nolen W, Ten Have M, van Os J. Evidence that the urban environment specifically impacts on the psychotic but not the affective dimension of bipolar disorder. Soc Psychiatry Psychiatr Epidemiol 2006;41:679-685.

23. Cantor-Graae E, Selten JP. Schizophrenia and migration: a meta-analysis and review. Am J Psychiatry 2005;162:12-24.

24. Van Os J, Castle DJ, Takei N, Der G, Murray RM. Psychotic illness in ethnic minorities: clarification from the 1991 census. Psychol Med 1996;26:203-208.

25. Kirkbride JB, Fearon P, Morgan $C$ et al. Heterogeneity in incidence rates of schizophrenia and other psychotic syndromes: findings from the 3-center AeSOP study. Arch Gen Psychiatry 2006;63:250-258.

26. WoHl M, Gorwood P. Paternal ages below or above 35 years old are associated with a different risk of schizophrenia in the offspring. Eur Psychiatry 2007;22:22-26.

27. Menezes PR, Lewis G, Rasmussen $F$ et al. Paternal and maternal ages at conception and risk of bipolar affective disorder in their offspring. Psychol Med 2009; [Epub ahead of print].

28. Frans EM, Sandin S, Reichenberg A, Lichtenstein P, Langstrom N, Hultman CM. Advancing paternal age and bipolar disorder. Arch Gen Psychiatry 2008;65:1034-1040.

29. Susser E, Neugebauer R, Hoek HW et al. Schizophrenia after prenatal famine. Further evidence [see comments]. Arch Gen Psychiatry 1996;53:25-31.

30. Brown AS, Van Os J, Driessens C, Hoek HW, Susser ES. Further evidence of relation between prenatal famine and major affective disorder. Am J Psychiatry 2000;157:190 195.

31. Cannon M, Jones PB, Murray RM. Obstetric complications and schizophrenia: historical and meta-analytic review. Am J Psychiatry 2002;159:1080-1092.

32. Scott J, McNeill Y, Cavanagh J, Cannon M, Murray R. Exposure to obstetric complications and subsequent development of bipolar disorder: systematic review. $\mathrm{Br} \mathrm{J}$ Psychiatry 2006;189:3-11.

33. Zornberg GL, Buka SL, Tsuang MT. Hypoxic-ischemiarelated fetal/neonatal complications and risk of schizophrenia and other nonaffective psychoses: a 19-year longitudinal study. Am J Psychiatry 2000;157:196-202.

34. Laursen TM, Munk-Olsen T, Nordentoft M, Bo Mortensen P. A comparison of selected risk factors for unipolar depressive disorder, bipolar affective disorder, schizoaffective disorder, and schizophrenia from a Danish population-based cohort. J Clin Psychiatry 2007;68:1673-1681.

35. Van Snellenberg JX, de Candia T. Meta-analytic evidence for familial coaggregation of schizophrenia and bipolar disorder. Arch Gen Psychiatry 2009;66:748-755.

36. O'Donovan MC, Craddock NJ, Owen MJ. Genetics of psychosis; insights from views across the genome. Hum Genet 2009;126:3-12.
37. Arts B, Jabben N, Krabbendam L, van Os J. Meta-analyses of cognitive functioning in euthymic bipolar patients and their first-degree relatives. Psychol Med 2008;38:771-785.

38. Krabbendam L, Arts B, van Os J, Aleman A. Cognitive functioning in patients with schizophrenia and bipolar disorder: a quantitative review. Schizophr Res 2005;80:137-149.

39. van Hooren S, Versmissen D, JansSen I et al. Social cognition and neurocognition as independent domains in psychosis. Schizophr Res 2008;103:257-265.

40. Toulopoulou T, Picchioni M, Rissdijk F et al. Substantial genetic overlap between neurocognition and schizophrenia: genetic modeling in twin samples. Arch Gen Psychiatry 2007;64:1348-1355.

41. Dickinson D, Ramsey ME, Gold JM. Overlooking the obvious: a meta-analytic comparison of digit symbol coding tasks and other cognitive measures in schizophrenia. Arch Gen Psychiatry 2007;64:532-542.

42. Bora E, Yucel M, Pantelis C. Cognitive endophenotypes of bipolar disorder: a meta-analysis of neuropsychological deficits in euthymic patients and their first-degree relatives. J Affect Disord 2009;113:1-20.

43. Sanchez-Morla EM, Garcia-Jimenez MA, Barabash A et al. P50 sensory gating deficit is a common marker of vulnerability to bipolar disorder and schizophrenia. Acta Psychiatr Scand 2008;117:313-318.

44. Welham J, Isohanni M, Jones P, McGrath J. The antecedents of schizophrenia: a review of birth cohort studies. Schizophr Bull 2009;35:603-623.

45. Woodberry KA, Giuliano AJ, Seidman LJ. Premorbid IQ in schizophrenia: a meta-analytic review. Am J Psychiatry 2008;165:579-587.

46. Tarbox SI, Pogue-Geile MF. Development of social functioning in preschizophrenia children and adolescents: a systematic review. Psychol Bull 2008;134:561-583.

47. Cannon M, Caspi A, Mofitt TE et al. Evidence for earlychildhood, pan-developmental impairment specific to schizophreniform disorder: results from a longitudinal birth cohort. Arch Gen Psychiatry 2002;59:449-456.

48. Reichenberg A, Weiser M, Rabinowitz J et al. A populationbased cohort study of premorbid intellectual, language, and behavioral functioning in patients with schizophrenia, schizoaffective disorder, and nonpsychotic bipolar disorder. Am J Psychiatry 2002;159:2027-2035.

49. Zammit S, Allebeck P, David AS et al. A longitudinal study of premorbid IQ Score and risk of developing schizophrenia, bipolar disorder, severe depression, and other nonaffective psychoses. Arch Gen Psychiatry 2004;61:354-360.

50. Gur RE, Keshavan MS, Lawrie SM. Deconstructing psychosis with human brain imaging. Schizophr Bull 2007;33:921-931.

51. McIntosh AM, Moorhead TW, McKirdy J et al. Prefrontal gyral folding and its cognitive correlates in bipolar disorder and schizophrenia. Acta Psychiatr Scand 2009;119:192198. 


\title{
Extended psychosis phenotype - yes: single continuum - unlikely
}

A commentary on 'Why we need more debate on whether psychotic symptoms lie on a continuum with normality’ by David (2010)

\author{
N. Kaymaz ${ }^{1,2}$ and J. van $\mathrm{Os}^{1,3 *}$ \\ ${ }^{1}$ Maastricht University Medical Centre, South Limburg Mental Health Research and Teaching Network, EURON, Maastricht, The Netherlands \\ ${ }^{2}$ Mediant GGZ/Mental Health Care, Postbus 775, 7500 AT Enschede, The Netherlands \\ ${ }^{3}$ Division of Psychological Medicine, Institute of Psychiatry, King's College London, De Crespigny Park, Denmark Hill, London, UK
}

Received 7 February 2010; Accepted 8 February 2010

Key words: Diagnosis, psychosis, risk factors.

The accepted dogma is that psychotic disorders come as diagnosable 'things', categories, the carriers of which form a diagnostic boundary, below which reside the healthy non-carriers who do not display the mental phenomena observed in patients. This model has come under some pressure, as population research has shown high rates of psychotic experiences in people who are not readily diagnosable according to International Classification of Diseases (ICD) criteria, Diagnostic and Statistical Manual of Mental Disorders (DSM) criteria and Research Diagnostic Criteria (RDC) - suggesting an extended psychosis phenotype. Research on psychotic experiences in the general population is in its early stages. A recent meta-analysis showed that half of the heterogeneity in rates of subclinical psychotic experiences across studies is due to study cohort and design factors (Linscott \& Van Os, 2010). Furthermore, systematic review of the literature shows that there is evidence not only for a psychometric 'continuum' (in the sense of an extended psychosis phenotype blending gradually into clinical syndromes) (Van Os et al. 2009), but also for an underlying latent categorical structure of the population (in the sense that regardless of the presence of a psychometric continuum, the population may still be composed of two different types of people) (Linscott \& Van Os, 2010).

Therefore, more, and more detailed and finegrained work is necessary. Nevertheless, research on psychotic experiences suggesting an extended psychosis phenotype already is producing certain 'side

* Address for correspondence: J. van Os, Ph.D., Department of Psychiatry and Psychology, Maastricht University Medical Centre, PO Box 616 (location DOT12), 6200 MD Maastricht, The Netherlands.

(Email: j.vanos@sp.unimaas.nl) effects', essentially to do with perceived blurring or undermining of diagnostic boundaries, expressed from a statistical (type I and type II continuum), philosophical (continuity in risk or essence) or moral (madness is rare or common) perspective (David, 2010). However, the notion that high rates of psychotic experiences undermine diagnostic categories only has relevance if (ICD, DSM, RDC) diagnoses like 'schizophrenia' represent valid nosological entities, i.e. 'exist'. As the evidence for the hypothesis of valid nosological entities is weak, it may be necessary to formulate an alternative, but scientifically productive, approach. In this context, it may be helpful to not use the word 'continuum', as it carries the implication of a specific theory, but instead refer to the more agnostic psychosis 'extended phenotype' (coined by Howes \& Kapur, 2009).

\section{Extended psychosis phenotype and need for care}

Psychotic disorders, spread over a myriad of diagnostic categories in the different classification systems, in reality represent highly variable syndromal clusters of continuous psychotic and affective symptom dimensions, in combination with variable degrees of motivational and neurocognitive impairments (van Os \& Kapur, 2009). Until recently, research on syndromal clustering of these psychosis dimensions was carried out almost exclusively in the population of people attending mental health services. The implicit assumption was that symptoms observed in patients with psychotic disorder naturally did not exist outside the mental health service. However, now that general population research is showing that similar clusters of psychotic, affective, motivational and neurocognitive phenomena are also expressed as extended 
Table 1. Factors influencing transition to clinical disorder in representative general population studies of extended psychosis phenotype

\begin{tabular}{lll}
\hline \multicolumn{2}{c}{ Factors } & References \\
\hline 1 & Number of psychotic experiences & Poulton et al. (2000); Hanssen et al. (2005); Welham et al. (2008) \\
2 & 'Definite' versus 'likely' psychotic experience & Poulton et al. (2000) \\
3 & Degree of persistence of psychotic experience over time & Dominguez et al. (2009) \\
4 & Presence of affective dysregulation & van Rossum et al. (2009) \\
5 & Pre-morbid social dysfunction & Werbeloff et al. (2009) \\
6 & Presence of negative symptoms & Dominguez et al. (in press) \\
7 & Functional versus 'symptomatic' coping & Bak et al. (2003) \\
\hline
\end{tabular}

(a)

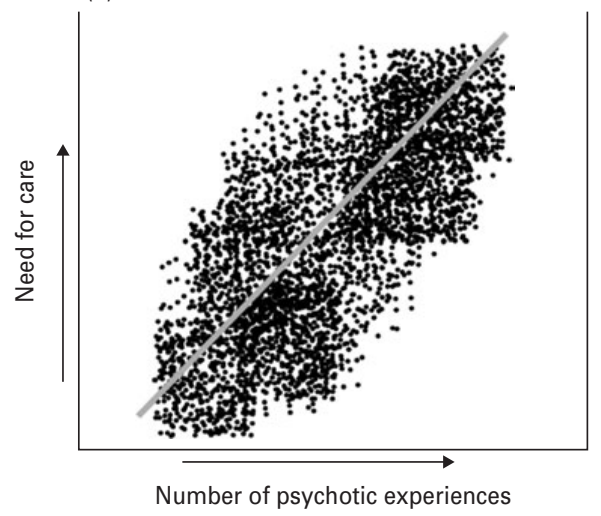

(b)

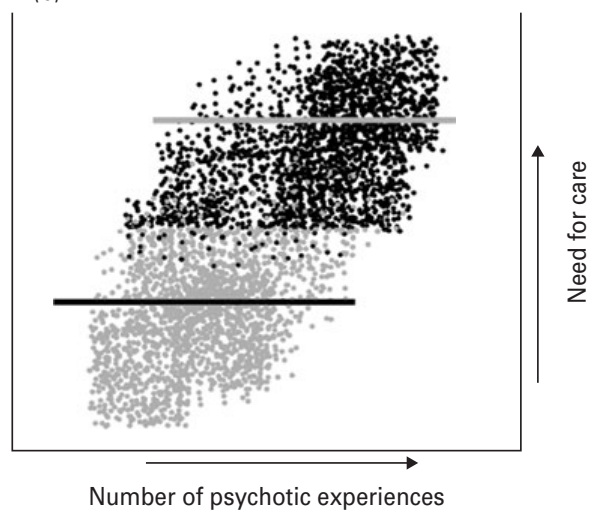

Fig. 1. Simulation of psychosis continuum model (a) versus latent categorical structure model of psychosis (b). On the left side (a) is depicted the apparent psychosis continuum, greater load of subclinical psychotic experiences predicting greater probability of clinical outcome. On the right side $(b)$ is depicted a latent categorical structure representing two different groups: one with psychotic experiences in the context of cognitive and motivational impairments, associated with high probability of need for care $(\bullet)$ and one group with psychotic experiences of a different origin, associated with low likelihood of need for care $(\bullet)$.

phenotypes in the general population (Stip \& Letourneau, 2009), a conceptual switch is required: it may not be productive to consider populations inside and outside mental health services qualitatively different at the level of symptoms per se, but at the level of whether or not need for care has developed. One person with hallucinatory experiences may experience distress to such a degree that he will visit his GP; another may not. The first person may become a patient with a diagnosis of schizophrenia; the second may never receive a diagnosis.

Need for care and the psychopathological, neurodevelopmental and psychological context of psychotic experiences

To date, very little research has been carried out in trying to determine which persons, given a certain level of expression of the extended psychosis phenotype, will develop need for care and helpseeking behaviour. Several longitudinal studies in representative non-help-seeking general population samples, following individuals with subclinical psychotic experiences over time to determine the likelihood of transition to a clinical outcome, have produced a number of variables predicting transition (Table 1). These suggest that not only the 'load' of psychotic experiences is important, and what type of coping the person develops, but also the degree of persistence over time. Another important observation is that admixture with affective dysregulation, negative symptoms and pre-morbid social dysfunction also increases the likelihood of transition to a clinical psychotic outcome. In other words, not just the presence of psychotic experiences per se, but the psychopathological, developmental and psychological context determines the outcome.

\section{A model for future research}

It is generally accepted that the risk for psychotic disorder treated in mental health services is much more 
prevalent than the rate of psychotic disorder itself; more people have risk than there are people with the disease. Research has demonstrated that (genetic and non-genetic) risk for psychotic disorder is not behaviourally silent: it is expressed in the area of cognition, subtle psychotic experiences and sensitivity to stress (reviewed by van Os \& Kapur, 2009). Therefore, the fact that psychotic experiences are encountered in non-diagnosed individuals in the general population is not surprising: psychotic experiences probably represent the behavioural expression of distributed risk for psychotic disorder. There is also evidence, however, that the causes of positive psychotic symptoms may only partly overlap with the causes of developmental and cognitive impairment seen in psychotic disorder (Murray et al. 2004; Kaymaz \& van Os, $2009 b$ ). Therefore, the hypothesis of a single psychosis continuum lacks explanatory power, and also is not in agreement with the observation that motivational and developmental impairments, possibly of genetic origin (Kaymaz \& van Os, 2009a; Picchioni et al. 2009), moderate the probability of clinical outcome in those with subclinical psychotic experiences. Instead, we suggest that the model depicted in Fig. 1 (simulated data) may apply. On the one hand, there is an observed apparent continuum (Fig. 1a), indicating that the greater the load of subclinical psychotic experiences, the greater the probability of clinical outcome. This concept is heuristically useful, as it allows for examination, for example, of how coping and the degree of distress associated with psychotic experiences may affect development of need for care. On the other hand, the apparent continuum model may be 'confounded', at least to a degree, as underneath the continuum, a latent categorical structure may exist, representing two different groups: one with psychotic experiences in the context of cognitive and motivational impairments, associated with high probability of need for care (Fig. 1b; black dots) and one group with psychotic experiences of a different origin, associated with lower likelihood of need for care (Fig. 1b; grey dots). Future research will examine to what degree the continuum model, the latent categorical structure model, or both (a distinct possibility), apply.

\section{Acknowledgements}

N.K. was supported by The Netherlands Organization for Scientific Research (NWO), project no. 017.002.048.

\section{Declaration of Interest}

None.

\section{References}

Bak M, Myin-Germeys I, Hanssen M, Bij1 R, Vollebergh W, Delespaul P, van Os J (2003). When does experience of psychosis result in need for care? A prospective general population study. Schizophrenia Bulletin 29, 349-358.

David AS (2010). Why we need more debate on whether psychotic symptoms lie on a continuum with normality. Psychological Medicine. Published online: 11 February 2010. doi: 10.1017/S0033291710000188.

Dominguez M, Can Saka M, Lieb R, Wittchen H-U, Van Os J (in press). Onset of clinical psychosis: do negative/disorganized symptoms increase risk for positive symptoms and for impairment? A 10-year study. American Journal of Psychiatry.

Dominguez MD, Wichers M, Lieb R, Wittchen HU, van Os J (2009). Evidence that onset of clinical psychosis is an outcome of progressively more persistent subclinical psychotic experiences: an 8-year cohort study. Schizophrenia Bulletin. Published online: 21 May 2009. doi: 10.1093/schbul/sbp022.

Hanssen M, Bak M, Bijl R, Vollebergh W, van Os J (2005). The incidence and outcome of subclinical psychotic experiences in the general population. British Journal of Clinical Psychology 44, 181-191.

Howes OD, Kapur S (2009). The dopamine hypothesis of schizophrenia: version III - the final common pathway. Schizophrenia Bulletin 35, 549-562.

Kaymaz N, van Os J (2009a). Heritability of structural brain traits: an endophenotype approach to deconstruct schizophrenia. International Review of Neurobiology 89, 85-130.

Kaymaz N, van Os J (2009b). Murray et al. (2004) revisited: is bipolar disorder identical to schizophrenia without developmental impairment? Acta Psychiatrica Scandinavica 120, 249-252.

Linscott RJ, Van Os J (2010). Systematic reviews of categorical versus continuum models in psychosis: evidence for discontinuous subpopulations underlying a psychometric continuum. Implications for DSM-V, DSM-VI, and DSM-VII. Annual Review of Clinical Psychology 6. Published online: 4 January 2010. doi: 10.1146/ annurev.clinpsy.032408.153506.

Murray RM, Sham P, Van Os J, Zanelli J, Cannon M, McDonald C (2004). A developmental model for similarities and dissimilarities between schizophrenia and bipolar disorder. Schizophrenia Research 71, 405-416.

Picchioni MM, Walshe M, Toulopoulou T, McDonald C, Taylor M, Waters-Metenier S, Bramon E, Regojo A, Murray RM, Rijsdijk F (2009). Genetic modelling of childhood social development and personality in twins and siblings with schizophrenia. Psychological Medicine. Published online: 29 October 2009. doi : 10.1017/ S0033291709991425.

Poulton R, Caspi A, Moffitt TE, Cannon M, Murray R, Harrington H (2000). Children's self-reported psychotic symptoms and adult schizophreniform disorder: a 15-year longitudinal study. Archives of General Psychiatry 57, 1053-1058. 
Stip E, Letourneau G (2009). Psychotic symptoms as a continuum between normality and pathology. Canadian Journal of Psychiatry Revue Canadienne de Psychiatrie 54, 140-151.

Van Os J, Kapur S (2009). Schizophrenia. Lancet 374, 635-645.

Van Os J, Linscott RJ, Myin-Germeys I, Delespaul P,

Krabbendam L (2009). A systematic review and meta-analysis of the psychosis continuum: evidence for a psychosis proneness-persistence-impairment model of psychotic disorder. Psychological Medicine 39, 179-195. van Rossum I, Dominguez M, Lieb R, Wittchen H-U, van Os J (2009). Affective dysregulation and reality distortion: a 10-year prospective study of their association and clinical relevance. Schizophrenia Bulletin. Published online: 30 September 2009. doi: 10.1093/schbul/sbp101. Welham J, Scott J, Williams G, Najman J, Bor W, O'Callaghan M, McGrath J (2008). Emotional and behavioural antecedents of young adults who screen positive for non-affective psychosis: a 21-year birth cohort study. Psychological Medicine 39, 625-634.

Werbeloff N, Drukker M, Dohrenwend BP, Levav I, Yoffe R, Van Os J, Davidson M, Weiser M (2009).

Self-reported psychotic symptoms in the community are associated with increased risk of later hospitalization for non-affective psychotic disorders (conference abstract). Schizophrenia Bulletin 35, 74. 

CHAPTER 3

Affective studies of psychosis 


\section{Nil Kaymaz • Lydia Krabbendam • Ron de Graaf • Willem Nolen • Margreet ten Have • Jim van Os Evidence that the urban environment specifically impacts on the psychotic but not the affective dimension of bipolar disorder}

Abstract Objectives High rates of psychotic disorders and psychotic symptoms have been found in urban environments but reports for bipolar affective illness have been inconsistent, possibly due to failure to stratify for comorbid psychotic symptoms. It was hypothesised, therefore, that any effect of urbanicity on the bipolar phenotype would be moderated by comorbid psychotic symptoms. Methods In a random, representative population cohort of 7049 adults with no history of non-affective psychotic disorder, the cumulative incidence of bipolar and psychotic symptoms and syndromes, assessed with the CIDI, was examined over five levels of population density of place of residence. Similarly, the degree of comorbidity between broadly and narrowly defined bipolar phenotypes on the one hand, and the dichotomous presence of broadly (17.2\%) and narrowly defined (3.8\%) psychotic symptoms on the other, was examined as a function of population density of place of

N. Kaymaz, MD · L. Krabbendam, MA, PhD

J. van Os, MD, PhD ( $)$

Dept. of Psychiatry and Neuropsychology

South Limburg Mental Health Research and Teaching Network

EURON

Maastricht University

P.O. Box 616 (DRT 10)

6200 MD Maastricht, The Netherlands

Tel.: +31-43/3875-443

Fax: $+31-43 / 3875-444$

E-Mail: j.vanos@sp.unimaas.nl

R. de Graaf, MA, PhD - M. ten Have, MA, PhD

The Netherlands Institute of Mental Health and Addiction

Trimbos Institute

Utrecht, The Netherlands

W. Nolen, MD, PhD

Dept. Psychiatry

University Hospital Groningen

Groningen, The Netherlands

J. van Os, MD, $\mathrm{PhD}$

Division of Psychological Medicine

Institute of Psychiatry

London, UK residence. Results The rate of bipolar disorder, however defined, was progressively higher in more urbanised areas. However, in models of bipolar phenotypes, a strong interaction between comorbid psychosis and level of urbanicity was apparent, indicating that the greater the degree of psychotic comorbidity, the greater the effect size of the urban environmental factor. For bipolar disorder without psychosis, no effect of urbanicity was apparent. Conclusions The results suggest differential environmental causal effects on affective and cognitive dimensions of bipolar psychopathology that are nevertheless strongly comorbid within the same categorically defined disorder, possibly due to the effect of shared genetic risk factors.

Key words bipolar disorder - urbanisation psychosis

\section{Introduction}

There is remarkably consistent evidence that the rate of psychotic disorder and subclinical psychotic experiences is higher in urban environments, which is thought to reflect the impact of an as yet unidentified environmental causal risk factor [1]. Similar risks, albeit of lower effect size, have been reported for affective disorder in some studies [2, 3], but not in others [4]. One likely reason for the inconsistent results is failure to stratify for comorbid psychotic symptoms. It is attractive to speculate that the urban environment will affect the rate of affective disorder in those who also have a propensity to develop psychosis, but not in those without this propensity. The importance of such stratification has been shown in family and high risk studies, where inconsistent results on the familial association between bipolar disorder and non-affective psychotic disorder could be retraced in part by failure to 
stratify for the presence of psychotic symptoms in bipolar probands [5-7]. In the current study, we examined main effects of urbanicity on the rate of the bipolar phenotype narrowly and broadly defined $[8,9]$, and hypothesised that any effect of urbanicity would be modified synergistically by comorbid psychotic symptoms.

\section{Patients and methods}

The Netherlands Mental Health Survey and Incidence Study (NEMESIS), is a prospective study with three measurement points over a period of 3 years [10-12]. All procedures were approved by the local Ethical Committee, and were in accordance with the Helsinki Declaration of 1975. The current report is based on the baseline data. A multistage, stratified, random sampling procedure was used to first select 90 municipalities, then a sample of private households, and finally a Dutch-speaking individual aged 1864 years within each household. Selected households were sent an introductory letter by the Minister of Health, inviting them to participate. A total of 7076 individuals provided informed consent and were interviewed at baseline, representing a response rate of $69.7 \%$. The sample was found to be representative of the Dutch population in terms of gender, marital status and level of urbanisation [11], with the exception of a slight underrepresentation of individuals in the age group 18-24 years.

\section{Instruments}

Subjects were interviewed at home. The Composite International Diagnostic Interview (CIDI) version 1.1 [13-15] was used, yielding DSM-III-R diagnoses. The CIDI was designed for trained interviewers who are not clinicians and has been found to have high inter-rater reliability $[16,17]$, and high test-retest reliability $[18$ 20]. A total of 90 interviewers, experienced in systematic data collection, collected the data, having received a 3-day training course in recruiting and interviewing, followed by a 4-day course at the WHO-CIDI training centre in Amsterdam. Extensive monitoring and quality checks took place throughout the entire data collection period [11].

\section{Psychosis ratings}

Baseline CIDI lifetime ratings, yielding cumulative incidence figures, from the 17 CIDI core psychosis items on delusions (13 items) and hallucinations (4 items) were used (items G1-G13, G15, G16, G20, G21). These concern classic psychotic symptoms involving, for example, persecution, thought interference, auditory hallucinations and passivity phenomena. All these items can be rated in six ways: " 1 "- - No symptom, "2"-Symptom present but not clinically relevant (not bothered by it and not seeking help for it), "3"-Symptom result of ingestion of drugs, "4"- Symptom result of somatic disease, "5"-True psychiatric symptom, "6"-Symptom may not really be a symptom because there appears to be some plausible explanation for it. Since psychotic symptoms are difficult to diagnose in a structured interview [21-23], clinical re-interviews were conducted over the telephone by an experienced trainee psychiatrist for all individuals who had at least one rating of " 5 " or " 6 ", using questions from the Structured Clinical Interview for DSM-III-R (SCID), an instrument with proven reliability and validity in diagnosing schizophrenia [24]. The proportion of eligible individuals that was successfully re-interviewed by the clinician was $47.2 \%$. Whether or not eligible individuals were reinterviewed was not associated with level of urbanicity $(\mathrm{OR}=0.9$, $95 \%$ CI: $0.8,1.02, P=0.10$; proportions in lowest and highest levels of urbanicity, respectively, re-interviewed: $13.9 \%$ and $15.4 \%$; not re- interviewed: $15.5 \%$ and $19.8 \%$ ). CIDI ratings were corrected on the basis of these clinical interviews, and the NEMESIS DSM-III-R diagnoses of psychotic disorder are based on the data from these clinical re-interviews.

Non-affective psychotic disorder was defined as any DSM-III-R non-affective psychotic diagnosis $(n=26,0.4 \%)$. A broad measure of psychosis was defined as any CIDI rating of 2,3,4,5 or 6 on any of the 17 CIDI core psychosis items. In a previous study, it was shown that all these 6 different ratings on the CIDI psychosis items were strongly associated with each other, including the clinical reinterview ratings of psychotic symptom (i.e. a rating of " 5 " on any of the CIDI psychosis items). In addition, the 6 different ratings independently showed a similar pattern of associations with known risk factors for psychosis $[25,26]$. As they, therefore, appear to reflect the same underlying latent dimension of "psychosis" they were joined together into a single broad rating of psychotic experience for the purpose of the current study (hereafter: "psychosis broadly defined"). In order to check on the validity of this procedure, associations were also examined with clinical psychotic symptoms, more narrowly defined as a clinical re-interview rating of psychosis (i.e. a rating of " 5 " on any of the CIDI psychosis items, hereafter: "psychosis narrowly defined").

\section{Bipolar phenotypes}

At baseline, a CIDI lifetime diagnosis of bipolar disorder, reflecting cumulative incidence, was made in 132 individuals (1.9\%). A mania symptom score was constructed using ratings from the 11 items of the CIDI core mania section (section F; see [27]). The mania symptom score consisted of the sum score of these 11 items. The range of this score was $0-10$ symptoms, and the minimum positive score was 3 symptoms (absence of score of 1 or 2 due to cut-off stem questions in the CIDI). Apart from the CIDI bipolar diagnosis, two broader bipolar outcomes, in line with current conceptualisation of the bipolar phenotype $[8,9]$ were used, derived from this score: a score of at least 3 symptoms (hereafter: mania 3-symptoms) and a score of at least 5 symptoms (hereafter: mania 5-symptoms). For the two broader phenotypes, manic rather than depressive symptoms were used, given the fact that mania is the distinguishing feature between unipolar and bipolar affective phenotypes and no accepted method exists for defining subclinical bipolar disorder using both depressive and manic symptoms.

\section{Level of urbanicity}

Five levels of urbanisation were defined, following the standard classification of urbanisation of place of residence according to the Dutch Central Bureau of Statistics. These are based on the density of addresses per $\mathrm{km}^{2}$ in an area and are classified as $<500,500-999$, $1000-1499,1500-2499$ and $\geq 2500$. This density is calculated by assessing, for each address, the density of addresses in a circle of $1 \mathrm{~km}$ around that address. The density of addresses in an area is then calculated as the mean address density of all the addresses in that area [28].

\section{Data analyses}

\section{Main effect of urbanicity}

The cumulative incidences of bipolar disorder, 3-symptom mania and 5-symptom mania were examined in relation to level of urbanicity of place of residence, adjusted for the a priori selected possible confounding effects of age in years, sex, level of education (4-levels) and cannabis use $[26,29,30]$.

Logistic regression yielding odds ratios and 95\% confidence intervals [31] was used to examine associations between bipolar outcomes and level of urbanicity. 
The classic problem with regard to possible co-participation between causes in nature (biological synergism) is how such synergism can be inferred from statistical manipulations with research data (statistical interaction), in particular with regard to the choice of additive (change in risk occurs by adding a quantity) or multiplicative (change in risk occurs by multiplying with a quantity) models. Recent progress in the study of interactions indicates that the most frequently used statistical models of interaction are not suitable to identify biological synergism. For example, the commonly used statistical models in which two causes multiply each other's effects (multiplicative models) assume that individuals who are exposed to both risk factor $\mathrm{A}$ and risk factor $\mathrm{B}$ could not have become ill because the effect of $\mathrm{A}$ alone or B alone [32]. It has recently been shown that the true degree of biological synergism can be better estimated from (but is not the same as) the additive statistical interaction (see [32]). This method was recently applied to schizophrenia showing synergy between traumatic head injury and familial liability [33], between cannabis and psychosis liability [34] and between urbanicity and familial morbid risk for psychosis [35].

In order to calculate the statistical interaction under an additive model, the BINREG procedure in the STATA statistical programme [36], which fits generalised linear models for the binomial family estimating risk differences, was used to model interactions.

\section{Risk set}

The risk set consisted of all individuals who had participated in the baseline CIDI interview, with the exception of the 26 individuals with a lifetime diagnosis of non-affective psychotic disorder $(n=26)$, resulting in a sample for analysis of 7049 individuals.

\section{Results}

\section{Sample description}

The sample included 3287 men (47\%) and 3762 women $(53 \%)$ and the mean age was 41.2 years $(\mathrm{SD}=12.2)$. The cumulative incidence of psychosis broadly defined was $17.2 \% \quad(n=1211)$ and the cumulative incidence of psychosis narrowly defined was $3.8 \%(n=267)$. The cumulative incidence of mania 3 -symptoms was $4.0 \%(n=283)$, of mania 5symptoms was $2.3 \%(n=161)$ and of DSM-III-R bipolar disorder $1.9 \%(n=132)$.

\section{Main effects urbanicity and psychosis comorbidity}

The five level urbanicity rating was strongly associated with the rate of mania, however defined. Both the CIDI bipolar diagnosis, as the two broader bipolar outcomes were all progressively more common in more urbanised areas (Table 1). Adjustment for the a priori selected possible confounding effects of age, sex, level of education (4-level) only changed the parameters by a small amount (Table 1).
Table 1 Cumulative incidences of mania 3-symptom, mania 5-symptom and bipolar disorder by 5 levels of population density

\begin{tabular}{|c|c|c|c|}
\hline Population density & $M 3^{\mathrm{a}}(\%)$ & $M 5^{\mathrm{a}}(\%)$ & $\operatorname{bip}^{a}(\%)$ \\
\hline 1 & 2.8 & 1.4 & 1.3 \\
\hline 2 & 2.7 & 0.9 & 1.2 \\
\hline 3 & 3.8 & 2.1 & 2.2 \\
\hline 4 & 5.0 & 2.9 & 2.1 \\
\hline 5 & 6.1 & 4.0 & 2.8 \\
\hline Total & 4.0 & 2.2 & 1.9 \\
\hline OR linear trend ${ }^{b}$ & 1.27 & 1.43 & 1.24 \\
\hline (95\% Cl) & $(1.16,1.39)$ & $(1.26,1.62)$ & $(1.09,1.42)$ \\
\hline$P$ & $<0.001$ & $<0.001$ & 0.001 \\
\hline $\begin{array}{l}\text { Adjusted }^{c} \mathrm{OR} \\
\text { linear trend }\end{array}$ & 1.22 & 1.34 & 1.18 \\
\hline (95\% Cl) & $(1.11,1.34)$ & $(1.18,1.53)$ & $(1.03,1.35)$ \\
\hline P & $<0.001$ & $<0.001$ & 0.016 \\
\hline
\end{tabular}

a "M3" is broad mania phenotype of at least 3 manic symptoms, "M5" is broad mania phenotype of at least 5 manic symptoms, "bip" is DSM-III-R bipolar disorder

${ }^{b}$ The summary increase in risk, expressed as odds ratio, associated with one unit change in the five-level exposure

c Adjusted for age in years, sex, level of education (4-levels) and cannabis use

Table 2 Cumulative incidences of mania 3-symptom, mania 5-symptom and bipolar disorder by 5 levels of population density, stratified by presence of psychosis broadly defined

\begin{tabular}{|c|c|c|c|}
\hline Population density & $M 3^{a}(\%)$ & $M 5^{\mathrm{a}}(\%)$ & $\operatorname{bip}^{\mathrm{a}}(\%)$ \\
\hline \multicolumn{4}{|l|}{ No psychotic symptom } \\
\hline 1 & 1.7 & 0.8 & 0.8 \\
\hline 2 & 1.4 & 0.4 & 0.7 \\
\hline 3 & 2.1 & 0.9 & 1.2 \\
\hline 4 & 2.0 & 0.8 & 0.9 \\
\hline 5 & 2.5 & 1.6 & 1.5 \\
\hline Total & 1.9 & 0.9 & 1.0 \\
\hline RD linear trend ${ }^{\mathrm{b}}(\%)$ & 0.22 & 0.16 & 0.16 \\
\hline$(95 \% \mathrm{Cl})$ & $(0.00,0.48)$ & $(0.00,0.33)$ & $(0.00,0.34)$ \\
\hline P & 0.095 & 0.076 & 0.10 \\
\hline \multicolumn{4}{|c|}{ At least one psychotic symptom } \\
\hline 1 & 9.9 & 4.9 & 4.3 \\
\hline 2 & 10.6 & 4.2 & 4.6 \\
\hline 3 & 12.2 & 7.9 & 7.1 \\
\hline 4 & 16.7 & 11.3 & 6.7 \\
\hline 5 & 18.3 & 12.2 & 7.2 \\
\hline Total & 14.1 & 8.7 & 6.2 \\
\hline RD linear trend ${ }^{\mathrm{b}}(\%)$ & 2.3 & 2.1 & 0.78 \\
\hline$(95 \% \mathrm{Cl})$ & $(0.92,3.7)$ & $(1.1,3.2)$ & $(0.00,1.8)$ \\
\hline$p$ & 0.001 & $<0.001$ & 0.12 \\
\hline \multicolumn{4}{|l|}{ Interaction ${ }^{c}$} \\
\hline$\left(\chi^{2}, P, \mathrm{df}=1\right)$ & $8.4,0.004$ & $13.0,0.0003$ & $1.5,0.21$ \\
\hline
\end{tabular}

a "M3" is broad mania phenotype of at least 3 manic symptoms, "M5" is broad mania phenotype of at least 5 manic symptoms, "bip" is DSM-III-R bipolar disorder

b The summary increase in risk, expressed as risk difference, associated with one unit change in the five-level exposure

c Tests whether RD linear trend for mania with psychosis is significantly different from RD linear trend for mania without psychosis

\section{Urbanicity and psychosis interaction effects}

There was a directionally positive interaction on the additive scale between urbanicity and broadly defined psychosis in the models of mania, reaching statistical significance for 2 of the 3 mania outcomes (mania 3- 
Table 3 Cumulative incidences of mania 3-symptom, mania 5-symptom and bipolar disorder by 5 levels of population density, stratified by presence of psychosis narrowly defined

\begin{tabular}{|c|c|c|c|}
\hline Population density & $M 3^{\mathrm{a}}(\%)$ & $M 5^{\mathrm{a}}(\%)$ & $\operatorname{bip}^{a}(\%)$ \\
\hline \multicolumn{4}{|l|}{ No psychotic symptom } \\
\hline 1 & 2.6 & 1.1 & 1.2 \\
\hline 2 & 2.0 & 0.6 & 0.8 \\
\hline 3 & 3.3 & 1.7 & 1.7 \\
\hline 4 & 3.5 & 1.8 & 1.6 \\
\hline 5 & 4.4 & 2.7 & 2.2 \\
\hline Total & 3.1 & 1.5 & 1.5 \\
\hline RD linear trend ${ }^{\mathrm{b}}(\%)$ & 0.50 & 0.39 & 0.27 \\
\hline$(95 \% \mathrm{Cl})$ & $(0.19,0.81)$ & $(0.18,0.60)$ & $(0.00,0.48)$ \\
\hline$P$ & 0.001 & $<0.001$ & 0.012 \\
\hline \multicolumn{4}{|l|}{$\begin{array}{l}\text { At least one } \\
\text { psychotic symptom }\end{array}$} \\
\hline 1 & 11.1 & 11.1 & 3.7 \\
\hline 2 & 28.2 & 15.4 & 15.4 \\
\hline 3 & 14.8 & 11.5 & 13.1 \\
\hline 4 & 30.4 & 22.8 & 10.1 \\
\hline 5 & 36.5 & 27.0 & 12.7 \\
\hline Total & 26.0 & 19.0 & 11.5 \\
\hline RD linear trend ${ }^{\mathrm{b}}(\%)$ & 5.4 & 3.9 & 0.82 \\
\hline$(95 \% \mathrm{Cl})$ & $(0.69,9.6)$ & $(0.63,7.4)$ & $(-0.02,3.8)$ \\
\hline$p$ & 0.024 & 0.020 & 0.59 \\
\hline $\begin{array}{l}\text { Interaction }{ }^{c} \\
\left(\chi^{2}, P, d f=1\right)\end{array}$ & $6.3,0.01$ & $4.4,0.04$ & $0.13,0.72$ \\
\hline
\end{tabular}

a "M3" is broad mania phenotype of at least 3 manic symptoms, "M5" is broad mania phenotype of at least 5 manic symptoms, "bip" is DSM-III-R bipolar disorder

b The summary increase in risk, expressed as risk difference, associated with one unit change in the five-level exposure

c Tests whether RD linear trend for mania with psychosis is significantly different from RD linear trend for mania without psychosis

symptoms: $\chi^{2}=8.4, P=0.004$, mania 5-symptoms: $\chi^{2}=13.0, P=0.0003$; DSM-III-R bipolar disorder: $\chi^{2}=1.5, P=0.21$ ) (Table 2 ). Similar results were apparent for interactions between urbanicity and psychosis narrowly defined (mania 3-symptoms: $\chi^{2}=6.3, \quad P=0.01$, mania 5-symptoms: $\chi^{2}=4.4$, $P=0.04$; DSM-III-R bipolar disorder: $\chi^{2}=0.13$, $P=0.72$ ) (Table 3 ). Stratified analyses revealed that in mania outcomes without comorbid psychosis narrowly defined, only a weak effect of urbanicity remained (Table 3), whereas in mania outcomes without comorbid psychosis broadly defined the effect of urbanicity disappeared altogether (Table 2).

\section{Discussion}

The main finding of this study was that in models of bipolar phenotypes, a strong interaction between psychosis and level of urbanicity was apparent, indicating that the greater the degree of psychotic comorbidity, the greater the effect size of the urban environmental factor. Although the interaction term was not significant for DSM-III-R bipolar disorder, the difference in urbanicity effect size in the groups with and without comorbid psychosis was equally large so that lack of power is the likely explanation for the inconclusive interaction.
For bipolar disorder without psychosis, no strong or clear effect of urbanicity was apparent. Thus, in the analyses of bipolar disorder where only narrowly defined comorbid psychosis had been excluded, a weak effect of urbanicity was still apparent. However, for bipolar disorder outcomes where all psychosis had been excluded, an (inconclusive) effect of urbanicity was only possibly apparent for the highest category of urbanicity and the broadest definition of mania. Thus, the conservative conclusion is that although a weak association between mania without psychosis and urbanicity cannot be excluded, by far the greatest part of the apparent association between bipolar phenotypes and urbanicity is due to comorbid psychosis. Indeed, although the incidence of other psychiatric disorders may also be higher in urban areas [3, 4], the effect size for psychotic disorders appears to be much larger, possibly explaining around $30 \%$ of all schizophrenia incidence $[1,4,44]$. Given the fact that associations with urbanicity are thought to reflect the impact of an environmental exposure that interacts with genetic liability to produce illness [1, 35, 37], these results should be interpreted in the light of previous work in the field of both molecular genetics and genetic epidemiology that has shown that there is substantial sharing of genetic risk between bipolar disorder and non-affective psychosis [38-40]. Thus, if two individuals have a similar amount of shared genetic liability for both bipolar disorder and schizophrenia, the one that becomes subsequently exposed to an urban environment may develop a more "psychotic" illness, whereas the one not exposed to an urban environment may develop a more "pure" manic illness, suggesting that within the bipolar spectrum, the impact of the urban environment on the occurrence of more "psychotic" illness may be mediated by a different pathway than the rate of more "pure" manic illness. Research suggests that this type of gene-environment interactions may not be uncommon. For example, a similar scenario has been described for anxiety and depression, two conditions that have been shown to share genes that, however, produce differential outcomes depending on subsequent exposure to divergent environmental risk factors, some resulting in anxiety outcomes, and others in depression [41-43].

\section{Possible mechanisms}

Recent studies have shown that the impact of the environmental factors that are thought to mediate the effect of urbanicity is conditional on pre-existing indicators of genetic risk for psychosis [35, 37, 45]. However, a plausible mechanism explaining the pathway from impact of the exposure to onset of psychotic symptoms is lacking, as it is unclear which underlying factors in urban areas are responsible for the causation of psychotic symptoms in genetically 
pre-disposed individuals [46]. Recent studies, focussing on within-city neighbourhood contrasts, have demonstrated that the impact of environmental factors in the urban area varies across neighbourhoods in such a way that the increase in the incidence of psychosis or psychosis-like phenomena is likely not associated with indicators of material deprivation, but with indicators of social isolation and social cohesion [47]. These studies have focused on the developmental effects of variables referred to as "social capital" and suggest that in particular cognitive social capital, or the degree of perceived mutual trust, bonding, safety and social control in neighbourhoods, exerts a developmental impact on the mental health of the children growing up in these environments [4851]. The hypothesised effects of cognitive social capital can be readily integrated in current hypotheses of cognitive neuropsychiatric models of psychotic symptoms $[52,53]$.

\section{Methodological issues}

These results should be considered in the light of several limitations: Psychotic symptom ratings were assessed by lay interviewers (CIDI ratings of 1-4), whereas the other CIDI ratings $[5,6]$ were assessed by clinicians through telephone interviews in approximately $50 \%$ of eligible cases. It is likely that with lay interviewer ratings a degree of misclassification did occur. However, the findings with both broad (only lay interviewer based) and narrow (also clinical reinterview based) psychosis concurred, suggesting that lay interviews were reasonably accurate, something which was previously reported [54].

Bias could also have been introduced by differential rating of psychosis due to incomplete clinical re-interview rates at baseline. This is unlikely, however, as the probability of re-interview was not associated with the exposure, urbanicity, which would have been required for bias to occur [55]. In order to examine the possibility of bias further, sensitivity analyses were conducted to examine whether differential re-interview rates could have biased the findings. This was done by setting values of psychosis narrowly defined to missing if individuals had been eligible for re-interview by clinicians but had not been re-interviewed $(n=253)$. Subsequently, multiple imputation of missing values [56, 57] of psychosis narrowly defined was applied using the HOTDECK command in STATA. The HOTDECK procedure is used several times within a multiple imputation sequence since missing data are imputed stochastically rather than deterministically. Five imputation sequences were run, yielding 5 data sets in which the average coefficient of the urbanicity $\times$ psychosis narrowly defined interaction term in the model of the two mania outcomes, which had shown significant interactions (mania 3-symptom and mania 5-symptom) was estimated within the
HOTDECK procedure. This revealed that the interaction term effect size decreased only slightly for the mania 5-symptom model (12\% reduction effect size) whereas it increased substantially for the mania 3symptom model ( $47 \%$ increase effect size). These results therefore, suggest that bias due to differential re-interview rate did not occur.

Another bias could be the examination of lifetime rates of psychotic disorder in relation to current urban residence. For example, symptomatic subjects could have 'drifted' to urban areas. However, in a previous study in the Netherlands we found that there was a high degree of lifetime stability of urban exposure status, indicating that current exposure is likely to reflect stable lifetime exposure in most cases. Furthermore, work from Denmark has suggested drift is an unlikely explanation for the urbanicity effect, since changing exposure status in childhood changes adult risk for schizophrenia, indicating causality rather than drift [58].

Acknowledgement Funded by the Dutch Department of Health.

\section{References}

1. Van Os J (2004) Does the urban environment cause psychosis? Br J Psychiat 184(4):287-288

2. Kessler RC, Rubinow DR, Holmes C, Abelson JM, Zhao S (1997) The epidemiology of DSM-III-R bipolar I disorder in a general population survey. Psychol Med 27(5):1079-1089

3. Sundquist K, Frank G, Sundquist J (2004) Urbanisation and incidence of psychosis and depression: follow-up study of 4.4 million women and men in Sweden. $\mathrm{Br} \mathrm{J}$ Psychiat 184(4):293-298

4. Mortensen PB, Pedersen CB, Melbye M, Mors O, Ewald H (2003) Individual and familial risk factors for bipolar affective disorders in Denmark. Arch Gen Psychiat 60(12):12091215

5. Kendler KS, McGuire M, Gruenberg AM, Spellman M, O'Hare A, Walsh D (1993) The Roscommon Family Study. II. The risk of nonschizophrenic nonaffective psychoses in relatives. Arch Gen Psychiat 50(8):645-652

6. Erlenmeyer Kimling L, Adamo UH, Rock D, Roberts SA, Bassett AS, Squires Wheeler E, et al. (1997) The New York High-Risk Project. Prevalence and comorbidity of axis I disorders in offspring of schizophrenic parents at 25-year follow-up. Arch Gen Psychiat 54(12):1096-1102

7. Kendler KS, Gruenberg AM, Tsuang MT (1986) A DSM-III family study of the nonschizophrenic psychotic disorders. Am J Psychiat 143(9):1098-1105

8. Judd LL, Akiskal HS (2003) The prevalence and disability of bipolar spectrum disorders in the US population: re-analysis of the ECA database taking into account subthreshold cases. J Affect Disord 73(1-2):123-131

9. Angst J, Gamma A, Benazzi F, Ajdacic V, Eich D, Rossler W (2003) Toward a re-definition of subthreshold bipolarity: epidemiology and proposed criteria for bipolar-II, minor bipolar disorders and hypomania. J Affect Disord 73(12):133-146

10. Bijl RV, Ravelli A, Van Zessen G (1998) Prevalence of psychiatric disorder in the general population: results from the Netherlands mental health survey and incidence study. Soc Psychiat Psychiat Epidemiol 33:587-596 
11. Bijl RV, Van Zessen G, Ravelli A, De Rijk C, Langendoen Y (1998) The Netherlands mental health survey and incidence study (NEMESIS): objectives and design. Soc Psychiat Psychiat Epidemiol 33:581-587

12. Alegria M, Bijl RV, Lin E, Walters EE, Kessler RC (2000) Income differences in persons seeking outpatient treatment for mental disorders: a comparison of the United States with Ontario and The Netherlands. Arch Gen Psychiat 57(4):383391

13. Robins LN, Wing J, Wittchen HU, Helzer JE, Babor TF, Burke J, et al. (1988) The Composite International Diagnostic Interview. An epidemiologic Instrument suitable for use in conjunction with different diagnostic systems and in different cultures. Arch Gen Psychiat 45(12):1069-1077

14. World Health Organisation (1990) Composite International Diagnostic Interview (CIDI) Version 1.0. World Health Organisation, Geneva

15. Smeets RMW, Dingemans PMAJ (1993) Composite International Diagnostic Interview (CIDI) Versie 1.1. World Health Organisation, Amsterdam/Geneva

16. Wittchen HU, Robins LN, Cottler LB, Sartorius N, Burke JD, Regier D (1991) Cross-cultural feasibility, reliability and sources of variance of the Composite International Diagnostic Interview (CIDI). The Multicentre WHO/ADAMHA Field Trials [published erratum appears in Br J Psychiatry 1992 Jan; 160:136]. Br J Psychiat 159:645-653

17. Cottler LB, Robins LN, Grant BF, Blaine J, Towle LH, Wittchen H-U, et al. (1991) The CIDI-core substance abuse and dependence questions: cross-cultural and nosological issues. $\mathrm{Br} \mathrm{J}$ Psychiat 159:653-658

18. Semler G, Von Cranach M, Wittchen H-U (1987) Comparison between the Composite International Diagnostic Interview and the present state examination. Report to the WHO/ADAMHA task force on instrument development. World Health Organisation, Geneva

19. Wacker HR, Battegay R, Mullejans R, Schlosser C (1990) Using the CIDI in the general population. In: Stefanis CN, Rabavilas AD, Soldatos CR (eds) Psychiatry: a world perspective. Elsevier Science Publishers, Amsterdam, pp 138-143

20. Wittchen HU (1994) Reliability and validity studies of the WHO - Composite International Diagnostic Interview (CIDI): a critical review. J Psychiat Res 28(1):57-84

21. Helzer JE, Robins LN, McEvoy LT, Spitznagel EL, Stoltzman RK, Farmer A, et al. (1985) A comparison of clinical and diagnostic interview schedule diagnoses. Physician reexamination of lay-interviewed cases in the general population. Arch Gen Psychiat 42(7):657-666

22. Anthony JC, Folstein M, Romanoski AJ, Von Korff MR Nestadt GR, Chahal R, et al. (1985) Comparison of the lay diagnostic interview schedule and a standardised psychiatric diagnosis. Experience in Eastern Baltimore. Arch Gen Psychiat 42:667-675

23. Cooper SA, Collacott RA (1994) Relapse of depression in people with Down's syndrome. Br J Dev Disabil 40(78, Pt 1):32-37

24. Spitzer RL, Williams JB, Gibbon M, First MB (1992) The Structured Clinical Interview for DSM-III-R (SCID). I: history, rationale, and description. Arch Gen Psychiat 49(8):624-629

25. Van Os J, Hanssen M, Bijl R-V, Ravelli A (2000) Straus (1969) revisited: a psychosis continuum in the general population? Schizophr Res 45(1-2):11-20

26. Van Os J, Hanssen M, Bijl RV, Vollebergh W (2001) Prevalence of psychotic disorder and community level of psychotic symptoms: an urban-rural comparison. Arch Gen Psychiat 58(7):663-668

27. Krabbendam L, Myin-Germeys I, Graaf Rd, Vollebergh W, Nolen WA, Os Jv (2004) Dimensions of depression, mania, and psychosis in the general population. Psychol Med 34(7):11771186

28. Central Bureau of Statistics (1993) Bevolking der Gemeenten van Nederland. CBS-Publications, The Hague

29. Lewis G, David A, Andreasson S, Allebeck P (1992) Schizophrenia and city life. Lancet 340(8812):137-140
30. Marcelis M, Navarro-Mateu F, Murray R, Selten JP, Van Os J (1998) Urbanization and psychosis: a study of 1942-1978 birth cohorts in The Netherlands. Psychol Med 28(4):871-879

31. Platt RW (1997) Logistic regression and odds ratios. Inj Prev 3(4):294

32. Darroch J (1997) Biologic synergism and parallelism [see comments]. Am J Epidemiol 145(7):661-668

33. Corcoran C, Malaspina D (2001) Traumatic brain injury and schizophrenia. Int J Mental Health 30:17-33

34. Van Os J, Bak M, Hanssen M, Bijl RV, de Graaf R, Verdoux H (2002) Cannabis use and psychosis: a longitudinal populationbased study. Am J Epidemiol 156(4):319-327

35. Van Os J, Hanssen M, Bak M, Bijl RV, Vollebergh W (2003) Do urbanicity and familial liability coparticipate in causing psychosis? Am J Psychiat 160(3):477-482

36. StataCorp (2001) STATA Statisctical Software: Release 7.0. College Station, Texas

37. Van Os J, Pedersen CB, Mortensen PB (2004) Confirmation of synergy between urbanicity and familial liability in the causation of psychosis. Am J Psychiat 161(12):2312-2314

38. Cardno AG, Rijsdijk FV, Sham PC, Murray RM, McGuffin P (2002) A twin study of genetic relationships between psychotic symptoms. Am J Psychiat 159(4):539-545

39. Berrettini W (2004) Bipolar disorder and schizophrenia: convergent molecular data. Neuromol Med 5(1):109-117

40. Berrettini W (2003) Evidence for shared susceptibility in bipolar disorder and schizophrenia. Am J Med Genet 123C(1):59-64

41. Kendler KS, Heath AC, Martin NG, Eaves LJ (1987) Symptoms of anxiety and symptoms of depression. Same genes, different environments? Arch Gen Psychiat 44(5):451-457

42. Kendler KS, Neale MC, Kessler RC, Heath AC, Eaves LJ (1992) Major depression and generalized anxiety disorder. Same genes, (partly) different environments? Arch Gen Psychiat 49(9):716-722

43. Kendler KS (1996) Major depression and generalised anxiety disorder. Same genes, (partly) different environments - revisited. Br J Psychiat Suppl (30):68-75

44. Mortensen PB, Pedersen CB, Westergaard T, et al. (1999) Effects of family history and place and season of birth on the risk of schizophrenia. N Engl J Med 340(8):603-608

45. Spauwen J, Krabbendam L, Roselind L, Wittchen HU, van Os J (2006) Evidence that the outcome of developmental expression of psychosis is worse for adolescents growing up in an urban environment. Psychol Med 36(3):407-415

46. Krabbendam L, van Os J (2005) Schizophrenia and urbanicity: a major environmental influence - conditional on genetic risk. Schizophr Bull 31(4):795-799

47. Van Os J, Driessen G, Gunther N, Delespaul P (2000) Neighbourhood variation in incidence of schizophrenia: evidence for person-environment interaction. Brit J Psychiat 176:243-248

48. McKenzie K, Whitley R, Weich S (2002) Social capital and mental health. Brit J Psychatry 181:280-283

49. De Silva MJ, McKenzie K, Harpham T, Huttly SR (2005) Social capital and mental illness: a systematic review. J Epidemiol Commun Health 59(8):619-627

50. Drukker M, Kaplan C, Feron F, van Os J (2003) Children's health related quality of life, neighbourhood socio-economic deprivation and social capital: a contextual analysis. Soc Sci Med 57(5):825-841

51. Drukker M, Buka SL, Kaplan C, McKenzie K, van Os J (2005) Social capital and young adolescents, perceived health in different sociocultural settings. Soc Sci Med 61(1):185-198

52. Blackwood NJ, Howard RJ, Bentall RP, Murray RM (2001) Cognitive neuropsychiatric models of persecutory delusions. Am J Psychiat 158(4):527-539

53. Garety PA, Kuipers E, Fowler D, Freeman D, Bebbington PE (2001) A Cognitive model of the positive symptoms of psychosis. Psychol Med 31(2):189-195

54. Bak M, Delespaul P, Hanssen M, de Graaf R, Vollebergh W, van Os J (2003) How false are "false" positive psychotic symptoms? Schizophr Res 62(1-2):187-189 
55. Hennekens CH, Buring JE (1987) Analysis of epidemiologic studies: evaluating the role of bias. In: Hennekens $\mathrm{CH}$, Buring JE (eds) Epidemiology in medicine. Little, Brown and Company, Toronto, pp 272-287

56. Hopke PK, Liu C, Rubin DB (2001) Multiple imputation for multivariate data with missing and below-threshold measurements: time-series concentrations of pollutants in the Arctic. Biometrics 57(1):22-33
57. Rubin DB, Schenker N (1991) Multiple imputation in healthcare databases: an overview and some applications. Stat Med 10(4):585-598

58. Pedersen CB, Mortensen PB (2001) Evidence of a doseresponse relationship between urbanicity during upbringing and schizophrenia risk. Arch Gen Psychiat 58(11):10391046 


\title{
Research report
}

\section{The impact of subclinical psychosis on the transition from subclinicial mania to bipolar disorder}

\author{
Nil Kaymaz ${ }^{\mathrm{a}}$, Jim van Os ${ }^{\mathrm{a}, \mathrm{b}, *}$, Ron de Graaf ${ }^{\mathrm{c}}$, Margreet ten Have ${ }^{\mathrm{c}}$, \\ Willem Nolen ${ }^{\text {d }}$, Lydia Krabbendam ${ }^{\text {a }}$ \\ ${ }^{a}$ Department of Psychiatry and Neuropsychology, South Limburg Mental Health Research and Teaching Network, EURON, \\ Maastricht University, PO BOX 616 (DRT 10), 6200 MD Maastricht, The Netherlands \\ ${ }^{\mathrm{b}}$ Division of Psychological Medicine, Institute of Psychiatry, De Crespigny Park, Denmark Hill, London SE5 8AF, UK \\ ${ }^{\mathrm{c}}$ The Netherlands Institute of Mental Health and Addiction (Trimbos Institute), Utrecht, The Netherlands \\ ${ }^{d}$ Department of Psychiatry, University Medical Center Groningen, PO BOX 30.001, 9700 RB Groningen, The Netherlands
}

Received 25 April 2006; received in revised form 29 June 2006; accepted 30 June 2006

Available online 28 August 2006

\begin{abstract}
Background: In the general population, symptoms of mania and psychosis are more broadly distributed than their associated clinical syndromes. Little is known, however, about how these subclinical population phenotypes co-vary with and impact on each other. Method: In a representative population cohort of 7076 adults, prevalence of mania and psychosis symptoms and syndromes were assessed with the CIDI at baseline, at one (T1) and two years later (T2). The degree of comorbidity between subclinical mania and subclinical psychosis was examined, as well as the impact of subclinical comorbidity on social impairment and transition from subclinical mania to onset of bipolar disorder.

Results: The lifetime prevalence of at least one manic and one psychotic symptom was $4.1 \%$ and $4.2 \%$ respectively. Excluding individuals with any lifetime DSM-III-R bipolar or psychotic disorder $(n=218)$, these prevalences were $2.3 \%$ (subclinical mania) and $2.8 \%$ (subclinical psychosis). Individuals with subclinical mania had a $17 \%$ risk of subclinical psychosis, compared with $2.3 \%$ in those without $(P<0.000)$. Comorbid subclinical psychosis in individuals with subclinical mania was much more predictive of a future diagnosis of bipolar disorder (positive predictive values of $3 \%$ versus $10 \%$ respectively).

Conclusion: Subclinical phenotypes of mania and psychosis are more prevalent than their clinical counterparts and cluster together. The risk factors for psychosis may facilitate the formation of more "toxic" combinations of subclinical mania and subclinical psychosis with a higher probability of transition to bipolar disorder. A better understanding of this pathway is crucial for the development of early interventions.
\end{abstract}

(C) 2006 Elsevier B.V. All rights reserved.

Keywords: Mania; Psychosis; Genetics; Environment; Prevention; Comorbidity

\footnotetext{
* Corresponding author. Department of Psychiatry and Neuropsychology, Maastricht University, PO BOX 616 (DRT 10), 6200 MD Maastricht, The Netherlands. Tel.: +31 43 3875443; fax: +3143 3875444.

E-mail address: j.vanos@sp.unimaas.nl (J.van Os).
}

\section{Introduction}

It is increasingly recognised that in the general population, the expression of mania and psychosis is more broadly distributed than the associated clinical syndromes (Akiskal et al., 2000; Angst, 2002; Johns and van Os, 2001; Judd et al., 2003; Peters et al., 1999; Stefanis et

0165-0327/\$ - see front matter (C) 2006 Elsevier B.V. All rights reserved. doi:10.1016/j.jad.2006.06.028 
al., 2002; van Os et al., 2001). Thus, even though the prevalence of a clinical disorder may be low, the prevalence of isolated symptoms can be much higher. In addition to phenomenological correspondence, continuity between the clinical and subclinical phenotypes is suggested by similar associations with demographic factors (Johns and van Os, 2001; van Os et al., 2000a; Verdoux et al., 1998), transitions over time from the subclinical to the clinical phenotype (Chapman et al., 1994; Hanssen et al., 2005; Poulton et al., 2000), familial co-clustering of the clinical and the subclinical phenotype (Kendler et al., 1993), sharing of cognitive and motor deficits (Lenzenweger, 1994; Matsui et al., 2004; Neumann and Walker, 2003; Voglmaier et al., 2000), and sharing of risk genes (Stefanis et al., 2004a).

There is substantial overlap between dimensions of mania and psychosis in clinical samples, which may be due to the sharing of genetic and non-genetic aetiological influences. Familial co-aggregation suggests that psychosis shares common genetic risk factors with mania (Bailer et al., 2002; Cardno et al., 2002; Kendler and Gardner, 1997; Potash et al., 2001; Valles et al., 2000) and recent studies have indeed implied shared susceptibility genes (Bramon and Sham, 2001; Green et al., 2005; Maier et al., 2005; Walss-Bass et al., 2005). Although there are quantitative differences in effect size (Van Os et al., 1998), risk factors such as life events, ethnic group, prenatal famine and urban birth also tend to overlap to a degree between psychotic and mood disorders (Bebbington et al., 1993; Brown et al., 2000; Marcelis et al., 1998; van Os, 1996) as do cognitive impairments and high levels of neuroticism prior to the onset of disorder (Goodwin et al., 2003; Jones et al., 1994; Myin-Germeys et al., 2002; Van Os and Jones, 2001b).

Given the continuity between clinical and subclinical levels of psychopathology within a particular symptom domain, it can be surmised that the overlap between mania and psychosis should also be detectable at lower levels of the continuum. However, little is known about how subclinical population phenotypes of mania and psychosis co-vary with and have impact on each other and which variables affect observed comorbidity between subclinical phenotypes. It was hypothesised that the demographic, familial, psychological, and social risk factors for clinical psychotic disorder (Van Os, 2000; Van Os et al., 2000b; Van Os et al., 2005) would also predict the presence of subclinical psychosis in individuals with subclinical mania. It was further hypothesised that since the presence of psychosis in clinical bipolar disorder predicts poorer outcome (Coryell et al., 2001), the coexistence of psychotic features with sub- clinical mania would similarly have a negative impact on social impairment and be predictive of a future diagnosis of bipolar disorder.

\section{Methods}

The Netherlands Mental Health Survey and Incidence Study (NEMESIS), is a prospective study with three measurement points over a period of 3 years (Alegria et al., 2000; Bijl et al., 1998a,b). The current report is based on the baseline data, with the exception of the predictive analysis of the post-baseline diagnosis of bipolar disorder. A multistage, stratified, random sampling procedure was used to first select 90 municipalities, then a sample of private households, and finally a Dutch-speaking individual aged 18-64 years within each household. Selected households were sent an introductory letter by the Minister of Health, inviting them to participate. A total of 7076 individuals provided informed consent and was interviewed at baseline, representing a response rate of $69.7 \%$. Nearly $44 \%$ of non-responders agreed to fill in a postal questionnaire, including a General Health Questionnaire (Goldberg and Williams, 1988), and were found to have the same mean GHQ score (responders: 1.19; non-responders: 1.16). At $\mathrm{T}_{1}, 5618$ subjects participated for the second time; at $T_{2}, 4848$ subjects participated. The sample was found to be representative of the Dutch population in terms of sex, marital status and level of urbanisation (Bijl et al., 1998b), with the exception of a slight underrepresentation of individuals in the age group 18-24 years. As this was a study of relative rather than absolute risk, no poststratification weightings were applied to the data.

\subsection{Instruments}

Subjects were interviewed at home. The Composite International Diagnostic Interview (CIDI; http://www3. who.int/cidi/) version 1.1 (Robins et al., 1988; Smeets and Dingemans, 1993) was used, yielding DSM-III-R diagnoses. The CIDI was designed for trained interviewers who are not clinicians and has been found to have high inter-rater reliability (Cottler, 1991; Wittchen et al., 1991), and high test-retest reliability (Semler et al., 1987; Wacker et al., 1990; Wittchen, 1994). Ninety interviewers experienced in systematic data collection collected the data, having received a 3-day training course in recruiting and interviewing, followed by a 4-day course at the WHO-CIDI training centre in Amsterdam. Extensive monitoring and quality checks took place throughout the entire data collection period (Bijl et al., 1998a). 


\subsection{Psychosis ratings}

Lifetime ratings from the 17 items of the CIDI core psychosis sections, assessed at baseline, on delusions (13 items) and hallucinations (4 items) were used (items G1 -G13, G15, G16, G20, G21). These concern classic psychotic symptoms involving, for example, persecution, thought interference, auditory hallucinations and passivity phenomena. All these items can be rated in six ways: "1"- no symptom, "2"- -symptom present but not clinically relevant (not bothered by it and not seeking help for it), " 3 "- - symptom result of ingestion of drugs, "4"- symptom result of somatic disease, "5"- true psychiatric symptom, "6"- symptom may not really be a symptom because there appears to be some plausible explanation for it. Because psychotic symptoms are difficult to diagnose in a structured interview (Anthony et al., 1985; Cooper and Collacott, 1994; Helzer et al., 1985), clinical reinterviews were conducted over the telephone by an experienced trainee psychiatrist at the level of senior registrar for all individuals who had at least one rating of "5" or "6", using questions from the Structured Clinical Interview for DSM-III-R (SCID), an instrument with proven reliability and validity in diagnosing schizophrenia (Spitzer et al., 1992). CIDI ratings were corrected on the basis of these clinical interviews, and the NEMESIS DSM-III-R diagnoses of psychotic disorder are based on the data from these clinical reinterviews; approximately 50\% of eligible people were reinterviewed. Of a possible $226 \times 17=3842$ CIDI ratings of psychotic symptoms in the 226 individuals who were reinterviewed, changes after clinical reinterview were introduced in 266 ratings (6.9\%).

Psychotic disorder was defined as any DSM-III-R affective or non-affective psychotic diagnosis. Subclinical psychosis was defined as a CIDI rating of 5 on any of the 17 CIDI core psychosis items.

\subsection{Bipolar diagnoses and mania symptom scores}

Lifetime manic symptoms were assessed using ratings from the 11 items of the CIDI core mania section $(\mathrm{F})$ at baseline. All these items can be rated either "yes"(1) or "no"(0). The manic symptom has to be present for at least 2 days. The mania section starts with assessing the presence of abnormally and persistently elevated, expansive or irritable mood, which, if positive, results in further questioning about other symptoms. Subclinical mania was defined as at least one manic symptom thus assessed.

The diagnosis of bipolar disorder was defined as DSM-III-R diagnosis on the basis of the CIDI. In order to assess social impairment, item 6 of the Short Form Health Survey, i.e. SF-36 (Van der Zee et al., 1993; Ware et al., 1994) was used. The SF-36 measures the healthrelated quality of life and item 6 of the SF-36 inquires about the interference of physical and emotional problems with normal social activities in the past 4 weeks (in the analyses used as: none, a little, more than a little).

\subsection{Predictors of comorbidity}

Guided by previous research as described above, the following predictors of psychotic symptoms occurring in the context of subclinical mania were examined: age (two groups around median split), sex, marital status (living alone or not), education (4 levels), unemployment (present or absent), urbanisation (three levels), family history of depression (present or absent), family history of delusions and hallucinations (present or absent), lifetime use of cannabis (present or absent), lifetime use of other drugs (present or absent), childhood trauma (present or absent), discrimination (present or absent) and neuroticism (two groups around median split of continuous score). Urbanisation was defined following the standard classification of urbanisation of place of residence according to the Dutch Central Bureau of Statistics, based on the density of addresses per $\mathrm{km}^{2}$ in an area (van Os et al., 2001). The three levels of urbanicity represented respectively 0-499, 500-1499 and 1500 and more persons per $\mathrm{km}^{2}$.

Family history of delusions and hallucinations as well as a family history of depression were assessed at T1 by asking the subjects, for each first-degree relative, whether any ever had presented with delusions or hallucinations (Van Os et al., 2003) or depression respectively, describing the symptoms associated with these disorders. Lifetime use of cannabis and lifetime use of other drugs (stimulant drug, cocaine, PCP and psychedelics) were assessed at baseline using the CIDI section on alcohol and drugs (van Os et al., 2002). All these items were classified dichotomously as either "no"(0) or "yes"(1).

At baseline, subjects were asked using a semi-structured interview whether they had experienced any kind of emotional, physical, psychological or sexual trauma before age of 16 years. Subjects answered "yes" or "no" to each of the questions and were able to give an indication about the frequency on a 6-point scale, " 1 " never, " 2 " once, " 3 " sometimes, "4" regular, "5" often and "6" very often. In the analyses, trauma was a priori dichotomised as follows; "no trauma" if the score on any item $\leq 3$ and "trauma" if the score on any item $>3$ (Janssen et al., 2004). Given a specific finding of early trauma 
predicting hallucinations in bipolar disorder (Hammersley et al., 2003), prediction was also tested using hallucinations only as the outcome. In order to assess exposure to discrimination, subjects were asked if they had experienced discrimination over the past year because of their skin colour or ethnicity, their sex, age, appearance, disability or sexual orientation (Janssen et al., 2003). Level of neuroticism was assessed with the 14-item Groningen Neuroticism Scale (Krabbendam et al., 2002; Ormel, 1980; Ormel et al., 2001).

\subsection{Data analyses}

All analyses were carried out using the software package STATA, version 9 (StataCorp, 2005). The risk for psychosis was calculated in individuals with and without subclinical mania, and at different levels of the predictor variables. In order to examine whether the risk for psychosis comorbidity was statistically different between different levels of the predictor variables, a STATA risk regression model of subclinical psychosis was used in which the interaction between subclinical mania and the predictor variable was estimated.

In order to assess whether the effect of any predictor was additive to that of others, a variable representing the sum score of significant predictor variables was constructed in order to assess whether comorbidity would increase in a dose-response fashion with higher levels of the predictor sum score.

In the predictive analyses, post-baseline onset of bipolar disorder was the outcome variable and the presence or absence of one or more manic symptoms at baseline (T0), outside any lifetime diagnosis of bipolar or psychotic disorder, was the predictor variable. Predictive power of the predictor variable was expressed as the post-test probability (PPs) calculated with the DIAGTEST procedure in the STATA statistical program, and calculated separately for i) those with subclinical psychosis at baseline and ii) those without subclinical psychosis at baseline. The PP is the likelihood of disease (post-baseline bipolar disorder) given a positive test result (baseline mania symptoms) (Sackett and Wennberg, 1997).

\subsection{Risk set}

The risk set consisted of all individuals who had participated in the baseline CIDI interview, with the exception of the 218 individuals with a lifetime diagnosis of psychotic disorder $(n=107)$ or bipolar disorder ( $n=132$, of whom 21 also had a diagnosis of psychotic disorder) resulting in a sample for analysis of 6857 individuals. For the predictive analysis, the risk set consisted of all individuals who had i) participated in the baseline CIDI interview with the exception of the 218 individuals with a lifetime diagnosis of psychotic disorder or bipolar disorder and ii) who had had at least one post-baseline CIDI interview (T1 or T2). After applying these criteria, the risk set for the predictive analysis consisted of 5501 individuals.

\section{Results}

\subsection{Sample description}

In the entire baseline sample of 7076 individuals, the lifetime population prevalence of at least one manic and one psychotic symptom were $4.1 \%$ and $4.2 \%$ respectively. The mean age of the risk set of 6857 individuals, in which persons with any lifetime DSM-III-R bipolar or psychotic disorder diagnosis $(n=218)$ had been excluded, was 41.2 years $(\mathrm{SD}=12.2)$ and $47 \%$ was male (Table 1). In the risk set of 6857 , the prevalence of subclinical mania was $2.3 \%$ (mean symptom sum score: $0.1, \mathrm{SD}=0.65$ ) and of subclinical psychosis was $2.8 \%$.

Table 1

Risk set demographics, mania outcome and moderator variable distributions

\begin{tabular}{lc}
\hline Variable & $\begin{array}{c}\text { Frequencies (\%) } \\
\text { or mean (SD) }\end{array}$ \\
\hline Age & $41.2(12.2 \%)$ \\
Male & $3214(47 \%)$ \\
Female & $3643(53 \%)$ \\
No partner & $1837(27 \%)$ \\
Unemployment & $451(7 \%)$ \\
$\quad$ Education & \\
Highest & $1865(28 \%)$ \\
High & $508(8 \%)$ \\
Low & $2485(37 \%)$ \\
Lowest & $1911(28 \%)$ \\
At least one subclinical manic symptom & $156(2.3 \%)$ \\
At least one subclinical psychotic symptom & $192(2.8 \%)$ \\
Psychological problems interfere with functioning & \\
A little & $16 \%$ \\
More than a little & $7 \%$ \\
Cannabis use & $629(9 \%)$ \\
Use of other drugs & $134(2 \%)$ \\
Neuroticism & $3.8(4.2 \%)$ \\
Urbanicity & \\
Lowest & $1164(17 \%)$ \\
High & $3071(45 \%)$ \\
Highest & $2622(38 \%)$ \\
Trauma & $845(12 \%)$ \\
Discrimination & $1056(15 \%)$ \\
Family history of delusions/hallucinations & $279(5 \%)$ \\
Family history depression & $1438(27 \%)$ \\
\hline &
\end{tabular}


Individuals with subclinical mania had a $17 \%$ risk of subclinical psychosis, compared with only $2 \%$ in those without $(P<0.000$; Table 2$)$. The subclinical psychosis risk increased from $12 \%, 23 \%$ to $83 \%$ in individuals with 1,2 and 3 or more manic symptoms respectively (test for trend: $\chi^{2}=25.7, d f=1, P<0.0001$ ).

\subsection{Predictors of comorbidity}

In the risk regression model of subclinical psychosis, there was a significant interaction between urbanicity and subclinical mania, indicating a higher risk of comorbidity between subclinical mania and subclinical psychosis for subjects living in more urbanised areas (Table 3). Similar positive interactions were apparent for cannabis use and a family history of depression, indicating more comorbidity in individuals using cannabis and in individuals with familial loading for depression. Although there was no significant interaction between childhood trauma and subclinical psychosis, there was a positive interaction using the outcome of hallucinations only, indicating a higher risk for comorbidity between subclinical mania and hallucinations in subjects with a history of recalled trauma (Table 3). Although the risk for mania and psychosis comorbidity was substantially higher in the expected direction for individuals who were younger $(19 \%$ versus $14 \%)$, those using other drugs than cannabis (38\% versus $15 \%)$, those with higher levels of neuroticism ( $20 \%$ versus $11 \%)$, those with a family history of psychosis $(24 \%$ versus $17 \%)$, those living alone (24\% versus $13 \%)$ and those in the highest level of social impairment due to physical or psychological problems (29\% versus $12 \%$ and $17 \%$ ), none of these differences was statistically significant by conventional alpha (Table 3). No large or significant differences were seen for sex, unemployment, and discrimination, whereas lower education was associated with lower rather than higher comorbidity, although this difference was not statistically significant (Table 3 ).

\subsection{Additivity of predictors}

A variable with score 0 to 3 representing the number of predictors (cannabis, urbanicity highest level and

Table 2

Comorbidity of subclinical manic and subclinical psychotic symptoms

\begin{tabular}{llc}
\hline Subclinical mania & \multicolumn{2}{l}{ Subclinical psychotic symptoms } \\
\cline { 2 - 3 } symptoms & Absent & Present \\
\hline Absent & 6536 & $165(2.5 \%)$ \\
Present & 129 & $27(17.3 \%)$ \\
Test risk difference & $\chi^{2}=23.9, d f=1, P<0.0001$ \\
\hline
\end{tabular}

Table 3

Comorbidity, stratified by moderator values

\begin{tabular}{|c|c|c|c|}
\hline & Moderator & $\begin{array}{l}\text { Comorbidity } \\
\text { between } \\
\text { psychosis and } \\
\text { mania }(\%)^{*}\end{array}$ & $\begin{array}{l}\text { Interaction } \\
\text { between the } \\
\text { moderator } \\
\text { and } \\
\text { psychosis@ } \\
\chi^{2}(p)\end{array}$ \\
\hline \multirow[t]{2}{*}{ Age } & $\begin{array}{l}\text { Lower median } \\
\text { group }(18-40)\end{array}$ & 19 & $0.5(0.47)$ \\
\hline & $\begin{array}{l}\text { Higher median } \\
\text { group }(41-64)\end{array}$ & 14 & \\
\hline \multirow[t]{2}{*}{ Sex } & Women & 16 & $0.2(0.63)$ \\
\hline & Men & 18 & \\
\hline \multirow[t]{2}{*}{ Caninabis } & Absent & 12 & $5.4(0.002)$ \\
\hline & Present & 36 & \\
\hline \multirow[t]{2}{*}{ Use other drugs } & Absent & 15 & $1.2(0.28)$ \\
\hline & Present & 38 & \\
\hline \multirow[t]{3}{*}{ Urbanicity\# } & Level 1 & 5 & $5.8(0.018)$ \\
\hline & Level 2 & 14 & \\
\hline & Level 3 & 23 & \\
\hline \multirow[t]{2}{*}{ Neuroticism } & $\begin{array}{l}\text { Lower median } \\
\text { group }(0-3)\end{array}$ & 11 & $0.6(0.44)$ \\
\hline & $\begin{array}{l}\text { Higher median } \\
\text { group }(4-28)\end{array}$ & 20 & \\
\hline \multirow{2}{*}{$\begin{array}{c}\text { Family history } \\
\text { psychosis }^{\wedge}\end{array}$} & Absent & 17 & $0.3(0.60)$ \\
\hline & Present & 24 & \\
\hline \multirow{2}{*}{$\begin{array}{r}\text { Family history } \\
\text { depressioin`}\end{array}$} & Absent & 17 & $7.1(0.0076)$ \\
\hline & Present & 24 & \\
\hline \multirow[t]{2}{*}{ Unemployment } & Absent & 18 & $0.5(0.49)$ \\
\hline & Present & 14 & \\
\hline \multirow[t]{2}{*}{ Living alone } & Absent & 13 & $1.9(0.17)$ \\
\hline & Present & 24 & \\
\hline \multirow[t]{2}{*}{ Childhood trauma } & Absent & 12 & $2.6(0.11)$ \\
\hline & Present & 28 & \\
\hline \multirow{2}{*}{$\begin{array}{l}\text { Childhood trauma: } \\
\text { hallucinations only }\end{array}$} & Absent & 3 & $4.1(0.044)$ \\
\hline & Present & 15 & \\
\hline \multirow[t]{4}{*}{ Education } & Highest & 26 & $2.9(0.09)$ \\
\hline & High & 27 & \\
\hline & Low & 11 & \\
\hline & Lowest & 14 & \\
\hline \multirow[t]{2}{*}{ Discrimination } & Absent & 18 & $0.9(0.34)$ \\
\hline & Present & 15 & \\
\hline \multirow{3}{*}{$\begin{array}{l}\text { Psychological } \\
\text { problems interfere } \\
\text { with social } \\
\text { functioning }\end{array}$} & None & 17 & $0.34(0.56)$ \\
\hline & Little & 12 & \\
\hline & $\begin{array}{l}\text { More than } \\
\text { a little }\end{array}$ & 29 & \\
\hline
\end{tabular}

* proportion of people with subclinical mania, dichotomously defined, who also had evidence of subclinical psychosis, dichotomously defined.

(a) tests whether differences in risk are significantly different between different levels of moderator variable.

\# three levels representing number of persons per square kilometre: $1: 0-499 ; 2: 500-1499 ; 3: 1500$ and more.

$\wedge$ family history of delusions and/or hallucinations (psychosis) or depression, as reported by respondent.

family history of depression) of each individual in the risk set was constructed in order to assess the level of comorbidity at each stratum. This revealed an increase 
Table 4

Prediction of incident bipolar disorder: the Post-test probabilities (PP) of developing post-baseline DSM-III-R bipolar disorder in those with subclinical mania at baseline with and without subclinical psychotic symptoms

\begin{tabular}{lll}
\hline & $\begin{array}{l}\text { PP Post-baseline } \\
\text { bipolar disorder }\end{array}$ & $\begin{array}{l}95 \% \text { confidence } \\
\text { interval }\end{array}$ \\
\hline $\begin{array}{c}\text { No subclinical } \\
\text { psychotic symptoms }\end{array}$ & $3.0 \%$ & $2.5,3.4$ \\
$\begin{array}{c}\text { With subclinical } \\
\text { psychotic symptoms }\end{array}$ & $9.5 \%$ & $4.7,14.4$ \\
\hline
\end{tabular}

in subclinical psychosis comorbidity given the presence of subclinical mania, increasing from $6 \%$ in those with zero predictors to $12 \%, 30 \%$ and finally $63 \%$ in those with 1,2 and 3 predictors respectively.

\subsection{Prediction of incident bipolar disorder}

The PP of developing post-baseline DSM-III-R bipolar disorder in those with subclinical mania at baseline given the co-occurrence of subclinical psychosis was $9.5 \%$ ( 2 out of 21 persons; 95\%CI: 4.7, 14.4), considerably and significantly (as evidenced by non-overlapping 95\% CIs) higher than the probability of developing bipolar disorder in the group without subclinical psychosis at baseline ( 3 out of 101 persons; $\mathrm{PP}=3.0 \%, 95 \%$ CI: $2.5,3.4$ ) (Table 4).

\section{Discussion}

This study examined the degree of comorbidity between subclinical mania and subclinical psychosis, the predictors of subclinical comorbidity and prospective post-baseline prediction of incident DSM-III-R diagnosis of bipolar disorder. Excluding the lifetime diagnosis for clinical mania and psychosis at baseline, strong associations between subclinical mania and subclinical psychosis were demonstrated. Subclinical comorbidity was predicted by variables that previously have been shown to increase the risk for psychosis such as urban residence, cannabis use, familial loading for depression, and victimisation (trauma with hallucinations as outcome). Subclinical comorbidity was not predicted by other predictors, that previously have been shown to increase the risk for psychosis such as age, gender, use of other drugs, trait anxiety (neuroticism), family history of psychosis, unemployment, single marital status, childhood trauma (without hallucinations), education, discrimination and social impairment due to physical and psychological problems. Coexistence of subclinical psychotic features with subclinical mania was much more predictive of a future diagnosis of bipolar disorder.

\subsection{Predictors of subclinical comorbidity}

Some of our findings suggest that similar factors that have previously been shown to increase the risk for psychosis and mania at the clinical level, also increase the risk for the co-occurrence for both symptoms at the subclinical level. In our study there was a strong association between urban residence and subclinical comorbidity. Previous studies (Lewis et al., 1992; Marcelis et al., 1998) have shown that urban residence is as a risk factor for psychosis, whereas contradictory findings for affective disorders exist. In some studies, urban residence has been found to be a risk factor for affective disorders (Kessler et al., 1997; Sundquist et al., 2004), but not in others (Mortensen et al., 2003). It was recently shown that urban environment specifically impacts on the psychotic, but not on the affective dimensions of clinical bipolar disorder (Kaymaz et al., 2006), which is compatible with the current findings in the subclinical phenotype.

Use of cannabis has been shown to be a specific risk factor for later psychosis (Andreasson et al., 1987; Henquet et al., 2005; van Os et al., 2002; Zammit and Lewis, 2004; Stefanis et al., 2004b; Fergusson et al., 2003), as well as for the development of mania (Henquet et al., 2006). In this study, only an association between the use of cannabis and subclinical comorbidity was found and not for the use of other drugs.

Although there are several studies showing common genetic contributions to the variance in liability to psychosis and mania at a clinical level (Craddock et al., 2006), in this study no association between familiar loading for psychosis and comorbidity between psychosis and mania at a subclinical level was found. However, a strong association between family history of depression and subclinical comorbidity was found. A significant association between trauma with hallucinations as outcome and subclinical comorbidity was found, entirely in line with the findings of a previous study (Hammersley et al., 2003). No association was found between childhood trauma and comorbidity between mania and psychosis at a subclinical level, whereas trauma has been found to be a risk factor for psychosis (Read et al., 2005) as well as bipolar disorder (Hammersley et al., 2003) (Bebbington, 2004; Garno et al., 2005; Levitan et al., 1998).

Although it is a robust epidemiological finding that younger age and male sex increase the risk for psychosis (Johns et al., 2004; Verdoux et al., 1998), inconsistent findings exist for the impact of age and gender on the prevalence in bipolar disorder. Some studies showed an impact of age and gender on bipolar disorder (Gonzalez- 
Pinto et al., 2003; Yildiz and Sachs, 2003) whereas others did not find any sex differences (Hendrick et al., 2000). In this study, no association between age and gender and subclinical comorbidity was found, nor was there an association between neuroticism and subclinical comorbidity in spite of findings in literature of a risk-increasing effect of neuroticism on psychosis (Krabbendam et al., 2002; van Os et al., 2001) and mania (Lozano and Johnson, 2001). No associations were found between lower educational achievement, single marital status, discrimination and unemployment in this study, although previous studies have shown impact of these findings on psychosis and increased mental disorders (Chakraborty and McKenzie, 2002; Janssen et al., 2003; Karlsen and Nazroo, 2002; van Os et al., 2000a; van Os et al., 1995). Although for the above mentioned variables no significant association with subclinical comorbidity was found, the risk for mania and psychosis comorbidity was nevertheless substantially higher in the expected direction for individuals who were younger, those using other drugs than cannabis versus those who did not use, those with higher levels of neuroticism versus those with a lower level, those with a family history of psychosis versus those without a family history of psychosis, those living alone versus those living together and those in the highest level of social impairment due to physical or psychological problems versus none, little or more than little. Therefore, the inconclusive findings regarding risk of comorbidity may be likely due to insufficient statistical power. For example, the interaction with family history of depression was significant, whereas the interaction with family history of psychosis was not, despite similar differences in comorbidity. The reason for this was that a family history of psychosis was much rarer than a family history of depression, yielding lower power.

There was a positive interaction between the variable social impairment due to physical and psychological problems and subclinical psychosis, indicating that for a given level of subclinical mania, the coexistence of subclinical psychotic symptoms was more predictive of social impairment, but this interaction was not significant.

To summarise, some of the findings suggest that genetic and non-genetic risk factors for psychosis and mania overlap on lower levels of the continuum, mirroring the risk factors for the clinical disorders. These shared aetiological factors may explain the substantial comorbidity between both disorders.

\subsection{Impact of subclinical comorbidity}

In addition, comorbidity at a subclinical level was predictive of a future diagnosis of bipolar disorder. The probability of developing incident bipolar disorder was $3 \%$ in the absence of subclinical psychotic symptoms and $10 \%$ in the presence of psychotic symptoms, indicating approximately a $7 \%$ higher risk of developing future bipolar disorder.

The risk factors for comorbidity that were studied, such as family history, use of cannabis, victimisation, neuroticism and indicators of the wider social environment have all been described before as risk factors for psychosis (Van Os et al., 2005), and thus may act in part by facilitating the formation of more "toxic" combinations of subclinical symptoms of mania and psychosis in the general population with higher probability of transition to clinical disorders. Thus, subclinical symptoms can be seen as intermediary phenotypes of a mood continuum that after exposure to additional risk factors may progress to a full-blown disorder (Hanssen et al., 2005), specifically in the presence of psychotic symptoms at subclinical level.

\subsubsection{Methodological issues}

This study mainly reports on cross-sectional associations between symptoms of mania and psychosis and demographic and other risk variables and lacks information on temporal relationships between these variables. However, an important finding was that subclinical psychosis was associated with a greater risk of transition to bipolar disorder over time.

Psychosis includes also dimensions of negative symptoms and disorganisation in addition to positive symptoms. However, the CIDI does not include adequate assessments of these dimensions so that their role could not be investigated.

Another limitation of the used instrument is that during this study, only respondents were interviewed and not their relatives. Therefore, under-reporting of (hypo) manic symptoms could have occurred, since these symptoms often are experienced as ego-syntonic by the patient, whereas family members may provide important contextual information. Another limitation of our study is that a lifetime prevalence of a single manic symptom for 2 days, as only assessed by lay interviews, may be underestimated; however there is no reason to assume that this would have affected comorbidity rates and predictors thereof.

Psychotic symptom ratings were assessed by lay interviewers (CIDI ratings of 1-4), whereas the other CIDI ratings (5-6) were assessed by clinicians through telephone interviews in approximately $50 \%$ of eligible cases. No clinical reinterview ratings were carried out for the mania symptoms. It is possible that with lay interviewer ratings a degree of misclassification did 
occur. However, the CIDI was designed for trained interviewers who are not clinicians and has been found to have high inter-rater reliability (Cottler, 1991; Wittchen et al., 1991), and high test-retest reliability (Semler et al., 1987; Wacker et al., 1990; Wittchen, 1994).

Bias could also have been introduced by differential rating of psychosis due to incomplete clinical reinterview rates at baseline. However, excluding the individuals who were eligible for clinical reinterview but who had not been contacted, thus leaving only those who had been rated by clinicians, did not affect the results.

Our findings depend in part on the assumption that the lay interviewers, using the CIDI, were enough experienced in the discrimination of manic and psychotic symptoms. This assumption has face value since i) the lay interviewers were trained during a three-day course, ii) there was an extensive monitoring and quality checks throughout the entire data collection period (Bijl et al., 1998a), iii) individuals who screened positive for psychosis were reinterviewed by clinicians. The CIDI has been designed for trained interviewers who are not clinicians and has been found to have a high inter-rater reliability (Cottler, 1991; Wittchen et al., 1991) and high test-retest reliability (Semler et al., 1987; Wacker et al., 1990; Wittchen, 1994). Nevertheless, a degree of misclassification may have occurred, although again it is difficult to see how this would have affected the findings relating to predictors of comorbidity.

\section{Acknowledgements}

Funded by the Dutch Department of Health.

\section{References}

Akiskal, H.S., Bourgeois, M.L., Angst, J., et al., 2000. Re-evaluating the prevalence of and diagnostic composition within the broad clinical spectrum of bipolar disorders. J. Affect. Disord. 59 (Suppl 1), S5-S30.

Alegria, M., Bijl, R.V., Lin, E., et al., 2000. Income differences in persons seeking outpatient treatment for mental disorders: a comparison of the United States with Ontario and The Netherlands. Arch. Gen. Psychiatry 57, 383-391.

Andreasson, S., Allebeck, P., Engstrom, A., et al., 1987. Cannabis and schizophrenia. A longitudinal study of Swedish conscripts. Lancet 2, 1483-1486.

Angst, J., 2002. Historical aspects of the dichotomy between manicdepressive disorders and schizophrenia. Schizophr. Res. 57, 5-13.

Anthony, J.C., Folstein, M., Romanoski, A.J., et al., 1985. Comparison of the lay Diagnostic Interview Schedule and a standardized psychiatric diagnosis. Experience in eastern Baltimore. Arch. Gen. Psychiatry 42, 667-675.

Bailer, U., Leisch, F., Meszaros, K., et al., 2002. Genome scan for susceptibility loci for schizophrenia and bipolar disorder. Biol. Psychiatry 52, 40-52.
Bebbington, P., 2004. Recent findings in bipolar affective disorder. Psychol. Med. 34, 767-776.

Bebbington, P., Wilkins, S., Jones, P., et al., 1993. Life events and psychosis. Initial results from the Camberwell Collaborative Psychosis Study. Br. J. Psychiatry 162, 72-79.

Bijl, R.V., Ravelli, A., van Zessen, G., 1998a. Prevalence of psychiatric disorder in the general population: results of The Netherlands Mental Health Survey and Incidence Study (NEMESIS). Soc. Psychiatry Psychiatr. Epidemiol. 33, 587-595.

Bijl, R.V., van Zessen, G., Ravelli, A., et al., 1998b. The Netherlands Mental Health Survey and Incidence Study (NEMESIS): objectives and design. Soc. Psychiatry Psychiatr. Epidemiol. 33, 581-586.

Bramon, E., Sham, P.C., 2001. The common genetic liability between schizophrenia and bipolar disorder: a review. Curr. Psychiatry Rep. 3, 332-337.

Brown, A.S., van Os, J., Driessens, C., et al., 2000. Further evidence of relation between prenatal famine and major affective disorder. Am. J. Psychiatry 157, 190-195.

Cardno, A.G., Rijsdijk, F.V., Sham, P.C., et al., 2002. A twin study of genetic relationships between psychotic symptoms. Am. J. Psychiatry 159, 539-545.

Chakraborty, A., McKenzie, K., 2002. Does racial discrimination cause mental illness? Br. J. Psychiatry 180, 475-477.

Chapman, L.J., Chapman, J.P., Kwapil, T.R., et al., 1994. Putatively psychosis-prone subjects 10 years later. J. Abnorm. Psychology 103, 171-183.

Cooper, S.A., Collacott, R.A., 1994. Clinical features and diagnostic criteria of depression in Down's syndrome. Br. J. Psychiatry 165, 399-403.

Coryell, W., Leon, A.C., Turvey, C., et al., 2001. The significance of psychotic features in manic episodes: a report from the NIMH collaborative study. J. Affect. Disord. 67, 79-88.

Cottler, L.B., 1991. The CIDI and CIDI-substance abuse module (SAM): cross-cultural instruments for assessing DSM-III, DSMIII-R and ICD-10 criteria. NIDA Res. Monogr. 105, 220-226.

Craddock, N., O’Donovan, M.C., Owen, M.J., 2006. Genes for schizophrenia and bipolar disorder? Implications for psychiatric nosology. Schizophr. Bull. 32, 9-16.

Fergusson, D.M., Horwood, L.J., Swain-Campbell, N.R., 2003. Cannabis dependence and psychotic symptoms in young people. Psychol. Med. 33, 15-21.

Garno, J.L., Goldberg, J.F., Ramirez, P.M., et al., 2005. Impact of childhood abuse on the clinical course of bipolar disorder. Br. J. Psychiatry 186, 121-125.

Goldberg, D., Williams, P., 1988. User's Guide to the GHQ. NFERNelson, Windsor.

Gonzalez-Pinto, A., van Os, J., Perez de Heredia, J.L., et al., 2003. Age-dependence of Schneiderian psychotic symptoms in bipolar patients. Schizophr. Res. 61, 157-162.

Goodwin, R.D., Fergusson, D.M., Horwood, L.J., 2003. Neuroticism in adolescence and psychotic symptoms in adulthood. Psychol. Med. 33, 1089-1097.

Green, E.K., Raybould, R., Macgregor, S., et al., 2005. Operation of the schizophrenia susceptibility gene, neuregulin 1, across traditional diagnostic boundaries to increase risk for bipolar disorder. Arch. Gen. Psychiatry 62, 642-648.

Hammersley, P., Dias, A., Todd, G., et al., 2003. Childhood trauma and hallucinations in bipolar affective disorder: preliminary investigation. Br. J. Psychiatry 182, 543-547.

Hanssen, M., Bak, M., Bijl, R., et al., 2005. The incidence and outcome of subclinical psychotic experiences in the general population. Br. J. Clin. Psychol. 44, 181-191. 
Helzer, J.E., Robins, L.N., McEvoy, L.T., et al., 1985. A comparison of clinical and diagnostic interview schedule diagnoses. Physician reexamination of lay-interviewed cases in the general population. Arch. Gen. Psychiatry 42, 657-666.

Hendrick, V., Altshuler, L.L., Gitlin, M.J., et al., 2000. Gender and bipolar illness. J. Clin. Psychiatry 61, 393-396 (quiz 397).

Henquet, C., Krabbendam, L., Spauwen, J., et al., 2005. Prospective cohort study of cannabis use, predisposition for psychosis, and psychotic symptoms in young people. BMJ 330, 11 .

Henquet, C., Krabbendam, L., de Graaf, R., et al., 2006. Cannabis use and expression of mania in the general population. J. Affect. Disord. (Jun 19; Electronic publication ahead of print).

Janssen, I., Hanssen, M., Bak, M., et al., 2003. Discrimination and delusional ideation. Br. J. Psychiatry 182, 71-76.

Janssen, I., Krabbendam, L., Bak, M., et al., 2004. Childhood abuse as a risk factor for psychotic experiences. Acta Psychiatr. Scand. 109, $38-45$.

Johns, L.C., Cannon, M., Singleton, N., et al., 2004. Prevalence and correlates of self-reported psychotic symptoms in the British population. Br. J. Psychiatry $185,298-305$.

Johns, L.C., van Os, J., 2001. The continuity of psychotic experiences in the general population. Clin. Psychol. Rev. 21, 1125-1141.

Jones, P., Rodgers, B., Murray, R., et al., 1994. Child development risk factors for adult schizophrenia in the British 1946 birth cohort. Lancet 344, 1398-1402.

Judd, L.L., Akiskal, H.S., Schettler, P.J., et al., 2003. The comparative clinical phenotype and long term longitudinal episode course of bipolar I and II: a clinical spectrum or distinct disorders? J. Affect. Disord. 73, 19-32.

Karlsen, S., Nazroo, J.Y., 2002. Relation between racial discrimination, social class, and health among ethnic minority groups. Am. J. Public Health 92, 624-631.

Kaymaz, N., Krabbendam, L., De Graaf, R., et al., 2006. Evidence that the urban environment specifically impacts on the psychotic but not the affective dimension of bipolar disorder. Soc. Psychiatry Psychiatr. Epidemiol. (Jul 3; Electronic publication ahead of print).

Kendler, K.S., Gardner, C.O., 1997. The risk for psychiatric disorders in relatives of schizophrenic and control probands: a comparison of three independent studies. Psychol. Med. 27, 411-419.

Kendler, K.S., McGuire, M., Gruenberg, A.M., et al., 1993. The Roscommon Family Study. II. The risk of nonschizophrenic nonaffective psychoses in relatives. Arch. Gen. Psychiatry 50, 645-652.

Kessler, R.C., Zhao, S., Blazer, D.G., et al., 1997. Prevalence, correlates, and course of minor depression and major depression in the National Comorbidity Survey. J. Affect. Disord. 45, 19-30.

Krabbendam, L., Janssen, I., Bak, M., et al., 2002. Neuroticism and low self-esteem as risk factors for psychosis. Soc. Psychiatry Psychiatr. Epidemiol. 37, 1-6.

Lenzenweger, M.F., 1994. Psychometric high-risk paradigm, perceptual aberrations, and schizotypy: an update. Schizophr. Bull. 20, 121-135.

Levitan, R.D., Parikh, S.V., Lesage, A.D., et al., 1998. Major depression in individuals with a history of childhood physical or sexual abuse: relationship to neurovegetative features, mania, and gender. Am. J. Psychiatry 155, 1746-1752.

Lewis, G., David, A., Andreasson, S., et al., 1992. Schizophrenia and city life. Lancet 340, 137-140.

Lozano, B.E., Johnson, S.L., 2001. Can personality traits predict increases in manic and depressive symptoms? J. Affect. Disord. 63 , $103-111$.

Maier, W., Hofgen, B., Zobel, A., et al., 2005. Genetic models of schizophrenia and bipolar disorder: overlapping inheritance or discrete genotypes? Eur. Arch. Psychiatr. Clin. Neurosci. 255, $159-166$.

Marcelis, M., Navarro-Mateu, F., Murray, R., et al., 1998. Urbanization and psychosis: a study of $1942-1978$ birth cohorts in The Netherlands. Psychol. Med. 28, 871-879.

Matsui, M., Sumiyoshi, T., Kato, K., et al., 2004. Neuropsychological profile in patients with schizotypal personality disorder or schizophrenia. Psychol. Rep. 94, 387-397.

Mortensen, P.B., Pedersen, C.B., Melbye, M., et al., 2003. Individual and familial risk factors for bipolar affective disorders in Denmark. Arch. Gen. Psychiatry 60, 1209-1215.

Myin-Germeys, I., Krabbendam, L., Jolles, J., et al., 2002. Are cognitive impairments associated with sensitivity to stress in schizophrenia? An experience sampling study. Am. J. Psychiatry 159, 443-449.

Neumann, C.S., Walker, E.F., 2003. Neuromotor functioning in adolescents with schizotypal personality disorder: associations with symptoms and neurocognition. Schizophr. Bull. 29, 285-298.

Ormel, J., 1980. Moeite met Leven of een Moeilijk Leven? University of Groningen, Groningen.

Ormel, J., Oldehinkel, A.J., Brilman, E.I., 2001. The interplay and etiological continuity of neuroticism, difficulties, and life events in the etiology of major and subsyndromal, first and recurrent depressive episodes in later life. Am. J. Psychiatry 158, 885-891.

Peters, E.R., Joseph, S.A., Garety, P.A., 1999. Measurement of delusional ideation in the normal population: introducing the PDI (Peters et al. Delusions Inventory). Schizophr. Bull. 25, 553-576.

Potash, J.B., Willour, V.L., Chiu, Y.F., et al., 2001. The familial aggregation of psychotic symptoms in bipolar disorder pedigrees. Am. J. Psychiatry 158, 1258-1264.

Poulton, R., Caspi, A., Moffitt, T.E., et al., 2000. Children's selfreported psychotic symptoms and adult schizophreniform disorder: a 15-year longitudinal study. Arch. Gen. Psychiatry 57, 1053-1058.

Read, J., van Os, J., Morrison, A.P., et al., 2005. Childhood trauma, psychosis and schizophrenia: a literature review with theoretical and clinical implications. Acta Psychiatr. Scand. 112, 330-350.

Robins, L.N., Wing, J., Wittchen, H.U., et al., 1988. The composite international diagnostic interview. An epidemiologic instrument suitable for use in conjunction with different diagnostic systems and in different cultures. Arch. Gen. Psychiatry 45, 1069-1077.

Sackett, D.L., Wennberg, J.E., 1997. Choosing the best research design for each question. BMJ 315, 1636.

Semler, G., Wittchen, H.U., Joschke, K., et al., 1987. Test-retest reliability of a standardized psychiatric interview (DIS/CIDI). Eur. Arch. Psychiatr. Neurol. Sci. 236, 214-222.

Smeets, R.M.W., Dingemans, P.M.A.J., 1993. Composite International Diagnostic Interview (CIDI) Versie 1.1. World Health Organisation, Amsterdam.

Spitzer, R.L., Williams, J.B., Gibbon, M., et al., 1992. The Structured Clinical Interview for DSM-III-R (SCID). I: history, rationale, and description0. Arch. Gen. Psychiatry 49, 624-629.

StataCorp, 2005. STATA Statistical Software: Release 9.0. College Station, Texas.

Stefanis, N.C., Hanssen, M., Smirnis, N.K., et al., 2002. Evidence that three dimensions of psychosis have a distribution in the general population. Psychol. Med. 32, 347-358.

Stefanis, N.C., Delespaul, P., Smyrnis, N., et al., 2004a. Is the excess risk of psychosis-like experiences in urban areas attributable to altered cognitive development? Soc. Psychiatry Psychiatr. Epidemiol. 39, 364-368.

Stefanis, N.C., Delespaul, P., Henquet, C., 2004b. Early adolescent cannabis exposure and positive and negative dimensions of psychosis. Addiction 99, 1333-1341. 
Sundquist, K., Frank, G., Sundquist, J., 2004. Urbanisation and incidence of psychosis and depression: follow-up study of 4.4 million women and men in Sweden. Br. J. Psychiatry 184, 293-298.

Valles, V., Van Os, J., Guillamat, R., et al., 2000. Increased morbid risk for schizophrenia in families of in-patients with bipolar illness. Schizophr. Res. 42, 83-90.

Van der Zee, K., Sanderman, R., Heyink, J., 1993. De Psychometrische kwaliteiten van de MOS 36-item Short Form Health Survey (SF36) in een Nederlandse populatie. Tijdschr. Soc. Gezondheidsz. 71, 183-191.

van Os, J., 1996. Risk factor assessment and prevention of psychosis. Ned. Tijdschr. Geneeskd. 140, 1295-1299.

Van Os, J., 2000. Social influences on risk for disorder and natural history. Curr. Opin. Psychiatry 13, 209-213.

Van Os, J., Jones, P.B., 2001. Neuroticism as a risk factor for schizophrenia. Psychol. Med. 31, 1129-1134.

van Os, J., Takei, N., Castle, D.J., et al., 1995. Premorbid abnormalities in mania, schizomania, acute schizophrenia and chronic schizophrenia. Soc. Psychiatry Psychiatr. Epidemiol. 30, 274-278.

Van Os, J., Jones, P., Sham, P., et al., 1998. Risk factors for onset and persistence of psychosis. Soc. Psychiatry Psychiatr. Epidemiol. 33, 596-605.

van Os, J., Driessen, G., Gunther, N., et al., 2000a. Neighbourhood variation in incidence of schizophrenia. Evidence for personenvironment interaction. Br. J. Psychiatry 176, 243-248

Van Os, J., Hanssen, M., Bijl, R.-V., et al., 2000b. Straus (1969) revisited: a psychosis continuum in the general population? Schizophr. Res. 45, 11-20.

van Os, J., Hanssen, M., Bijl, R.V., et al., 2001. Prevalence of psychotic disorder and community level of psychotic symptoms: an urban-rural comparison. Arch. Gen. Psychiatry 58, 663-668.

van Os, J., Bak, M., Hanssen, M., et al., 2002. Cannabis use and psychosis: a longitudinal population-based study. Am. J. Epidemiol. 156, 319-327.

Van Os, J., Hanssen, M., Bak, M., et al., 2003. Do urbanicity and familial liability coparticipate in causing psychosis? Am. J. Psychiatry 160, 477-482.
Van Os, J., Krabbendam, L., Myin-Germeys, I., et al., 2005. The Schizophrenia Envirome. Curr. Opin. Psychiatry 18, 141-145.

Verdoux, H., van Os, J., Maurice-Tison, S., et al., 1998. Is early adulthood a critical developmental stage for psychosis proneness? A survey of delusional ideation in normal subjects. Schizophr. Res. $29,247-254$.

Voglmaier, M.M., Seidman, L.J., Niznikiewicz, M.A., et al., 2000. Verbal and nonverbal neuropsychological test performance in subjects with schizotypal personality disorder. Am. J. Psychiatry 157, 787-793.

Wacker, H.R., Battegay, R., Mullejans, R., et al., 1990. In: Stefanis, C.N., Rabavilas, A.D., Soldatos, C.R. (Eds.), Using the CIDI in the general population. In Psychiatry: a world perspective. Elsevier Science Publishers, Amsterdam, pp. 138-143.

Walss-Bass, C., Escamilla, M.A., Raventos, H., et al., 2005. Evidence of genetic overlap of schizophrenia and bipolar disorder: linkage disequilibrium analysis of chromosome 18 in the Costa Rican population. Am. J. Med. Genet., B Neuropsychiatr. Genet.

Ware, J.E., Gandek, B., Group, I.P., 1994. The SF-36 Health Survey: development and use in mental health research and the IQOLA project. Int. J. Ment. Health 23, 49-73.

Wittchen, H.U., 1994. Reliability and validity studies of the WHOComposite International Diagnostic Interview (CIDI): a critical review. J. Psychiatr. Res. 28, 57-84.

Wittchen, H.U., Robins, L.N., Cottler, L.B., et al., 1991. Cross-cultural feasibility, reliability and sources of variance of the Composite International Diagnostic Interview (CIDI). The Multicentre WHO/ ADAMHA Field Trials. Br. J. Psychiatry 159, 645-653 (658).

Yildiz, A., Sachs, G.S., 2003. Age onset of psychotic versus nonpsychotic bipolar illness in men and in women. J. Affect. Disord. $74,197-201$

Zammit, S., Lewis, G., 2004. Exploring the relationship between cannabis use and psychosis. Addiction 99, 1353-1355. 


\title{
Evidence That Patients With Single Versus Recurrent Depressive Episodes Are Differentially Sensitive to Treatment Discontinuation: A Meta-Analysis of Placebo-Controlled Randomized Trials
}

\author{
Nil Kaymaz, M.D.; Jim van Os, M.D., Ph.D.; \\ Anton J. M. Loonen, M.D., Pharm.D., Ph.D.; and Willem A. Nolen, M.D., Ph.D.
}

Background: Antidepressants are effective in the prevention of relapse after remission from an acute depressive episode. It is unclear, however, to what degree duration of the continuation phase, level of abruptness of antidepressant discontinuation, or the number of previous episodes moderate the prophylactic effect of antidepressants.

Data Sources: Searches were conducted to identify all published randomized, placebocontrolled, double-blind clinical trials available for review by May 2007 on the efficacy of continuation or maintenance treatment of major depressive disorder with either selective serotonin reuptake inhibitors (SSRIs) or tricyclic antidepressants (TCAs) that included patients entering a maintenance phase after achieving remission from the acute phase. The MEDLINE and EMBASE databases were searched using the terms depression, antidepressants, discontinuation, and maintenance treatment; this was followed by reference checks of articles thus identified. In addition, the Cochrane Library was also searched using the same terms. Some authors of the identified papers were contacted for specific data.

Data Synthesis: Data were collected from 30 trials with 4890 participating patients. The overall reduction of relapse risk in the maintenance phase was highly significant for both SSRIs $(\mathrm{OR}=0.24$, $95 \% \mathrm{CI}=0.20$ to 0.29$)$ and TCAs $(\mathrm{OR}=0.29$, $95 \% \mathrm{CI}=0.23$ to 0.38 ) over 1 year of follow-up of maintenance treatment. The prophylactic effect appeared to be constant over the length of the continuation phase. Recurrent episode patients experienced less protection from antidepressants over the maintenance phase $(\mathrm{OR}=0.37,95 \%$ $\mathrm{CI}=0.31$ to 0.44$)$ than single episode patients $(\mathrm{OR}=0.12,95 \% \mathrm{CI}=0.06$ to 0.26$)$.

Conclusions: Antidepressants robustly reduce relapse risk in the maintenance phase, regardless of a number of clinical and pharmacologic factors. There is evidence, however, that with increasing number of episodes, patients develop a relative resistance against the prophylactic properties of antidepressant medication.

( J Clin Psychiatry 2008;69:1423-1436)
Received Nov. 28, 2006; accepted Dec. 16, 2007. From the Department of Psychiatry, University of Maastricht, Maastricht, the Netherlands (Drs. Kaymaz and van Os); the Department of Pharmacy, Division of Pharmacotherapy and Pharmaceutical Care (Dr. Loonen) and the Department of Psychiatry, University Medical Center Groningen (Dr. Nolen), University of Groningen, Groningen, the Netherlands; and the Division of Psychological Medicine, Institute of Psychiatry, London, United Kingdom (Dr. van Os).

The authors thank the anonymous referees for their detailed and extremely helpful comments on earlier versions of the manuscript.

Dr. van Os has received grants from or is a speaker for Eli Lilly, Bristol-Myers Squibb, Lundbeck, Organon, Janssen-Cilag,

GlaxoSmithKline, Otsuka, and AstraZeneca. Dr. Loonen is a speaker or advisory board member for Eli Lilly, Bristol-Myers Squibb, Lundbeck, Janssen-Cilag, Wyeth, Bional, and AstraZeneca. Dr. Nolen has received grants from the Netherlands Organization for Health Research and Development, Netherlands Organization for Scientific Research, Stanley Medical Research Institute, AstraZeneca, Eli Lilly, GlaxoSmithKline, and Wyeth and is a speaker or advisory board member for AstraZeneca, Cyberonics, Eli Lilly, GlaxoSmithKline, Johnson \& Johnson, Pfizer, and Servier. Dr. Kaymaz reports no financial or other relationship relevant to the subject of this article.

Corresponding author and reprints: Prof. Willem A. Nolen, M.D., Ph.D., Department of Psychiatry 5.17, University Medical Center Groningen, P.O. Box 30.0001, 9700 RB Groningen, the Netherlands (e-mail:w.a.nolen@psy.umcg.nl).

D epression often manifests itself as a chronic or a recurrent illness; $15 \%$ to $20 \%$ of depressed patients experience a chronic course, and $75 \%$ to $80 \%$ of patients experience recurrent episodes. ${ }^{1,2}$ Therefore, treatment should focus not only on improving symptoms of the acute episode but also on the prevention of relapse (return of symptoms of the index episode) and recurrence (the development of a subsequent episode). ${ }^{3}$ The efficacy of antidepressants in treating acute episodes (4-6 and up to 12 weeks) has been well established in placebocontrolled studies, although the effect sizes for antidepressant treatment are only moderately larger than for placebo. ${ }^{4,5}$ Moreover, antidepressants are effective in longterm treatment. In a 2003 meta-analysis of 31 randomized trials (4410 participants), Geddes et al. ${ }^{6}$ showed that continuing antidepressant therapy consistently reduced the risk of relapse and recurrence by $70 \%$ compared with continuation with placebo, and this seemed to be similar for all classes of antidepressants. They also found no differences in relapse and recurrence rates between patients 
with shorter (1-2 months) and longer (4-6 months) treatment after having achieved remission and prior to randomization or between patients with relatively short (6 months) versus longer (up to 36 months) follow-up, suggesting that the reduced risk is largely independent of the duration of treatment before randomization and the duration of the randomly allocated therapy.

Besides the question of how long treatment should be continued once remission has been attained, another important question facing clinicians in their daily practice is, first, to what degree do patients with multiple episodes acquire additional vulnerabilities that could make them more vulnerable not only to discontinuation of the antidepressant per se, but also to the mode of discontinuation (gradual or acute)? The rationale for such a distinction between single and multiple episode patients was proposed by Post and colleagues ${ }^{7}$ in an attempt to account for several phenomena observed in the course of affective illness; they emphasized the importance of preventing episodes with prophylactic treatment to inhibit sensitization. According to the sensitization model, a subgroup of patients exists who with each recurrent episode becomes more vulnerable, or "sensitized," to affective episode precipitants. The authors suggested that these patients show characteristics of a sensitization or kindling-like process, in which the biochemical and physiologic processes involved in the illness become progressively more easily triggered by the same circumstances or precipitants compared to the first episode.

Therefore, in the literature on relapse prevention by antidepressants, several questions remain unanswered. It is unclear (1) how long treatment should be continued after remission is achieved (e.g., 6 months, 1 year, longer?), (2) whether treatment should be continued longer in patients with multiple episodes compared to single episodes, and (3) how the antidepressant should be discontinued: can it be done abruptly or within 1 week, or should it be tapered off gradually for 1 or more weeks? In the present study, these questions were addressed, with the hypothesis that multiple episode patients would be more sensitive to antidepressant discontinuation, in particular abrupt discontinuation.

\section{METHOD}

In 1988, the MacArthur Foundation Research Network on the Psychobiology of Depression convened a task force to examine the ways in which change points in the course of depressive illness until that time had been described and the extent to which inconsistencies in these descriptions might hinder research on this disorder. ${ }^{8}$ Consistent conceptualization and empirical validation of these terms were considered desirable for the following reasons: (1) to be able to improve design, interpretation, and comparison of studies on natural course and treatment;
(2) to be able to clarify the relationship between biological and psychological correlates of illness; (3) to create improved guidelines for evaluation of clinical efficacy of drugs and other treatments by regulatory agencies; (4) to be able to conduct empirically based revisions of diagnostic criteria; and (5) to be able to develop improved treatment guidelines for clinical practice. Guided by these statements, the following definitions were constructed.

\section{Definitions}

In the literature, the terms response, remission, relapse, and recurrence and the terms describing the different treatment phases (acute treatment, continuation treatment, and maintenance treatment) are not uniformly defined. In this article, the definitions by Frank and colleagues ${ }^{8}$ were followed. The first phase in treatment is acute treatment, aimed at the suppression of the depressive symptoms. Response is defined as a clinically significant reduction of symptoms of depression (e.g., at least $50 \%$ reduction of the score on the Hamilton Rating Scale for Depression [HAM-D]), and remission is defined as the remaining of no or only minimal symptoms of depression (e.g., a score of less than 9 points on the HAM-D). During the first 6 months after remission is achieved, the underlying illness may still be present and discontinuation of the treatment can cause reappearance of symptoms of the original episode; this is called a relapse. In this context, continuation treatment is the term applied to the prevention of a relapse, i.e., the treatment phase during the first 6 months after having achieved remission. After these 6 months of remission, the underlying disorder is considered resolved, and when a new depressive episode appears after this period, it is called recurrence. The term maintenance treatment is applied for a treatment with antidepressants that aims at the prevention of a recurrence.

\section{Types of Studies}

We wished to identify all published randomized, placebo-controlled, double-blind clinical trials available for review by May 2007 on the efficacy of continuation or maintenance treatment of major depressive disorder with either selective serotonin reuptake inhibitors (SSRIs) or tricyclic antidepressants (TCAs) (the 2 groups of comparable and widely used antidepressants with the largest number of trials) in patients who had achieved remission during acute treatment with these antidepressants.

\section{Search Strategy for Identification of Studies}

A MEDLINE and EMBASE computerized search using the terms depression, antidepressants, discontinuation, and maintenance treatment was conducted and was supplemented with references cited in reports so identified (reference checking). In addition, the Cochrane Library was also searched using the same terms. Some authors of the identified papers were contacted for specific data. 


\section{Types of Participants}

Trials were eligible for the review if they included patients with major depressive disorder, single or recurrent episode, who were treated with an antidepressant (SSRI or TCA) until remission was attained. These patients had then to be followed up during the continuation and subsequent maintenance phases.

\section{Types of Interventions}

Patients obtaining remission and entering the continuation or the maintenance phase had to be randomly divided into at least 2 groups, with at least 1 group receiving active treatment with an antidepressant (SSRI or TCA) and another group receiving placebo, under double-blind conditions.

\section{Data Selection}

The search results and the data extracted from the trial reports on participant characteristics, intervention details, and outcome measures were checked by 2 reviewers (N.K. and A.J.M.L.) before analyses. When specific data were not given in the report, the authors were contacted; some authors responded to the 2 efforts we made to contact them, and some did not.

Data were entered into the STATA, version 9, software program (StataCorp, 2005) ${ }^{9}$ for further analyses.

\section{Methodological Quality of Included Studies}

The assessment of the methodological quality of the trials was carried out by 2 reviewers (N.K. and A.J.M.L.) who used the same checklist. The most crucial aspects of the included trials for the internal validity were (1) the method of randomization and achievement of a doubleblind condition and (2) the reporting of withdrawals and dropout rates and use of a suitable survival analysis.

\section{Data Aggregation}

The following data were extracted and tabulated from each paper (see Table 1): number of previous episodes, duration of active treatment, duration of stabilization/ continuation treatment, number of subjects, duration of follow-up, and duration of withdrawal of medication. Besides these tabulated data, the numbers of individuals at risk over each follow-up interval (at 3, 6, 9, and 12 months) were extracted from the publications whenever they were mentioned or, if they were not, from the survival curves in these publications.

\section{Data Analysis}

Data from the selected randomized controlled trials were combined to estimate the pooled odds ratio (OR) with $95 \%$ confidence intervals (CIs) using a randomeffects model. The presence of heterogeneity across trials was evaluated using a $\chi^{2}$ test for homogeneity, testing whether individual trials results varied more than could be explained by chance alone. When significant heterogeneity was found, possible causes were explored. In addition, meta-regression was used to assess the degree to which important clinical and study quality factors impacted on the meta-analytic results. Meta-regression extends a random-effects meta-analysis to estimate the extent to which 1 or more covariates, with values defined for each study in the analysis, explain heterogeneity in the treatment effects. In meta-regression, the log odds ratio, representing the antidepressant effect size, is regressed on the variables that are hypothesized to explain heterogeneity in the treatment effects.

Potential publication bias was tested for using Begg's test for asymmetry.

As to the question of effectiveness of continuation and maintenance treatment with antidepressants, relapse/ recurrence rates after randomization to either continuation of the antidepressant or switch to placebo were compared, whenever possible, over a 1-year follow-up period separately at $3,6,9$, and 12 months. If relapse/recurrence rates at these assessment points were not presented in the results of the publication, they were calculated when possible, e.g., by estimating these rates from the survival curves that were presented as figures in most of the publications. The effect of time at follow-up on relapse/recurrence rates was examined using meta-regression analysis with time at follow-up (3, 6, 9, or 12 months) as independent variable and the log odds ratio representing antidepressant effect size as the dependent variable. In order to compile the dataset for this analysis, each study with data (i.e., number of relapses/recurrences) at 3, 6, 9, and 12 months was separated into 4 different studies of 3 months' duration each with the variable "time" denoting whether follow-up was at $3,6,9$, or 12 months. This way, the effect of time on relapse rate could be assessed in the meta-regression of the effect sizes, using the STATA meta-regression routine in STATA (StataCorp, 2005, version 9). ${ }^{9}$ Using this dataset, controlling for time, meta-regression was also applied to investigate whether duration of continuation treatment, after achievement of remission, was associated with the risk of relapse/recurrence after discontinuation of antidepressants. To this end, studies were subdivided according to the duration of continuation treatment prior to randomization as follows: less than 1 month, 1 to 3 months, $>3$ to 6 months, and $>6$ months (i.e., beyond the continuation phase of 6 months recommended by the guidelines).

Similarly, meta-regression, controlling for time, was used to examine whether mode of discontinuation in controlled studies affected relapse rates by comparing abrupt discontinuation $(<1$ week) with gradual discontinuation (tapering for $\geq 1$ week).

Finally, meta-regression, controlling for time, was used to assess whether clinical features such as the number of previous episodes moderated relapse rates. To this end, the studies were subdivided further into those involving 
patients with no previous episode of depression versus those involving patients with multiple episodes, i.e., at least 1 previous episode prior to the index episode. As we had hypothesized that the patients most sensitive to the antidepressant discontinuation would be those with the combination of multiple episodes and an abrupt mode of discontinuation, a number of previous episodes-by-mode of discontinuation interaction term was fitted in the metaregression model.

In the event that a variable in the meta-regression was found to impact significantly on the meta-analytic result, separate meta-analyses were carried out for the different strata of this variable, so as to clarify the direction and magnitude of group differences in effect size.

A test for selection bias was carried out, visualizing the included studies in a Begg's funnel plot with pseudo $95 \%$ confidence limits.

\section{RESULTS}

\section{Identified Studies}

The search process yielded 44 studies possibly satisfying the inclusion criteria, i.e., the continuation/ maintenance treatment was with either an SSRI or a TCA. Fourteen studies were excluded due to methodological limitations: 1 because the study was single blind, ${ }^{10} 4$ because there was no placebo control group, ${ }^{11-14} 1$ because the antidepressant in the acute or continuation phase was not the same antidepressant as in the maintenance phase, ${ }^{15}$ 4 because lithium was added during the acute phase to achieve remission, ${ }^{16-19} 1$ because the study was not formally published, ${ }^{20}$ and 1 because patients with bipolar disorder were also included. ${ }^{21}$ We also excluded 1 study ${ }^{22}$ of maintenance treatment with a 5-year follow-up as it included patients who were also part of the 3-year maintenance study by Frank et al. ${ }^{45}$ One study (McGrath et al.$^{23}$ ) was excluded as it did not mention the number of relapses separately for the medication and placebo arms in this study. Only the active treatment arms, without crossover, and the placebo arm of the studies with different assignment groups in which relapse rates are mentioned separately for the different arms of the study were included.

The characteristics of the 30 studies included in this meta-analysis are listed in Table $1 .{ }^{24-53}$ Some of the studies were 4-armed or 5-armed studies, in which medication was compared to psychotherapy or their combination; from these studies, we only included data from the medication arm and the placebo arm. The 30 trials involved a total of 4890 patients, performed in both primary and secondary care settings, and described 2749 patients who continued with the antidepressant and 2141 patients who were switched to placebo. Fifteen studies were found in which the allocated drug was an SSRI, with a total of 2984 patients, and 15 studies were found in which the allocated drug was a TCA, with a total of 1906 patients.
There were no 3-arm studies with 2 medication arms (e.g., both an SSRI and a TCA) versus placebo.

\section{Duration of Continuation Phase}

In order to examine the impact of the prerandomization period (e.g., the duration of the continuation phase), studies were divided in 4 subgroups with a duration of less than 1 month, 1 to 3 months, $>3$ to 6 months of continuation phase, and $>6$ months of continuation plus maintenance phase.

In the subgroup of trials with a continuation treatment of less than 1 month (i.e., remission achieved for less than 1 month) prior to randomization, 9 trials (1261 patients in total) were found, and of these, 7 trials (954 patients) provided information at 3 months of follow-up, 6 trials (727 patients) provided information at 6 months of follow-up, 3 trials (339 patients) provided information at 9 months of follow-up, and 2 trials (101 patients) provided information at 12 months of follow-up. In the subgroup of trials with 1 to 3 months of continuation treatment prior to randomization, 2 trials (95 patients) provided information at 3 (85 patients), 6 (70 patients), 9 (63 patients), and 12 (59 patients) months of follow-up. In the subgroup of trials with $>3$ to 6 months of continuation treatment prior to randomization, 17 trials (3194 patients in total) were found, and of these 17 trials, 14 (2384 patients) provided information at 3 months of follow-up, 13 trials (2104 patients) at 6 months of follow-up, 11 trials (1846 patients) at 9 months of follow-up, and 9 trials (1547 patients) at 12 months of follow-up. Only 1 study was found (Bialos et al. $^{38}$ ) with a clearly mentioned treatment period prior to randomization of more than 6 months. Another study, by Cook et al., ${ }^{42}$ had a duration of 52 weeks, but did not clarify how long the duration of the acute and continuation treatment lasted. These publications were included in the subgroup of studies with a prerandomization period of 3 to 6 months. To examine the impact of time at followup (3, 6, 9, and 12 months) on relapse/recurrence rates, we have used meta-regression analysis on pooled results of 30 trials in total (4890 patients) (see Figure 2), 23 trials (3441 patients) providing information at 3 months of follow-up (see Figure 3), 21 trials (2914 patients) at 6 months of follow-up (see Figure 4), 16 trials (2259 patients) at 9 months of follow-up (see Figure 5), and 8 trials (1710 patients) at 12 months of follow-up (see Figure 6).

\section{Number of Previous Depressive Episodes}

With regard to the number of episodes prior to the index period, 4 trials (301 participants) included patients with no prior episodes, and 17 trials (2939 participants) included patients with at least 1 episode prior to the index episode. The remaining 9 studies of the total of 30 were left out of the analysis, because some studies included both single- and recurrent episode patients. Some studies 
Table 1. Characteristics of the Included Studies

\begin{tabular}{|c|c|c|c|c|}
\hline Study & Diagnosis & Diagnostic Criteria & No. of Previous Episodes & $\begin{array}{l}\text { Treatment Phas } \\
\text { (wk) }\end{array}$ \\
\hline Montgomery et al, $1988^{24}$ & MDD & DSM-III & $\geq 2$ & 6 \\
\hline Doogan and Caillard, $1992^{25}$ & MDD & DSM-III-R & Not reported & 8 \\
\hline Montgomery and Rasmussen, $1992^{26}$ & MDD & DSM-III-R & Not reported & 6 \\
\hline Montgomery and Dunbar, $1993^{27}$ & MDD & DSM-III-R & $\geq 2$ & 8 \\
\hline Robert and Montgomery, $1995^{28}$ & MDD & DSM-III-R & $\geq 2$ & 8 \\
\hline Keller et al, $1998^{29}$ & $\begin{array}{l}\text { Chronic depression, } \\
\text { MDD, double depression }\end{array}$ & DSM-III-R, HAM-D & Mixed & 12 \\
\hline Reimherr et al, $1998^{30}$ & MDD & DSM-III-R & Not reported & $12-14$ \\
\hline Terra and Montgomery, $1998^{31}$ & MDD & DSM-III-R & $\geq 2$ & 6 \\
\hline Hochstrasser et al, $2001^{32}$ & MDD & DSM-IV & $\geq 2$ & $6-9$ \\
\hline Klysner et al, $2002^{33}$ & MDD & DSM-IV & 0 & 8 \\
\hline Mindham et al, $1972^{34}$ & Depression & MRC & Not reported & $3-10$ \\
\hline Klerman et al, $1974^{35}$ & Depression & DSM-II & 0 & $4-6$ \\
\hline Coppen et al, $1978^{36}$ & Depression & $\mathrm{MRC}$ & 11 patients $=0 ; 21$ patients $\geq 1$ & Not reported \\
\hline Stein et al, $1980^{37}$ & MDD & Feighner $^{\mathrm{b}}$ & $\geq 1$ & 6 \\
\hline Bialos et al, $1982^{38}$ & Depression & RDC & Chronic depression & Not reported \\
\hline Kane et al, $1982^{39}$ & Depression & RDC & $\geq 2$ & Not reported \\
\hline Glen et al, $1984^{40}$ & Depression & MRC & 0 & Average $81 / 2$ \\
\hline Prien et al, $1984^{41}$ & Depression & RDC & $\geq 1$ & Not reported \\
\hline Cook et al, $1986^{42}$ & MDD & RDC & $\geq 1$ & Not reported \\
\hline Georgotas et al, $1989^{43}$ & MDD & RDC & $\geq 3$ & $7-9$ \\
\hline Rouillon et al, $1989^{44}$ & MDD & DSM-III & $\geq 1$ & 8 \\
\hline Frank et al, $1990^{45}$ & Depression & RDC & $\geq 2$ & Not reported \\
\hline OADIG, $1993^{46}$ & MDD & RDC & $50 \%=1 ; 50 \% \geq 1$ & 16 \\
\hline Reynolds et al, $1999^{47}$ & MDD & RDC & Average 5 & Not reported \\
\hline Alexopoulos et al, $2000^{48}$ & MDD & RDC, DSM-IV & Most $=1$ or $>2$ & Not reported \\
\hline Wilson et al, $2003^{49}$ & MDD & DSM-III-R, HAM-D & 0 & 8 \\
\hline Gilaberte et al, $2001^{50}$ & MDD & DSM-III-R & $\geq 1$ & 8 \\
\hline Schmidt et al, $2000^{51}$ & MDD & DSM-IV & Mixed & 13 \\
\hline McGrath et al, $2006^{52}$ & MDD & DSM-IV & Chronic depression & 12 \\
\hline Perahia et al, $2006^{53}$ & MDD & DSM-IV & $\geq 1$ & 12 \\
\hline
\end{tabular}

${ }^{\mathrm{a}}$ Major depression with antecedent dysthymic disorder.

${ }^{\mathrm{b}}$ Feighner et al. 1972 criteria.

Abbreviations: CGI = Clinical Global Impressions scale, CGI-S = Clinical Global Impressions-Severity of Illness scale,

GAS = Global Assessment Scale, HAM-D = Hamilton Rating Scale for Depression, MADRS = Montgomery-Asberg Depression Rating Scale,

included only patients with a chronic depressive disorder or did not specify the number of previous episodes.

\section{Mode of Discontinuation of the Antidepressant}

Antidepressant medication was discontinued abruptly ( $<1$ week) in 22 trials (4320 participants) and gradually ( $\geq 1$ week) in 8 trials (630 participants). No studies were found that included both abrupt and gradual discontinuation.

\section{Publication Bias}

The distribution of effect size-related measures relative to sample size-related measures did not suggest publication bias in the studies used for this meta-analysis (Figure 1).

\section{Treatment Effects}

Overall, the results showed that continuing antidepressant therapy consistently reduced the risk of relapse $(\mathrm{OR}=0.30,95 \% \mathrm{CI}=0.25$ to $0.35, \mathrm{p}<.001)$ compared to placebo (Figure 2), with no significant heterogeneity detected $\left(\chi^{2}=40.21\right.$, df $\left.=29, p=.081\right)$. This effect was highly significant for SSRIs (OR $=0.24,95 \% \mathrm{CI}=0.20$ to $0.29, \mathrm{p}<.001)$ as well as for TCAs $(\mathrm{OR}=0.29,95 \%$ $\mathrm{CI}=0.23$ to $0.38, \mathrm{p}<.001)$.

Using meta-regression, the overall relapse-reducing effects of the SSRIs were not significantly different from those of the TCAs (meta-regression coefficient $=-0.30$, $95 \% \mathrm{CI}=-0.78$ to $0.17, \mathrm{p}=.209$ ). However, it should be noted that none of the studies involved (next to placebo) a head-to-head comparison of TCAs versus SSRIs. 


\begin{tabular}{|c|c|c|c|c|}
\hline $\begin{array}{l}\text { Duration of Stabilization/ } \\
\text { Continuation Phase } \\
\text { (prerandomization phase) } \\
\text { (wk) }\end{array}$ & No. of Patients in Trial & Criteria for Relapse/Recurrence & $\begin{array}{c}\text { Duration of } \\
\text { Follow-Up (mo) }\end{array}$ & $\begin{array}{l}\text { Withdrawal of } \\
\text { Medication (wk) }\end{array}$ \\
\hline 24 & Fluoxetine $=88$, placebo $=94$ & HAM-D > 18 & 12 & $<1$ \\
\hline 0 & Sertraline $=185$, placebo $=110$ & Clinical criteria, $\mathrm{CGI} \geq 4$ & 11 & 3 \\
\hline 0 & Citalopram $=105$, placebo $=42$ & MADRS $\geq 22$ & 6 & $<1$ \\
\hline 0 & Paroxetine $=68$, placebo $=67$ & $\mathrm{CGI} \geq 4$, clinical criteria & 12 & $<1$ \\
\hline 0 & Citalopram $=152$, placebo $=74$ & MADRS $\geq 25$, clinical criteria & 6 & $<1$ \\
\hline 16 & Sertraline $=77$, placebo $=84$ & $\begin{array}{l}\text { DSM-III criteria for at least } 3 \mathrm{wk} \text {, } \\
\text { CGI } \geq 4 \text {, HAM-D } \geq 4 \text { points higher } \\
\text { than maintenance phase baseline }\end{array}$ & 19 & Maximum 3 \\
\hline 0 & Fluoxetine $=102$, placebo $=96$ & $\begin{array}{l}\text { HAM-D } \geq 14 \text { for } 3 \text { successive wk, } \\
\text { DSM criteria for minimum } 2 \mathrm{wk}\end{array}$ & $12^{1 / 2}$ & $<1$ \\
\hline 18 & Fluvoxamine $=109$, placebo $=94$ & Clinical criteria & 12 & $<1$ \\
\hline 16 & Citalopram $=132$, placebo $=132$ & $\begin{array}{l}\text { MADRS } \geq 22 \text { confirmed at } 3-7 \mathrm{~d}, \\
\quad \mathrm{CGI} \geq 5\end{array}$ & $12-19$ & $<1$ \\
\hline 16 & Citalopram $=60$, placebo $=61$ & MADRS $\geq 22$ & 12 & $<1$ \\
\hline 0 & Amitriptyline $=50$, placebo $=42$ & Clinical criteria on monthly screenings & 6 & $<1$ \\
\hline 0 & Amitriptyline $=25$, placebo $=25$ & Clinical criteria & 8 & $<1$ \\
\hline 6 & Amitriptyline $=16$, placebo $=16$ & $\begin{array}{l}\text { Increase in symptoms sufficient } \\
\text { to warrant hospital admission }\end{array}$ & 12 & $<1$ \\
\hline 2 & Amitriptyline $=28$, placebo $=27$ & Clinical criteria & 6 & $<1$ \\
\hline 192 & Amitriptyline $=7$, placebo $=10$ & Clinical criteria & 6 & 3 \\
\hline 24 & Imipramine $=6$, placebo $=6$ & RDC, clinical criteria & 24 & $<1$ \\
\hline 0 & Amitriptyline $=8$, placebo $=9$ & Clinical criteria & 36 & 2 \\
\hline Not reported & Imipramine $=39$, placebo $=34$ & RDC, GAS $\leq 60$, clinical criteria & 24 & $<1$ \\
\hline$\geq 52$ & $\mathrm{TCA}=6$, placebo $=9$ & Clinical criteria & 8 & $4-8$ \\
\hline 16 & Nortriptyline $=13$, placebo $=23$ & RDC, HAM-D $\geq 16$ & 12 & $<1$ \\
\hline 24 & Maprotiline $=767$, placebo $=374$ & MADRS $>27$ or $>25$ for $2 \mathrm{wk}$ & 12 & $<1$ \\
\hline 17 & Imipramine $=28$, placebo $=23$ & RDC, HAM-D $\geq 15$, Raskin $\geq 7$ & 36 & $<1$ \\
\hline 8 & Dothiepin $=33$, placebo $=36$ & MADRS $>10$, clinical criteria & 24 & $<1$ \\
\hline 16 & Nortriptyline $=28$, placebo $=29$ & $\mathrm{RDC}$ & 36 & 6 \\
\hline 16 & Nortriptyline $=22$, placebo $=21$ & RDC, DSM-IV criteria, HAM-D $\geq 17$ & 24 & 10 \\
\hline $16-20$ & Sertraline $=56$, placebo $=57$ & HAM-D $\geq 13$, DSM-III-R clinical criteria & 24 & $<1$ \\
\hline 24 & Fluoxetine $=70$, placebo $=70$ & HAM-D $\geq 18$, CGI $\geq 4$, DSM-III-R & 12 & $<1$ \\
\hline Not reported & Fluoxetine $=189$, placebo $=122$ & $\begin{array}{l}\text { Criteria for depressive episode determined } \\
\text { by the SCID-P, CGI-S } \geq 2\end{array}$ & 25 & $<1$ \\
\hline 24 & Fluoxetine $=131$, placebo $=131$ & $\begin{array}{l}2 \text { wk of ratings of less than } \\
\text { "much improved" on the CGI, } \\
\text { compared with ratings at study entry }\end{array}$ & 8 & $<1$ \\
\hline 24 & Duloxetine $=136$, placebo $=142$ & $\begin{array}{l}\text { CGI } \geq 2 \text { compared to baseline } \\
\text { MINI criteria for MDD }\end{array}$ & $1 / 2$ & 1 \\
\hline
\end{tabular}

Comparing the relapse rates as a function of time at follow-up revealed that antidepressants at 3 months of follow-up significantly reduced relapse rates compared to placebo $(\mathrm{OR}=0.25,95 \% \mathrm{CI}=0.17$ to $0.36, \mathrm{p}<.001)$ (Figure 3). At further follow-up, this remained unchanged at 6 months $(\mathrm{OR}=0.19,95 \% \mathrm{CI}=0.13$ to $0.29, \mathrm{p}<.001)$, at 9 months $(\mathrm{OR}=0.29,95 \% \mathrm{CI}=0.21$ to $0.40, \mathrm{p}<.001)$, and at 12 months $(\mathrm{OR}=0.27,95 \% \mathrm{CI}=0.12$ to 0.60 , $\mathrm{p}=.001$ ) (Figures 4-6). Meta-regression confirmed this result: with longer follow-up, there was no significant additive relapse-reducing effect, neither at 6 months compared to the first 3 months (meta-regression coefficient $=-0.24,95 \% \mathrm{CI}=-0.77$ to $0.28, \mathrm{p}=.367$ ), nor at 9 months compared to the first 3 months (meta-regression coefficient $=0.14,95 \% \mathrm{CI}=-0.44$ to $0.72, \mathrm{p}=.635)$,
Figure 1. Begg's Funnel Plot With Pseudo 95\% Confidence Limits

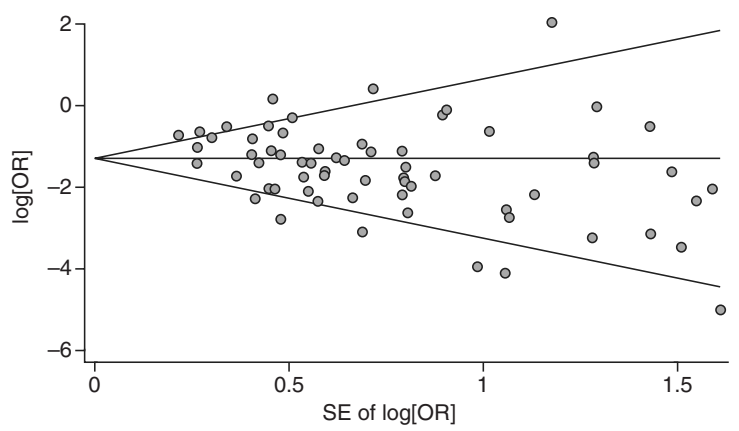

Abbreviation: $\mathrm{OR}=$ odds ratio. 


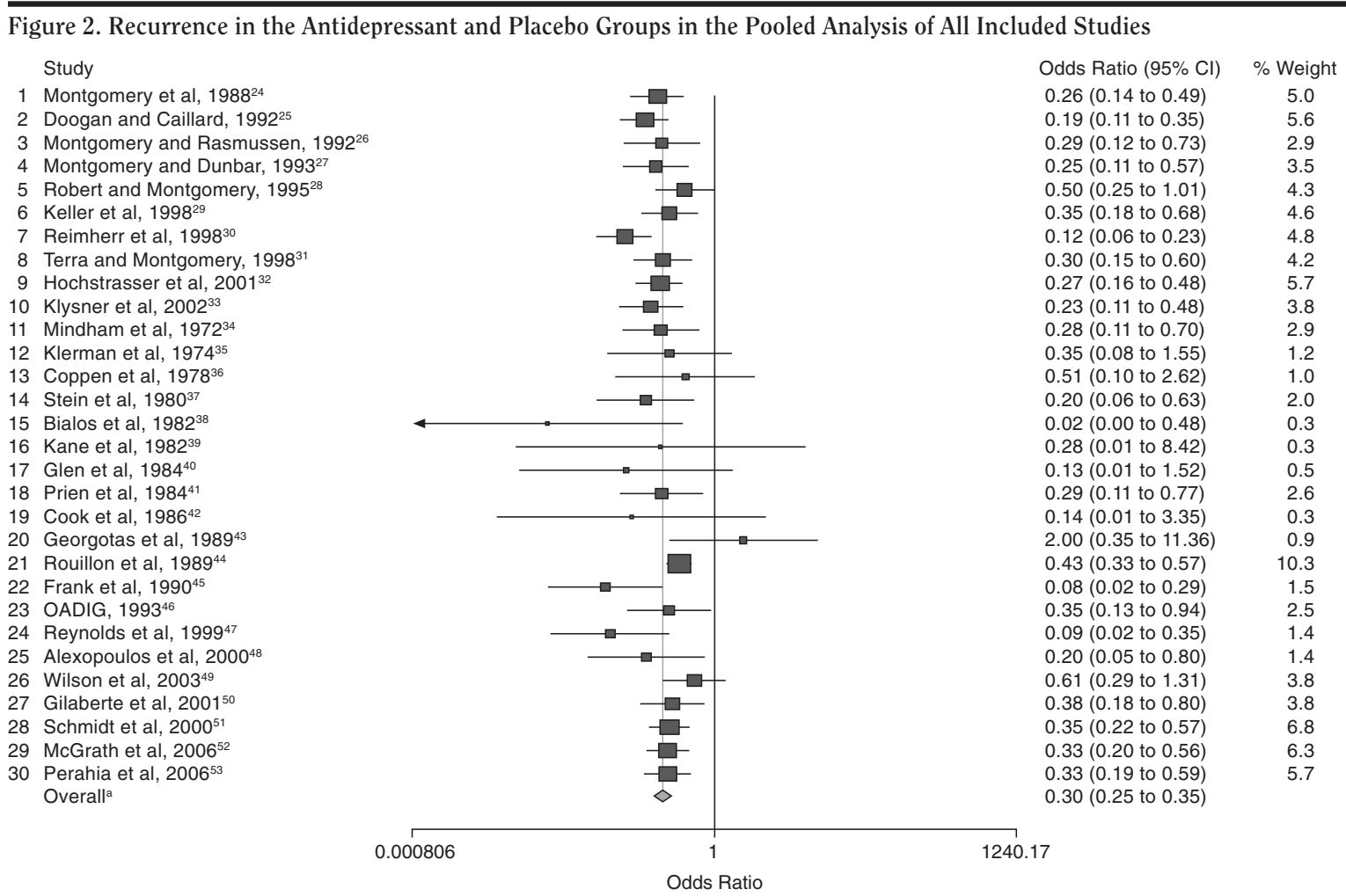

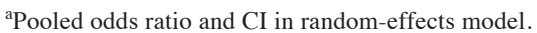

Abbreviations: $\mathrm{CI}=$ confidence interval, $\mathrm{OADIG}=$ Old Age Depression Interest Group.

nor at 12 months compared to the first 3 months (metaregression coefficient $=0.10,95 \% \mathrm{CI}=-0.65$ to 0.85 , $\mathrm{p}=.790)$.

\section{Duration of Continuation Phase}

In meta-regression, the prerandomization periods of 1 to 3 months and of $>3$ to 6 months after achievement of remission showed no significantly different relapsereducing effect of the antidepressant compared to a prerandomization treatment period of less than 1 month (meta-regression coefficient $=0.41,95 \% \mathrm{CI}=-0.73$ to $1.57, \mathrm{p}=.478$ and meta-regression coefficient $=0.20$, $95 \% \mathrm{CI}=-0.26$ to $0.68, \mathrm{p}=.389$, respectively).

\section{Number of Previous Depressive Episodes}

The meta-regression comparing patients with recurrent episode(s) versus those with a single episode revealed a significant positive regression coefficient, indicating less antidepressant benefit for patients with recurrent episodes (meta-regression coefficient $=1.6,95 \% \mathrm{CI}=0.60$ to $2.59, \mathrm{p}=.002$ ). Meta-analyses stratified for this variable revealed that the pooled OR for relapse in single episode patients was considerably lower $(\mathrm{OR}=0.12,95 \%$
$\mathrm{CI}=0.06$ to $0.26, \mathrm{p}<.001)$, without significant heterogeneity $\left(\chi^{2}=10.79\right.$, df $\left.=7, p=.148\right)$, compared to the OR for relapse in recurrent episode patients $(\mathrm{OR}=0.37,95 \%$ $\mathrm{CI}=0.31$ to $0.44, \mathrm{p}<.001)$, also without significant heterogeneity $\left(\chi^{2}=23.15\right.$, df $\left.=22, p=.393\right)$.

\section{Mode of Discontinuation of the Antidepressant}

With regard to the question of possible moderation of the effect size of antidepressant as a function of mode of discontinuation of the antidepressant, it was found that the relapse rates in studies with gradual discontinuation of the antidepressant (i.e., $\geq 1$ week) were not different from those in studies with abrupt discontinuation (i.e., $<1$ week) (meta-regression coefficient $=-0.56,95 \% \mathrm{CI}=$ -1.37 to $0.24, \mathrm{p}=.174)$.

\section{Interaction Between the Number of Previous Episodes and Mode of Discontinuation of the Antidepressant}

In the meta-regression, there was a significant positive interaction between the variables number of previous episodes and mode of discontinuation (meta-regression coefficient $=2.15,95 \% \mathrm{CI}=1.01$ to $3.29, \mathrm{p}<.001$ ). Thus, in the recurrent episode patients, abrupt discontinuation was 
Figure 3. Recurrence in the Antidepressant and the Placebo Groups in the Pooled Analysis at 3 Months of Follow-Up in the Maintenance Treatment

\author{
Study \\ 1 Montgomery et al, $1988^{24}$ \\ 2 Doogan and Caillard, $1992^{25}$ \\ 3 Montgomery and Rasmussen, $1992^{26}$ \\ 4 Montgomery and Dunbar, $1993^{27}$ \\ 5 Robert and Montgomery, $1995^{28}$ \\ 6 Keller et al, $1998^{29}$ \\ 7 Reimherr et al, $1998^{30}$ \\ 8 Terra and Montgomery, $1998^{31}$ \\ 9 Hochstrasser et al, 200132 \\ 10 Klysner et al, $2002^{33}$ \\ 11 Mindham et al, $1972^{34}$ \\ 17 Glen et al, $1984^{40}$ \\ 18 Prien et al, $1984^{41}$ \\ 20 Georgotas et al, $1989^{43}$ \\ 21 Rouillon et al, $1989^{44}$ \\ 22 Frank et al, $1990^{45}$ \\ 23 OADIG, $1993^{46}$ \\ 24 Reynolds et al, $1999^{47}$ \\ 25 Alexopoulos et al, $2000^{48}$ \\ 26 Wilson et al, $2003^{49}$ \\ 27 Gilaberte et al, $2001^{50}$ \\ 29 McGrath et al, $2006^{52}$ \\ 30 Perahia et al, $2006^{53}$ \\ Overalla $^{a}$
}

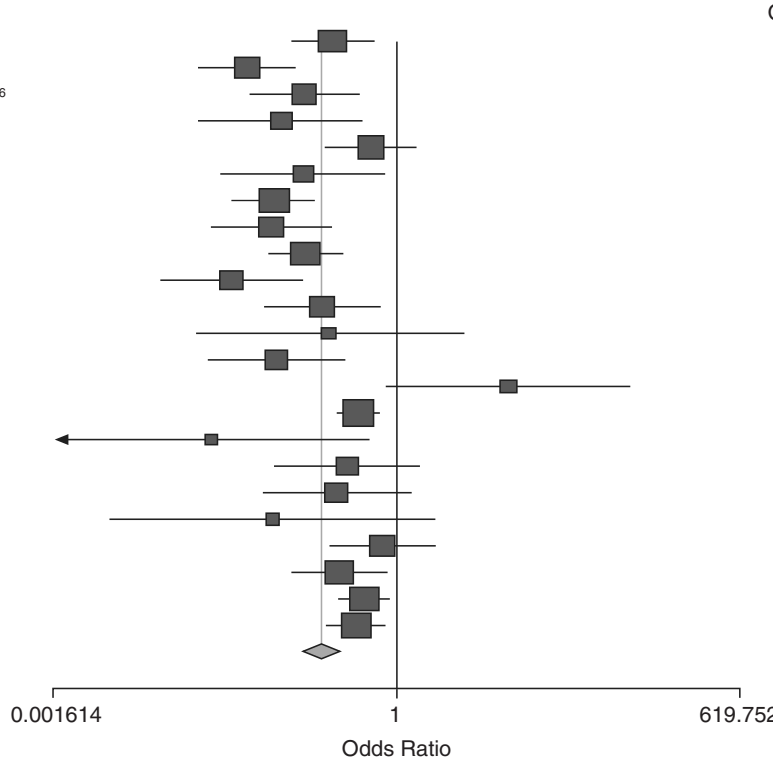

Odds Ratio $(95 \% \mathrm{Cl}) \quad \%$ Weight

$0.30(0.14$ to 0.67$) \quad 5.7$

$0.06(0.02$ to 0.16$) \quad 5.2$

$0.18(0.06$ to 0.51$) \quad 4.7$

$0.11(0.02$ to 0.54$) \quad 3.2$

$0.61(0.25$ to 1.46$) \quad 5.4$

$0.17(0.04$ to 0.82$) \quad 3.2$

$0.10(0.05$ to 0.23$) \quad 5.7$

$0.10(0.03$ to 0.29$) \quad 4.5$

0.18 (0.09 to 0.37$) \quad 6.0$

$0.05(0.01$ to 0.17$) \quad 3.8$

$0.25(0.08$ to 0.73$) \quad 4.6$

0.29 (0.02 to 3.52$) \quad 1.7$

$0.11(0.03$ to 0.39$) \quad 3.9$

$8.00(0.80$ to 79.65$) \quad 1.9$

$0.49(0.32$ to 0.74$) \quad 7.1$

$0.03(0.00$ to 0.60$) \quad 1.3$

$0.40(0.10$ to 1.52$) \quad 3.8$

$0.32(0.08$ to 1.30$) \quad 3.7$

$0.10(0.00$ to 2.04$) \quad 1.2$

$0.75(0.28$ to 2.04$) \quad 4.9$

$0.34(0.14$ to 0.82$) \quad 5.3$

$0.53(0.32$ to 0.90$) \quad 6.7$

$0.47(0.26$ to 0.84$)-6.5$

$0.25(0.17$ to 0.36$)$

Figure 4. Recurrence in the Antidepressant and the Placebo Groups in the Pooled Analysis at 6 Months of Follow-Up in the Maintenance Treatment

apooled odds ratio and $\mathrm{CI}$ in random-effects model.

Abbreviations: CI = confidence interval, OADIG = Old Age Depression Interest Group.

Study

1 Montgomery et al, $1988^{24}$

2 Doogan and Caillard, $1992^{25}$

3 Montgomery and Rasmussen, $1992^{26}$

4 Montgomery and Dunbar, $1993^{27}$

5 Robert and Montgomery, $1995^{28}$

6 Keller et al, $1998^{29}$

7 Reimherr et al, $1998^{30}$

8 Terra and Montgomery, $1998^{31}$

9 Hochstrasser et al, 200132

10 Klysner et al, 2002 33

11 Mindham et al, $1972^{34}$

17 Glen et al, $1984^{40}$

18 Prien et al, $1984^{41}$

21 Rouillon et al, $1989^{44}$

22 Frank et al, $1990^{45}$

23 OADIG, $1993^{46}$

25 Alexopoulos et al, $2000^{48}$

26 Wilson et al, $2003^{49}$

27 Gilaberte et al, $2001^{50}$

29 McGrath et al, $2006^{52}$

30 Perahia et al, $2006^{53}$

Overall ${ }^{a}$

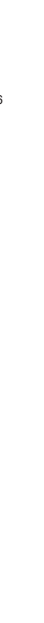

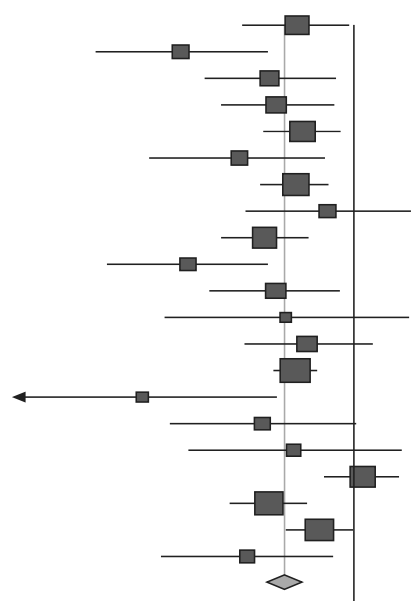

0.000288
Odds Ratio $(95 \% \mathrm{Cl})$

0.27 (0.08 to 0.93 )

$0.02(0.00$ to 0.13$)$

$0.14(0.03$ to 0.70$)$

$0.16(0.04$ to 0.63$)$

$0.30(0.12$ to 0.77$)$

0.07 (0.01 to 0.53 )

0.25 (0.11 to 0.57$)$

0.55 (0.07 to 3.98$)$

0.12 (0.04 to 0.36 )

0.02 ( 0.00 to 0.13 )

$0.16(0.03$ to 0.74$)$

0.20 (0.01 to 3.66$)$

0.33 (0.07 to 1.56$)$

0.25 (0.15 to 0.41$)$

0.01 (0.00 to 0.16$)$

0.11 (0.01 to 1.04 )

$0.25(0.02$ to 3.10$)$

$1.20(0.49$ to 2.93$)$

$0.13(0.05$ to 0.33$)$

0.45 (0.20 to 0.99$)$

0.08 (0.01 to 0.63$)$

0.19 (0.13 to 0.29$)$
$\%$ Weight

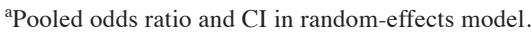

Abbreviations: CI = confidence interval, OADIG = Old Age Depression Interest Group. 


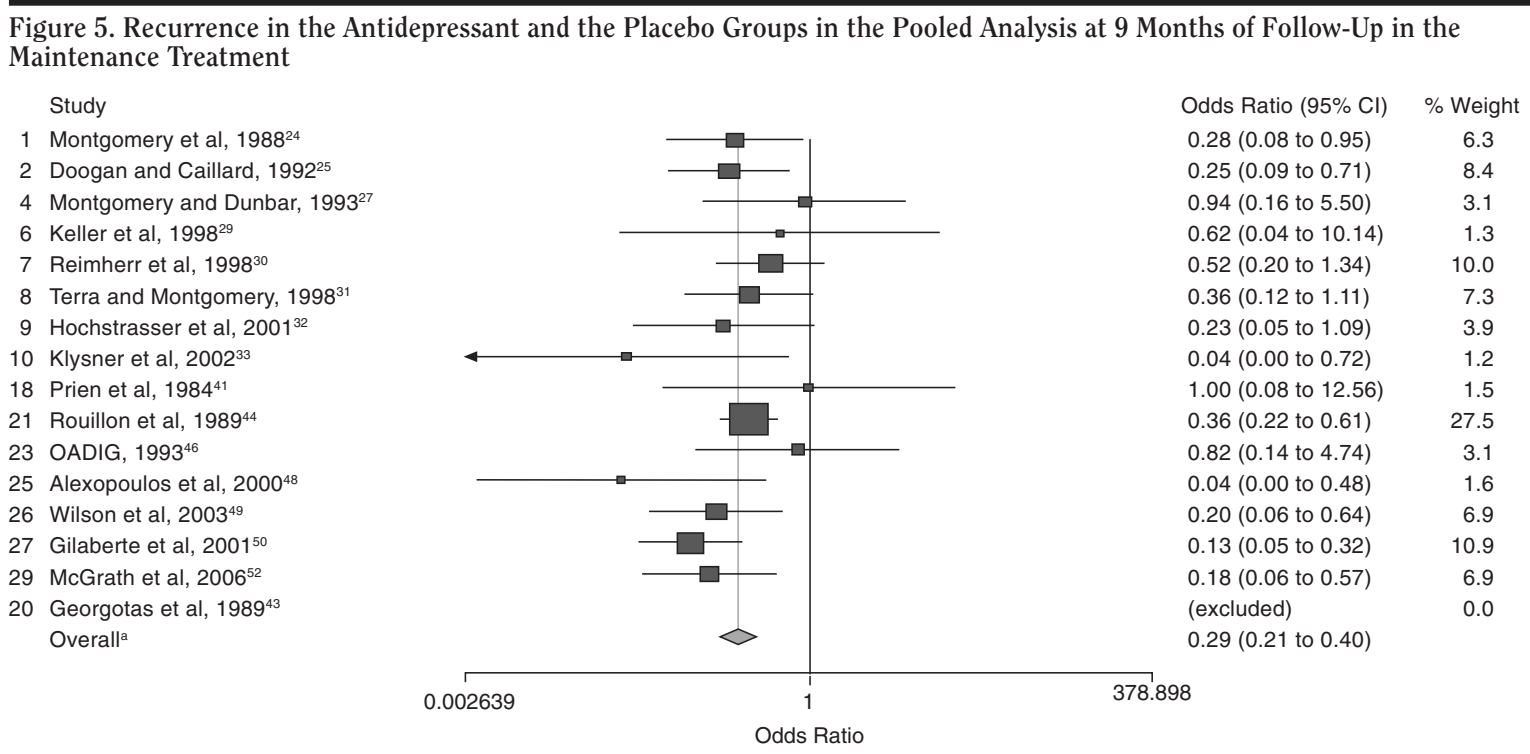

apooled odds ratio and CI in random-effects model.

Abbreviations: $\mathrm{CI}=$ confidence interval, $\mathrm{OADIG}=$ Old Age Depression Interest Group.

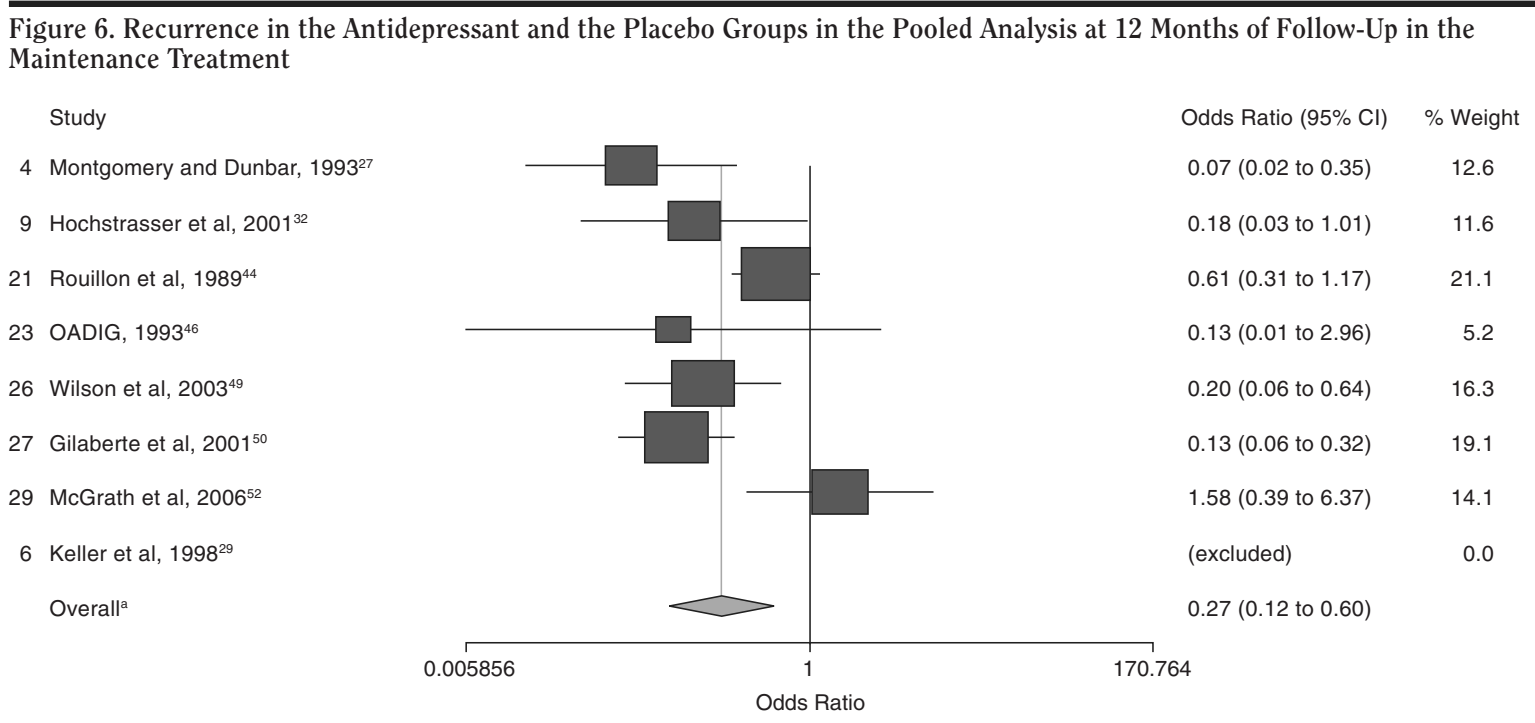

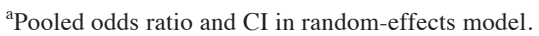

Abbreviations: $\mathrm{CI}=$ confidence interval, $\mathrm{OADIG}=$ Old Age Depression Interest Group.

associated with a lower relapsing preventive effect of antidepressants $(\mathrm{OR}=0.32,95 \% \mathrm{CI}=0.27$ to $0.38, \mathrm{p}<$ .001 ; heterogeneity: $\left.\chi^{2}=57.20, \mathrm{df}=41, \mathrm{p}=.048\right)$, compared to multiple episode patients with gradual discontinuation $(\mathrm{OR}=0.11,95 \% \mathrm{CI}=0.06$ to $0.21, \mathrm{p}<.001$; heterogeneity: $\chi^{2}=8.30, \mathrm{df}=9, \mathrm{p}=.504$ ), with nonoverlapping confidence intervals of the ORs in the 2 groups.
In single episode patients, no such large difference was apparent, and confidence intervals were largely overlapping (abrupt: $\mathrm{OR}=0.10,95 \% \mathrm{CI}=0.03$ to $0.28, \mathrm{p}<.001$; gradual: $\mathrm{OR}=0.19,95 \% \mathrm{CI}=0.04$ to $0.87, \mathrm{p}=.032$ ). The significant heterogeneity in the meta-analysis of recurrent episode patients with abrupt discontinuation was largely due to 1 small study with an unusually large effect size in 
the opposite direction (Robert and Montgomery ${ }^{28}$ ). This study has a meta-analytic weight of less than $1 \%$; therefore, excluding it has little impact on the effect size (but does reduce heterogeneity). Exclusion of this study from the analysis reduced heterogeneity $\left(\chi^{2}=46.00, \mathrm{df}=39\right.$, $\mathrm{p}=.205 ; \mathrm{OR}=0.32,95 \% \mathrm{CI}=0.27$ to $0.37, \mathrm{p}<.001)$.

\section{DISCUSSION}

On the basis of the pooled results of 30 randomized clinical trials, it can be concluded that treatment with an antidepressant results in an approximately $70 \%$ reduction of risk of relapse. Thus, the current study confirms the effectiveness of continuation treatment with antidepressants once remission has been achieved, as was reported in previous meta-analyses by Loonen et al., ${ }^{3}$ Geddes et al., ${ }^{6}$ and Viguera et al ${ }^{54}$ In agreement with the latter 2 meta-analyses, it was found that the difference between active medication and placebo was not greater in the studies with SSRIs compared to the studies with TCAs. However, it should be emphasized that no studies were found in which SSRIs and TCAs were compared head-to-head with each other.

In this meta-analysis, several additional questions concerning the continuation and maintenance treatment of depressive disorder were addressed.

\section{Duration of Continuation Phase}

Regarding the first question (of how long treatment with antidepressants should be continued once remission has been attained), no significant difference was found between studies with patients who were randomized within 1 month after having achieved remission compared to those in which patients were randomized after a continuation treatment of 1 to 3 months or after 3 to 6 months. This is in line with the results of previous metaanalyses $^{6,54}$ that also did not find a difference in relapse rates in relation to the duration of the stabilization prior to discontinuation of the antidepressant.

In answering the question of how long antidepressants should be continued, another perspective can be gained from the comparison of relapse/recurrence rates over the follow-up at 3, 6, 9, and 12 months after randomization. We found significant relapse-reducing effects of antidepressants compared to placebo at 3,6, and 9 months as well as 12 months of follow-up. However, the difference between antidepressant and placebo was already achieved within 3 months after randomization, with no additional reduction in risk at 6,9 , and 12 months compared to the effect already obtained during the previous periods (up to 3,6 , and 9 months, respectively).

Unfortunately, it was not possible to include studies in which patients were randomized during maintenance treatment, i.e., more than 6 months after remission was achieved. The only available data are from 2 small stud- ies. The first was by Bialos et al., ${ }^{38}$ who studied 17 patients who had been receiving long-term amitriptyline treatment. Eight of 10 patients who had their medication tapered and discontinued had a relapse within 4 months compared to none of the 7 control subjects during the 6 months of the study. The second small study was by Cook et al., ${ }^{42}$ who studied 15 patients who had been receiving a long-term treatment with a tricyclic antidepressant agent. None of the 9 patients who continued on active medication experienced a relapse, whereas 3 of the 9 patients switched to placebo experienced a relapse. With the exception of these small studies, no other studies have specifically addressed the question of whether treatment with antidepressants should be continued longer than 6 months after remission is achieved.

On the basis of the above data taken together, it is not possible to give recommendations for an optimal duration of continuation and maintenance treatment with antidepressants. In fact, there is also no evidence from the reviewed studies of the effect of discontinuation of antidepressants to justify the defined distinction between continuation treatment (up to 6 months) and maintenance treatment (beyond 6 months).

\section{Number of Previous Depressive Episodes}

A history of severe and frequently recurring depressive episodes is considered to be a plausible clinical predictor of increased risk of relapse or recurrences after discontinuation of the antidepressant..$^{22,26,55}$

Regarding the second question (of whether treatment should be continued longer in patients with recurrent episodes than in patients who have suffered from a first or second episode), it was found that the reduction in relapse rates was greater for recurrent episode patients compared to single episode patients. In fact, the results support previous findings that patients with 1 or more previous depressive episodes have significantly less benefit from the relapse-reducing effect of the antidepressant than patients with a first episode..$^{29,54,56}$ Thus, the results suggest that with longer duration of illness, the risk of relapse is more difficult to control, conforming to the sensitization hypothesis proposed by Post et al. ${ }^{7}$ In addition, the data showed that the reduction in the protective effect of antidepressants was specifically evident in the subgroup of patients in which the antidepressant was discontinued abruptly. Post et al. hypothesized that stress of a particular type, intensity, and intermittency may produce sensitization in a fashion similar to the behavioral sensitization. Even in cases of anticipated stresses or imagined losses, if sufficiently conditioned, the behavioral, physiologic, and biochemical alterations usually associated with an affective episode might be produced. It may also explain how stress-induced mood alterations might become so sensitized that they also occur spontaneously. However, it should also be emphasized that it was not possible to 
specifically address the question of whether maintenance treatment is especially indicated for patients with recurrent depression, again because there are no studies in which patients were randomized more than 6 months after having achieved remission.

\section{Mode of Discontinuation of the Antidepressant}

Regarding the third question (of how quickly the antidepressant should be discontinued), it was found that relapse rates in studies in which patients did discontinue medication abruptly (i.e., <1 week) were not different from rates in studies in which patients gradually discontinued their antidepressant (i.e., $\geq 1$ week), but that instead mode of discontinuation was relevant only for the particular subgroup of recurrent episode patients. This subgroup effect quite likely explains why Viguera et al ${ }^{54}$ found that relapse rates off medication did not differ significantly between studies involving rapid discontinuation and those in which tapering was more gradual for the total group of different types of antidepressants that they included, as the interaction with number of previous episodes was not investigated in that study. Differential distribution of recurrent episode patients may explain why Geddes and colleagues ${ }^{6}$ reported an excess of relapse immediately following discontinuation of the antidepressant in the first month of drug discontinuation. Thus, when the interaction with recurrent episode patients is modeled, there is clear evidence that acute withdrawal of medication might induce a relapse, a problem that has also been identified for lithium, for which acute withdrawal can lead to manic relapses, ${ }^{57-60}$ and antipsychotics, for which a higher risk of psychotic relapse was found within 6 months of discontinuation, particularly in hospitalized patients and patients in whom the antipsychotics were withdrawn abruptly. ${ }^{61}$

\section{Other Factors}

One of the possible mechanisms for the high relapse rates in the first 3 months of randomization may be associated with differences in the half-lives of the various antidepressant agents, ${ }^{62,63}$ assuming that the shorter the halflife of the antidepressant, the greater the risk of relapse. However, addressing this question with adequate precision was not possible, since the range of half-lives of the antidepressants used in the different studies is extremely heterogeneous and in addition imprecise, given a great level of interindividual variation, depending on whether the patient is a fast or a slow metabolizer and depending on gender- and age-specific aspects of the elimination of the antidepressant.

\section{Consequences}

Several guidelines on the treatment of patients with depressive disorder have addressed the issue of long-term treatment with antidepressants: continuation treatment during the first 6 months after achievement of remission and maintenance treatment thereafter. We looked at the different guidelines and compared the recommendations with the findings of this study.

The recommendations in most guidelines ${ }^{64-67}$ stating that patients should be treated for at least 6 months after having achieved remission, and especially that patients with frequent/more previous episodes should receive maintenance treatment, cannot be supported on the basis of the current findings. More specifically, any recommendation about maintenance treatment is not evidence based, due to the fact that studies in which patients were randomized more than 6 months after having achieved remission are lacking. The ORs reported in this article indicate that gradual discontinuation leads to more relapse than abrupt discontinuation. However, it is not possible to differentiate to what extent the smaller OR for single episode studies $(\mathrm{OR}=0.12)$ than for recurrent episode studies $(\mathrm{OR}=0.36)$ can be explained by more relapse with placebo in single episode studies or by less relapse with antidepressant medication in single episode studies. Further investigation of the above mentioned possible pathways for smaller ORs is warranted before firm conclusions can be drawn. Furthermore, in the group of patients with recurrent depressive episodes, those with abrupt discontinuation of the antidepressant appeared to benefit less from the relapse-reducing effect of the antidepressant $(\mathrm{OR}=0.32)$ than those with gradual discontinuation $(\mathrm{OR}=0.11)$. The interpretation of this finding is that since the relapse rate during continuing treatment with an antidepressant should not be different in these studies, the ORs can arguably only be taken to indicate that gradual discontinuation leads to more relapse in placebo groups than abrupt discontinuation. This is a somewhat counterintuitive finding and suggests that findings resulting from models including interaction terms may be due to chance. Furthermore, gradual withdrawal can be recommended in order to prevent other withdrawal symptoms. ${ }^{68-70}$

Another issue is how to perform continuation or maintenance treatment. Some studies detailing the management of a relapse or a recurrence point out that patients who did relapse in the continuation phase after initially having responded to an antidepressant can benefit from an increase in the dose of the same antidepressant or from an increase using an enteric-coated antidepressant initially dosed once a week to twice a week..$^{71,53,63}$ In the case of a recurrence after the discontinuation of medication in the maintenance phase, patients can benefit from a reinstatement of the antidepressant. We did not address these aspects in our meta-analysis.

\section{Limitations}

The results of our study should be seen in the light of several methodological limitations.

Several reports did not specify certain relevant details, such as the specific antidepressant studied (some reports 
just mentioned TCA), doses of the antidepressant, the illness history and more specifically the precise number of previous depressive episodes, the precise duration of treatment after achievement of remission and prior to randomization, and in some studies the mode of discontinuation of the antidepressant. Diagnostic criteria varied, and some studies included an unspecified number of patients with other disorders such as a depression in the course of bipolar II disorder, dysthymia, atypical depression/ depression not otherwise specified, or a major depressive episode with a significant comorbid disorder. When relevant details could not be retrieved, the studies were excluded from the subanalyses.

Definitions of remission as well as of relapse/ recurrence usually varied between the studies from formal definitions including clinical assessment with application of diagnostic criteria or the use of rating scales, to more global criteria such as worsening of depressive symptoms severe enough to warrant hospitalization or reinstitution of antidepressant treatment. Therefore, it remained unclear in some studies to what degree patients actually had attained full remission prior to randomization and/or to what degree they indeed suffered from a relapse or recurrence of a formal major depressive episode.

The trials were also heterogeneous in terms of diagnostic criteria, dropout rates, the power at the start of the trial, drugs used, and outcome criteria (Table 1). Although the main meta-analytic result did not display significant heterogeneity, the $\mathrm{p}$ value was close to .05 , suggesting underlying sources of variance. Some of these factors were most likely identified in the meta-regression, in particular the number of previous depressive episodes and the interaction of this variable with mode of discontinuation. Further exploration of other potential variables contributing to heterogeneity, such as age, gender, year of publication, or drug regimen, was not possible due to the limitations inherent to all meta-analyses performed without access to individual patient data, and potential differences between trials in the definition and validation of end points as well as the clinical characteristics of the randomized patients.

Most of the patients participating in the trials consisted of patients in secondary care settings with a more severe and often recurrent type of depressive disorder and thus a high risk of relapse. Patients with milder depressive disorders, such as patients treated in primary care, were underrepresented, so that we can make no inference about the generalizability of our results to this group of patients.

Whether the relapse rates can be explained by the degree of resistance in patients participating in the different studies remains unclear, since the degree of resistance to therapy, prior to participation, was not mentioned in the studies included.

Another limitation is that our results may be subject to publication bias as negative trials are more likely to re- main unpublished..$^{72}$ This is a general limitation of any conclusion based on perusal of the literature. Using a Begg's funnel plot, however, it was found that there was symmetry in the relationship between effect size and sample size (see Figure 1), with only a slight overrepresentation of small studies with a positive result.

Drug names: citalopram (Celexa and others), duloxetine (Cymbalta), fluoxetine (Prozac and others), fluvoxamine (Luvox and others), imipramine (Tofranil and others), nortriptyline (Pamelor, Aventyl, and others), paroxetine (Paxil, Pexeva, and others), sertraline (Zoloft and others)

\section{REFERENCES}

1. Angst J. Epidemiology of depression. Psychopharmacology (Berl) 1992;106(suppl):S71-S74

2. Spijker J, de Graaf R, Bijl RV, et al. Duration of major depressive episodes in the general population: results from The Netherlands Mental Health Survey and Incidence Study (NEMESIS). Br J Psychiatry 2002; 181:208-213

3. Loonen AJ, Peer PG, Zwanikken GJ. Continuation and maintenance therapy with antidepressive agents: meta-analysis of research. Pharm Weekbl Sci 1991;13:167-175

4. Joffe R, Sokolov S, Streiner D. Antidepressant treatment of depression: a meta-analysis. Can J Psychiatry 1996;41:613-616

5. Storosum JG, van Zwieten BJ, Vermeulen HD, et al. Relapse and recurrence prevention in major depression: a critical review of placebocontrolled efficacy studies with special emphasis on methodological issues. Eur Psychiatry 2001;16:327-335

6. Geddes JR, Carney SM, Davies C, et al. Relapse prevention with antidepressant drug treatment in depressive disorders: a systematic review. Lancet 2003;361:653-661

7. Post RM, Rubinow DR, Ballenger JC. Conditioning and sensitisation in the longitudinal course of affective illness. Br J Psychiatry 1986;149: 191-201

8. Frank E, Prien RF, Jarrett RB, et al. Conceptualization and rationale for consensus definitions of terms in major depressive disorder: remission, recovery, relapse, and recurrence. Arch Gen Psychiatry 1991;48:851-855

9. STATA Statistical Software: Release 9.0. College Station, Tex: StataCorp; 2005

10. Kocsis JH, Friedman RA, Markowitz JC, et al. Maintenance therapy for chronic depression: a controlled clinical trial of desipramine. Arch Gen Psychiatry 1996 Sep;53(9):769-774; discussion 775-766

11. Franchini L, Gasperini M, Perez J, et al. Dose-response efficacy of paroxetine in preventing depressive recurrences: a randomized double-blind study. J Clin Psychiatry 1998 May;59(5):229-232

12. Franchini L, Zanardi R, Gasperini M, et al. Two-year maintenance treatment with citalopram, $20 \mathrm{mg}$, in unipolar subjects with high recurrence rate. J Clin Psychiatry 1999 Dec;60(12):861-865

13. Franchini L, Gasperini M, Zanardi R, et al. Four-year follow-up study of sertraline and fluvoxamine in long-term treatment of unipolar subjects with high recurrence rate. J Affect Disord 2000;58:233-236

14. Koran LM, Gelenberg AJ, Kornstein SG, et al. Sertraline versus imipramine to prevent relapse in chronic depression. J Affect Disord 2001;65: $27-36$

15. Kishimoto A, Mizukawa R, Matsuzaki R, et al. Prophylactic effect of mianserin on recurrent depression. Acta Psychiatr Scand 1994;89:46-51

16. Flint AJ, Rifat SL. Recurrence of first-episode geriatric depression after discontinuation of maintenance antidepressants. Am J Psychiatry 1999; 156:943-945

17. Flint AJ, Rifat SL. Maintenance treatment for recurrent depression in late life: a four-year outcome study. Am J Geriatr Psychiatry 2000;8:112-116

18. Lepine JP, Caillard V, Bisserbe JC, et al. A randomized, placebocontrolled trial of sertraline for prophylactic treatment of highly recurrent major depressive disorder. Am J Psychiatry 2004;161:836-842

19. Bjork K. The efficacy of zimeldine in preventing depressive episodes in recurrent major depressive disorders: a double-blind placebo-controlled study. Acta Psychiatr Scand Suppl 1983;308:182-189

20. Eric L. A prospective double-blind comparative multi-centre study 
of paroxetine in preventing recurrent major depressive episodes. Biol Psychiatry 1991;29:11-14

21. May M, Veltro F, Pirozzi R, et al. Pattern of recurrence of illness after recovery from an episode of major depression: a prospective study. Am J Psychiatry 1992;149:795-800

22. Kupfer DJ, Frank E, Perel JM, et al. Five-year outcome for maintenance therapies in recurrent depression. Arch Gen Psychiatry 1992;49:769-773

23. McGrath PJ, Stewart JW, Petkova E, et al. Predictors of relapse during fluoxetine continuation or maintenance treatment of major depression. J Clin Psychiatry 2000 Jul;61(7):518-524

24. Montgomery SA, Dufour H, Brion S, et al. The prophylactic efficacy of fluoxetine in unipolar depression. Br J Psychiatry Suppl 1988 Sep;(3):69-76

25. Doogan DP, Caillard V. Sertraline in the prevention of depression. Br J Psychiatry 1992;160:217-222

26. Montgomery SA, Rasmussen JG. Citalopram $20 \mathrm{mg}$, citalopram $40 \mathrm{mg}$ and placebo in the prevention of relapse of major depression. Int Clin Psychopharmacol 1992;6:71-73

27. Montgomery SA, Dunbar G. Paroxetine is better than placebo in relapse prevention and the prophylaxis of recurrent depression. Int Clin Psychopharmacol 1993;8:189-195

28. Robert P, Montgomery SA. Citalopram in doses of 20-60 mg is effective in depression relapse prevention: a placebo-controlled 6 month study. Int Clin Psychopharmacol 1995;10:29-35

29. Keller MB, Kocsis JH, Thase ME, et al. Maintenance phase efficacy of sertraline for chronic depression: a randomized controlled trial. JAMA 1998;280:1665-1672

30. Reimherr FW, Amsterdam JD, Quitkin FM, et al. Optimal length of continuation therapy in depression: a prospective assessment during long-term fluoxetine treatment. Am J Psychiatry 1998;155:1247-1253

31. Terra JL, Montgomery SA. Fluvoxamine prevents recurrence of depression: results of a long-term, double-blind, placebo-controlled study. Int Clin Psychopharmacol 1998;13:55-62

32. Hochstrasser B, Isaksen PM, Koponen H, et al. Prophylactic effect of citalopram in unipolar, recurrent depression: placebo-controlled study of maintenance therapy. Br J Psychiatry 2001;178:304-310

33. Klysner R, Bent-Hansen J, Hansen HL, et al. Efficacy of citalopram in the prevention of recurrent depression in elderly patients: placebocontrolled study of maintenance therapy. Br J Psychiatry 2002;181:29-35

34. Mindham RH, Howland C, Shepherd M. Continuation therapy with tricyclic antidepressants in depressive illness. Lancet 1972;2:854-855

35. Klerman GL, Dimascio A, Weissman M, et al. Treatment of depression by drugs and psychotherapy. Am J Psychiatry 1974;131:186-191

36. Coppen A, Ghose K, Montgomery SA, et al. Continuation therapy with amitriptyline in depression. Br J Psychiatry 1978;133:28-33

37. Stein MK, Rickels K, Weise CC. Maintenance therapy with amitriptyline: a controlled trial. Am J Psychiatry 1980;137:370-371

38. Bialos D, Giller E, Jatlow P, et al. Recurrence of depression after discontinuation of long-term amitriptyline treatment. Am J Psychiatry 1982; 139:325-329

39. Kane JM, Quitkin FM, Rifkin A, et al. Lithium carbonate and imipramine in the prophylaxis of unipolar and bipolar II illness: a prospective, placebo-controlled comparison. Arch Gen Psychiatry 1982;39: $1065-1069$

40. Glen AI, Johnson AL, Shepherd M. Continuation therapy with lithium and amitriptyline in unipolar depressive illness: a randomized, doubleblind, controlled trial. Psychol Med 1984 Feb;14(1):37-50

41. Prien RF, Kupfer DJ, Mansky PA, et al. Drug therapy in the prevention of recurrences in unipolar and bipolar affective disorders: report of the NIMH Collaborative Study Group comparing lithium carbonate, imipramine, and a lithium carbonate-imipramine combination. Arch Gen Psychiatry 1984;41:1096-1104

42. Cook BL, Helms PM, Smith RE, et al. Unipolar depression in the elderly: reoccurrence on discontinuation of tricyclic antidepressants. J Affect Disord 1986;10:91-94

43. Georgotas A, McCue RE, Cooper TB. A placebo-controlled comparison of nortriptyline and phenelzine in maintenance therapy of elderly depressed patients. Arch Gen Psychiatry 1989;46:783-786

44. Rouillon F, Phillips R, Serrurier D, et al. Recurrence of unipolar depression and efficacy of maprotiline [in French]. Encephale 1989;15:527-534

45. Frank E, Kupfer DJ, Perel JM, et al. Three-year outcomes for maintenance therapies in recurrent depression. Arch Gen Psychiatry 1990;47:1093-1099
46. Old Age Depression Interest Group. How long should the elderly take antidepressants? a double-blind placebo-controlled study of continuation/prophylaxis therapy with dothiepin. Br J Psychiatry 1993;162: 175-182

47. Reynolds CF, Frank E, Perel JM, et al. Nortriptyline and interpersonal psychotherapy as maintenance therapies for recurrent major depression: a randomized controlled trial in patients older than 50 years. JAMA 1999;281:39-45

48. Alexopoulos GS, Meyers BS, Young RC, et al. Executive dysfunction and long-term outcomes of geriatric depression. Arch Gen Psychiatry 2000;57:285-290

49. Wilson KC, Mottram PG, Ashworth L, et al. Older community residents with depression: long-term treatment with sertraline: randomised, double-blind, placebo-controlled study. Br J Psychiatry 2003;182: 492-497

50. Gilaberte I, Montejo AL, de la Gandara J, et al. Fluoxetine in the prevention of depressive recurrences: a double-blind study. J Clin Psychopharmacol 2001;21:417-424

51. Schmidt ME, Fava M, Robinson JM, et al. The efficacy and safety of a new enteric-coated formulation of fluoxetine given once weekly during the continuation treatment of major depressive disorder. J Clin Psychiatry 2000 Nov;61(11):851-857

52. McGrath PJ, Stewart JW, Quitkin FM, et al. Predictors of relapse in a prospective study of fluoxetine treatment of major depression. Am J Psychiatry 2006;163:1542-1548

53. Perahia DG, Gilaberte I, Wang F, et al. Duloxetine in the prevention of relapse of major depressive disorder. Br J Psychiatry 2006;188:346-353

54. Viguera AC, Baldessarini RJ, Friedberg J. Discontinuing antidepressant treatment in major depression. Harv Rev Psychiatry 1998;5:293-306

55. Depression Guideline Panel. Depression in Primary Care, vol 2: Treatment of Major Depression. Rockville, Md: Agency for Health Care Policy and Research, US Department of Health and Human Services; 1993

56. Ramana R, Paykel ES, Cooper Z, et al. Remission and relapse in major depression: a two-year prospective follow-up study. Psychol Med 1995; 25:1161-1170

57. Faedda GL, Tondo L, Baldessarini RJ, et al. Outcome after rapid vs gradual discontinuation of lithium treatment in bipolar disorders. Arch Gen Psychiatry 1993;50:448-455

58. Suppes T, Baldessarini RJ, Faedda GL, et al. Discontinuation of maintenance treatment in bipolar disorder: risk and implications. Harv Rev Psychiatry 1993;1:131-144

59. Baldessarini RJ, Tondo L, Faedda GL, et al. Effects of the rate of discontinuing lithium maintenance treatment in bipolar disorders. J Clin Psychiatry 1996 Oct;57(10):441-448

60. Baldessarini RJ, Tondo L, Floris G, et al. Reduced morbidity after gradual discontinuation of lithium treatment for bipolar I and II disorders: a replication study. Am J Psychiatry 1997;154:551-553

61. Viguera AC, Baldessarini RJ, Hegarty JD, et al. Clinical risk following abrupt and gradual withdrawal of maintenance neuroleptic treatment. Arch Gen Psychiatry 1997;54:49-55

62. Fava M, Mulroy R, Alpert J, et al. Emergence of adverse events following discontinuation of treatment with extended-release venlafaxine. Am J Psychiatry 1997;154(12):1760-1762

63. Fava M, Detke MJ, Balestrieri M, et al. Management of depression relapse: re-initiation of duloxetine treatment or dose increase. J Psychiatr Res 2006;40(4):328-326

64. National Institute for Clinical Excellence. Management of Depression in Primary and Secondary Care. Clinical Guide 23: National Collaborating Centre for Mental Health; 2004. Available at: http://www.nice.org.uk/ guidance/index.$j s p ?$ action $=$ byID $\& \mathrm{r}=$ true $\& o=10958$. Accessibility verified May 16, 2008

65. American Psychiatric Association. Practice Guideline for the Treatment of Patients With Major Depressive Disorder (Revision). Am J Psychiatry 2000 Apr;157(4 suppl):1-45

66. Bauer M, Whybrow PC, Angst J, et al. World Federation of Societies of Biological Psychiatry (WFSBF) Task Force on Treatment Guidelines for Unipolar Depressive Disorders, pt 2: maintenance treatment of majo depressive disorder and treatment of chronic depressive disorders and subthreshold depressions. World J Biol Psychiatry 2002;3:69-86

67. Kennedy SH, Lam RW, Cohen NL, et al. CANMAT Depression Work Group. Clinical guidelines for the treatment of depressive disorders, 4: medications and other biological treatments. 
Can J Psychiatry 2001 Jun;46(suppl 1):38S-58S

68. Dilsaver SC, Greden JF. Antidepressant withdrawal phenomena. Biol Psychiatry 1984;19:237-256

69. Rosenbaum JF, Zajecka J. Clinical management of antidepressant discontinuation. J Clin Psychiatry 1997;58(suppl 7):37-40

70. Schatzberg AF, Haddad P, Kaplan EM, et al. Serotonin reuptake inhibitor discontinuation syndrome: a hypothetical definition.
Discontinuation Consensus Panel. J Clin Psychiatry 1997;58(suppl 7): $5-10$

71. Schmidt ME, Fava M, Zhang S, et al. Treatment approaches to major depressive disorder relapse, pt 1: dose increase. Psychother Psychosom 2002;71(4):190-194

72. Sterne JA, Egger M. Funnel plots for detecting bias in meta-analysis: guidelines on choice of axis. J Clin Epidemiol 2001;54:1046-1055 
CHAPTER 4

Prodromal studies of psychosis 


\title{
DSM-5 and the 'Psychosis Risk Syndrome': Babylonic Confusion
}

\author{
Nil Kaymaz ${ }^{\mathrm{a}, \mathrm{b}}$ and Jim van Os ${ }^{\mathrm{a}, \mathrm{c}}$ \\ ${ }^{a}$ Maastricht University Medical Centre, South Limburg Mental Health Research and Teaching \\ Network, EURON, Maastricht, The Netherlands.Email: j.vanos@sp.unimaas.nl; ${ }^{b}$ Mediant \\ GGZ/Mental Health Care, Postbus 775, 7500 AT Enschede, The Netherlands; ' Division of \\ Psychological Medicine, Institute of Psychiatry, King's College London, De Crespigny Park, \\ Denmark Hill, London, UK
}

\begin{abstract}
The notion that the important paradigm shift in clinical psychiatry, associated with early intervention, should now become a diagnostic issue is misguided. The 'risk' in Psychosis Risk Syndrome will not make sense to treatment-seeking patients with distressing symptoms and real need for care, is based on the notion that labeling people with invalid diagnostic terms has more clinical relevance than simply addressing care needs, is contingent on elusive sampling strategies posing as precise diagnostic criteria, and is associated with a false-positive rate of at least $90 \%$ in the year after diagnosis. In the $21^{\text {st }}$ century, opinion-based diagnostics continues to pose a threat to the process of diagnostic revision.
\end{abstract}

Keywords: Psychosis; Diagnosis; Risk; Schizophrenia; DSM-5

\section{Introduction}

DSM-5, for the first time in the history of psychiatry, is considering the inclusion of a Psychosis Risk Syndrome as a category (www.dsm5.org). The good thing is that the proposal stems from increased efforts to intervene early in psychotic disorder. Early intervention improves subsequent course and outcome given that psychotic disorders, arising during adolescence and early adulthood, disrupt important maturational tasks and increase the risk of long term exclusion from meaningful societal participation. The international efforts that have been developed towards intervening earlier during the initial manifestations of psychotic illness have had a major impact, and are an example of how outstanding early pioneering work can grow into a true paradigm shift in clinical psychiatry (Cannon et al., 2008; McGlashan et al., 2006; McGorry et al., 2002). This exceptional work serves as an example to us all.

There is also a downside however. The same enthusiasm that created the paradigm of early intervention is now used to turn early intervention into a diagnostic issue, based on flawed reasoning. The word "risk" is now being used in the Psychosis Risk Syndrome proposal conceptually has nothing to do with risk, and more to do with labeling and elusive sampling strategies. Furthermore, no additional diagnostic category is required: DSM already has a category where early psychotic states can be classified. Below, these issues will be discussed in more detail.

\section{If one already is help-seeking and in need of care, how can one still be at risk of something?}

The proposed criteria for the Psychosis Risk Syndrome stipulate that "symptoms are sufficiently distressing and/or disabling to the patient and/or others to lead to helpseeking". This raises several interesting issues. The first issue is to do with the concept of risk. If individuals already have reached services and are in need of care, how can it be that they are still at risk of something? Clearly these individuals are "cases in 
need of care", therefore they are no longer "at risk" because they already have reached a clinical outcome. In DSM terms, they fulfil criteria for Psychotic Disorder, Not Otherwise Specified (NOS). In fact, the NOS category is ideal as it is commonly used to describe psychotic states early on in the diagnostic process, when it is not clear how best to classify symptoms. As a patient's condition becomes better understood with the passage of time, the "NOS" can often be replaced by a more precise category. It is highly confusing for a patient with specific psychotic symptoms, which do not appear "attenuated" to him, and for which he is seeking treatment, to hear that his diagnosis is that he is at risk of something: the patient does not feel at risk, he feels in need of treatment for real problems.

The argument of the Psychosis Risk Syndrome advocates is that the "thing" these individuals are at risk for is a diagnostic label such as schizophrenia: they may be in need of treatment, but they do not meet criteria for schizophrenia. For example, in the North American Multicentre study, 56\% of treatment-seeking high risk individuals "converted" to schizophrenia (Cannon et al., 2008; Woods et al., 2009). It could be argued, however, that a (ICD, RDC, DSM) diagnosis of schizophrenia represents an odd outcome for risk defined as a state of symptomatic treatment-seeking. Psychotic disorders, spread over a myriad of diagnostic categories in the different classification systems, in reality represent highly variable syndromal clusters of continuous psychotic and affective symptom dimensions, in combination with variable degrees of motivational and neurocognitive impairments (van Os \& Kapur, 2009). The notion that a person may be at risk for a specific diagnostic category such as schizophrenia only makes sense if (ICD, DSM, RDC) diagnoses like "schizophrenia" represent valid nosological entities, i.e. "exist". As the scientific evidence for the hypothesis of valid nosological entities is very weak (van Os \& Kapur, 2009), it is difficult to see how any person may be helped by being called "at risk" of meeting criteria for labels that do not represent disease entities. The obsession with arbitrary diagnostic labels in psychiatry apparently has taken on such proportions that a patient with real symptoms and real need for care now must remain in the category "at risk" as long as he does not meet criteria for a non-existent and non-relevant diagnostic label.

\section{How "risky" is the risk, and how replicable is it?}

The reason the criterion of distress and treatment seeking was included in the Psychosis Risk Syndrome is because of a very interesting, and hitherto unresolved issue. Attenuated psychotic symptoms are weak predictors of transition to psychotic disorder in unselected general population samples, but become strong predictors of psychotic disorder in selected samples of help-seeking individuals in the ultra-high risk literature. For example, Hanssen and colleagues studied the outcome of psychotic experiences with onset in the past year, which conform to the criterion of the Psychosis Risk Syndrome (symptoms must have begun in or significantly worsened in the past year) (Hanssen, Bak, Bijl, Vollebergh, \& van Os, 2005). A two-year follow-up of 79 of these individuals revealed that 6 converted to clinical psychotic disorder. The one-year incidence rate therefore is $3.8 \%(6 / 158$ person-years). A yearly risk of $3.8 \%$ is not negligible, but cannot be considered very useful for the purpose of prediction, particularly as longer term follow-up studies of up to 25 years have shown that risk of conversion is spread evenly over the follow-up period (Werbeloff et al., 2009). The ultra-high risk literature, however, displays a different trend. For example, in the 
Multisite North-American study (Cannon et al., 2008), 82 out of 291 patients converted over a period of 2.5 years, resulting in an incidence rate of $11.3 \%$, around three times higher than the Hanssen study. How to explain these differences? Clearly, the difference must reside in the way the samples were collected and "enriched" with risk. Hanssen and colleagues conducted a follow-up of a representative general population sample, whereas ultra-high risk samples invariably are opportunistic, each study using a different, unique strategy that cannot be replicated. For example, the sampling strategy of the ultra-high risk North-American study was described as: "Each site recruited potential subjects through clinical referrals as stimulated by talks to school counselors and mental health professionals in community settings".

Therefore, two questions arise. First, is a yearly risk of around 10\% something that needs to be diagnosed as a "risk syndrome"? For example, the yearly risk for any person in the general population to develop any kind of psychiatric disorder is around $5-10 \%$, depending on how inclusive the list of disorders is. Clearly, we are all at risk at any moment during our lives. Is it necessary to specifically label individuals with a $10 \%$ risk, even if it concerns a severe disorder? Have we become so health conscious that we take it for granted that $90 \%$ of those diagnosed with the Psychosis Risk Syndrome in fact are not at risk in the year after the diagnosis?

The second question is also important: How is it possible to introduce a new diagnostic category that essentially is the product of a non-replicable elusive sampling strategy occasioning a 300\% enrichment in risk, compared to representative general population samples? Surely the diagnostic criteria should also stipulate how clinicians should go about collecting a sample with attenuated psychotic symptoms in such a way that the result is an enriched group yielding $10 \%$ conversion per year, instead of the much lower rate that they can expect from individuals with attenuated symptoms in the general population? In other words, the "risk" in the Psychosis Risk Syndrome is contingent on a sampling enrichment strategy that remains indefinable. However, the criteria of the Psychosis Risk Syndrome misleadingly make no mention of this.

\section{Conclusion}

In conclusion, the appearance of Psychosis Risk Syndrome in the draft of DSM-5 exemplifies how diagnostic revisions in psychiatry remain at risk of opinion-based rather than evidence-based changes.

\section{Acknowledgements}

Nil Kaymaz was supported by the Netherlands Organisation for Scientific Research (NWO), project number: 017.002.048. Jim van Os is member of the APA DSM-V Psychotic Disorders Work Group. The views expressed are his own.

\section{References}

Cannon, T.D., Cadenhead, K., Cornblatt, B., Woods, S.W., Addington, J., Walker, E., Seidman, L.J., Perkins, D., Tsuang, M., McGlashan, T., \& Heinssen, R. (2008). Prediction of psychosis in youth at high clinical risk: a multisite longitudinal study in North America. Arch Gen Psychiatry, 65(1), 28-37.

Hanssen, M., Bak, M., Bijl, R., Vollebergh, W., \& van Os, J. (2005). The incidence and outcome of subclinical psychotic experiences in the general population. Br J Clin Psychol, 44(Pt 2), 181-191. 
McGlashan, T.H., Zipursky, R.B., Perkins, D., Addington, J., Miller, T., Woods, S.W., Hawkins, K.A., Hoffman, R.E., Preda, A., Epstein, I., Addington, D., Lindborg, S., Trzaskoma, Q., Tohen, M., \& Breier, A. (2006). Randomized, double-blind trial of olanzapine versus placebo in patients prodromally symptomatic for psychosis. Am J Psychiatry, 163(5), 790-799.

McGorry, P.D., Yung, A.R., Phillips, L.J., Yuen, H.P., Francey, S., Cosgrave, E.M., Germano, D., Bravin, J., McDonald, T., Blair, A., Adlard, S., \& Jackson, H. (2002). Randomized controlled trial of interventions designed to reduce the risk of progression to first-episode psychosis in a clinical sample with subthreshold symptoms. Arch Gen Psychiatry, 59(10), 921-928.

van Os, J., \& Kapur, S. (2009). Schizophrenia. Lancet, 374(9690), 635-645.

Werbeloff, N., Drukker, M., Dohrenwend, B.P., Levav, I., Yoffe, R., Van Os, J., Davidson, M., \& Weiser, M. (2009). Self-reported psychotic symptoms in the community are associated with increased risk of later hospitalization for non-affective psychotic disorders (Conference Abstract). Schizophr Bull, 35(Supplement 1), 74.

Woods, S.W., Addington, J., Cadenhead, K.S., Cannon, T.D., Cornblatt, B.A., Heinssen, R., Perkins, D.O., Seidman, L.J., Tsuang, M.T., Walker, E.F., \& McGlashan, T.H. (2009). Validity of the prodromal risk syndrome for first psychosis: findings from the North American Prodrome Longitudinal Study. Schizophr Bull, 35(5), 894-908. 



\section{The case of the missing evidence: Do psychotic experiences predict clinical outcomes in unselected population-based samples? A systematic review and meta-analysis, enriched with new results.}

Kaymaz $\mathrm{N} \mathrm{MD}^{1,2}$, Lataster $\mathrm{TPhD}^{1}$, Lieb R PhD ${ }^{3,4}$, Wittchen H-U PhD ${ }^{3,5}$, Werbeloff? , Weiser?, Van Os, JPhD ${ }^{1,6}$, Drukker $\mathrm{MPhD}^{1}$

${ }^{1}$ Department of Psychiatry and Psychology, South Limburg Mental Health Research and Teaching Network, EURON, Maastricht University Medical Centre, PO Box 616 (DRT 12), 6200 MD Maastricht, The Netherlands

${ }^{2}$ Mediant GGZ / Mental Health Care, Enschede, the Netherlands

${ }^{3}$ Max Planck Institute of Psychiatry, Kraepelinstrasse 2, D-80804 Munich, Germany.

${ }^{4}$ University of Basel, Department of Psychology, Division of Epidemiology and Health Psychology, Missionsstrasse 60-62, 4055 Basel, Switzerland

${ }^{5}$ Institute of Clinical Psychology and Psychotherapy, Technical University Dresden, Chemnitzerstr. 46, 01187 Dresden, Germany.

${ }^{6}$ King's College London, King's Health Partners, Department of Psychosis Studies, Institute of Psychiatry, London, UK

Correspondence: Jim van Os, Dept. Psychiatry and Psychology, Maastricht University Medical Centre, PO BOX 616, (DRT12), 6200MD Maastricht, The Netherlands. Tel 31-43-3875443; Fax 31-43-3875444. Email: j.vanos@maastrichtuniversity.nl 


\begin{abstract}
Objectives: The reported $10 \%-20 \%$ yearly conversion rate from psychotic experience to clinical psychotic outcome forms the major rational for the practice of intervention in individuals at ultra high-risk, and the proposed DSM-5 Psychosis Risk Syndrome. However, the base rate of transition from subthreshold psychotic experience (the exposure) to clinical psychotic disorder (the outcome) in unselected representative population-based samples is unknown.
\end{abstract}

Methods: A systematic review and meta-analysis was conducted of representative, longitudinal population-based cohorts with baseline assessment of subclinical psychotic experiences and follow-up assessment of psychotic and non-psychotic clinical outcomes.

Results: Six cohorts were identified with 3-24 year follow-up of baseline psychotic experiences. The yearly risk of conversion to a clinical psychotic outcome in exposed individuals $(0.56 \%)$ was 3.5 times higher than for individuals without psychotic experiences $(0.16 \%)$. Conversion risk increased with the number, certainty, frequency, persistence and degree of affective dysregulation of psychotic experiences. There was also evidence of specificity, as psychotic experiences only weakly predicted non-psychotic clinical outcomes.

Conclusions: Subclinical psychotic experiences index psychometric risk for psychotic disorder. However, the discrepancy between the $10 \%$ conversion rate in the high-risk literature and the $0.56 \%$ conversion base rate in unselected population-based samples points to the crucial influence of sample enrichment strategies through community awareness campaigns and other selective alterations of the permeability of filters on the pathway to mental health care that lie at the heart of all ultra high-risk studies. Sample enrichment strategies, rather than clinical high-risk criteria per se, may be the critical factor determining the success of high-risk early intervention initiatives.

Key words: Psychotic Disorders, Risk, Meta-analysis, Prevention, Delusions, Hallucinations 


\section{Introduction}

Psychotic disorders typically affect young people, disrupting critical maturational tasks. This fact, together with the observation that longer duration of untreated psychosis predicts poorer outcome, provides a powerful rational for intervening as early as possible $e^{1-3}$. Given the fact that psychotic disorders are usually preceded by sometimes lengthy prodromes, attempts have been made to intervene when individuals are in the early throws of a psychosis prodrome or 'at risk mental state ${ }^{4,5}$. However, early intervention based on risk can only be considered productive if samples are sufficiently enriched with cases that will actually make the conversion to a clinical psychotic disorder in a reasonably short period of time ${ }^{6,7}$. For example, if the risk of conversion in an 'at-risk mental state' sample is $5 \%$ over the course of a year (i.e. at least 100 times higher than the incidence of psychotic disorder in the general population), $95 \%$ of the sample would be treated unnecessarily if the sample underwent preventive pharmacological or psychotherapeutic treatment. Even if the treatment would be $50 \%$ effective in preventing conversion to a psychotic disorder (i.e. half of the $5 \%$ would be prevented from making a conversion), the number needed to inconvenience to prevent one case of conversion would be 40 (calculated as: 100/2.5), arguably too high for cost-effective use of sparse resources.

In order to shift the above mathematical considerations to more favourable values, a considerable amount of literature now exists on attempts to enrich samples in such a way that the risk of conversion is high enough for effective intervention ${ }^{8}$. Sample enrichment strategies may include advertising, increasing awareness in the community and targeting teachers and primary care physicians. Sample enrichment strategies are not usually described in detail so that standardized approaches have not been developed. For example, the sample enrichment strategy of the multisite North-American study on prediction of psychosis was described as: "Each site recruited potential subjects through clinical referrals as stimulated by talks to school counselors and mental health professionals in community settings" whereas in the European Prediction of Psychosis Study ${ }^{10}$ it was described as: "Knowledge about early warning signs (eg, concentration and attention disturbances, unexplained functional decline) and inclusion criteria was disseminated (through local workshops, articles in professional journals and newsletters, informational flyers, and Web sites) to mental health professionals as well as institutions and persons who might be contacted by at-risk persons seeking help". Using these unspecified enrichment strategies, and combining them with criteria on presence of "attenuated" or "transitory" psychotic experiences, family history and decline in functioning ${ }^{11}$ initially appeared to yield samples with high conversion rates of up to $54 \%$ over 12 months $^{8}$. However, more recent and more systematically conducted studies in North America and Europe concur in finding 12-month cumulative conversion rates of $11.3 \%$ ( 82 out of 291 patients over a period of 2.5 years) $;{ }^{9}$ and $10.1 \%$ (37 out of 245 subjects over 18 months); ${ }^{10}$ respectively.

A major and hitherto unresolved issue regarding the interpretation of these studies is that the base risk of conversion given expression of subclinical psychotic experiences in the general population is not known. Therefore, to date it remains unknown to what degree the $10 \%$ conversion rate in enriched samples is due to (i) non-standardized and therefore nonreplicable sample enrichment strategies including awareness and education campaigns, (ii) specific criteria involving family history or decline in functioning and (iii) presence of subclini- 
cal psychotic experiences ${ }^{6,12}$. In addition, research suggests that the risk for non-psychotic outcomes may also be increased, but non-psychotic disorders as an outcome of subclinical psychotic experiences are rarely reported ${ }^{6}$.

In order to address this issue, we reviewed the literature on the risk of developing psychotic disorder given earlier expression of subclinical psychotic experiences in representative, general population samples. To this end, the method of systematic review and metaanalysis was used, as these generally provide a transparent and quantitative approach to identify, summarise and critically appraise relevant studies, enabling an integrated presentation of results. Furthermore, systematic review and meta-analysis can address metahypotheses over and above primary studies by quantitative exploration of the patterns of results from single investigations. Specific aims of this meta-analysis were: (i) to examine the risk of conversion to psychotic disorder given presence of subclinical psychotic experiences in representative general population samples, (ii) to examine the risk of conversion to nonpsychotic disorder given presence of subclinical psychotic experiences in representative general population samples, (iii) to examine which symptom factors moderate risk of conversion. In order to achieve these goals, methodology for systematic review as laid down in Metaanalysis of Observational Studies in Epidemiology (MOOSE) guidelines ${ }^{13}$ was applied. For some studies, additional analyses were conducted in the original data in order to be able to also report non-psychotic outcomes that had not been included in the original publications.

\section{Methods}

A computerized search strategy was developed to sensitively query the MEDLINE, PsycINFO and EMBASE databases to identify potentially relevant articles in English, Spanish, German, French or Dutch, published from 1951 to April 2010. A sensitive search string was composed with medical subject headings, specific for each database, for concepts relating to "subclinical psychotic experience", "psychotic disorder" and "conversion/transition". Reference lists of articles thus identified were screened in order to encounter additional articles. In addition, a process of forward and backward citation tracking was executed using the Web of Science database. Finally, researchers with expertise in the field were contacted in order to identify additional data potentially relevant for the meta-analysis. Thus, original individual participant data from two cohort studies, the NEMESIS study ${ }^{14,15}$ and the EDSP study ${ }^{16,17}$, were subjected to additional analyses in order to add information on non-psychotic outcomes, not published before, to the meta-analysis database.

In order to reduce methodological variations of studies to be entered in the metaanalysis, a priori criteria for inclusion were formulated. Thus, data of published studies were added to the meta-analysis database if they (i) were published in a peer-reviewed journal after 1950; (ii) were written using the English, Spanish, French, German or Dutch language; (iii) represented a population-based follow-up study of individuals with and without a defined measure of subclinical psychotic experiences at baseline (the exposure) and (iv) provided cumulative incidence rates (or data allowing computation of these) of defined psychotic disorder outcomes (the outcome).

Two investigators independently screened citations and selected publications for further consideration on the basis of consensus, using three consecutive filters. The first selection 
filter was at the level of citations, applying the broad criterion of relevance for the topic of the meta-analysis. The second selection filter was applied at the level of abstracts, excluding studies that did not meet a single inclusion criterion as defined above. The final filter was based on inspection of full-text articles. In the case of multiple reports involving a single study population, the publication with the largest sample size and/or the longest follow-up was selected.

In the next step, two investigators independently extracted quantitative and qualitative data from each selected publication. Qualitative data included factors impacting on internal validity such as methodological and design features as well as the potential for confounding as well as bias due to differential attrition or possible differential assessment of exposure and/or outcome. Quantitative data included cumulative conversion rates as a function of baseline exposure status (i.e. with and without subclinical psychotic experiences). Data pertaining to studies using continuous exposure measures were extracted and analysed according to the original continuous exposure format, and additionally analysed as a dichotomous exposure in order to facilitate comparison of results across studies. Dichotomisation was carried out by contrasting, in the case of three-level exposure variables (e.g. no symptoms, weak symptom, strong symptom), the highest category versus the lowest two. In the case of four-level exposures, the highest category was similarly compared to lowest three. In case data could not be extracted in a format suitable for meta-analysis, authors were contacted for re-analysis of the original data in the required format.

Table $1 \mathrm{~A}$ was compiled to provide a descriptive summary of selected studies, showing, for both psychotic and non-psychotic outcomes, the principal study characteristics including populations, observation periods, exposure and outcome definitions, main results and sample and study design features. Tables $1 \mathrm{~B}$ and $1 \mathrm{C}$ show the quantitative data extracted from each study for psychotic and non-psychotic outcomes, respectively.

\section{Approach to meta-analysis}

Data from the selected studies were combined to estimate pooled rates with their corresponding 95\% Confidence Intervals (Cls) under a random effects model, assuming that true effects were randomly distributed around the mean effect size. The random effect model presumes that variation in samples and design factors will occasion different true effect sizes across studies and represented a valid a priori choice given the fact that methods and populations across studies did not correspond to a degree that they could be regarded as estimating the same underlying effect. The between-study variance in the random effects model reflects heterogeneity across studies, the magnitude of which was evaluated using a chisquare test for heterogeneity, testing whether individual studies varied more than could be explained by chance alone. In the phase of reading and comparing the articles, various hypotheses for heterogeneity were identified. In case significant heterogeneity was encountered, possible causes were explored by analysing subgroups as well as by including variables occasioning heterogeneity (modifiers) in meta-regression analyses. 


\section{Additional analyses undertaken in original datasets}

For the specific purpose of the meta-analysis, exposure and outcome data as reported in the NEMESIS study by Hanssen and colleagues ${ }^{18}$ and the EDSP study by Dominguez and colleagues $^{19}$ were subjected to additional analyses. Both the NEMESIS and EDSP studies followed general population cohorts, interviewing the entire cohort with the CIDI on three occasions (EDSP: T0, T2 and T3; NEMESIS: T0, T1 and T2) over time ${ }^{14,15,16,17}$. In the NEMESIS study, fresh analyses were conducted to provide additional risk estimates for prevalent exposure (defined as lifetime report of subclinical psychotic experiences at T0, as described $\mathrm{in}^{20}$ ) in addition to the incident exposure reported in the original paper ${ }^{18}$. In both the NEMESIS and the EDSP data sets, additional analyses were conducted with the following non-psychotic outcomes: T2 (NEMESIS) or T3 (EDSP) CIDI diagnosis of bipolar disorder, excluding individuals with a similar diagnosis at T0/T1 (Nemesis) or T0/T2 (EDSP) ${ }^{21-24}$; T2 (NEMESIS) or T3 (EDSP) $\mathrm{CIDI}$ diagnosis of depressive disorder, excluding individuals with a similar diagnosis at TO/T1 (NEMESIS) or TO/T2 (EDSP) and individuals with a T2 (NEMESIS) or T3 (EDSP) CIDI diagnosis of bipolar disorder ${ }^{21-24}$; T2 (NEMESIS) or T3 (EDSP) CIDI diagnosis of anxiety disorder, excluding individuals with a similar diagnosis at TO/T1 (NEMESIS) or TO/T2 (EDSP) as well as individuals with a T2 (NEMESIS) or T3 (EDSP) CIDI diagnosis of depressive disorder or bipolar disorder ${ }^{14}$, 15, 25. All extra analyses were conducted in strict accordance with the methodology described in the original studies and therefore are not reported in detail again here (details available upon request).

\section{Statistical analysis}

All analyses were performed using Stata $11^{26}$. A data file including data pertaining to both psychotic and non-psychotic outcomes was constructed. One study reported 5 different psychotic outcomes ${ }^{27}$ - these were combined into a single psychotic outcome.

First, dichotomised exposures were analysed. For these analyses, each record in the data included sample size, number of subjects with a negative outcome, years of study follow up and information on modifiers. Using the first three variables, rates per 100,000 person years were calculated. For each study, at least two records were filled (exposed, non-exposed). More records were used when rates were stratified by possible outcome modifiers (psychotic/non-psychotic disorder, hospital admission yes/no, incident/prevalent exposure, see below). Bar charts were generated to present the rates per study for psychotic as well as non-psychotic outcomes ${ }^{28,29}$.

A meta-analysis stratified by exposure and by type of outcome (psychotic/non-psychotic) generated forest-plots (Stata METAN command). Subsequently, the rates were analysed using meta-regression analysis (Stata METAREG command). As rates are not normally distributed, and because the number of studies was small and heterogeneity was expected, metaregression was repeated using 1000 permutations (Stata METAREG command with option PERMUTE). In addition, meta-regression analyses were repeated for more homogeneous subsets of studies (as described below).

Second, in order to study dose-response effects, exposures were analysed as three-level variables including 3 categories of graded severity/frequency where available; if there were 4 categories, the two lowest categories were combined to create a similar three-level exposure 
variable. For this analysis, rates were also presented in a figure and meta-regression analysis was performed.

\section{Results}

\section{Search results}

The search yielded 7 articles with data that were pertinent to the meta-analysis as specified in the criteria above. One study ${ }^{30}$ was excluded as it concerned a subgroup of persons included in the study by Chapman and colleagues ${ }^{27}$, already included in the meta-analysis.

The characteristics of the 6 studies, included in the meta-analysis, are listed in table $1 \mathrm{~A}$. All studies had general population sampling frames (two birth cohorts ${ }^{31,32}$, three representative general population cohorts ${ }^{18,19,33}$ ) although in one study the selection was limited to undergraduate students ${ }^{27}$; follow up varied from 3 years to 24 years. All studies reported on variably defined psychotic experiences in the general population and the rate of transition to variably defined psychotic and non-psychotic clinical outcomes. One study used high level of schizotypy as predictor ${ }^{27}$, all other studies used CIDI or related measures of psychotic experiences. Non-psychotic outcomes were depression, mania, anxiety disorder and admission to hospital for non-psychotic disorder. Some studies described various exposure subgroups, varying from classification on the basis of number of symptoms (no symptom, single symptom, multiple symptoms); frequency/certainty of psychotic symptom (no symptom, "weak" symptom and "strong" symptom); psychopathological context (no symptom, symptom without depression, symptom with depression); degree of persistence over 5 years (present at none, one, two or three assessments over 5 years). Some studies also described rates as a function of combinations of subgroups (e.g. multiple symptoms with and without comorbid depression ${ }^{18}$ ). All 6 studies reported on psychotic clinical outcomes, and 5 studies additionally reported on other, non-psychotic, clinical outcomes. For one study ${ }^{18}$, measures of both incident (psychotic experiences with first onset in the previous year) and prevalent (lifetime presence of psychotic experiences) exposure were available. One study ${ }^{33}$ reported servicebased clinical outcomes, defined as admission to hospital. 


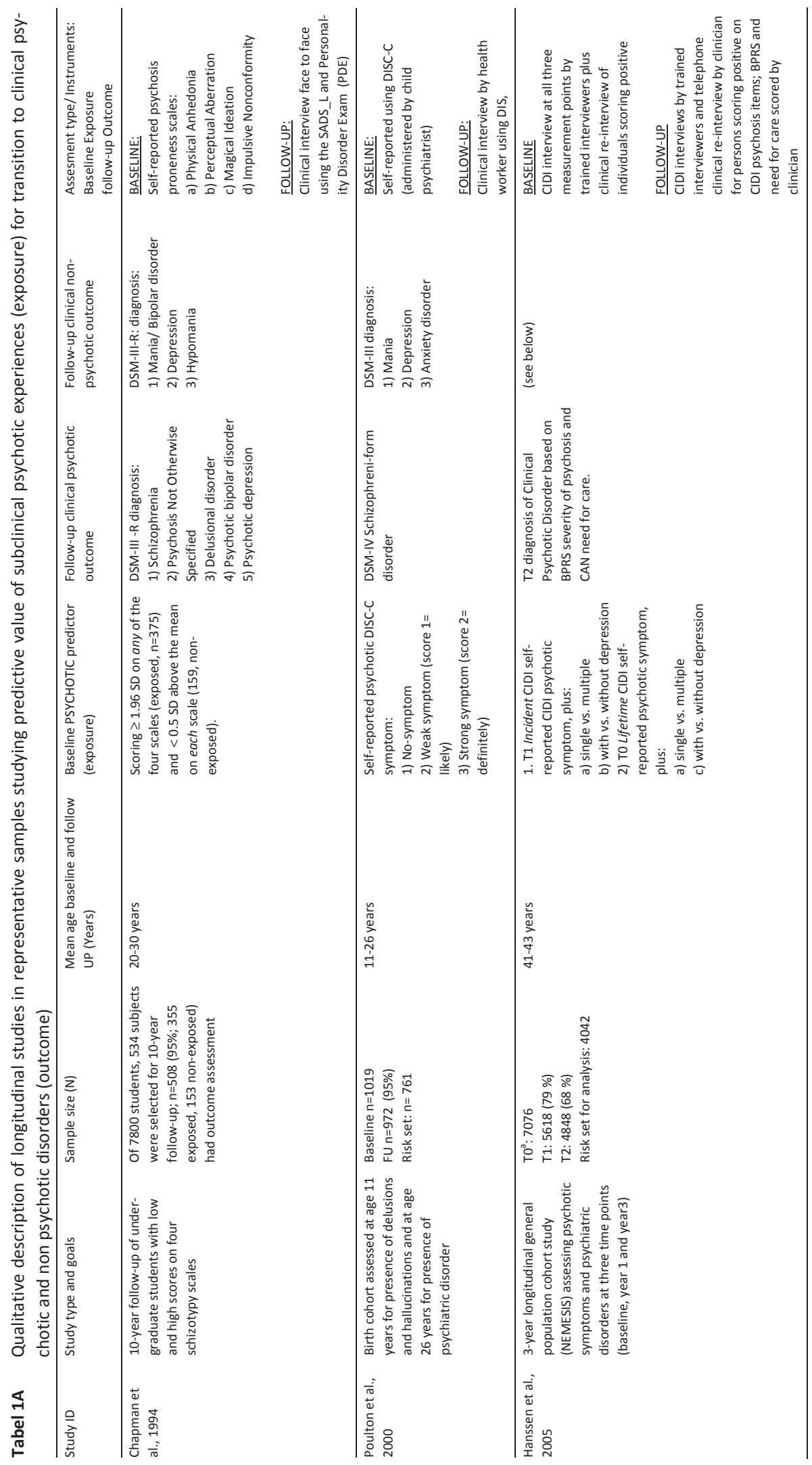




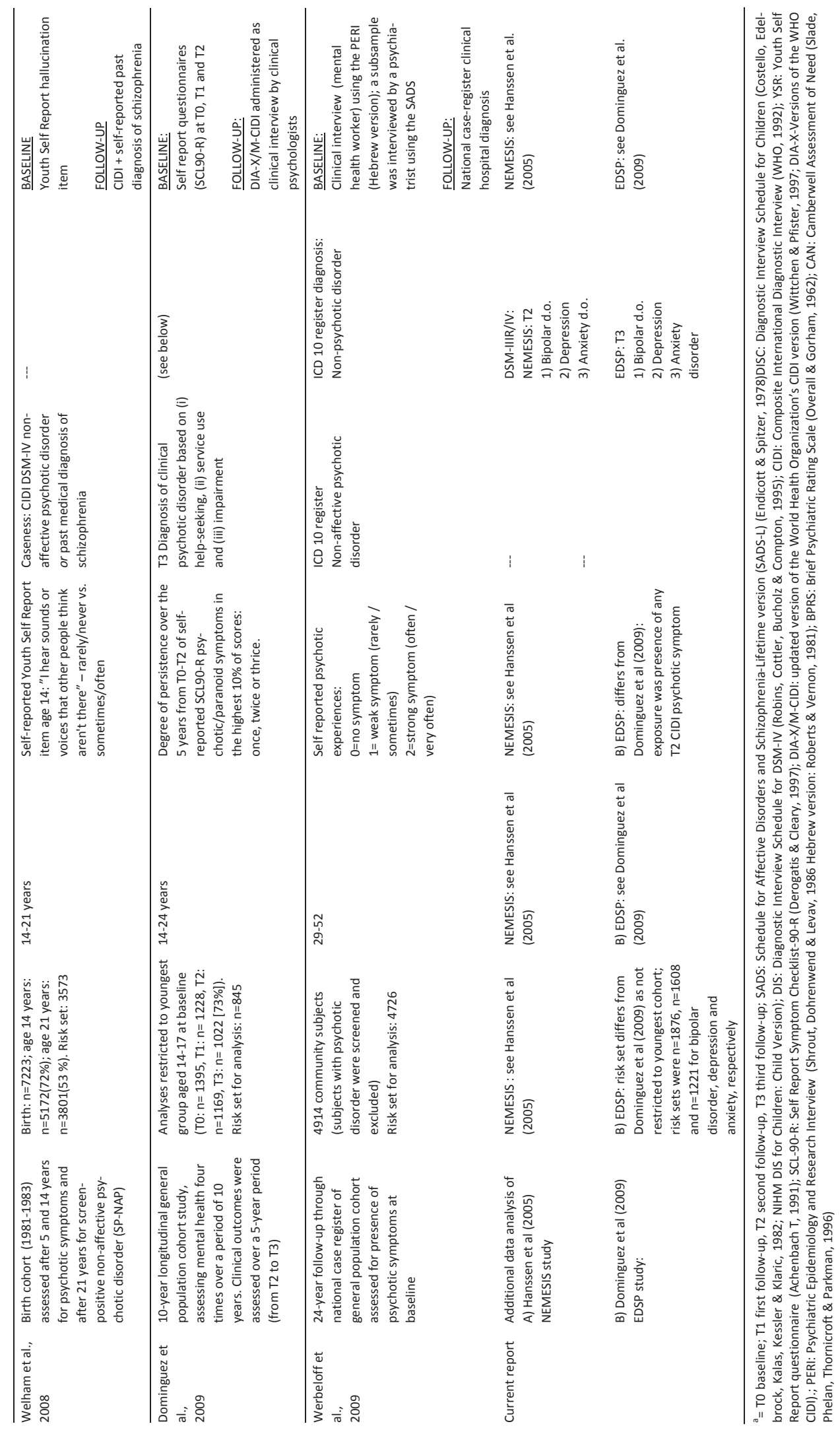


Description of the possible modifiers as causes of heterogeneity of the studies Four studies ${ }^{18,19,31,32}$ used similar methodology for exposure and outcome assessment based on the Composite International Diagnostic Interview ${ }^{34}$ whereas other studies ${ }^{27,33}$ used different instruments. Similarly, all studies reported exposure assessment based on prevalence estimates whereas one study also reported assessment of incident exposure ${ }^{18}$. Another important factor was that one study provided outcomes based on hospital admission ${ }^{33}$, whereas all other studies were independent of health care use. Thus, three modifiers were included in meta-regression analyses (psychotic/non-psychotic disorder, hospital admission yes/no and incident/prevalent exposure); in addition sensitivity analyses excluded results that were outliers with respect to outcome assessment (hospital admission in the study by Werbeloff and colleagues ${ }^{33}$ ).

\section{Results for dichotomous exposure meta-analysis}

Original study results

Findings from individual studies are summarised in tables $1 B$ (psychotic outcomes) and $1 \mathrm{C}$ (non-psychotic outcomes). 


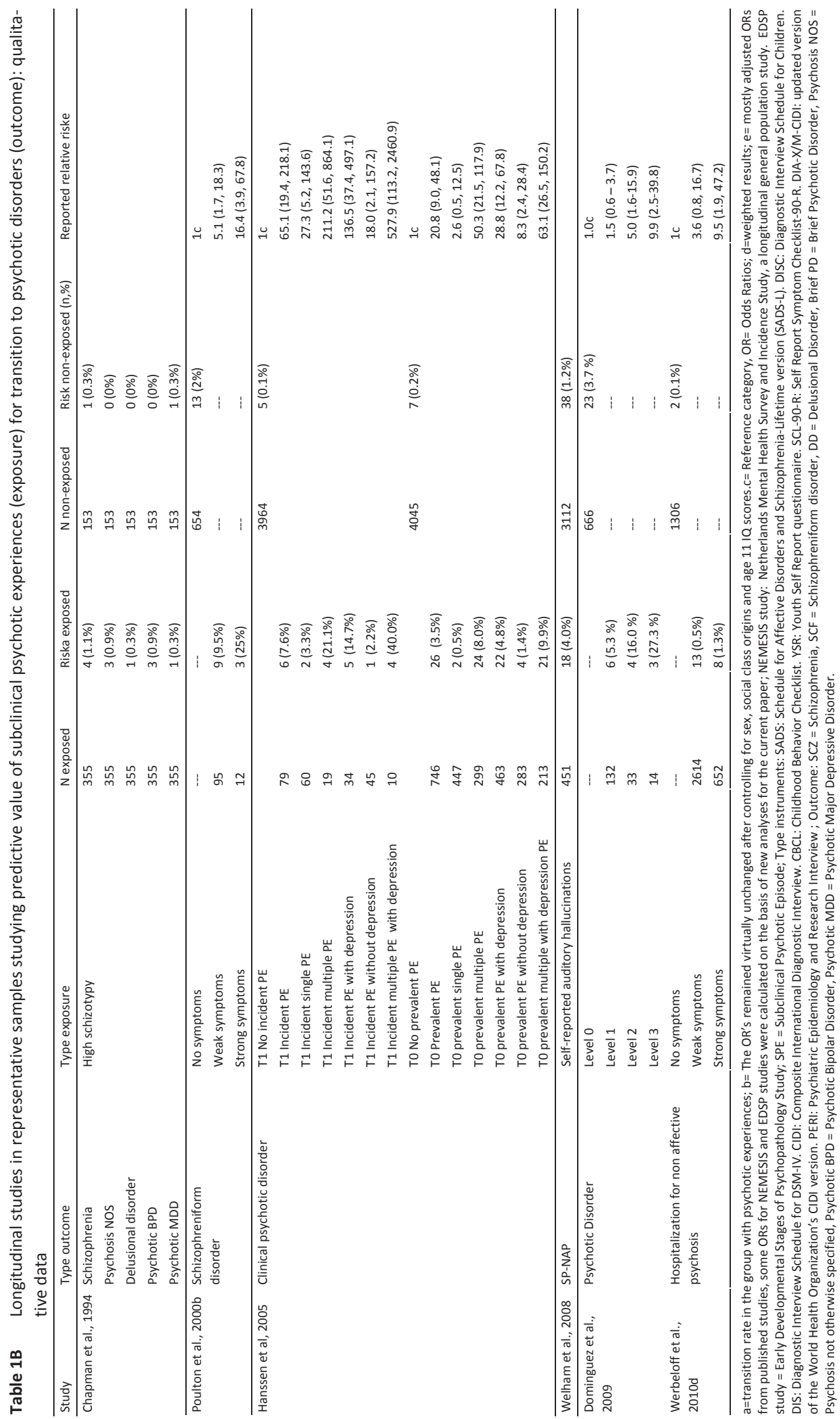




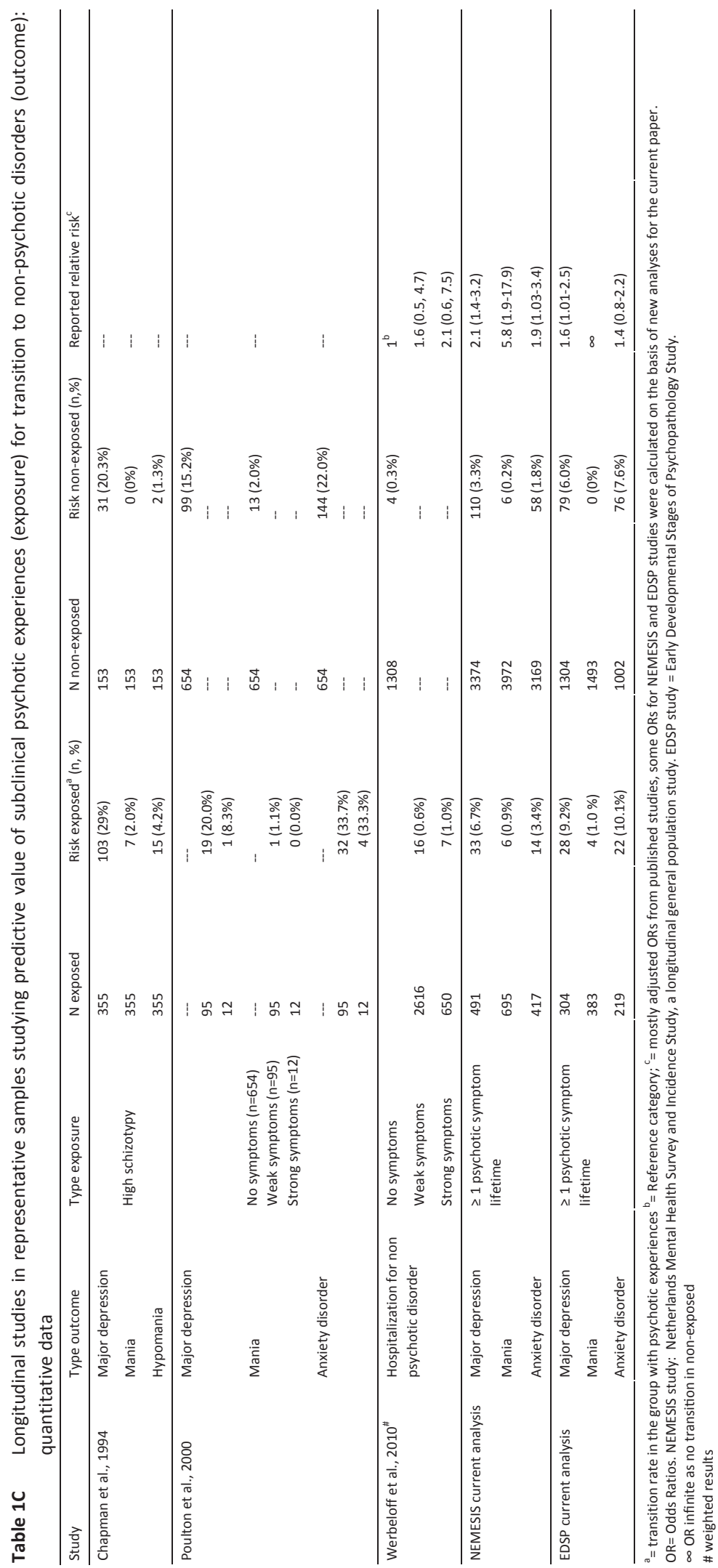


All studies showed that subclinical psychotic experiences strongly predicted clinical psychotic outcomes. The 3-24 year risk for the exposed was in the range of 5\%-25\%, substantially higher than the corresponding risk in the non-exposed (ranging from 0.1-3.7\%), with 3-24 year odds ratios in excess of 10 for the strongest level of exposure (Table 1B). A degree of outcome specificity was clearly present, as ORs for non-psychotic outcomes were mostly in the order of 2 (Table 1C).

\section{Meta-analysis}

In order to facilitate comparison, rates for all studies were uniformly transformed to express incidence of psychotic and non-psychotic outcomes per 100,000 person-years (Fig. 1a and Fig. 1b). This confirmed the pattern of results in Tables $1 \mathrm{~B}$ and $1 \mathrm{C}$, in that the incidence of psychotic clinical outcome in the exposed was much higher than in the non-exposed, and that the difference in incidence between exposed and non-exposed was much greater for psychotic than for non-psychotic clinical outcome. In addition, the results showed that the absolute risk for clinical outcome in the only study based on hospital admission ${ }^{33}$ was only a fraction of the risk in studies that did not depend on service use.

Figure 1 Rate per 100,000 person years of psychotic (a) and non-psychotic (b) outcomes in exposed and unexposed subjects (prevalent exposure only).

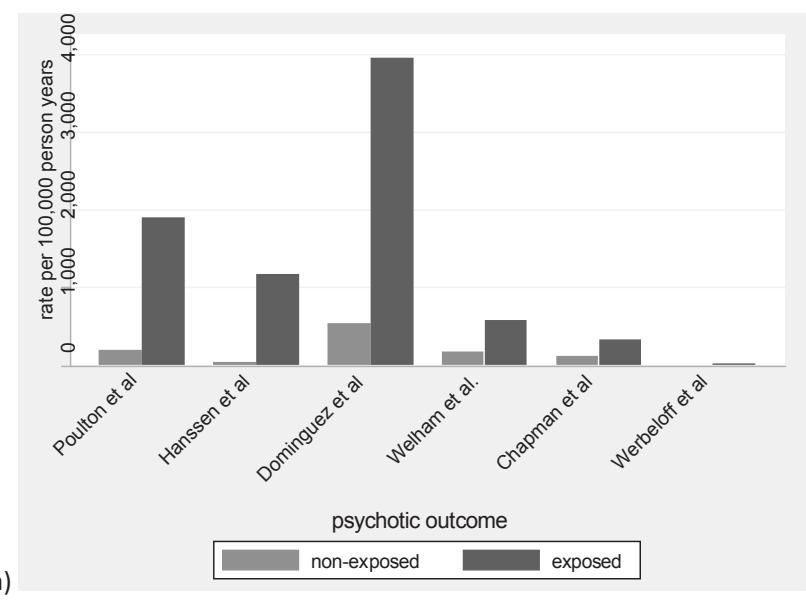

(a)

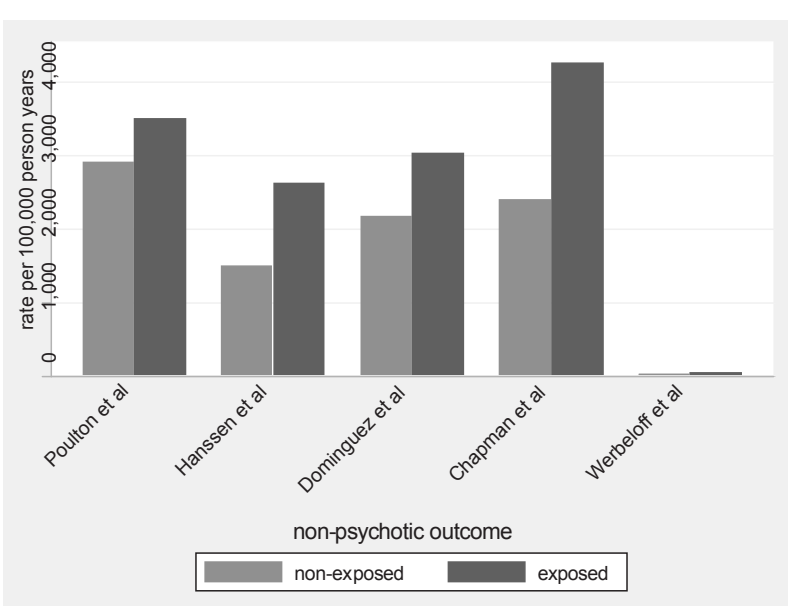


Meta-analysis results for psychotic (Fig. 2a) and non-psychotic (Fig. 2b) clinical outcomes (for the Hanssen study, based on NEMESIS data ${ }^{18}$, results with prevalence exposure were included), show that the combined yearly incidence rate of psychotic clinical outcome given the presence of a prevalent subclinical psychotic experience was 159 per 100,000 personyears ( $0.2 \%$ per year) in the non-exposed, and 558 per 100,000 person-years ( $0.6 \%$ per year) in the exposed. For the non-psychotic outcomes, yearly transition incidence rates for exposed and non-exposed were $1.8 \%$ and $2.6 \%$, respectively. For non-psychotic outcomes, confidence intervals were wide and for both psychotic and non-psychotic outcomes, confidence intervals overlap (Fig. $2 \mathrm{a}$ and Fig. $2 \mathrm{~b}$ ), indicating that the difference in yearly incidence rate between exposed and non-exposed was non-significant for both psychotic and nonpsychotic clinical outcome. Heterogeneity was large (psychotic outcome non-exposed: $\chi^{2}=81.6, d f=5, p<0.001 ;$ psychotic outcomes exposed: $\chi^{2}=54.1, d f=5, p<0.001$; non psychotic outcomes non-exposed: $\chi^{2}=666.9, \mathrm{df}=4, p<0.001$; non psychotic outcomes non-exposed: $\chi^{2}=$ 235.4, $d f=4, p<0.001$ ).

Figure 2 Forest plot of rates per 100,000 person years in each study for the exposed and the nonexposed of psychotic (a) and non-psychotic (b) outcomes, prevalent exposure only.

\begin{tabular}{|c|c|c|c|}
\hline \multicolumn{3}{|l|}{ Study } & \multirow{2}{*}{$\begin{array}{l}\% \\
\text { Weight }\end{array}$} \\
\hline ID & & ES $(95 \% \mathrm{Cl})$ & \\
\hline \multicolumn{4}{|l|}{ nonexposed } \\
\hline Poulton et al & $\rightarrow$ & $198.74(115.77,281.70)$ & 12.60 \\
\hline Hanssen et al & fis & $57.73(14.98,100.49)$ & 14.50 \\
\hline Dominguez et al & $1 \bullet$ & $547.45(361.18,733.71)$ & 7.32 \\
\hline Welham et al. & $\phi$ & $175.51(119.76,231.27)$ & 13.97 \\
\hline Chapman et al & + & $131.58(-50.66,313.81)$ & 7.49 \\
\hline Werbeloff et al & to & $17.28(8.54,26.02)$ & 15.30 \\
\hline Subtotal (I-squared $=93.9 \%, p=0.000$ ) & $\theta$ & $158.67(69.85,247.49)$ & 71.18 \\
\hline \multicolumn{4}{|l|}{ exposed } \\
\hline Poulton et al & & $1904.76(-230.01,4039.54)$ & 0.11 \\
\hline Hanssen et al & - & $1182.36(730.58,1634.14)$ & 2.06 \\
\hline \multicolumn{4}{|c|}{$3947.37(-430.37,8325.11)$} \\
\hline Welham et al. & in & $581.77(313.79,849.75)$ & 4.70 \\
\hline Chapman et al & $\rightarrow$ & $343.84(149.63,538.05)$ & 7.00 \\
\hline Werbeloff et al & p & $39.91(10.35,69.48)$ & 14.93 \\
\hline Subtotal (1-squared $=90.8 \%, p=0.000$ ) & 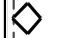 & $558.19(170.58,945.80)$ & 28.82 \\
\hline Overall $($ I-squared $=92.2 \%, p=0.000)$ & i & $195.25(125.53,264.96)$ & 100.00 \\
\hline \multicolumn{4}{|l|}{ NOTE: Weights are from random effeds analysis } \\
\hline $\begin{array}{c}1 \\
-8325\end{array}$ & 0 & & \\
\hline
\end{tabular}

(a) 


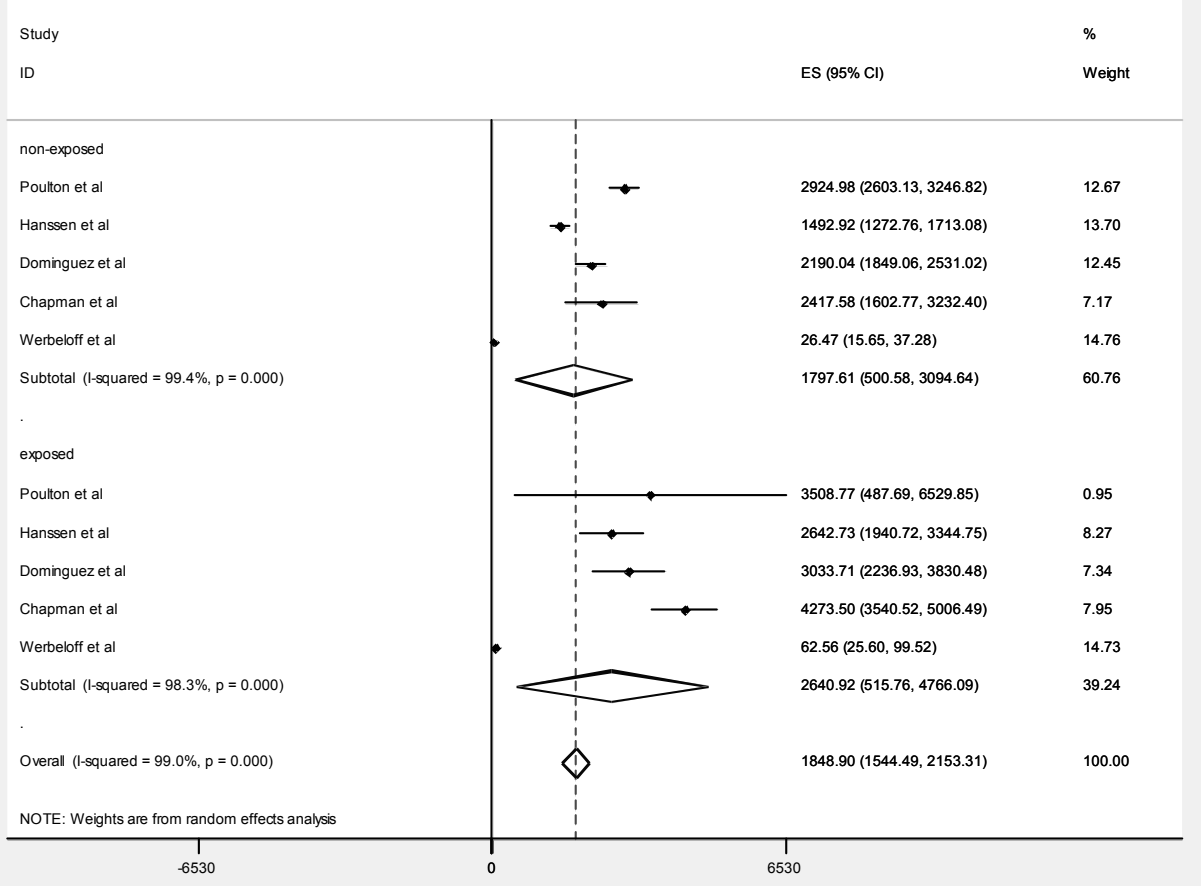

(b)

Meta-regression, including the four studies that used similar CIDI-based methodology for exposure and outcome assessment ${ }^{18,19,31,32}$ suggested that the effect of subclinical psychotic experiences on psychotic clinical outcome was significant (difference in incidence between exposed and non-exposed 648 per 100,000 person-years, $p=0.043$ ), whereas the effect for non-psychotic clinical outcome, although directionally similar, was not statistically significant (difference in incidence 694 per 100,000 years, $p=0.31$ )(Table 2). Meta-regression using permutations showed similar or more conservative $p$-values (non-psychotic outcomes exposure $p=0.52$; psychotic outcomes exposure $p=0.11 ; T$-values were all in the same direction).

Table 2 Meta-regression results stratified by psychotic/non-psychotic outcome including the four studies that used similar methodology for exposure and outcome assessment based on the Composite International Diagnostic Interview ${ }^{18,19,31,32}$.

\begin{tabular}{ccclcc}
\hline \multicolumn{3}{c}{ non-psychotic outcomes (6 records) } & \multicolumn{3}{c}{ psychotic outcomes (8 records) } \\
\hline $\begin{array}{l}\text { regression } \\
\text { coefficient }\end{array}$ & $95 \% \mathrm{Cl}$ & $\mathrm{p}$-value & $\begin{array}{l}\text { regression } \\
\text { coefficient }\end{array}$ & $95 \% \mathrm{Cl}$ & $\mathrm{p}$-value \\
Exposure* 694 & $-953 ; 2342$ & 0.31 & 648 & $28 ; 1269$ & 0.043 \\
\hline
\end{tabular}

*Exposure was the measure of subclinical psychotic experiences used (see Table 1)

\section{Modifier effects}

Including all studies, all psychotic and non-psychotic outcomes and all identified modifiers in a meta-regression analysis (Table 3) revealed that (i) rates were significantly lower for psychotic outcomes, (ii) rates were significantly higher in the exposed group, (iii) incident expo- 
sure was not a modifier and (iv) the one study analysing hospital admissions reported significantly lower rates.

Table 3 Meta-regression results, including all categories of all modifiers in one meta-regression model.

\begin{tabular}{lccc}
\hline (24 records) & regression coefficient & $95 \% \mathrm{Cl}$ & $\mathrm{p}$-value \\
\hline Exposure* & -1706 & $-2411 ;-1001$ & 0.000 \\
Psychotic & 771 & $73 ; 1470$ & 0.03 \\
Hospital admission & -1590 & $-2440 ;-740$ & 0.001 \\
Incident exposure* & 120 & $-1361 ; 1602$ & 0.87 \\
\hline
\end{tabular}

*Exposure was the measure of subclinical psychotic experiences used (see Table 1)

\section{Results for dose-response meta-analysis}

\section{Original study results}

Where examined, studies reported clear dose-response relationships for variably defined levels of exposure severity (certainty of symptom, frequency of symptom, number of symptoms, persistence over time, comorbid depression) in relation to risk of transition to psychotic clinical outcome (Tables $1 \mathrm{~A}$ and $1 \mathrm{~B}$ ). Only weak evidence for dose-response was present for non-psychotic clinical outcome (Tables $1 \mathrm{~A}$ and $1 \mathrm{C}$ ).

\section{Meta-analysis}

Transformation of all studies to the same person-year denominator showed comparable dose-response effects for psychotic clinical outcome, also for the study reporting hospitalbased outcomes ${ }^{33}$ and incident exposure assessment ${ }^{18}$. Thus, bars in Fig. 3 show that rates increase when exposure severity increases. Meta-regression including the three studies with linear multiple categories of exposure ${ }^{19,32} 18$ showed statistically a significant linear increase in yearly incidence per unit increase in exposure severity $(\beta=962, p=0.002)$.

\section{Discussion}

Subjects with a history of subclinical psychotic experiences displayed higher yearly rates of psychotic clinical outcome which was largely specific as the evidence for an increase in nonpsychotic clinical outcome was inconclusive. There was evidence for dose-response associated with number, certainty, frequency, persistence and level of affective comorbidity of psychotic experiences.

\section{Subclinical psychotic experiences as psychometric expression of risk for psychotic disorder}

In combination, these studies provide strong evidence for the validity of the notion that subclinical psychotic experiences represent psychometric risk for later psychotic clinical outcome. Although it could be argued that CIDI measures of clinical outcome yield high rates of false-positives, the predictive value of subclinical psychotic experiences was also apparent in 
predicting the "hard" outcome of hospital admission. Additional validity is suggested by the presence of dose-response and specificity.

\section{Comparison with 'high risk' in the ultra high-risk literature}

As mentioned earlier, the two more recent systematic European and US studies on yearly rate of transition in help-seeking individuals with 'high risk' psychotic experiences is around $10 \%{ }^{9,10}$. As for the great majority of individuals in these studies high risk criteria were fulfilled because of the presence of the same "attenuated" or "transitory" psychotic experiences as reviewed here, the discrepancy between the yearly risk of $0.6 \%$ in the populationbased studies reviewed here and the $10 \%$ in the high-risk studies presented in the ultra highrisk literature requires an explanation. Even if we assume that the yearly risk of conversion in the representative population-based studies may be as high as $1 \%$, allowing for the possible underestimation associated with non-linear transition patterns over time (see below), and focussing on the most severe level of psychotic experiences, the at least 10 times higher yearly conversion rate in help-seeking individuals presented in the ultra high-risk literature is remarkable. An important factor that at least in part explains the discrepancy is the unspecified sample enrichment strategies that have been employed in the ultra high-risk studies. These studies show that by conducting extensive community awareness campaigns, it is possible to select help-seeking individuals with psychometric risk in such a way that a $10 \%$ yearly conversion rate is brought about. The fact that many studies now have shown that this is possible represents an important milestone for early intervention, and may benefit many individuals at high risk for psychotic illness. The problem, however, is that the high yearly risk of conversion observed in the ultra high-risk literature is invariably attributed to variably defined high risk criteria, the main one being presence of "attenuated" or "transitory" psychotic experiences, whereas the current meta-analysis demonstrates that the contribution of psychotic experiences per se is quite low. Therefore, what can be deduced is that the critical factor feeding prediction of conversion is the use of hitherto largely unspecified sample enrichment strategies through community awareness campaigns and other means of selective alteration of the permeability of the filters on the pathway to mental health care. The current results suggest that these sample enrichment strategies, rather than clinical high risk criteria per se, are the critical factor allowing for the successful completion of the first stage of any high-risk early intervention initiative: to generate a sampling frame at high enough risk to consider the use of intervention in the first place. Therefore, there is an urgent need to clearly describe and operationalise these strategies.

The fact that psychotic experiences were relatively specific in predicting psychotic outcomes is disappointing from the point of view of intervention at the stage of risk, as the 'yield' of such interventions is logically much greater if risk is associated with a much broader outcome than clinical psychosis alone.

\section{Relevance for the DSM-5 Risk Syndrome}

For the reasons outlined above, the current results are relevant for the debate regarding the possible inclusion of a Psychosis Risk Syndrome (PRS) in DSM-5. If the risk function in PRS is occasioned not by psychometric criteria but instead is largely fed by unspecified sample en- 
richment strategies that are not mentioned in the criteria, the inclusion of PRS in DSM-5 would be misleading and likely confuse its users ${ }^{12}$. Therefore, if PRS is to be included in DSM5, operationalised criteria for sample enrichment strategies need to be added. However, given the paucity of data on replicable strategies to occasion sample enrichment, this may be premature.

\section{Methodological issues}

In calculating yearly incidence rates, the assumption was that the rate of transition would be spread evenly over the follow-up periods. This may not be valid, as there is some evidence that transition rates may be higher in the first 5-10 years ${ }^{33}$. Therefore, yearly incidence rates in two studies with longer follow-ups ${ }^{31,32}$ may vary and be somewhat higher in the earlier phases of the follow-up. Similarly, rates may vary according to age and sex, factors that could not be taken into account. Nevertheless, most studies were carried out in young people in the similar age range as samples in ultra-high risk studies.

The study by Chapman and colleagues ${ }^{27}$ was carried out in a sample of students; students are easy to recruit, but deviate from the general population as they are of younger age and higher educational level, associated with higher and lower level of psychotic experiences, respectively ${ }^{35}$. Inferences drawn from student data may therefore not be generalisable to the general population. Nevertheless, the pattern of results in the study with the student population was very similar to that of the others, and excluding the study in the metaregression showed similar results.

Because the present analysis included only six studies and the analyses focussed on rates rather than odds ratios, funnel plots are difficult to interpret. Publication bias cannot be ruled out. However, given the rarity of these types of studies and the fact that included studies cannot be considered as small yet with large effect size, publication bias is unlikely.

Permutation methods within meta-regression have been developed and implemented in Stata ${ }^{26}$. Permutation is necessary because meta-regression gives increased rates of falsepositives when the number of studies is small and when heterogeneity is present ${ }^{36}$. In addition, in the present study the outcomes, which are rates, are not normally distributed, another reason to conduct permutations. As expected, $p$-values were more conservative after permutations, but because results were similar original coefficients and $p$-values were presented.

\section{Acknowledgements}

This project was supported by the Netherlands Organisation for Scientific Research (NWO) under project number: 017.002.048. 


\section{References}

1. Marshall M, Lewis S, Lockwood A, Drake R, Jones $P$, Croudace T. Association between duration of untreated psychosis and outcome in cohorts of first-episode patients: a systematic review. Arch Gen Psychiatry Sep 2005;62(9):975-983.

2. Perkins DO, Gu H, Boteva K, Lieberman JA. Relationship between duration of untreated psychosis and outcome in first-episode schizophrenia: a critical review and meta-analysis. Am J Psychiatry Oct 2005;162(10):1785-1804.

3. Farooq $\mathrm{S}$, Large $\mathrm{M}$, Nielssen $\mathrm{O}$, Waheed $\mathrm{W}$. The relationship between the duration of untreated psychosis and outcome in low-and-middle income countries: A systematic review and meta analysis. Schizophr Res 2009;109(1-3):15-23.

4. Marshall M, Rathbone J. Early intervention for psychosis. Cochrane Database Syst Rev 2006(4):CD004718.

5. Yung AR, McGorry PD. The prodromal phase of first-episode psychosis: past and current conceptualizations. Schizophr Bull 1996;22(2):353-370.

6. Van Os J, Delespaul P. Toward a world consensus on prevention of schizophrenia. Dialogues Clin Neurosci 2005;7(1):53-67.

7. Bosanac P, Patton GC, Castle DJ. Early intervention in psychotic disorders: faith before facts? Psychol Med Mar;40(3):353-358.

8. Olsen KA, Rosenbaum B. Prospective investigations of the prodromal state of schizophrenia: review of studies. Acta Psychiatr Scand Apr 2006;113(4):247-272.

9. Cannon TD, Cadenhead K, Cornblatt B, et al. Prediction of psychosis in youth at high clinical risk: a multisite longitudinal study in North America. Arch Gen Psychiatry Jan 2008;65(1):28-37.

10. Ruhrmann S, Schultze-Lutter F, Salokangas RK, et al. Prediction of psychosis in adolescents and young adults at high risk: results from the prospective European prediction of psychosis study. Arch Gen Psychiatry Mar;67(3):241-251.

11. Olsen KA, Rosenbaum B. Prospective investigations of the prodromal state of schizophrenia: assessment instruments. Acta Psychiatr Scand Apr 2006;113(4):273-282.

12. Kaymaz N, Van Os J. DSM-5 and The 'Psychosis Risk Syndrome': Babylonic Confusion. Psychosis 2010;DOI: 10.1080/17522431003753233.

13. Stroup DF, Berlin JA, Morton SC, et al. Meta-analysis of observational studies in epidemiology: a proposal for reporting. Meta-analysis of Observational Studies in Epidemiology (MOOSE) group. JAMA Apr 19 2000;283(15):2008-2012.

14. Bijl RV, van Zessen G, Ravelli A, de Rijk C, Langendoen Y. The Netherlands Mental Health Survey and Incidence Study (NEMESIS): objectives and design. Soc Psychiatry Psychiatr Epidemiol 1998;33(12):581-586.

15. Bijl RV, Ravelli A, van Zessen G. Prevalence of psychiatric disorder in the general population: results of the Netherlands Mental Health Survey and Incidence Study (NEMESIS). Soc Psychiatry Psychiatr Epidemiol 1998;33(12):587-595.

16. Wittchen HU, Perkonigg A, Lachner G, Nelson CB. Early developmental stages of psychopathology study (EDSP): objectives and design. Eur Addict Res Mar 1998;4(1-2):18-27.

17. Lieb R, Isensee B, von Sydow K, Wittchen HU. The Early Developmental Stages of Psychopathology Study (EDSP): a methodological update. Eur Addict Res Dec 2000;6(4):170-182.

18. Hanssen $M, B a k M, B i j l ~ R$, Vollebergh $W$, van Os J. The incidence and outcome of subclinical psychotic experiences in the general population. Br J Clin Psychol Jun 2005;44(Pt 2):181-191.

19. Dominguez MD, Wichers M, Lieb R, Wittchen HU, van Os J. Evidence That Onset of Clinical Psychosis Is an Outcome of Progressively More Persistent Subclinical Psychotic Experiences: An 8-Year Cohort Study. Schizophr Bull 2011;37(1):84-93

20. Van Os J, Hanssen M, Bijl R, Ravelli A. Straus (1969) revisited: A psychosis continuum in the general population? Schizophr Res 2000;45(1-2):11-20.

21. Regeer EJ, Krabbendam L, de Graaf R, ten Have M, Nolen WA, van Os J. A prospective study of the transition rates of subthreshold (hypo)mania and depression in the general population. Psychol Med May 2006;36(5):619627.

22. Regeer EJ, Krabbendam L, De Graaf R, Have MT, Nolen WA, Van Os J. Berkson's bias and the mood dimensions of bipolar disorder. Int J Methods Psychiatr Res Dec 2009;18(4):279-286.

23. Tijssen MJ, van Os J, Wittchen HU, Lieb R, Beesdo K, Mengelers R, Krabbendam L, Wichers M. Evidence that bipolar disorder is the poor outcome fraction of a common developmental phenotype: an 8-year cohort study in young people. Psychol Med Feb 2010;40(2):289-299. 
24. Tijssen MJ, van Os J, Wittchen HU, Lieb R, Beesdo K, Mengelers R, Wichers M. Prediction of transition from common adolescent bipolar experiences to bipolar disorder: 10-year study. Br J Psychiatry Feb 2010;196(2):102108.

25. Zimmermann P, Wittchen HU, Hofler M, Pfister H, Kessler RC, Lieb R. Primary anxiety disorders and the development of subsequent alcohol use disorders: a 4-year community study of adolescents and young adults. Psychol Med Oct 2003;33(7):1211-1222.

26. StataCorp. STATA Statistical Software: Release 11. Texas: College Station; 2009.

27. Chapman L, Chapman JP, Kwapil TR, Eckblad M, Zinser MC. Putatively psychosis-prone subjects 10 years later. J Abnorm Psychol 1994;103(2):171-183.

28. Saha S, Chant D, McGrath J. Meta-analyses of the incidence and prevalence of schizophrenia: conceptual and methodological issues. Int J Methods Psychiatr Res 2008;17(1):55-61.

29. Linscott RJ, van Os J. Systematic reviews of categorical versus continuum models in psychosis: evidence for discontinuous subpopulations underlying a psychometric continuum. Implications for DSM-V, DSM-VI, and DSMVII. Annu Rev Clin Psychol Apr 27;6:391-419.

30. Kwapil TR, Miller MB, Zinser MC, Chapman J, Chapman L. Magical ideation and social anhedonia as predictors of psychosis proneness: a partial replication. J Abnorm Psychol 1997;106(3):491-495.

31. Welham J, Scott J, Williams G, Najman J, Bor W, O'Callaghan M, McGrath J. Emotional and behavioural antecedents of young adults who screen positive for non-affective psychosis: a 21-year birth cohort study. Psychol Med Jul 8 2008:1-10.

32. Poulton R, Caspi A, Moffitt TE, Cannon M, Murray R, Harrington H. Children's self-reported psychotic symptoms and adult schizophreniform disorder: A 15-year longitudinal study. Arch Gen Psychiatry 2000;57(11):1053-1058.

33. Werbeloff N, Drukker M, Dohrenwend BP, Levav I, Yoffe R, Van Os J, Davidson M, Weiser M. Self-Reported Psychotic Symptoms in the Community are Associated with Increased Risk of Later Hospitalization for NonAffective Psychotic Disorders (Conference Abstract). Schizophr Bull 2009;35(Supplement 1):74.

34. Robins LN, Wing J, Wittchen HU, et al. The Composite International Diagnostic Interview. An epidemiologic Instrument suitable for use in conjunction with different diagnostic systems and in different cultures. Arch Gen Psychiatry 1988;45(12):1069-1077.

35. Van Os J, Linscott RJ, Myin-Germeys I, Delespaul P, Krabbendam L. A systematic review and meta-analysis of the psychosis continuum: evidence for a psychosis proneness-persistence-impairment model of psychotic disorder. Psychol Med Feb 2009;39(2):179-195.

36. Higgins JP, Thompson SG. Controlling the risk of spurious findings from meta-regression. Stat Med Jun 15 2004;23(11):1663-1682. 
CHAPTER 5

Summary 


\section{General comments}

In this thesis, several studies are described concerning the developmental and affective aspects of schizophrenia and bipolar disorder, in terms of where they differ and overlap, and how that potentially overlaps in the prodrome.

Examination of the developmental and non-developmental risks of affective and nonaffective psychotic disorders has important diagnostic implications, which led us to include work focusing on examination of diagnostic likelihood ratios of developmental and nondevelopmental risks in relation to the diagnoses of schizophrenia and bipolar disorder. This is discussed in Chapters 2 and 3.

The study of the developmental domains of affective and non-affective psychosis was carried out by examining areas where they differ and overlap in genetic and environmental factors shared by these two disorders (Chapter 3). In addition, several aspects of the prodrome, in terms of the distinction between bipolar disorder and schizophrenia, were investigated, examining the view that transition from subclinical states of psychometric risk in the general population to psychotic disorder can be viewed from the perspective of a psychosis continuum. In order to investigate this, aspects of the epidemiology of psychotic experiences in the general population, which may predict transition to various clinical psychotic disorders, was investigated (Chapter 4).

In the above-mentioned studies, data pertaining to both the NEMESIS and the EDSP data were examined. Additionally, we examined evidence from the literature using the methodology of qualitative and quantitative review of both observational and experimental studies.

\section{Our findings}

In Chapter 2, the developmental domains of affective and non-affective psychosis - in particular schizophrenia and bipolar disorder - were investigated. A common and well accepted position regarding the causes of psychiatric disorders, especially with schizophrenia, is the supposition of a multifactorial component (Johns \& Van Os, 2001) similar to chronic physiological disease such as diabetes or cardiovascular disease. In the case of schizophrenia and bipolar disorder, this generally is taken to indicate that apart from the genetic component with reported heritabilities of around $80 \%$ for schizophrenia and bipolar disorder - environmental factors may play a role as well. However, it is unclear what impact genetic and environmental factors have in terms of attributable fraction within these highly heritable diagnostic constructs. It is also unclear to what extent genetic factors play in their contribution to domains generally taken to reflect aberrant neurodevelopment, such as brain structural alterations associated with these disorders. Since pathophysiological findings demonstrate that there are brain changes in most psychiatric disorders, we wanted to investigate to what extent there is a genetic contribution to the development of brain structures. We also wanted to see if this genetic influence is also the cause of the brain changes in schizophrenia, because the brain changes in schizophrenia have been investigated more extensively than in any other psychiatric disorder.

In the first article, 'Heritability of structural brain traits: an endophenotype approach to deconstruct schizophrenia', a literature search on the heritability of brain structures in 
healthy people, in people with schizophrenia and pedigrees was carried out. In this article, evidence from literature on the heritability of brain structures in healthy monozygotic twins was examined and the heritability rates in studies with monozygotic and dizygotic twins concordant and discordant for schizophrenia were summarised in order to be able to estimate the contribution of genetic and environmental factors to brain structures. Examination of the contribution of genetic and environmental factors was also investigated in pedigree studies, in which the genetic component can be estimated more accurately as environmental factors are assumed to play a minor role in pedigree effects. In addition, the genes that may be involved in these brain structures in the different subgroups were investigated.

The following conclusions were drawn from the studies: the brain structures that were formed earlier in life and also the deeper structures were more genetically influenced than structures formed later in life, which are more environmentally influenced. The findings were similar for most of the brain structures across the different groups. However, there were also conflicting results in different studies on the same brain structures both in healthy people and in patients with schizophrenia. The brain changes in schizophrenia are present in about $50 \%$ of the patients that are included in these neuroimaging findings. As for the genes underlying these effects on brain structures, there are not enough studies showing evidence for effects of specific genes on specific brain structures.

The use of brain structures as an endophenotype may be valuable in deconstructing the genetics of brain traits in healthy people, people with schizophrenia and in pedigrees. Taking into account the limitations of neuroimaging as well of genetic epidemiological studies, and considering the problematic assumption that monozygotic twins share the (prenatal and postnatal) environment to the same degree as dizygotic twins, that most studies included rely on, the results of this review can only be described as helpful for further research in defining which brain structures might be more genetically influenced and represent genetic effects underlying the aetiology of schizophrenia. More research is necessary, and it is too early to state to what extent brain structural alterations represent the genetics of schizophrenia, let alone bipolar disorder, in a meaningful way.

In the second article, 'Murray et al. (2004) revisited: is bipolar disorder identical to schizophrenia without developmental impairment?', the developmental factors in the overlap or non-overlap between the two disorders, i.e. schizophrenia and bipolar disorder, were investigated in a qualitative review. The search was carried out by examining the evidence from the literature in the past ten years and by revisiting the view by Murray et al., who published an article in 2004 which advocated the view that bipolar disorder was identical to schizophrenia without, however, expression of developmental impairment.

Most of the findings by Murray et al. (2004) are still relevant, according to our findings from the literature. An additional finding was that in the past ten years, more evidence has arisen that genetic risk for schizophrenia is expressed in part as neurocognitive impairments, whereas genetic risk for bipolar disorder is only mildly expressed with neurocognitive alterations. General population studies show that both disorders have phenotypes that are associated with psychometric risk states in healthy individuals and that these psychometric states are similarly highly comorbid with each other. One other finding was that exposure to an urban environment impacts on specific developmental associations with schizophrenia which is not observed in bipolar disorder, although we did find in one of our analyses with the NEMESIS data (Chapter 3, first article), that urbanicity specifically impacts on the psychotic 
but not on the affective dimension of bipolar disorder, suggesting dimension-specific effects across diagnostic categories.

In the third article, 'Extended psychosis phenotype - yes: single continuum - unlikely', an alternative theory opposing the categorical view of psychiatric disorder, in the sense of ill versus not ill (in contrast to the use of continuum as denoting a lack of contrast between disorder categories within psychotic illness), e.g. the continuum theory of psychosis, was investigated conceptually in an attempt to clarify whether a population psychosis continuum or, perhaps better described as extended psychosis phenotype exists and, if so, how this extended psychosis phenotype is distributed fully or quasi-continuous, and what determines whether some people experiencing psychotic experiences develop psychotic disorders later in life whereas others do not. Until recently, research on syndromal clustering of dimensions of psychosis was carried out almost exclusively in the population of people already attending mental health services, based on the assumption that symptoms observed in patients with psychotic disorder naturally did not exist outside mental health services. However, general population studies are showing that syndromal clusters of psychotic and affective symptoms not only exist in populations attending mental health services, but also are expressed as extended phenotypes in the general population (Stip \& Letourneau, 2009). In order to be able to make a conceptual shift from studying clusters of psychosis dimensions in mental health services to the general population, it may not be productive to consider populations inside and outside the hospital as different at the level of symptoms per se, but at the level of whether or not need for care has developed. Not every person with a psychotic symptom will develop a clinical need, resulting in a visit to a general practitioner or to psychiatric services.

This subject is further investigated in the last article of chapter 4 . We present in this article the first meta-analysis to ever attempt to estimate which people, given a certain level of expression of the extended psychosis phenotype in the general population (i.e. not in highly selected high-risk samples) will develop need for care, help-seeking behaviour and diagnostic status. Data were extracted from all published longitudinal studies in non-help-seeking general populations. We conclude that there are a number of variables predicting the transition of subclinical symptoms in general populations to clinical disorders. Not only the load of psychotic experiences is important, but also what type of coping the person develops, and the degree of persistence of these subclinical psychotic symptoms over time. We further suggested a new model for research across the psychotic spectrum, suggesting that there is a psychosis continuum, but not a single psychosis continuum.

In Chapter 3, studies concerning the affective domains of psychosis are presented. In the first two articles, NEMESIS data were analysed, in search for evidence for overlap (or nonoverlap) between affective and non-affective psychosis. In the first article, 'Evidence that the urban environment specifically impacts on the psychotic but not the affective dimension of bipolar disorder', urbanicity as an environmental risk factor for bipolar disorder was investigated, because reports on this issue have been inconsistent, whereas high rates of psychotic disorders have already been shown in numerous studies related to the urban environment. Our hypothesis was that any effect of urbanicity on the bipolar phenotype would be moderated by comorbid psychotic symptoms. The cumulative incidence of bipolar and psychotic symptoms and syndromes - assessed with the CIDI in relation to five levels of population density of place of residence - were examined. In addition, we examined the degree of comorbidity between broadly and narrowly defined bipolar phenotypes on the one hand and 
the dichotomous presence of broadly (17.2\%) and narrowly (3.8\%) defined psychotic symptoms on the other, as a function of population density of place of residence.

Higher rates of bipolar disorder, however defined, were observed in more urbanized areas, as well as a strong interaction between comorbid psychosis and level of urbanicity, indicating that with greater degree of psychotic comorbidity, a greater effect size of the urban environment was observed. For bipolar disorder without psychosis, no effect of urbanicity was apparent. These results suggest differential environmental causal effects on affective and psychotic dimensions of bipolar psychopathology.

Given the fact that associations with urbanicity are thought to reflect the impact of an environmental exposure that interacts with genetic liability to produce illness (Van Os, 2003a, 2003b, 2004), these results should be examined in light of previous work in the field of both molecular genetics and genetic epidemiology that has shown that there is a substantial sharing of genetic risk between bipolar disorder and non-affective psychosis (Cardno et al., 2002; Berrettini W, 2003a, 2003b). This means that when two individuals have a similar amount of shared genetic liability for both bipolar disorder and schizophrenia, the one that becomes exposed to an urban environment may develop a more psychotic illness, whereas the one not exposed to an urban environment may develop a more mania-only illness, suggesting that within the bipolar spectrum the impact of urban environment on the occurrence of more psychotic illness may be mediated by a different pathway than the rate of more mania-only illness. These mechanisms of gene-environment interaction have also been described for other psychiatric disorders such as depression and anxiety, two conditions that have been shown to share genes that, however, produce differential outcomes depending on subsequent exposure to divergent environmental risk factors, some resulting in anxiety outcomes and other in depression (Kendler et al., 1987, 1992, Kendler, 1996).

In the second article, 'The impact of subclinical psychosis on the transition from subclinical mania to bipolar disorder', the prevalence of subclinical psychotic and manic symptoms was investigated, in terms of how these subclinical population phenotypes co-vary with and impact on each other. Again, NEMESIS data were used and the degree of comorbidity between subclinical mania and subclinical psychosis was investigated. In addition, the impact of subclinical comorbidity on social impairment and on the transition from subclinical mania to onset of bipolar disorder was also investigated.

The lifetime prevalences of at least one manic and one psychotic symptom were $4.1 \%$ and $4.2 \%$, respectively, but, after excluding the people with DSM-III-R diagnoses of bipolar disorder or psychotic disorder, these prevalences were $2.3 \%$ (subclinical mania) and $2.8 \%$ (subclinical psychosis). Regarding the question as to how these phenotypes co-vary with each other, it was found that individuals with subclinical mania had a $17 \%$ risk of subclinical psychosis, compared to $2.3 \%$ in those without $(p<0.000)$. Subclinical psychosis in individuals with subclinical mania was much more predictive of a future diagnosis of bipolar disorder. As for social impairment, there was a positive interaction between social impairment due to physical and psychological problems and subclinical psychosis, indicating that for a given level of subclinical mania, the coexistence of subclinical psychotic symptoms was more predictive of social impairment, although this statistical interaction was not significant.

Thus, the subclinical phenotypes of mania and psychosis are more prevalent than their clinical counterparts and cluster together. One of the mechanisms by which the clustering of subclinical mania and subclinical psychosis may be relevant for clinical outcomes is that pos- 
sibly the formation of more toxic combinations of subclinical mania and subclinical psychosis may facilitate a higher transition to bipolar disorder. A better understanding of this pathway is crucial for the development of early intervention.

The study is important in showing that subclinical symptoms should not be neglected, since they result in higher transition rates from subclinical to clinical disorders; specifically the comorbidity of psychotic symptoms may be toxic in this regard. Subclinical phenotypes can be seen as intermediary phenotypes of a mood continuum that after exposure to additional risk factors may progress to a full-blown disorder (Hanssen et al., 2005), specifically in the presence of psychotic symptoms at the subclinical level.

In the third article, 'Evidence that patients with single versus recurrent depressive episodes are differentially sensitive to treatment discontinuation: a meta-analysis of placebocontrolled randomized trials', the focus was on the maintenance treatment of depression, as a paradigm for sensitisation. Antidepressants are effective in the treatment of depression, but also in prevention of relapse after remission from an acute episode. It is unclear though, to what extent the prophylactic effect of antidepressants is moderated by the duration of the continuation phase, level of abruptness of antidepressants discontinuation, or the number of previous episodes. This study attempted to address these questions.

All published randomized, placebo-controlled, double-blind clinical trials available before May 2007 were identified that addressed the efficacy of continuation or maintenance treatment of major depressive disorder with either SSRIs or TCAs and included patients entering a maintenance phase after achieving remission from the acute phase.

The conclusions were that the overall reduction of relapse risk in the maintenance phase was highly significant for both SSRIs and TCAs over one year of follow-up of maintenance treatment. Treatment with an antidepressant results in approximately $70 \%$ reduction of risk of relapse, confirming previous findings by Loonen et al. (1991), Geddes et al. (2003) and Viguera et al. (1998). The prophylactic effect appeared to be constant over the length of the continuation phase. The major conclusion in this study was that recurrent episode patients experience less protection from antidepressants over the maintenance phase than single episode patients. This suggests that with increasing number of episodes, patients may develop a relative resistance against prophylactic properties of antidepressant medication. There was no difference between abrupt discontinuation of antidepressants versus gradual discontinuation on relapse rates, except for a particular subgroup of recurrent episode patients, for which the mode of discontinuation was important. In these patients, abrupt discontinuation may lead to a relapse, a problem that has been identified for lithium as well. This finding may be interpreted in the context of sensitisation or a kindling-like process, in which biochemical and physiological processes involved in the illness become progressively more easily triggered by the same circumstances or precipitants.

We develop the hypothesis that sensitisation, as a form of progressive behavioural sensitisation, would be evident in depressive disorder manifested by evidence of decreased response to treatment with an increasing number of depressive relapses. However, the sensitisation model may not only be applicable to depression. There is accumulating evidence that behavioural sensitisation may also be relevant for psychotic disorder and in particular for positive symptoms in psychotic disorders (Collip et al., 2010). In other words, sensitisation may be important for the affective pathway in psychotic disorder (Myin-Germeys \& Van Os, 2007). Future studies should take this issue further, possibly focusing on both affective and 
psychotic symptoms in psychotic disorder, also in relation to antidepressant treatment in this group.

In Chapter 4, we described to what extent findings in the literature and research in psychiatry on developmental and affective domains of psychosis are applicable to the prodrome. Research on the prodrome is important because it is known that disorders such as schizophrenia or bipolar disorder do not have a sudden onset. In many patients, the first episode is preceded by a lengthy pre-phase in which symptoms manifest themselves in attenuated form for prolonged periods, sometimes as long as years. These trajectories may be amenable to early intervention, in order to reduce the psychological, social and possibly biological disruption that can lead to poor outcome (Pantelis et al., 2003).

Although there are many studies on the prodrome, these may be biased to a degree due to the vagaries of the selection processes that underlie the ultra-high-risk samples. Moreover, there is considerable confusion about the meaning conveyed by the term at risk mental state.

In the first article, 'DSM-V and the 'Psychosis Risk Syndrome': Babylonic confusion', the focus is on whether DSM-V should consider the inclusion of a new category, called the psychosis risk syndrome - or possibly the related term attenuated psychotic symptoms syndrome. We make the point that this should not occur, since risk is not an appropriate term in this context because subjects already, by definition, have a need for care, and the predictive value in even ultra-high-risk samples is too low for use in clinical practice.

In the second article, 'The case of the missing evidence: what do subclinical psychosis spectrum experiences predict in unselected representative population samples? A systematic review enriched with new results', a meta-analysis on psychotic experiences in the general population is presented, with a specific focus on unselected general population samples with psychotic experiences that are at risk of making the transition to a clinical disorder. The yearly risk of conversion to a clinical psychotic outcome in exposed individuals $(0.56 \%)$ was 3.5 times higher than for individuals without psychotic experiences $(0.16 \%)$. Conversion to a clinical disorder increased with the number, certainty, frequency, persistence and degree of affective dysregulation of psychotic experiences. The major finding in this study was the discrepancy between the $10 \%$ conversion rate in the high-risk literature compared to the actual $0.56 \%$ conversion rate in unselected population-based samples. The explanation for the discrepancy lies in the sample enrichment strategies through community awareness campaigns and other selective inclusion methods by which people participating in these highrisk studies are selected, creating a very high density of risk. The high conversion rates of the high-risk early intervention studies thus are based on sample enrichment strategies, rather than on clinical high-risk criteria per se. 

CHAPTER 6

Future directions 


\section{Future direction of diagnosis across the spectrum of psychosis}

Given the results of the studies included in this thesis, we can conclude that a multidimensional approach to the broad range of psychotic disorders, whether it is the affective domain or non-affective psychotic (syndromal) domain, would be more useful (Van Os et al, Nature, 2010) than conceiving of these syndromes as categorical entities. Thus, psychotic disorders may be viewed as the variable expression of a general psychotic syndrome consisting of various symptom dimensions that cross-sectionally cluster together in different degrees and combinations in different people. These symptom dimensions may, longitudinally, differ within the same people over time.

In this multidimensional approach four main dimensions of symptoms characterize the general psychotic syndrome: affective dysregulation (depression, mania or anxiety), psychosis (delusions, hallucinations), negative symptoms (motivational impairment) and cognitive alterations. In the general population, low levels of these four dimensional phenotypes represent the behavioural expression of vulnerability (extended phenotype in Figure 2, prevalence of $10 \%-20 \%$ ) for psychosis. Instead of estimating heritability rates for the diagnostic construct schizophrenia, from a scientific point of view it is more useful to investigate the heritability rates of these four symptom dimensions. The four symptom dimensions display moderately high heritability levels of their own, varying from $40 \%$ heritability rates for affective and psychosis domains to a range of $40 \%-60 \%$ of heritability rates for cognitive domains. For example, in the study by Chen and colleagues (2009), it was shown that in a sample of 278 subjects consisting of patients with schizophrenia, their non-psychotic siblings, healthy controls and their healthy full siblings, many clinical cognitive domains were impaired in patients with schizophrenia and their non-psychotic siblings compared to healthy controls and siblings of these controls. Negative symptoms, working memory, episodic memory and executive function were found to be significantly heritable in sibling pairs. Significant genetic correlations were observed between negative symptoms and the cluster of working memory, episodic memory and executive function. Similar findings on the heritability of cognitive functions were found by Antila and colleagues (2009). They found that the heritability of cognitive functions was generally similar irrespective of psychopathology in families of bipolar I disorder patients (bipolar families) and unaffected relatives with bipolar I disorder only in the family compared to another group of families with both bipolar I disorder and schizophrenia or schizoaffective disorder (mixed families).

The symptom domains, at subclinical level, show low levels of correlation in the general population as indicated by less overlap at the level of behavioural expression of vulnerability (heritability of $40 \%-60 \%$ ) seen in Figure 2 . The heritability of schizophrenia is around $80 \%$ $90 \%$, however these high heritability rates are not purely due to genetic factors. Part of the high heritability rate is due to the effect of genetic and environmental interactions that give rise to more severe levels of phenotypic expression, which in turn contribute to the likelihood of clinical detection by psychiatric services, by passing the filters on the pathway to mental health care (see mental health care filter in Figure 2). The symptom dimensions contribute independently to the clinical detection by psychiatric services and give rise to clinical diagnostic descriptions such as schizophrenia that have a relatively low prevalence on its own. However, these four symptom dimensions are subject to comorbidity bias (Berkson's 
bias), meaning that they are much more correlated and comorbid at the level of psychiatric services.

Current psychiatric diagnostic entities may not be as scientific or useful as we think. Ideally, a diagnosis in psychiatry should fulfil the following criteria (Van Os, 2010): the diagnostic construct of disease has: 1) some link with a measurable phenotype in nature, 2) is valid in combining aetiological, symptomatic, prognostic and treatment specificity, 3) is useful and 4) is acceptable to those who are invited to carry its label. These four elements do not apply to schizophrenia or bipolar disorder, or to any other psychiatric disorder (Bentall, 2004; Brockington, 1992; Kendell \& Jablensky, 2003; van Praag, 1976). Psychosis is easy to identify, but it is not exclusive to schizophrenia, and it occurs across a range of diagnostic categories of psychotic disorders. And, more important, the psychotic symptoms that are known to characterize psychotic patients are also prevalent in the general population at a subclinical level and show characteristic patterns of clustering that strongly resemble the disease phenotype. Van Os and colleagues (2000) showed that in the general population, subclinical delusional experiences are strongly associated with subclinical hallucinatory experiences, and that similarly, subclinical positive psychotic experiences are associated with depressive symptoms and blunting of affect. The prevalence and incidence of positive psychotic experience is much higher than reported rates for the (clinical) psychotic disorder (Van Os et al., 2009). The same data exist with regard to symptoms pertaining to the bipolar spectrum (Angst, 2007).

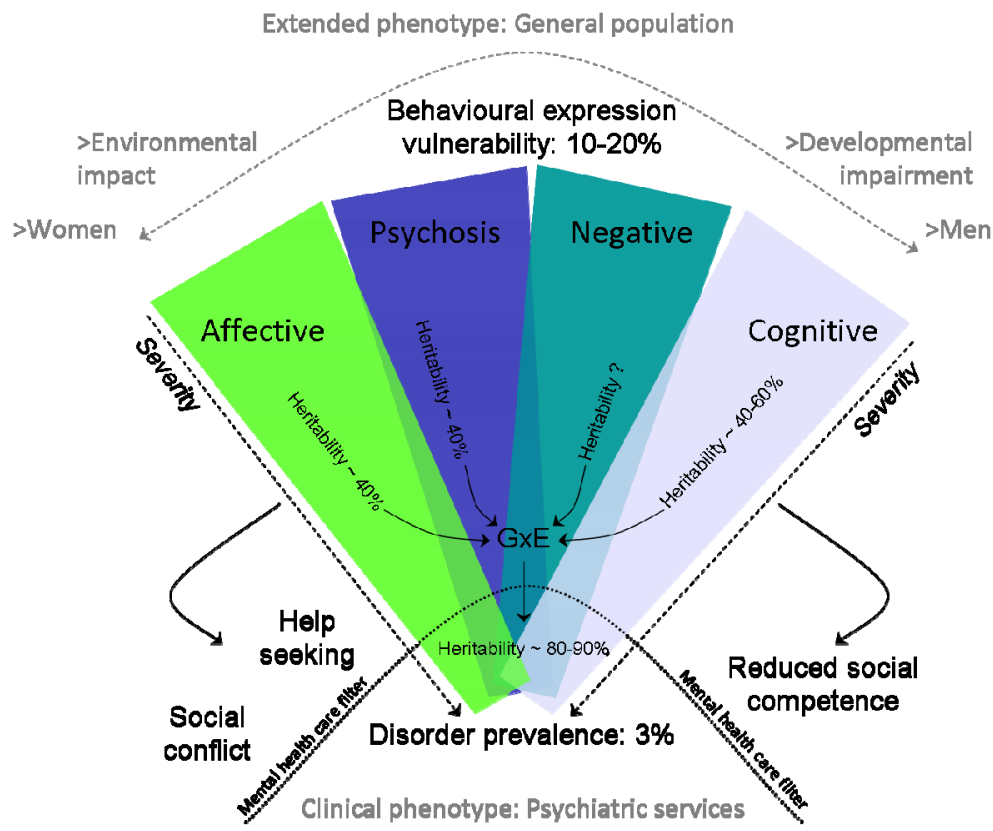

Figure 2 Complexity of the psychotic disorder phenotype in aetiological research (Van Os et al, Nature, 2010)

This broader syndromal view of clustered dimensions, depicted in Figure 2, may be more useful for aetiological research as the impact of environmental influences in psychotic disorders appears to be dimensional rather than categorical. The subclinical expressions of these four symptom dimensions are also encountered in the non-diagnosed general population at a rate of 10\%-20\% (Van Os \& Kapur, S, 2009; Dominguez et al., 2010) and are also associated 
with the same demographic, familial and other risk factors as the clinical syndrome of schizophrenia and related psychotic disorders (Dominguez et al., 2010; Polanczyk et al., 2010; Van Os et al., 2009; Kelleher \& Cannon, 2010). Therefore, this model is not only applicable to those who have permeated the filters of mental health care and thus are already in need for care, but also to those in the general population, who might show transient low levels of these dimensional phenotypes, representing the behavioural expression of vulnerability for the different dimensions of the psychotic range. The heritability levels of these four dimensions can be estimated taking into account the specific factors that impact this vulnerability, but also the non-specific commonalities, which are a result of the gene-environment interplay.

Research to date has shown that the cognitive alterations, psychosis (hallucinations and delusions) and affective dysregulations observed in psychotic disorders such as schizophrenia and bipolar disorder, are also encountered in common mental disorders, like anxiety disorders and depression. Differences between these groups are quantitative rather than qualitative (Hanssen et al., 2003; Weiser et al., 2008). The relative non-specificity of symptoms in psychiatric disorders extends to the level of familial aggregation (Van Os et al, 2010). For example, siblings of patients with common mental disorders also display cognitive alterations (Weiser et al., 2008) and brain changes (Boos et al., 2008), albeit to a lesser degree. Although a family risk of history of schizophrenia is associated with the strongest relative risk, almost any psychiatric disorder in first-degree relatives is associated with an increased risk for schizophrenia. This means, that in terms of attributable risk, $30 \%$ of schizophrenia in the general population can be attributed to psychiatric family history in general, compared to $6 \%$ that is attributable to a family history of schizophrenia specifically (Mortensen et al, 2010). This suggests that, in addition to possible specific factors impacting on liability to specific psychiatric disorders, shared genetic and environmental factors may also impact on broader neurodevelopmental alterations resulting in liability to broad dimensions of mental health (Argyropoulus et al., 2008).

\section{Future directions high-risk and aetiological research across the spectrum}

After decades of research, schizophrenia and related psychotic disorders are still among the most debilitating disorders in medicine. Research on the psychosis risk syndrome (or attenuated psychotic symptoms syndrome), known variably as clinical high risk, or ultra-high risk mental state was inspired by observations of chronic illness courses in most individuals, greater treatment responsiveness during the first episode, possible progressive gray matter decline during early disease stages, and retrospective accounts of prodromal or early illness signs and symptoms. Research on psychosis risk syndrome was mainly focused on evidence from research in high-risk groups selected for presence of need for care, and has a focus on prevention of deterioration of the already ongoing onset of psychosis in this subgroup of patients, who have already passed the filters on the pathway to mental health care. However, the examination of conversion rates in general population cohorts show only minimal yearly conversion risks, throwing doubt on the high-risk paradigm. Results from intervention 
studies are encouraging, but only apply to highly selected and non-representative samples. Therefore, they cannot yet be generalised to general psychiatric care. The next phase of research on psychosis risk syndrome has moved to larger, multicentre projects to increase generalisability and to ensure that sufficiently large samples at true risk for psychosis are included. However, samples are still highly selected and artificial density of risk of conversion is brought about by non-replicable sample enrichment strategies. Thus, it may be misleading that much emphasis in these new studies is on identification of biomarkers for conversion to psychosis that mainly focus on neuroimaging and genetics because results are only valid in the uniquely selected sample in which they are produced, which precludes generalisation. None of these high-risk studies to date have shown replicated evidence for biological or nonbiological causal factors. However, one positive note on high-risk research conducted to date is that it has shown that it is time to critically re-examine our diagnostic entities, the methodological approaches and consequences of sampling strategies in high-risk studies, and the need for a priori formulated hypotheses.

Future research therefore should attempt to integrate the genetic and epidemiological aspects of the psychosis spectrum in representative longitudinal general population samples followed over time. Genetic epidemiology should integrate the study of the relevant liability phenotypes with variables relating to the timing, severity and experience of environmental exposures within the same study design. This suggests that population cohort study approaches need be combined with clinical sample approaches, in order to investigate all syndromes across the entire non-clinical and clinical spectrum. This would represent a novel approach, as such work has not been undertaken before. Combining genome-wideassociation studies with environmental-wide assessments and exploring the geneenvironment wide-interactions (GEWIS) (Van Os \& Rutten, 2009) may represent the next step in future study designs. From these studies, information on the genetic and environmental determinants of onset of psychosis in representative population samples, describing the trajectory from risk state to clinical outcome, may be produced, helping us to understand the true nature of psychosis and its disorders more thoroughly. 

CHAPTER 7

Summary in Dutch

Nederlandse samenvatting 


\section{Inleiding}

Deze thesis behandelt verschillende onderzoeken naar een mogelijke overlap van schizofrenie en bipolaire stoornis. We zijn uitgegaan van de klassieke diagnoses van schizofrenie (niet-affectieve psychose) en bipolaire stoornis (affectieve psychose), zoals geclassificeerd in de diagnostische handboeken DSM-IV en ICD-9 (Hoofdstuk 1). In de affectieve psychose staat de stemmingscomponent op de voorgrond, terwijl in de niet-affectieve psychose de cognitieve component de hoofdrol speelt. We hebben naar een eventuele overlap, of juist een gebrek daaraan, gezocht op een tweetal domeinen van de affectieve en niet-affectieve psychose, nl. het ontwikkelings- en het affectieve domein; verder hebben we gekeken hoe deze domeinen van invloed zijn op de prodromale fase van de twee stoornissen.

\section{Bevindingen}

In hoofdstuk 2 begonnen we met het ontwikkelingsdomein van de affectieve en nietaffectieve psychoses, in het bijzonder keken we naar de diagnoses bipolaire stoornis en schizofrenie. We deden dit aan de hand van 3 artikelen.

Een theorie met brede consensus over de oorzaken van psychiatrische aandoeningen is, dat het ontstaan kan worden teruggevoerd op een multifactoriële aetiologie, d.w.z. dat er meerdere factoren bijdragen aan het ontstaan van de aandoening. Schizofrenie en bipolaire stoornis kennen een erfelijkheid van rond de $80 \%$, maar onduidelijk is hierin de bijdrage van gen/omgevingsinteracties. De genetische contributie als oorzakelijke factor kan tot expressie komen in de ontwikkeling van het brein en worden onderzocht met beeldvormend onderzoek van de hersenen van patiënten met schizofrenie in vergelijking met (i) hun broers/ zusters/familieleden en (ii) gezonde controlepersonen.

Omdat de ontwikkelingsneurologische breinveranderingen het beste onderzocht zijn in de schizofrenie, hebben we in het eerste artikel van hoofdstuk 2, Heritability of structural brain traits: an endophenotype approach to deconstruct schizophrenia, een literatuurstudie gedaan naar de erfelijkheid van breinstructuren in 1) gezonde personen, 2) personen met schizofrenie en 3) niet-menselijke primaten, om zo een conclusie te kunnen trekken over de invloed van genetische en omgevingsfactoren op breinstructuren. Daarnaast hebben we gekeken of er genen zijn die bij de ontwikkeling van specifieke breinstructuren betrokken zijn.

We kwamen tot de volgende conclusies:

1) De breinstructuren die vroeg in het leven ontwikkeld zijn, of die diep in het brein liggen, ondervinden meer invloed van genetische factoren dan breinstructuren die later in het leven gevormd zijn en meer worden beïnvloed door omgevingsfactoren.

2) In de gepubliceerde onderzoeken zijn tot op heden geen specifieke genen gevonden die coderen voor specifieke breinstructuren; er is nog maar weinig onderzoek verricht op dit gebied.

3) Ondanks de beperkingen van neuroimaging en genetisch onderzoek, kunnen de bevindingen tot nu toe als leidraad dienen voor verder onderzoek naar genetische oorzaken die aan de basis van schizofrenie liggen. 
In het tweede artikel, Murray et al. (2004) revisited: is bipolar disorder identical to schizophrenia without developmental impairment, hebben we gekeken naar een mogelijke overlap (of juist gebrek daaraan) van ontwikkelingsfactoren bij enerzijds schizofrenie en anderzijds bipolaire stoornis. De volgende conclusies konden worden getrokken:

1) De bipolaire stoornis is in vele opzichten "identiek" aan schizofrenie, maar mist, of vertoont in veel mindere mate, de ontwikkelingsneurologische beperkingen die de schizofrenie kenmerken zoals beschreven door Murray et al, 2004.

2) Uit de onderzoeken van de afgelopen 10 jaar komt naar voren dat het genetische risico op schizofrenie onder meer tot expressie komt als neurocognitieve beperking, terwijl dat bij de bipolaire stoornis veel minder het geval is.

3) Urbanisatie (leven in de grote stad) als omgevingsfactor heeft invloed op het voorkomen van de ontwikkelingsneurologische stoornis schizofrenie, maar niet op het voorkomen van bipolaire stoornis.

In het derde artikel, Extended psychosis phenotype-yes: single continuum-unlikely, is de zogenaamde continuümtheorie van psychosen onderzocht en is getracht een conceptueel model te maken van een dergelijk psychosecontinuüm (in de zin van overlap met de normale mentale gesteldheid in de algemene populatie; ook wel extended psychosis continuum genoemd): wat maakt dat sommige mensen over het continuüm bewegen van lage waarden naar de hogere, klinische relevante expressiewaarden van psychose? Hiertoe werd onder andere een meta-analyse uitgevoerd (zie hieronder).

De conclusies die getrokken werden uit dit onderzoek zijn:

1) Er zijn meerdere variabelen die de overgang van subklinische symptomen in de algemene bevolking naar een klinische stoornis kunnen verklaren.

2) Niet alleen de hoeveelheid psychotische ervaringen, en hun frequentie, zijn belangrijk, maar ook wat voor soort mechanismen iemand ontwikkelt om hiermee om te gaan, alsmede de mate van persistentie (duur) van de klachten over de tijd.

3) Op basis van de huidige gegevens in de literatuur valt nog niet met zekerheid te zeggen of er werkelijk sprake is van een lineair continuüm, of dat er toch mogelijk kwalitatieve verschillen optreden op het uiterste einde van het continuüm.

In hoofdstuk 3 zijn affectieve (stemmings-) domeinen van psychose onderzocht aan de hand van 3 artikelen. In de eerste twee artikelen zijn data van de NEMESIS-studie geanalyseerd en is er onderzoek gedaan naar evidentie van overlap (of gebrek aan overlap) tussen affectieve en niet-affectieve psychoses.

In het eerste artikel, Evidence that the urban environment specifically impacts on the psychotic but not on the affective dimension of bipolar disorder, is onderzoek gedaan naar wonen in de stad als omgevingsrisicofactor bij bipolaire stoornissen.

De conclusie van de analyses was dat urbaniteit invloed heeft op het voorkomen van bipolaire stoornis, maar alleen in samenhang met psychotische comorbiditeit: het voorkomen van bipolaire stoornis zonder psychose is niet afhankelijk van de mate van stedelijkheid van de omgeving. Bij gelijke genetische kwetsbaarheid kan blootstelling aan urbaniteit dus meer schade aanrichten op het ontwikkelingsneurologisch domein. 
In het tweede artikel, The impact of subclinical psychosis on the transition from subclinical mania to bipolar disorder, is de prevalentie van subklinische psychotische en manische symptomen onderzocht, met name hoe deze subklinische symptomen covariëren en op welke manier ze elkaar beïnvloeden.

De conclusies waren:

1) Subklinische manie in aanwezigheid van subklinische psychotische symptomen is meer voorspellend voor een toekomstige diagnose van bipolaire stoornis (is dus meer "toxisch" voor het beloop).

2) Er is een suggestieve positieve interactie tussen het optreden van sociale beperkingen in het kader van medisch-psychiatrische aandoeningen en subklinische psychose; de aard van de interactie was dat voor een gegeven niveau van subklinische manie, de (co-) aanwezigheid van subklinische psychotische symptomen meer voorspellend is voor het optreden van sociale beperkingen.

In het derde artikel, Evidence that patients with single versus recurrent depressive episodes are differentially sensitive to treatment discontinuation: a meta-analysis of placebocontrolled randomized trials, is via de methode van de meta-analyse het fenomeen van de progressieve sensitisatie bij affectieve dysregulatie nader onder de loep genomen. Het onderzoek richtte zich op de onderhoudsbehandeling van depressies. Antidepressiva zijn effectief in behandeling van acute depressies en in het voorkomen van terugval na een acute fase ('relapse'). De vraag van het onderzoek was met name of de hoeveelheid eerdere depressieve periodes de beschermende effecten van antidepressiva kunnen beïnvloeden, wat compatibel is met het idee van progressieve sensitisatie: de kans om depressief te worden naar aanleiding van een zelfde hoeveelheid stress wordt met het verstrijken van de tijd steeds groter omdat het individu gesensitiseerd is. De conclusie van de meta-analyse was inderdaad dat patiënten die eerdere depressieve periodes achter de rug hebben, minder profiteren van het profylactisch (beschermend) effect van antidepressiva dan patiënten die een eerste periode van depressie doormaken. Dit kan worden verklaard door 'sensitisatie' of 'kindling-like' processen: door de ontstane gevoeligheid worden de biochemische en fysiologische processen die tot de ziekte leiden gemakkelijker in gang gezet. Gezien het feit dat affectieve dysregulatie een kerncomponent is van psychose, verwachten we dat deze sensitisering ook een rol speelt bij psychose.

In hoofdstuk 4 wordt aan de hand van 2 artikelen beschreven in welke mate de bevindingen uit de literatuur over de ontwikkelings- en affectieve domeinen van psychoses, toe te passen zijn op de prodromale fase. Onderzoek van de prodromale fase is erg belangrijk, omdat stoornissen als schizofrenie of bipolaire stoornissen meestal niet een plotselinge start of ontstaan kennen, maar vaak een lange prodromale fase hebben, waarin vroege interventie mogelijk is. $\mathrm{Er}$ is veel onderzoek gedaan naar deze prodromale fase, maar de onderzoeken geven mogelijk een vertekend beeld (bias) vanwege een idiosyncratische selectie van 'ultrahigh risk' populaties, waardoor de voorspellende waarde meer wordt bepaald door de selectieve samenstelling van de onderzochte groep dan door 'ultra high risk'- criteria, met name attenuated psychotic symptoms. Echter wat nu de voorspellende waarde van attenuated psychotic symptoms in de algemene populatie is, blijft onbekend. 
In het eerste artikel, DSM-5 and the 'Psychosis Risk Syndrome': Babylonic confusion, wordt de DSM-V (in opzet) nader bekeken, met name wat betreft de eventuele inclusie van een psychosis risk syndrome (of mogelijk de daaraan verwante term attenuated psychotic symptoms syndrome). We tonen aan dat dit mogelijk verkeerd zou zijn, met name vanwege de boven beschreven selective sampling in de onderzoeken en het verkeerde gebruik van het woord "risk" in psychosis risk syndrome.

In het tweede artikel, The case of the missing evidence: what do subclinical psychosis spectrum experiences predict in unselected representative population samples? A systematic review enriched with new results, wordt een meta-analyse uitgevoerd met betrekking tot psychotische ervaringen in niet-geselecteerde representatieve populaties uit de algemene bevolking, en de voorspellende waarde van deze ervaringen voor het ontstaan van een psychotische stoornis. De conclusies waren dat:

1) het jaarlijkse risico op het ontwikkelen van een psychotische stoornis bij mensen met een of meer subklinische psychotische ervaringen (0,56\%) 3,5 keer hoger is dan voor mensen zonder een psychotische ervaring,

2) het risico op transitie van subklinische psychotische ervaring naar psychotische stoornis toeneemt met aantal, frequentie, persistentie en mate van affectieve dysregulatie van de psychotische ervaringen,

3) de hoofdbevinding van de studie is de discrepantie tussen het $10 \%$ jaarlijkse transitierisico uit de ultra high risk- literatuur en het $0,56 \%$ transitierisico in ongeselecteerde algemene bevolkingsonderzoeken. De verklaring voor deze forse discrepantie ligt ons inziens in de manier van selective sample enrichment die wordt toegepast in de ultra-high risk- onderzoeken maar onterecht wordt toegeschreven aan psychopathologische 'ultra-high risk' -criteria.

\section{Toekomstige ontwikkelingen}

Naar aanleiding van onze publicaties en literatuurgegevens kan geadviseerd worden om de psychotische stoornis, zowel affectieve als niet-affectieve, multidimensioneel te benaderen; dit vanwege de beperkingen die een categorale indeling van psychiatrische stoornissen met zich meebrengt voor de dagelijkse klinische praktijk, voor wetenschappelijk onderzoek in de psychiatrie en voor de hanteerbaarheid van deze diagnoses voor patiënten en familieleden. Daarbij kan worden uitgegaan van verschillende symptoomdimensies, die cross-sectioneel in verschillende mate en in verschillende combinaties aanwezig zijn in verschillende individuen, zoals voorgesteld door Van Os en collega's in een recente publicatie (Nature, 2010). In dit multidimensionele model kan uitgegaan worden van in ieder geval vier symptoomdimensies in het psychosesyndroom: affectieve dysregulatie (depressie, manie, angst), psychose (wanen, hallucinaties), negatieve symptomen (o.a. verminderde motivatie) en cognitieve veranderingen. In de algemene bevolking zijn lage gradaties van deze vier symptoomdimensies ook aanwezig, die beschouwd kunnen worden als de expressie van genetische en niet-genetische kwetsbaarheid voor psychose (prevalentie van rond de 10-20\%). In plaats van ons vast te bijten op de erfelijkheid van grote en vage diagnostische entiteiten zoals schizofrenie, waarbij onduidelijk is welk deel van het erfelijkheidspercentage werkelijk door genetische factoren wordt bepaald en welk deel door gen/omgevingsinteractie, is het misschien beter om de 
erfelijkheid van deze vier symptoomdimensies apart te bepalen. De symptoomdimensies zelf tonen matig tot hoge erfelijkheidspercentages, variërend van $40 \%$ erfelijkheid voor affectieve dimensies tot $40-60 \%$ erfelijkheid voor cognitieve dimensies.

Toekomstige onderzoekslijnen zouden de genetische en epidemiologische aspecten van het psychosespectrum moeten integreren; genetische epidemiologie zou het relevante fenotype (of de symptoomdimensie) moeten koppelen aan variabelen van timing, ernst en invloed van omgevingsfactoren, in een en dezelfde studieopzet. Dat betekent dat populatiecohortonderzoeken gecombineerd zouden kunnen worden met klinische onderzoeken om zo alle syndromen van het klinische en niet-klinische spectrum bij elkaar te brengen. Op deze manier zou het moleculair genetisch onderzoek (zoals Genome-wide association studies [GWAS] en de speurtocht naar zeldzame varianten met grote of kleine effecten) gecombineerd kunnen worden met onderzoek naar omgevingsfactoren, en gen/omgevingsinteracties in kaart kunnen worden gebracht.

\section{Referenties}

Angst J (2007). The bipolar spectrum. Br J Psychiatry. Mar 190, 189-191.

Antila M, Partonen T, Kieseppä T, Suvisaari J, Eerola M, Lönnqvist J, Tuulio-Henriksson A (2009). Cognitive functioning of bipolar I patients and relatives from families with or without schizophrenia or schizoaffective disorder. J Affect Disord. Jul;116(1-2):70-9.

Argyropoulos SV, Landau S, Kalidindi S, Toulopoulou T, Castle DJ, Murray RM, Picchioni MM (2008). Twins discordant for schizophrenia: psychopathology of the non-schizophrenic co-twins. Acta Psychiatrica Scandinavica, 118 (3), 214-219.

Bentall R (2004). Madness explained. Psychosis and human nature. London: Penguin Books.

Berrettini W (2003a). Bipolar disorder and schizophrenia: not so distant relatives? World Psychiatry, 2(2):68-72.

Berrettini W (2003b). Evidence for shared susceptibility in bipolar disorder and schizophrenia. Am J Med Genet C Semin Med Genet, 123C(1):59-64.

Boos HB, Aleman A, Cahn W, Hulshoff Pol H \& Kahn RS (2008). Brain volumes in relatives of patients with schizophrenia: a meta-analysis. Arch Gen Psychiatry, 64(3), 297-304.

Brockington, I (1992). Schizophrenia: Yesterday's concept. Eur Psychiatry, 7, 203-207.

Cardno AG, Rijsdijk FV, Sham PC, Murray RM, McGuffin P (2002). A twin study of genetic relationships between psychotic symptoms. Am J Psychiatry, 159(4):539-45.

Chen LS, Rice TK, Thompson PA, Barch DM, Csernansky JG (2009). Familial aggregation of clinical and neurocognitive features in sibling pairs with and without schizophrenia. Schizophr Res. Jun;111(1-3):159-66.

Collip D, Oorschot M, Thewissen V, Van Os J, Bentall R \& Myin-Germeys I (2010). Social world interactions: how company connects to paranoia. Psychol Med, 1-11.

Dominguez, MD, Saka, MC, Lieb R, Wittchen HU \& Van Os J. (2010). Early expression of negative/disorganized symptoms predicting psychotic experiences and subsequent clinical psychosis: a 10 -year study. Am J Psychiatry, 167(9), 1075-1082.

Geddes JR, Carney SM, Davies C, Furukawa TA, Kupfer DJ, Frank E, Goodwin GM (2003). Relapse prevention with antidepressant drug treatment in depressive disorders: a systematic review. Lancet, 361(9358):653-61.

Hanssen M, Peeters F, Krabbendam L, Radstake S, Verdoux H, \& Van Os J (2003). How psychotic are individuals with non-psychotic disorders? Soc Psychiatry Psychiatr Epidemiol, 38(3), 149-154.

Kelleher I \& Cannon M (2010). Psychotic-like experiences in the general population: characterizing a high-risk group for psychosis. Psychol Med. 19:1-6.

Kendell R \& Jablensky A (2003). Distinguishing between the validity and utility of psychiatric diagnoses. Am J of Psychiatry, 160 (1), 4-12.

Kendler KS, Heath AC, Martin NG, Eaves $\amalg$ (1987). Symptoms of anxiety and symptoms of depression. Same genes, different environments? Arch Gen Psychiatry, 44(5):451-7.

Kendler KS, Neale MC, Kessler RC, Heath AC, Eaves L (1992). Major depression and generalized anxiety disorder. Same genes, (partly) different environments? Arch Gen Psychiatry, 49(9):716-22. 
Kendler KS (1996). Major depression and generalised anxiety disorder. Same genes, (partly)different environments-revisited. Br J Psychiatry, Suppl. (30):68-75.

Loonen AJ, Peer PG, Zwanikken GJ (1991). Continuation and maintenance therapy with antidepressive agents. Metaanalysis of research. Pharm Weekbl Sci, Aug 13(4):167-75.

Mortensen PB, Pedersen MG \& Pedersen CB (2010). Psychiatric family history and schizophrenia risk in Denmark: which mental disorders are relevant? Psychol Med, 40(2), 201-210.

Murray RM, Sham P, Van Os J, Zanelli J, Cannon M, McDonald C (2004). A developmental model for similarities and dissimilarities between schizophrenia and bipolar disorder. Schizophr Res, 71(2-3):405-16.

Myin-Germeys I \& Van Os J (2007). Stress-reactivity in psychosis: evidence for an affective pathway to psychosis. Clin Psychol Rev, 27(4), 409-424.

Pantelis C, Yücel M, Wood SJ, McGorry PD, Velakoulis D (2003). Early and late neurodevelopmental disturbances in schizophrenia and their functional consequences. Aust N Z J Psychiatry, 37(4):399-406.

Polanczyk G, Moffitt TE, Arseneault L, Cannon M, Ambler A, Keefe RS, Houts R, Odgers CL \& Caspi A (2010). Etiological and clinical features of childhood psychotic symptoms: results from a birth cohort. Arch Gen Psychiatry, 67(4), 328-338.

Stip E, Letourneau G (2009). Psychotic symptoms as a continuum between normality and pathology. Can J Psychiatry, 54(3):140-51.

Van Os J, Hanssen M, Bijl R \& Ravelli A (2000). Straus (1969) revisited: A Psychosis continuüm in the general population? Schizophrenia Res, 45 (1-2), 11-20.

Van Os J, Hanssen M, Bak M, Bijl RV, Vollebergh W (2003a). Do urbanicity and familial liability coparticipate in causing psychosis? Am J Psychiatry, 160(3):477-82.

Van Os J, Sham P, (2003b). Gene-environment interactions. In: Murray, R.M, Jones, P.B, Susser, E, et al. (Eds.), The Epidemiology of Schizophrenia. Cambridge University Press, Cambridge, pp. 235-254.

Van Os J, Pedersen CB, Mortensen PB (2004). Confirmation of synergy between urbanicity and familial liability in the causation of psychosis. Am J Psychiatry, 161(12):2312-4.

Van Os J \& Kapur S (2009). Schizophrenia. Lancet, 374(9690):635-45.

Van Os J, Linscott RJ, Myin-Germeys I, Delespaul P \& Krabbendam L (2009). A systematic review and meta-analysis of the psychosis continuum: evidence for a psychosis proneness-persistence-impairment model of psychotic disorder. Psychol Med, 39(2), 179-195.

Van Os J \& Rutten BPF (2009).Gene-Environment-Wide Interaction Studies in Psychiatry. Am J Psychiatry 166:964966.

Van Os J, Kenis G, Rutten BP (2010). The Environment and Schizophrenia; Clues for Genetic and Biological Discovery. Nature, Nov 11;468(7321):203-12.

Van Os J (2010). Are psychiatric diagnosis of psychosis scientific and useful? The case of schizophrenia. Journal of Mental Health 19 (4): 305-317.

Van Praag, HM (1976). About the impossible concept of schizophrenia. Compr Psychiatry, Jul-Aug; 17 (4), 481-497.

Viguera AC, Baldessarini RJ, Friedberg J (1998). Discontinuing antidepressant treatment in major depression. Harv Rev Psychiatry, 5(6):293-306.

Weiser M, Reichenberg A, Kravitz E, Lubin G, Shmushkevich M, Glahn DC, Gross R, Rabinowitz J, Noy S \& Davidson M (2008). Subtle cognitive dysfunction in nonaffected siblings of individuals affected by non-psychotic disorders. Biol Psychiatry, 63(6), 602-608.

Wiersma D, Nienhuis FJ, Slooff CJ, Giel R (1998). Natural course of schizophrenic disorders: a 15-year follow-up of a Dutch incidence cohort. Schizophr Bull.;24(1):75-85. 



\section{Dankwoord}

Het is erg moeilijk om één van de coryfeeën in psychiatrie en onderzoekswereld te bedanken... ik heb het over mijn promotor prof. dr. J. van Os. Waarmee moet ik beginnen... met zijn bodemloze statistische en wetenschappelijke kennis? Met de vele wetenschappelijke publicaties en jaren achtereen tot medisch specialist van het jaar benoemd te worden? Of hoe hij stigmatisering in de psychiatrie, en de bijdrage van onze diagnostische systemen daaraan, bespreekbaar maakt? Hij is een van de meest inspirerende hoogleraren voor de GGZ professionals, hij brengt wetenschap dicht bij de clinici.

Jim, ik geloof dat ik één van je 'enfants terribles' (of misschien de enige) ben geweest, maar ik dank je voor je betrokkenheid en uithoudingsvermogen dit proefschrift tot een goed einde te brengen. Wat mij het meest opgevallen is, dat jij mij en mijn promotie nooit opgegeven hebt, ondanks het feit dat ik bij momenten door allerlei teleurstellingen niet verder wilde..... en nog steeds vraag ik me af of $i k$ het verdiend heb en of mij al deze eer toekomt.

Ik dank de leden van de leescommissie: prof. dr. M. de Vries, dr. Ph. Delespaul, dr. F. Peeters, prof. dr. D. Wiersma en prof. dr. W.A. Nolen.

Prof. Nolen, beste Willem, ik wil je in het bijzonder bedanken, omdat ik van jou de kans heb gekregen om aan onderzoek te proeven tijdens mijn arts-assistentschap en mijn eerste artikel, een meta-analyse over onderhoudsbehandeling van depressie, met je te schrijven. Ook ben je gaandeweg de promotie continu betrokken geweest en heb je met een aantal artikelen mee gepubliceerd. Ik heb zeer veel van je geleerd: ik dank je hiervoor!

Prof. Wiersma wil ik bedanken voor zijn enthousiasme in het laatste traject van de promotie om het tot een afronding te brengen.

Lex Wunderink, mijn eerste (ja, ik heb er vele gehad!) A-opleider: Lex, ik dank je voor de kansen die je me gegeven hebt: te beginnen met de mogelijkheid om met de A-opleiding van start te gaan! Van jou heb ik vooral geleerd om goed psychiatrisch onderzoek en goede diagnostiek te doen; altijd in beweging te blijven en jezelf te ontwikkelen... ook jij doet veel dingen tegelijkertijd en gaat op nieuwe uitdagingen af.

Een dankwoord richt ik ook graag tot Peter Turpijn, voorzitter van Mediant, alsmede Henk van den Berg, lid van de Raad van Bestuur, voor de jarenlange ondersteuning en hulp bij het tot stand brengen van mijn promotie en het faciliteren daarin. Peter, ik kan je niet genoeg bedanken voor je eindeloze energieke en motiverende houding; Henk, ik wil je bedanken voor je voortdurende ondersteuning, de inspiratie en de coaching die ik van je heb gekregen, niet alleen als beginnend psychiater, maar ook in mijn huidige baan als manager behandelzaken, en daarnaast gedurende mijn hele promotietraject. Zelfs toen ik een jaar in de USA zat, bleef je me adviezen geven en steunen bij alle perikelen rondom promotie. Ook was het 
nodig dat je de laatste maanden tijdens elke managementvergadering zowat als vast agendapunt mijn promotietraject aan de orde liet komen, om me continu met de afronding ervan bezig te houden, voor het geval dat ik teveel met andere zaken bezig was.

De samenwerking met jullie ervaar ik als zeer prettig en zeer dynamisch.

Dank ook aan de leden van het managementteam van Mediant voor hun ondersteuning gedurende mijn promotietraject: Paul Deursen, manager Bedrijfsvoering, bij Acute en Curatieve Zorg, voor voor de fantastische samenwerking met veel humor en daadkracht! Willem Snelleman, Hans Agelink en tot recent Hesie Chung, managers behandelzaken, Jurrien Smit, Marcel Hooch Antink, Gabriëlle Parel, Vincent van Antwerpen, Frans van de Pol, Annelies ter Huurne, Arie Holkers, Yvette Loves, Janet Poels, Ger Geuke, Wynand Koekkoek, allen lid van het managementteam bij Mediant, dank ik voor hun samenwerking. Peter Dingemans wil ik bedanken voor alle steun en begeleiding bij de laatste fase van mijn promotieonderzoek; Peter, dank voor alle uitleg en de voorbereidingen voor mijn promotie!

Bovendien wil ik mijn collega's bij Acute en Curatieve Zorg, de team- en programmanagers bedanken voor het geduld dat ze hebben uitgeoefend ondanks alle drukte en de weinige tijd die er was voor overleg of patiëntencontacten. Met name de collega's van crisis-voordeurteam en bemoeizorg zijn zeer begripvol geweest in deze fase en hebben naast de dagelijkse bezigheden steeds hun interesse getoond voor mijn promotieonderzoek. Er was afgelopen jaar zelfs weinig tijd over om de krant te lezen, maar dankzij jullie was ik toch op de hoogte van de interviews die mijn promotor had gegeven in allerlei dagbladen.

De secretaresses van het circuitmanagement en A\&CZ wil ik bedanken, met name Bibiane, Sandra en Petra, voor al hun hulp en inzet in de laatste fase van mijn promotietraject, ik was zeer blij met jullie ondersteuning. De secretaresses van het crisis-voordeurteam heb ik soms, misschien wel -erg -vaak, tot wanhoop gedreven met voortdurende wijzigingen van afspraken en aanpassingen in de agenda, maar zonder het eeuwige geduld van Jeanne, Juliette, Ingrid en Tineke was werken aan mijn promotie het afgelopen jaar niet mogelijk geweest.

Aan de UM heb ik zeer veel hulp gehad van Elsa Misdom met het realiseren van dit proefschrift; Elsa, dank voor al je hulp!

In het bijzonder dank ik Ellemieke Nederlof, psychiater en vriendin, niet alleen voor alle steun en aanmoediging voor mijn onderzoek, maar ook voor de leuke sociale contacten. Ellemieke, ik wil je enorm bedanken voor je steun en hulp en ik ben zeer vereerd dat je mijn paranimf wilt zijn. Ik hoop dat we nu wat rustiger tijden tegemoet gaan, al is het de vraag of wij in staat zijn ons bezig te houden met maar één of twee dingen en niet met tig dingen tegelijkertijd. Ik dacht altijd dat ik na de promotie in een groot gat, ook wel 'post-promotie depressie' genoemd, zou vallen, omdat ik dan wellicht veel te veel tijd over zou houden. Maar, als ik zie hoe druk jij nog steeds bent na je promotie, en hoe we ons continu nieuwe dingen op de hals halen, dan maak ik me daar niet meer zo druk over... tegen die tijd heb ik niet eens meer tijd om depressief te worden!

Chantal Theunissen wil ik bedanken voor de leuke en ontspannen momenten, waarbij we over totaal andere zaken dan werk en onderzoek konden praten. Chantal, super, om je na zoveel jaren weer terug te zien en dat je mijn paranimf wilt zijn; ik was gelukkig net op tijd, 
om in je paranimf- agenda, die bijna volgeboekt is voor het voorjaar, nog een dag te kunnen claimen voor mijn promotie!

Ik wil verder Fred Dreef en zijn vrouw Janine bedanken voor de gekkigheid, humor en gezellige gesprekken... dank Fred! Dankzij jouw humor kon ik dingen beter relativeren en soms zodanig dat ik een paar maanden voor het afronden zowat alles opgaf om meer van het leven te kunnen genieten... al duurde dat maar een paar seconden, het was wel geweldig! Een zorgeloos bestaan, helemaal overtuigd van de zinloosheid van ons bestaan!

Lieve Serap, hoe vaak hebben we onze afspraken niet uitgesteld vanwege de zoveelste deadline... het gaat binnenkort echt lukken om af te spreken! En geweldig, dat je temidden van alle drukte, stress en slapeloze nachten mij opbelde, om me uit te nodigen voor een trektocht door het Midden-Oosten en de zijderoute naar China! Misschien dit jaar dan?

Isik, jij was mijn eerste leermeester in de psychiatrie en hebt me, tijdens mijn coschappen, laten zien wat voor een geweldig vak psychiatrie is! Nog altijd leg ik mensen uit dat ik niet de enige Koerdische psychiater in Nederland ben en dat jij de eerste was!

Verder wil ik alle vrienden die altijd betrokken, steunend zijn geweest bedanken voor hun betrokkenheid; Diederik ten Back, Tekleh Zandi, Pieter de Nijs, Albert Meyer en natuurlijk Agnieszka Ederveen, dank voor alles!

Lieve Nicole, we gaan nu vaker uit!

... en nu even met $z$ 'n allen omschakelen naar een andere taal: Rozelin Aydina, benim Dersimli bilim arkadasima tesekkur etmek istiyorum... sen, Turkiyeden ta buralara geldin, bilimle ugrasmak icin, oysa ben burada, bu rahatliklar icinde bazen sikayetleniyorum, Sana cok saygi duyuyorum, tabii adinin Rozelin olmasida herseyi daha anlamli yapiyor; biliyorsun, benim dunyalarca sevdegim yegenimin adida Rozelin!

Dear Prof. N. Freimer, I would like to thank you for giving me the opportunity to work at your lab at the UCLA and learn the basics of science and be very critical, even about the biological findings, which most researchers and clinicians seem to be accepting as conclusive. It was a wonderful year and I did learn a lot during that year!

My dear Ania Jansinska, how can I thank you for the wonderful time we have spent together at the UCLA and in Los Angeles/California! I miss you a lot and miss our visits to botanical gardens, to the opera and into the nature! You're probably the only scientist I know who has two PhDs and I admire your relentless focus on good methodology, analyses and also your modesty. Well, I hope we can meet soon in California or in your homeland Poland.

Dear Emery and JD; thanks for all the fun we had in LA! Hope to visit you guys soon! Debra, querida amiga, muchas gracias por todo! Ojala, encontramos en verano en Sueca.... of all places!

En last but not least... wat zou ik zijn zonder mijn familie, en daarbij bedoel ik mijn grote familie, dus niet alleen mijn broer, mijn twee zusjes en mijn moeder en vader, maar ook mijn tantes, ooms, neefjes, nichtjes en oma. Bij Koerden is het niet gebruikelijk familie te bedanken voor het feit dat ze er voor je zijn, dat is zoiets waardevols en tegelijkertijd vanzelfsprekends, dat je dat niet eens ter discussie of ter sprake kunt brengen door ze te bedanken... het is ergens ook 'not done'... en toch ga ik het wel een beetje doen. 
Zoals dat hoort in een groot Koerdisch gezin is iedereen erg betrokken bij elke fase van je leven en zo ook mijn familie. Ze hebben me gesteund vanaf het begin tot het eind. Al was het soms moeilijk te begrijpen waar ik mee bezig was, jullie zijn er altijd voor mij geweest. Niet alleen tijdens mijn promotietraject, maar vanaf het begin dat ik naar de universiteit ging tot en met het afronden van het specialisme psychiatrie, tot het promotieonderzoek.

Ook de bezorgde momenten dat jullie af en toe me zelfs adviseerden om 'mijn hersenen rust te geven'.

Ercan dayi ve Fatos yengeye tesekkurler! Insallah, gelecek sefer Dersime geldigimde sizinle rahat rahat oturup oradaki doganin guzelliginin tadina varirim. Bu sefer bilgi sayarimi getirmiyecegim!

Murat dayi, cher oncle, et Sidar, Berivan, Serkan et ma cherie Meral, Paris n'est pas très loin, mais j'ai toujours manque du temps... mais après juin nous allons nous voir souvent, et surtout à Paris, comme d'habitude!

Lieve Thea en Asmen, Yasar dayi is niet meer bij ons, maar hij is mijn grootste inspirator geweest voor de psyche van de mens en zo ook van grote invloed op mijn keuze om psychiatrie te doen!

Mijn andere ooms en tantes en mijn oma wil ik bedanken voor al hun steun, ook mijn neefjes en nichtjes en hun partners: Serda en Siska en Nino, Laser, Murat, Seval, Ozgur, Ozge, Aynur teyze, Ayten teyze en Pierre, Unal dayi en Songul, met jullie geniet ik van de familiemomenten... na al die jaren is het nog steeds amazing om te zien met hoeveel mensen we soms in een kleine woonkamer passen bij zulke gelegenheden... hoe doen we dat toch?

Mijn zusje Meral wil ik bedanken voor alle hulp die ik de afgelopen jaren heb gekregen om dit promotieonderzoek af te kunnen ronden. $\mathrm{Er}$ is geen wereldstad waar we naar afgereisd zijn waar we het niet over mijn promotieperikelen hebben gehad. Je eeuwige steun om vooruit te kijken, ondanks tegenslagen, is geweldig! Zonder jou had ik het waarschijnlijk niet gered, je bent een grote inspiratiebron geweest.

Mijn zusje Safak dank ik voor de bemoedigende woorden, de rationaliteit waarmee je naar de zaken kijkt en de nuchterheid waarmee je dingen aanhoorde en zorgvuldig je adviezen gaf. Ik heb er vijf jaar over gedaan om hier iets van te bakken en intussen ben jij in de afgelopen jaren moeder geworden. Jij en Kurtulus, mijn zwager, geweldig dat jullie je dochtertje, mijn schatje Rozelin Sarya, regelmatig aan mij toevertrouwen in de weekenden (met mijn moeder op de achtergrond weliswaar)... tja, heb weinig maternale instincten, maar ben volgens mij wel een leuk maatje voor Rozelin! En als ik eens afdwaalde tijdens het spelen, omdat ik aan werk of onderzoek dacht, dan kreeg ik een klap in mijn gezicht van Rozelin om mijn aandacht weer bij het spelletje te houden! Kijk, dat zijn nou momenten waar je dankbaar voor bent, dat zo'n kleintje van 3 jaar je even terug in de realiteit brengt.

Mijn broer Akansel wil ik bedanken voor de rust en kalmte en laat ik het zeggen, toch de structuur, die je steeds bij mij, je tegenpool, wist aan te brengen. Telkens als ik in paniek raakte en het niet meer zag zitten, wist jij mij gerust te stellen en met je zakelijke kijk op dingen tot logische keuzes te brengen... En als ik eens weer radicale beslissingen had genomen, dan was jij er altijd om snel wat 'damage control' te doen. Je bent er altijd voor mij geweest en je bent een enorme steun voor me, maakt niet uit in welke stad ik woon, of in welk land ik me op dat moment bevind of in welke fase van mijn leven. De tijden die ik met jou, je vrouw Dagmar en de kinderen, lieve Miro, Amber en Sofie heb kunnen doorbrengen, dat zijn geweldige momenten! Mijn vader wil ik bedanken voor de inspiratie die ik van hem 
heb gekregen en voor de discipline. We hebben weinig tijd om elkaar te zien, maar van jou heb ik veel geleerd, met name niet opgeven, risico's durven nemen, vallen en opstaan en gaan voor je ambities...

Mijn lieve moeder, waar moet ik beginnen... ergens denk ik dat jij vandaag ook promoveert, dat er ook een last van jou afvalt, omdat je de hoeveelheid stress die ik heb gehad de afgelopen jaren net zo goed doorgemaakt hebt. Sevgili annecigim, Derman hanim, sensiz hic bir yere kavusamazdim! 



\section{Curriculum vitae}

Nil Kaymaz was born on 2 July 1972 in Mazgirt, East Turkey (Kurdish section). She completed her pre-university education in the Netherlands at the Christelijke Streeklyceum in Ede, Gelderland. After that, she studied medicine in Belgium, the first three years at the Free University of Brussel and the last four years at Ghent University. She did part of her clinical rotations at the Vall d'Hebron University Hospital in Barcelona, Spain. In 1999, Nil completed her medical studies and began working as a junior doctor in the adolescent clinic at the Sophia Children's Hospital in Rotterdam. Subsequently, she worked as a junior doctor at Midden-Brabant Mental Healthcare (GGZ) agency in Tilburg, the Netherlands. In 2000, she worked as a junior doctor at Grote Rivieren, an organization for mental health care in Dordrecht, the Netherlands, to begin her specialization in psychiatry. She completed her education in psychiatry in 2005 and then went to work as a psychiatrist/team psychiatrist at Altrecht Mental Healthcare agency in Utrecht. In the same year, she was awarded a Mozaïek grant from The Netherlands Organization for Scientific Research (NWO) and she began her postdoctoral research. Since 2005, Nil has been following the Master's programme in Epidemiology given by the Free University of Amsterdam/Institute for Health and Care Research (EMGO). In 2008, she carried out research on neuroimaging for one year at the University of California in Los Angeles (UCLA) in the United States, where she also lectured college students in psychopathology and neuroimaging. In 2009, after returning to the Netherlands, she started working at Arkin in Amsterdam as a psychiatrist/psychiatrist administrator in longterm care.

During the winter of 2009-2010, she moved to a post at the Mediant Mental Healthcare agency in Enschede, the Netherlands, where she is currently employed as treatment manager of the curative division and as psychiatrist with the critical time intervention team. 



\section{Publications}

1. Kaymaz N, Lataster T, Lieb R, Wittchen H-U, Van Os J, Drukker M. The case of the missing evidence: what do subclinical psychosis spectrum experiences predict in unselected representative population samples? A systematic review enriched with new results. Submitted, 2010.

2. Kaymaz N, Van Os J. DSM-5 and the 'Psychosis Risk Syndrome': Babylonic confusion. Psychosis, Volume 2, Issue 2 June 2010, pages 100 - 103

3. Kaymaz N, Van Os J. Extended psychosis phenotype - yes: single continuum - unlikely. Psychol Med. 2010 Mar 18:1-4.

4. Kaymaz N, Van Os J. Heritability of structural brain traits: an endophenotype approach to deconstruct schizophrenia. Int Rev Neurobiol. 2009;89:85-130.

5. Kaymaz N, Van Os J. Murray et al. (2004) revisited: is bipolar disorder identical to schizophrenia without developmental impairment? Acta Psychiatr Scand. 2009 Oct;120(4):24952.

6. Kaymaz N, Van Os J, Loonen AJ, Nolen WA. Evidence that patients with single versus recurrent depressive episodes are differentially sensitive to treatment discontinuation: a meta-analysis of placebo-controlled randomized trials. J Clin Psychiatry. 2008 Sep;69(9):1423-36.

7. Kaymaz N, Van Os J, de Graaf R, Ten Have M, Nolen W, Krabbendam L. The impact of subclinical psychosis on the transition from subclinical mania to bipolar disorder. J Affect Disord. 2007 Feb;98(1-2):55-64

8. Kaymaz N, Krabbendam L, de Graaf R, Nolen W, Ten Have M, Van Os J. Evidence that the urban environment specifically impacts on the psychotic but not the affective dimension of bipolar disorder. Soc Psychiatry Psychiatr Epidemiol. 2006 Sep;41(9):679-85. 